Mecanismos de apoio para usabilidade e acessibilidade na interação de adultos mais velhos na Web 

SERVIÇO DE PÓS-GRADUAÇÃO DO ICMC-USP

Data de Depósito:

Assinatura:

\title{
Mecanismos de apoio para usabilidade e acessibilidade na interação de adultos mais velhos na Web
}

\author{
Silvana Maria Affonso de Lara
}

Orientadora: Profa. Dra. Renata Pontin de Mattos Fortes

Tese apresentada ao Instituto de Ciências Matemáticas e de Computação - ICMC-USP, como parte dos requisitos para obtenção do título de Doutor em Ciências - Ciências de Computação e Matemática Computacional. VERSÃO REVISADA. 
Ficha catalográfica elaborada pela Biblioteca Prof. Achille Bassi e Seção Técnica de Informática, ICMC/USP, com os dados fornecidos pelo(a) autor(a)

Lara, Silvana Maria Affonso de
Mecanismos de apoio para usabilidade e
acessibilidade na interação de adultos mais velhos na
Web / Silvana Maria Affonso de Lara; orientador
Renata Pontin de Mattos Fortes. -- São Carlos, 2012.
252 p.
Tese (Doutorado - Programa de Pós-Graduação em
Ciências de Computação e Matemática Computacional) --
Instituto de Ciências Matemáticas e de Computação,
Universidade de São Paulo, 2012.
1. Acessibilidade. 2. Usabilidade. 3. Interação
Humano-Computador. I. Fortes, Renata Pontin de
Mattos, orient. II. Título.




\section{Agradecimentos}

Em primeiro lugar agradeço a Deus pela minha vida, pela fé e força de vontade que sempre nortearam meus trabalhos.

Agradeço a Renata, minha orientadora, que me acolheu de volta com confiança e que sempre me incentivou com bons conselhos, tanto na minha vida profissional quanto pessoal. Sei que os momentos que compartilhamos marcaram profundamente nossas vidas e jamais sairão de nossas memórias.

Agradeço a CAPES e a FAPESP pelo apoio financeiro.

Agradeço a todos do ICMC, professores, funcionários e amigos que contribuíram para que este trabalho fosse realizado.

Agradeço aos amigos e colegas que foram muito importantes durante essa trajetória, em especial: André, Eduardo, Willian, Denis, Welington, Daniel, Cibele, David, Thiago, Américo, Rigolin e Ricardo.

Agradeço aos amigos do IFSP-São Carlos pelo apoio e por me fazerem acreditar que todo esforço vale a pena.

Agradeço também a todos aqueles que sempre se dispuseram e atenderam às minhas solicitações de colaboração com esta pesquisa.

Por fim, agradeço à minha família, meu marido Eduardo e meus filhos Gabriela e Kaio, por me darem, a todo instante, o estímulo e a força necessária para a conclusão deste trabalho. Agradeço o apoio incondicional de minha mãe, Maria Elena, e o apoio diário da Aparecida, minha fiel companheira do lar durante todo o tempo de trabalho neste doutorado. 
"Grandes oportunidades para ajudar aos outros raramente aparecem, mas pequenas delas nos cercam todos os dias."

Sally Koch 


\section{Resumo}

Como uma das consequências do crescimento populacional que atualmente ocorre em escala mundial, é possível observar um aumento significante no número de pessoas mais velhas. Com a evolução da Internet, que oferece atualmente uma ampla variedade de serviços que ultrapassam os limites do entretenimento e da comunicação, os adultos de meia-idade e os idosos podem usufruir de vários benefícios, tais como: compras, bancos on-line, serviços governamentais e informações de forma geral, de modo a preservar sua autonomia e independência funcional na realização das suas tarefas diárias. Mas, apesar de todos os benefícios que podem ser obtidos por meio da Web, existe ainda grande resistência por parte dos adultos mais velhos em utilizá-la. Muitas pessoas, com o passar dos anos, passam a conviver com dificuldades sensoriais, motoras e principalmente com declínios da capacidade cognitiva, que podem comprometer o seu acesso à Web. A acessibilidade na Web se destina a garantir, principalmente, que haja meios para que pessoas com necessidades especiais possam utilizar a Web de forma natural e independente. Os adultos de meia-idade são usuários que, de modo geral, estão propensos a sofrer com os declínios de suas capacidades ao longo do tempo. Para enriquecer a experiência dos adultos de meia-idade e idosos com a Web é essencial considerar as necessidades de diferentes perfis de usuários, bem como suas necessidades visuais, de audição, motoras e cognitivas, as quais se tornam mais evidentes a partir dos 40 anos de idade. O objetivo do presente trabalho foi identificar recursos e mecanismos de usabilidade e acessibilidade que atendam às várias dificuldades encontradas por grande parte dos adultos mais velhos que buscam utilizar a Web, de modo que possam auxiliá-los a superarem os declínios provenientes do envelhecimento e os incentivem a continuar utilizando a Web como uma fonte de informação, comunicação e serviços. Muitos avanços já foram obtidos com a utilização da tecnologia assistiva, que busca, por meio de equipamentos e softwares, dar apoio a vários tipos de deficiências apresentadas pelos usuários durante a sua interação com aplicativos e com a Web. Esforços também têm sido realizados por meio da criação de diretrizes e normas, como forma de incentivar programadores e autores de conteúdo a produzirem material para a Web que seja acessível. Nesta dissertação, defende-se a tese de que a melhoria da qualidade na experiência de uso da Web por parte dos adultos mais velhos também contribui para a usabilidade universal. Assim, é apresentada uma pesquisa que engloba revisão da literatura, observação em campo, aplicação de questionários, levantamento de dificuldades com deficientes visuais, e testes com protótipos; os resultados mostram que a utilização de mecanismos de apoio à interação de adultos com mais idade com a Web promove também a melhoria da interação das pessoas mais jovens. Finalmente, pôde-se diagnosticar barreiras que ainda permanecem e quais mecanismos de apoio foram mais bem aceitos pelos adultos de meia-idade e idosos. 


\section{Abstract}

The current worldwide population growth has been followed by a significant increase in the number of older people. The evolution of the internet has brought an increase in the variety of services that go beyond entertainment and communication. Older adults and elderly people can benefit from many such services available on the internet, such as online shopping, banking, governmental services and many other sources of information, in order to preserve their autonomy and independence to undertake their daily activities. However, despite all the benefits brought by the use of the Web, many older adults still present some resistance to use websites. As a consequence of ageing, many older adults may start to present certain difficulties that can jeopardise the way they use the Web, such as sensory, motor, and especially cognitive difficulties. Web accessibility is concerned with providing means to enable people with special needs to use the Web in a natural and independent manner. Older adults tend to be affected with decline in their abilities with time. In order to enrich the experience of older adults and elderly people with the Web, it is essential that the needs of different user profiles be taken into account, particularly concerning visual, auditory, motor and cognitive aspects that become more evident from 40 years of age. The goal of the present work is to identify usability and accessibility resources and mechanisms to address the difficulties encountered by large part of older adults that use the Web, in order to help them overcome difficulties associated with ageing and help them continue using the Web as a source of information, communication and services. Much advancement have been achieved with the use of assistive technology, which consists of equipment and software that supports several types of disabilities and provides aids to the use of computer applications and the Web. Many efforts have also been targeted at creating guidelines and standards to incentivise programmers and web authors to produce more accessible Web material. In this thesis, the work developed supports the argument that improvements in the quality of the experience in the use of the Web by older adults also contributes to enhancing universal usability. The research presented involves a literature review, field observation of users, questionnaires with users, interviews with visually impaired users about their difficulties in using websites, and tests with software prototypes. The results showed that the use of mechanisms to support the interaction of older adults with the Web also promotes improvements in the interaction of younger users. Finally, it was possible to diagnose barriers that still remain and which mechanisms had best acceptance by older adults and elderly users. 
1 Introdução 1

1.1 Contexto . . . . . . . . . . . . . . . . . . . . . . 1

1.2 Objeto de Estudo . . . . . . . . . . . . . . . . . . . . . . . . . . . . . . . . . . . . .

1.3 Questão da Pesquisa . . . . . . . . . . . . . . . . . . . . . . . 10

1.3.1 Questão de Partida . . . . . . . . . . . . . . . . . . 11

1.3.2 Definição do escopo . . . . . . . . . . . . . . . . . . . . . 11

1.3 .3 Justificativas . . . . . . . . . . . . . . . . . . . . 11

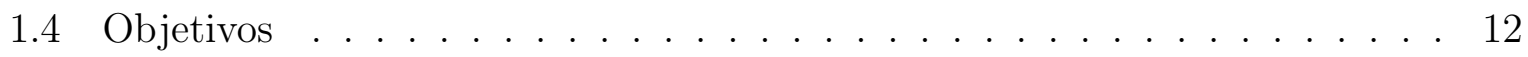

1.4.1 Objetivos Gerais . . . . . . . . . . . . . . . . . 12

1.4.2 Objetivos Específicos . . . . . . . . . . . . . . . 13

1.5 Procedimentos Metodológicos . . . . . . . . . . . . . . . . 13

1.6 Estrutura . . . . . . . . . . . . . . . . . . 16

2 Usabilidade e Acessibilidade $\quad 17$

2.1 Usabilidade . . . . . . . . . . . . . . . . . . . . . . . . . 18

2.2 Princípios de usabilidade na Web . . . . . . . . . . . . . . 20

2.3 Acessibilidade . . . . . . . . . . . . . . . . . . . . . . 23

2.4 Diretrizes de acessibilidade na Web . . . . . . . . . . . . 25

2.5 Legislação sobre acessibilidade no Brasil e no mundo . . . . . . . . . . . . 30

2.6 Usabilidade x Acessibilidade . . . . . . . . . . . . . . . . . . . . 37

2.7 Considerações finais . . . . . . . . . . . . . . . . . . . . 41

3 Os Adultos Mais Velhos e a Web 43

3.1 Considerações iniciais . . . . . . . . . . . . . . . . . . . . . . . 43

3.2 Os adultos de meia-idade e idosos no Brasil . . . . . . . . . . . . . . . . 44

3.3 Qualidade de vida na velhice . . . . . . . . . . . . . . . . . . 46

3.4 Os impactos do envelhecimento . . . . . . . . . . . . . . . . . 47

3.5 O adulto de meia-idade e o mercado de trabalho . . . . . . . . . . . . . 51

3.6 A interação dos "mais velhos" com a Web . . . . . . . . . . . . . . 52

3.7 Considerações finais . . . . . . . . . . . . . . . . . . . . . . 55 
4 Trabalhos Relacionados $\quad 57$

4.1 O Uso de Redes Sociais por Adultos Mais Velhos . . . . . . . . . . . . . 58

4.2 Trabalhos relacionados à interação com tecnologias diversas . . . . . . . . . 60

4.3 Trabalhos relacionados à especialização de diretrizes para adultos mais velhos 64

4.4 Trabalhos relacionados às deficiências cognitivas . . . . . . . . . . . . . 69

4.5 Trabalhos relacionados a customizações de interfaces . . . . . . . . . . . 72

4.6 Trabalhos relacionados ao Apoio Contextual . . . . . . . . . . . . . 78

4.7 Considerações finais . . . . . . . . . . . . . . . . . . . . . . . . . . 83

5 Identificação das Dificuldades $\quad 87$

5.1 Observação em Campo . . . . . . . . . . . . . . . . . . . . . . . 90

5.2 Questionário para adultos com experiência (Survey) . . . . . . . . . . 94

5.2 .1 Coleta de Dados . . . . . . . . . . . . . . . . . . . . . . 94

5.2 .2 Resultados . . . . . . . . . . . . . . . . 95

5.3 Entrevistas com Deficientes Visuais . . . . . . . . . . . . . . . . 102

5.4 Reconhecimento de Elementos . . . . . . . . . . . . . . . 105

5.4.1 Coleta de Dados . . . . . . . . . . . . . . . . . . . 105

5.4 Resultados . . . . . . . . . . . . . . . . . 107

5.5 Comportamento em Comércio Eletrônico ～. . . . . . . . . . . . . . . 110

5.5 .1 Interface . . . . . . . . . . . . . . . . . . . 113

5.5.2 Coleta de Dados . . . . . . . . . . . . . . . . . . . . 116

5.5 .3 Resultados . . . . . . . . . . . . . . . . . 117

5.6 Menus Horizontais . . . . . . . . . . . . . . . . . . . . . 118

5.6 .1 Coleta de Dados . . . . . . . . . . . . . . . . . . . . 119

5.6.2 Resultados . . . . . . . . . . . . . . . . . . . 122

5.7 Considerações finais . . . . . . . . . . . . . . . . . . . . . 126

6 Mecanismos para Interação de Adultos Mais Velhos na Web 127

6.1 Sugestões de Critérios de Sucesso para Interação . . . . . . . . . . . . . . 127

6.1.1 Perceptível . . . . . . . . . . . . . . . . . . . . . . . 129

6.1 .2 Operável . . . . . . . . . . . . . . . . . . . . . 130

6.1.3 Compreensível . . . . . . . . . . . . . . . . . . . . . . . . . . 132

6.2 Sugestões de Solução para os Principais Problemas . . . . . . . . . . . . . 135

6.2.1 Dificuldade de leitura e compreensão de textos . . . . . . . . . . . . 136

6.2.2 Dificuldade de reconhecimento e acesso aos links . . . . . . . . . . 138

6.2 .3 Dificuldade de navegação . . . . . . . . . . . . . . . . . . . 138

6.2.4 Dificuldade na realização de tarefas específicas . . . . . . . . . . . . 140

6.2.5 Dificuldade na realização de compras em lojas on-line . . . . . . . . 140

6.2.6 Dificuldade na busca e localização da informação . . . . . . . . . . . 140

6.2.7 Dificuldade de comunicação com os responsáveis pelo site . . . . . . 140

6.3 Um Apoio Sensível ao Contexto . . . . . . . . . . . . . . . . . . . . . . . . 145

6.3.1 Projeto Tuki: um protótipo para apoio sensível ao contexto . . . . 147

6.3.2 Avaliação Heurística do Projeto Tuki . . . . . . . . . . . . . . . . . 155

6.3.3 Avaliação com Usuários . . . . . . . . . . . . . . . . . . . . . 158

6.4 Mecanismos de Apoio . . . . . . . . . . . . . . . . . . . 161

6.4.1 Questões sobre os mecanismos . . . . . . . . . . . . . . . 162

6.4.2 Coleta de Dados . . . . . . . . . . . . . . . . . 176

6.4.3 Perfil dos participantes . . . . . . . . . . . . . . . . . 177

6.4.4 Análises e Discussões . . . . . . . . . . . . . . . . . . . . . 178 
6.4.5 Resultados . . . . . . . . . . . . . . . . . 188

6.5 Considerações finais . . . . . . . . . . . . . . . . . . . . . 202

7 Conclusões $\quad 205$

7.1 Principais contribuições . . . . . . . . . . . . . . . . 206

7.2 Limitações e Trabalhos futuros . . . . . . . . . . . . . . . . . . . 209

7.3 Considerações finais . . . . . . . . . . . . . . . . . . . . . . . 210

Referências Bibliográficas $\quad 213$

A Questionário - Adultos Mais Velhos com Experiência na Web 227

B Questionário On-line - Reconhecimento de Elementos da Web 231

C Teste com protótipo - Menus Horizontais na Web 241

D Comentários - Mecanismos de Apoio 247 


\section{Lista de Figuras}

1.1 Uso da Internet no Brasil por idade e regiões no ano de 2000 . . . . . . . . 2

1.2 Uso da Internet no Brasil por idade e regiões no ano de 2010 . . . . . . . . 2

1.3 Comparativo de Uso da Web na America do Sul em 2011. Figura adaptada do site Internet World Stats: http://www.internetworldstats.com . . . . . . . . . . . 4

1.4 Uso da Internet no Brasil por idade e regiões . . . . . . . . . . . . . . . . . 4

1.5 Uso da Internet no Brasil por idade e regiões em percentuais . . . . . . . . 5

1.6 Uso da Internet no Brasil por idade e regiões em percentuais relativos ao total da população . . . . . . . . . . . . . . . . . . 5 5

1.7 Métodos de Pesquisa executados neste trabalho . . . . . . . . . . . . 15

2.1 Abordagem da WAI. Figura adaptada do site da WAI: http://www.w3.org/WAI/intro/ specs.png . . . . . . . . . . . . . . . . . . . 27

3.1 Classificação de gerações segundo o projeto "Generation and the gadgets" (Kathryn Zickuhr, 2011) . . . . . . . . . . . . . . . 53

3.2 Percentual de uso de equipamentos pelas gerações (Kathryn Zickuhr, 2011) 54

4.1 Exemplos de Portable Multimedia Players . . . . . . . . . . . . . . . 61

4.2 Página inicial . . . . . . . . . . . . . . . . . . . . . 71

4.3 (a) Apresentação das funcionalidades básicas (nível 1) e (b) Aumento no número de funcionalidades apresentadas (nível 2) . . . . . . . . . . 72

4.4 Página Normal (Hanson, 2004) . . . . . . . . . . . . . . . . . . 73

4.5 (a) Ampliação do texto em banner (b) Ampliação do texto da imagem (Hanson, 2004) . . . . . . . . . . . . . . . . . . . . 74

4.6 (a) Ampliação do menu do navegador (b) Ampliação da Imagem (Hanson, 2004) . . . . . . . . . . . . . . . . . . 74

4.7 Configuração de cores e contraste (Hanson, 2004) . . . . . . . . . . . . 75

4.8 Leitura de texto via voz (Hanson, 2004) . . . . . . . . . . . . . 75

4.9 Tela inicial da ferramenta de e-mail (Hawthorn, 2003) . . . . . . . . . . 76

4.10 Caixa de entrada de e-mails (Hawthorn, 2003) . . . . . . . . . 76

4.11 Setas auxiliares para rolagem de texto (Hawthorn, 2003) . . . . . . . 76

4.12 Seleção de arquivo anexo $($ Hawthorn, 2003) . . . . . . . . . . . . . 77

4.13 Classificação de e-mails (Hawthorn, 2003) . . . . . . . . . . . . . . . 77

4.14 Apresentação do Toolclips na ferramenta Paint.NET (Grossman e Fitzmaurice, 2010) . . . . . . . . . . . . . . . . 80

4.15 Execução dos recursos de texto e vídeo oferecidos pelo Toolclips . . . . . . 81

5.1 Percentual de Incidência dos Princípios de Usabilidade entre Usuários Inexperientes . . . . . . . . . . . . . . . . . . . . . . 93 
5.2 Percentual de Incidência das Diretrizes de Acessibilidade entre Usuários Inexperientes . . . . . . . . . . . . . . . . . . .

5.3 Percentual de Incidência dos Princípios de Usabilidade entre Usuários Experientes . . . . . . . . . . . . . . . . . . 97

5.4 Comparativo do Percentual de Incidência dos Princípios de Usabilidade entre Usuários Inexperientes e Experientes . . . . . . . . . . . . . . . . . . 97

5.5 Percentual de Incidência das Diretrizes de Acessibilidade entre Usuários Experientes . . . . . . . . . . . . . . . . . . . . . . 98

5.6 Comparativo do Percentual de Incidência das Diretrizes de Acessibilidade entre Usuários Inexperientes e Experientes . . . . . . . . . . . . . . . . . . 98

5.7 Enunciado e alternativas da Questão 1 . . . . . . . . . . . . . . . . 108

5.8 Percentual de Erros por Questões para Idosos, Adultos de Meia-Idade e Jovens . . . . . . . . . . . . . . . . . . . . . . . . . . . . 110

5.9 Percentual de Erros por Questões por Categorias de Frequência de Uso . . 111

5.10 Tela Inicial . . . . . . . . . . . . . . . . . . . . . . . . . . 114

5.11 Informações necessárias para o cadastramento . . . . . . . . . . . . . . 114

5.12 Primeiro Passo do Cadastramento . . . . . . . . . . . . . . . . . . . 115

5.13 Telas intermediárias do processo de compra on-line . . . . . . . . . . . 115

5.14 Tela de inclusão dos dados finais da compra . . . . . . . . . . . . . . . . 116

5.15 Representação gráfica dos oito menus e os mockups . . . . . . . . . . . . 120

5.16 Classificação para a Tarefa 1 (esquerda) e para a Tarefa 2 (direita) para cada menu . . . . . . . . . . . . . . . . . . . . . . 123

5.17 Número de erros cometidos por tarefa em cada menu . . . . . . . . . . . . 123

5.18 Mediana dos tempos por classificação de idade dos usuários . . . . . . . . . 124

5.19 Relação tempo e porcentagem para cada menu . . . . . . . . . . . . . . . . 124

5.20 Relação tempo e porcentagem para cada menu . . . . . . . . . . . . . . 125

5.21 Relação tempo e porcentagem para cada menu . . . . . . . . . . . . . . . . 125

6.1 Adaptação das propostas de acessibilidade para integrar a WCAG 2.0 . . . 128

6.2 Proposta de integração das recomendações aos Critérios de Sucesso da WCAG 2.0. . . . . . . . . . . . . . . . . . . . . . 129

6.3 Ideia inicial da funcionalidade do mecanismo de auxílio Tuki . . . . . . . . 148

6.4 Mecanismo de auxílio Tuki . . . . . . . . . . . . . . . . . . . . . 149

6.5 Mecanismo categorizador para páginas Web . . . . . . . . . . . . 149

6.6 Relatório de classificação do mecanismo Tuki . . . . . . . . . . . . . . . . 150

6.7 Mecanismo Tuki ativo na página da Wikipédia . . . . . . . . . . . . . . . . 151

6.8 Mecanismo Tuki indicando a opção de login na página da Wikipédia . . . . 151

6.9 Mecanismo Tuki indicando a opção de menu na página da Wikipédia . . . 152

6.10 Mecanismo Tuki indicando o campo de formulário a ser preenchido . . . . 152

6.11 Mecanismo Tuki indicando o campo de formulário a ser preenchido . . . . 153

6.12 Arquitetura do Jetpack . . . . . . . . . . . . . . . . . . . . . . . . . . 155

6.13 Questionário de avaliação do mecanismo Tuki . . . . . . . . . . . . . . . 158

6.14 Questão 1 - Recurso de aumento do tamanho da letra . . . . . . . . . . . . 163

6.15 Questão 2 - Recurso de aumento do contraste . . . . . . . . . . . . . . 164

6.16 Questão 3 - Recurso de abreviação de caminho . . . . . . . . . . . . . . 165

6.17 Questão 4 - Recurso para a assistência na entrada de dados da caixa de busca165

6.18 Questão 5 - Recurso de eliminação de banners . . . . . . . . . . . . . . 166

6.19 Questão 6 - Recurso de indicação de barra de rolagem . . . . . . . . . . . 167 
6.20 Questão 7 - Recurso de visualização de resumo de texto . . . . . . . . . . . 168

6.21 Questão 8 - Recurso de visualização de tópicos . . . . . . . . . . . . . . 168

6.22 Questão 9 - Recurso sobre links: assunto, segurança e endereçamento . . . 169

6.23 Questão 10 - Recurso de escolha de cor para links visitados . . . . . . . . 170

6.24 Questão 11 - Recurso de escolha de cores para opções do menu . . . . . . . 170

6.25 Questão 12 - Recurso de diminuição da velocidade de menus . . . . . . . . 171

6.26 Questão 13 - Recurso de diminuição da velocidade do vídeo . . . . . . . . . . 171

6.27 Questão 14 - Recurso de áudio para figuras . . . . . . . . . . . . . . . . . . 172

6.28 Questão 15 - Recurso de guia de funcionalidades . . . . . . . . . . . . . 173

6.29 Questão 16 - Recurso de quebra de formulário . . . . . . . . . . . . . . . . 174

6.30 Questão 17 - Recurso de lembrete de documentos . . . . . . . . . . . . . . 174

6.31 Questão 18 - Recurso para preenchimento de informações . . . . . . . . . . . 175

6.32 Questão 19 - Recurso de reconhecimento de procedimentos . . . . . . . . . 176

6.33 Uso do recurso de aumento de fonte agrupados por alternativa e faixa etária179

6.34 Uso do recurso de aumento de fonte por pessoas que utilizam a Web uma vez por semana ou menos agrupados por faixa etária . . . . . . . . . . . . 179

6.35 Uso do recurso de aumento de contraste agrupados por alternativa e faixa etária . . . . . . . . . . . . . . . . . . . 180

6.36 Uso do recurso de abreviação do caminho agrupados por alternativa e faixa etária . . . . . . . . . . . . . . . . . . . . 180

6.37 Uso do apoio para utilização do campo de busca agrupados por alternativa e faixa etária . . . . . . . . . . . . . . . . . . 181

6.38 Uso do recurso para eliminação de banners agrupados por alternativa e faixa etária . . . . . . . . . . . . . . . . . . 181

6.39 Uso do recurso de indicação de barra de rolagem agrupados por alternativa e faixa etária . . . . . . . . . . . . . . . . . . . 182

6.40 Uso do recurso de visualização de resumo de texto agrupados por alternativa e faixa etária . . . . . . . . . . . . . . . . . . . . . 182

6.41 Uso do recurso de visualização de tópicos do texto agrupados por alternativa e faixa etária . . . . . . . . . . . . . . . . . . 183

6.42 Uso do apoio para a utilização de links: assunto, segurança, endereçamento agrupados por alternativa e faixa etária . . . . . . . . . . . . . 183

6.43 Uso do recurso de escolha de cor para links visitados agrupados por alternativa e faixa etária . . . . . . . . . . . . . . . . . . . . . 184

6.44 Uso do recurso de escolha de cores para opções de menu agrupados por alternativa e faixa etária . . . . . . . . . . . . . . . . . . . . 184

6.45 Uso do recurso para controle de velocidade de menus agrupados por alternativa e faixa etária . . . . . . . . . . . . . . . . . . 185

6.46 Uso do recurso para diminuição da velocidade de apresentação de vídeo agrupados por alternativa e faixa etária . . . . . . . . . . . . 185

6.47 Uso do recurso de áudio para figuras agrupados por alternativa e faixa etária186

6.48 Uso do recurso de guia de funcionalidades agrupados por alternativa e faixa etária . . . . . . . . . . . . . . . . . . . 186

6.49 Uso do recurso de divisão de formulário em unidades menores agrupados por alternativa e faixa etária . . . . . . . . . . . . . . . . . . 187

6.50 Uso do recurso de lembrete de documentos da vida real agrupados por alternativa e faixa etária . . . . . . . . . . . . . . . . . . . 188 
6.51 Uso do apoio para preenchimento de campos de entrada agrupados por alternativa e faixa etária . . . . . . . . . . . . . . . . . . . 188

6.52 Uso do recurso para reconhecimento de procedimentos agrupados por alternativa e faixa etária . . . . . . . . . . . . . . . . . 189

C.1 Renderização e mockup dos menus 1 e 2 . . . . . . . . . . . . . . . . . 243

C.2 Renderização e mockup dos menus 3 e 4 . . . . . . . . . . . . . . . . 244

C.3 Renderização e mockup dos menus 5 e 6 . . . . . . . . . . . . . . . 245

C.4 Renderização e mockup dos menus 7 e 8 . . . . . . . . . . . . . . . . . . 246 


\section{Lista de Tabelas}

5.1 Totais de incidências por característica . . . . . . . . . . . . . . . . . . . . 99

5.2 Perfis dos Deficientes Visuais . . . . . . . . . . . . . . . . . . . 103

5.3 Experiência, frequência e finalidades de uso da Internet pelos deficientes visuais . . . . . . . . . . . . . . . . . . . . . 103

5.4 Quantidade de respondentes por faixa etária . . . . . . . . . . . 106

5.5 Escolaridade dos Respondentes das Faixas Etárias de Meia-idade e Idosos 106

5.6 Experiência no Uso dos Respondentes das Faixas Etárias de Meia-idade e Idosos . . . . . . . . . . . . . . . . . . . . . 106

5.7 Frequência de Uso dos Respondentes das Faixas Etárias de Meia-idade e Idosos . . . . . . . . . . . . . . . . . . . . . . . 107

5.8 Quantidade e percentual de respostas erradas por questão . . . . . . . . . 108

5.9 Respostas erradas para a Questão 1 . . . . . . . . . . . . . . . . . 109

5.10 Tempo Médio de Conclusão das Tarefas por Grupos . . . . . . . . . . . . . 117

6.1 Comparação entre navegadores . . . . . . . . . . . . . . . . . . . . 154

6.2 Avaliação sobre a utilidade do mecanismo . . . . . . . . . . . . . . . . . 159

6.3 Avaliação sobre a utilização do mecanismo em sites . . . . . . . . . . . . 160

6.4 Idade mínima e idade máxima da amostra de dados . . . . . . . . . . . . 177

6.5 Quantidade e percentual de usuários por faixa etária . . . . . . . . . . 178

6.6 Experiência dos usuários por faixa etária . . . . . . . . . . . . . . . 178

6.7 Análise das respostas da Questão 1 . . . . . . . . . . . . . . . . . . . 190

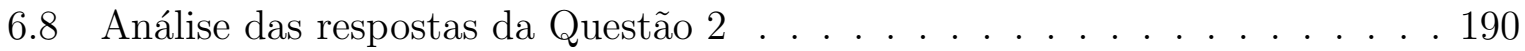

6.9 Análise das respostas da Questão 3 . . . . . . . . . . . . . . . . . . 191

6.10 Análise das respostas das questões de 4 a 11 . . . . . . . . . . . . . . . 191

6.11 Análise das respostas das questões de 12 a 19 . . . . . . . . . . . . . . . 192

6.12 Influência da experiência nas opções de uso dos mecanismos na Questão 1 . 195

6.13 Teste Qui-Quadrado para a influência da experiência nas opções de uso dos mecanismos na Questão 1 . . . . . . . . . . . . . . . . . 195

6.14 Influência da frequência de uso nas opções de uso dos mecanismos na Questão $6 \ldots \ldots \ldots \ldots$. . . . . . . . . . . . . . . . . . . . . . . . . . .

6.15 Teste Qui-Quadrado para a influência da frequência de uso nas opções de uso dos mecanismos na Questão 6 . . . . . . . . . . . . . . . 196

6.16 Influência da frequência de uso nas opções dos mecanismos na Questão 8 . 197

6.17 Teste Qui-Quadrado para a influência da frequência de uso nas opções dos mecanismos na Questão 8 . . . . . . . . . . . . . . . . . . . 197

6.18 Análise da idade em relação aos grupos de uso . . . . . . . . . . . . . . . 198

6.19 Levantamento dos 3 mecanismos mais aceitos e mais rejeitados por faixa etária . . . . . . . . . . . . . . . . . . . . . . . 198

6.20 Estatísticas a respeito dos índices de utilização dos 16 novos mecanismos . 199 
6.21 Análise de uso de comércio eletrônico e bancos on-line pelas faixas etárias . 200

C.1 Propriedades dos oitos menus . . . . . . . . . . . . . . . . . . 242 


\section{Lista de Quadros}

1 Propriedades dos oitos menus . . . . . . . . . . . . . . . . 121

2 Problemas e sugestões de ajustes para a legibilidade . . . . . . . . . . . 137

3 Problemas e sugestões de ajustes para a navegação . . . . . . . . . . . . . 139

4 Problemas e sugestões de ajustes para a realização de tarefas específicas . . 141

5 Problemas e sugestões de ajustes para sistemas de compras on-line . . . . . 142

6 Problemas e sugestões de ajustes para sistemas de compras on-line - continuação . . . . . . . . . . . . . . . . . . . . . . 143

7 Problemas e sugestões de ajustes para a busca de informações . . . . . . . 144 


\section{Lista de Acrônimos}

AAVD Atividades Avançadas da Vida Diária

AIVD Atividades Instrumentais da Vida Diária

AVD Atividades da Vida Diária

e-MAG Modelo de Acessibilidade de Governo Eletrônico

IBGE Instituto Brasileiro de Geografia e Estatística

IHC Interação Humano-Computador

PDA Personal Digital Assistants / Assistente Pessoal Digital

PNAD Pesquisa Nacional por Amostra de Domicílios

SPSS Statistical Package for the Social Sciences

TA Tecnologia Assistiva

TIC Tecnologia da Informação e Comunicação

W3C World Wide Web Consortium / Consórcio World Wide Web

WAI Web Accessibility Initiative / Iniciativa em Acessibilidade na Web

WCAG Web Content Accessibility Guidelines / Diretrizes de Acessibilidade na Web

WEB World Wide Web / Rede de Alcance Mundial 


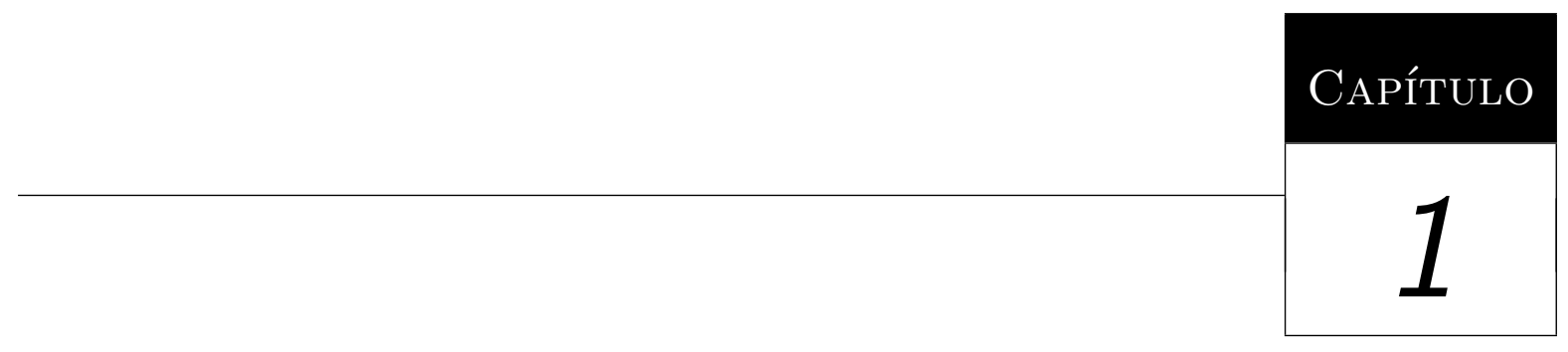

\section{Introdução}

\subsection{Contexto}

O envelhecimento populacional é hoje um fenômeno mundial e como consequência natural desse envelhecimento, pode-se observar que grande parte das pessoas sofre com a diminuição ou perda de suas habilidades.

A população dos EUA, bem como a da maioria das nações industrializadas, está passando por fortes mudanças em diversos setores da administração pública e serviços para atender às novas demandas provenientes do envelhecimento populacional, pois existe uma expectativa de tempo de vida bem maior do que há alguns anos atrás. A Organização das Nações Unidas estima que até 2050, uma em cada cinco pessoas terá mais do que 60 anos de idade. A estimativa na Europa é de que, em 2020, haverá cerca de 20,7 \% de idosos (European Commission, 2007). Em outros países essa proporção poderá ser ainda mais elevada. No Japão, a população idosa já representava $20 \%$ da população em 2005 e a previsão é que atinja os $27 \%$ em 2015 (Reuters, 2007).

No cenário nacional, segundo o portal G1 (2012), ao longo dos últimos 50 anos, a população brasileira quase triplicou: passou de 70 milhões, em 1960, para 190,7 milhões, em 2010. O crescimento do número de idosos, no entanto, foi ainda maior. Em 1960, 3,3 milhões de brasileiros tinham 60 anos ou mais e representavam 4,7\% da população. Em 2000, 14,5 milhões, ou 8,5\% dos brasileiros, estavam nessa faixa etária. Na última década, o salto foi grande, e em 2010 a representação passou para 10,8\% da população (20,5 milhões). A comparação foi realizada com base nos censos demográficos do Instituto Brasileiro de Geografia e Estatística (IBGE) de 1960, de 2000 e de 2010. O IBGE estima ainda que, em 2020, esse percentual deve chegar a 13\%, em 2040 pode ser de quase $24 \%$ e em 2050, deve atingir 30\% da população (IBGE, 2008b). 
Os resultados do Censo 2010 publicados pelo IBGE (2010a) revelam que o Brasil possui mais de 190 milhões de habitantes e mostram um país com estrutura etária mais envelhecida. Segundo esses dados (Figura 1.2), todas as faixas etárias até 25 anos têm peso menor na população do que em 2000 (Figura 1.1), ao passo que os demais grupos ampliaram sua participação. Na base da pirâmide, a representatividade do grupo de 0 a 4 anos no total da população caiu de 4,9\% (meninos) e 4,7\% (meninas) em 2000 para 3,7\% e 3,6\% em 2010. Simultaneamente, a participação da faixa com mais de 65 anos avançou de 5,9\% em 2000 para 7,4\% em 2010. A taxa média anual de crescimento da população baixou de 1,64\% no Censo 2000 (de 1991 a 2000) para 1,17\% no de 2010 (2001 a 2010).

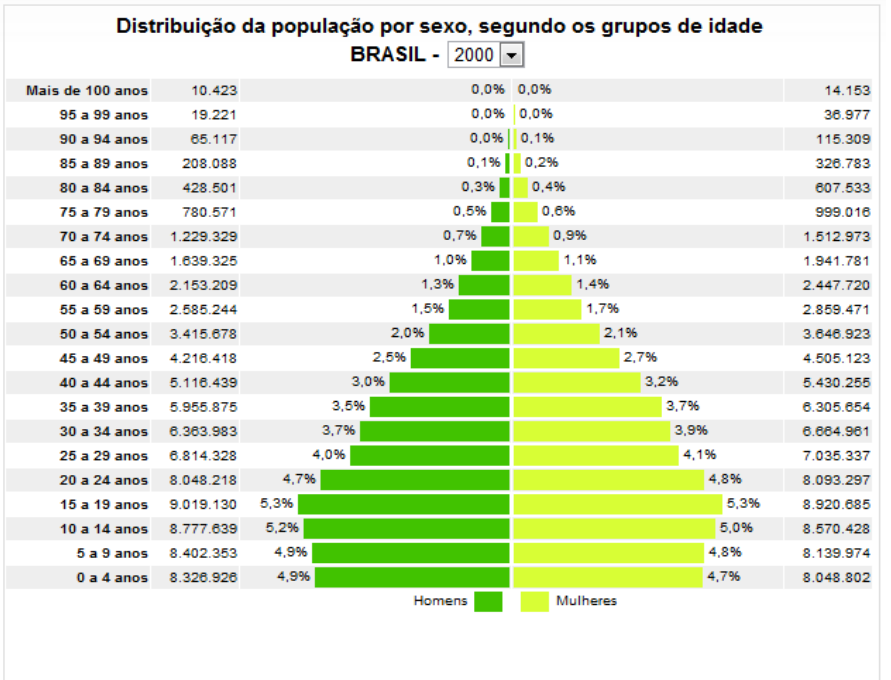

Figura 1.1: Uso da Internet no Brasil por idade e regiões no ano de 2000

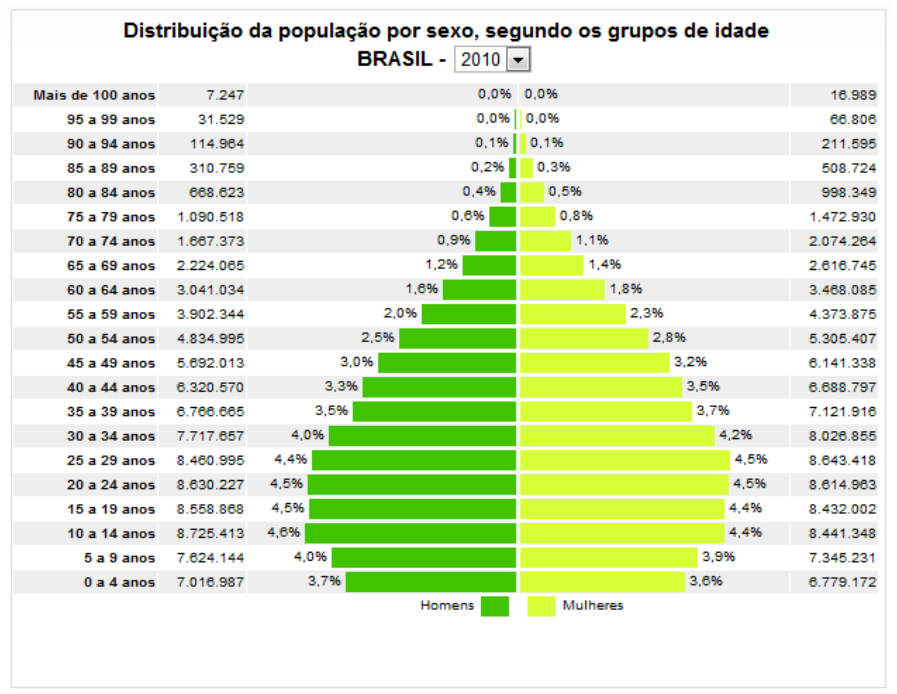

Figura 1.2: Uso da Internet no Brasil por idade e regiões no ano de 2010

O envelhecimento é reflexo do baixo crescimento populacional aliado a menores taxas de natalidade e fecundidade, bem como da melhoria da qualidade de vida dos mais velhos. 
Como pode ser observado, o Brasil tem experimentado um crescimento sem precedentes no número de pessoas idosas (com idade a partir de 60 anos) e outras que se tornarão idosas num curto período de tempo, as quais denominamos neste trabalho de "adultos de meia-idade" (40-59 anos). Esta denominação segue a revisão de literatura para adultos mais velhos realizada pela W3C (W3C, 2008a), que sugere a adoção da classificação proposta pela Associação Americana de Aposentados (AARP), na qual as denominações para as faixas etárias são: jovem (18-39 anos), meia-idade (40-59 anos) e idosos (acima de 60 anos). Para facilitar a leitura e a compreensão será utilizado o termo "adultos mais velhos" para referenciar os adultos de meia-idade e idosos nesta tese.

O crescimento da utilização da Internet tem acontecido em paralelo com o envelhecimento da população. Isso se deve à própria evolução da Web, uma vez que ela deixou de ser apenas um repositório de informações que oferecia páginas estáticas aos seus usuários e passou a oferecer apoio em vários segmentos de suas vidas. Atualmente, além de oferecer serviços on-line, como sites de compras, bancos, governo, aprendizado, entre outros, são oferecidas também aplicações para apoio à comunicação e ao entretenimento, tais como fóruns, chats, blogs, comunidades virtuais, redes sociais, compartilhamento de fotos e vídeos, entre outros. O crescimento do uso da Web por pessoas de meia-idade com pouca ou nenhuma experiência em interações com a Web, idosas e/ou com necessidades especiais tem motivado o desenvolvimento de técnicas para produzir páginas Web usáveis e acessíveis.

Segundo o Censo 2010 do IBGE (2010a), com relação à presença de computadores em domicílio e acesso à Internet, foi verificada a elevação em 27,7 pontos percentuais na presença de microcomputadores nos domicílios, que passou de 10,6\% em 2000 para 38,3\% no ano de 2010. Do total de domicílios, 30,7\% tinham acesso à Internet. Na análise por região, foi constatado que o percentual de domicílios com este bem na Região Sudeste (48,0\%) representa mais que o dobro do existente na Região Norte (22,7\%). Os domicílios com microcomputador com acesso à Internet na Região Sudeste revelam, também, um percentual acima do dobro relativo ao da Região Norte $(39,6 \%$ e 15,4\%, respectivamente) (IBGE, 2010a). O crescimento no uso da Internet no Brasil em comparação com outros países de América do Sul no ano de 2011 foi disponibilizado pelo site Internet World Stats 1 e pode ser verificado na Figura 1.3.

Em 2009, a Pesquisa Nacional por Amostra de Domicílios investigou o acesso à Internet, resultante de convênio entre o IBGE e o Comitê Gestor da Internet no Brasil - CGI.br, objetivando ampliar o conhecimento sobre a utilização das tecnologias da informação no País, não só com vistas à necessidade de indicadores para o atendimento no contexto nacional como também à comparação internacional de estatísticas sobre a sociedade da informação (IBGE, 2010b). Foram analisadas as principais características das pessoas que utilizaram a Internet no Brasil em função do local, finalidade/frequência

\footnotetext{
${ }^{1}$ Disponível em http://www.internetworldstats.com/
} 


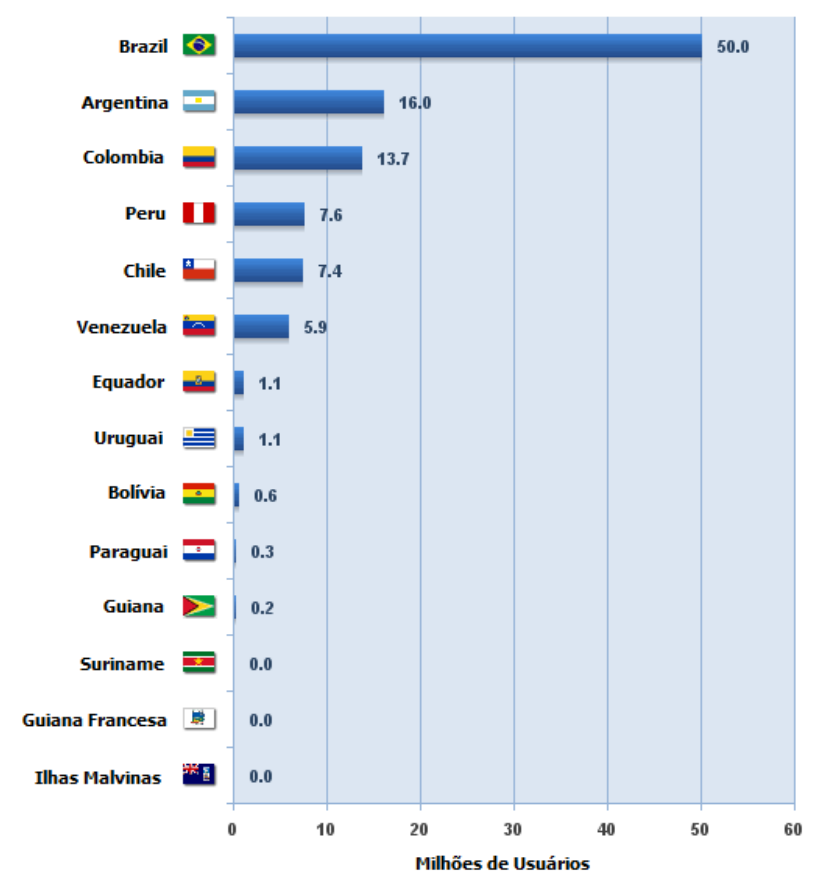

Figura 1.3: Comparativo de Uso da Web na America do Sul em 2011. Figura adaptada do site Internet World Stats: http://www.internetworldstats.com

do acesso e tipo de conexão no domicílio. Traça também os perfis dos usuários e não-usuários da Internet, segundo sexo, idade, nível de instrução, rendimento mensal domiciliar per capita, condição de estudante e situação de ocupação. As Figuras 1.4, 1.5 e 1.6 mostram números absolutos e relativos ao total da população, bem como seus respectivos percentuais.

\begin{tabular}{|c|c|c|c|c|c|c|}
\hline \multirow{4}{*}{$\begin{array}{c}\text { Sexo } \\
e \\
\text { grupos de idade }\end{array}$} & & & & & & (conclusăo) \\
\hline & \multicolumn{6}{|c|}{$\begin{array}{l}\text { Pessoas de } 10 \text { anos ou mais de idade que utilizaram a Internet, } \\
\text { no periodo de referência dos últimos três meses ( } 1000 \text { pessoas) }\end{array}$} \\
\hline & \multirow{2}{*}{ Brasil } & \multicolumn{5}{|c|}{ Grandes Regióes } \\
\hline & & Norte & Nordeste & Sudeste & Sul & Centro-Oeste \\
\hline \multicolumn{7}{|c|}{2009} \\
\hline Total & 67893 & 4263 & 13522 & 33531 & 11031 & 5546 \\
\hline 10 a 14 anos & 10238 & 668 & 2279 & 4769 & 1646 & 875 \\
\hline 15 a 17 anos & 7397 & 579 & 1802 & 3181 & 1211 & 624 \\
\hline 18 ou 19 anos & 4493 & 342 & 1026 & 2067 & 697 & 362 \\
\hline 20 a 24 anos & 10188 & 749 & 2357 & 4765 & 1484 & 832 \\
\hline 25 a 29 anos & 8849 & 599 & 1759 & 4359 & 1394 & 738 \\
\hline 30 a 39 anos & 12160 & 730 & 2192 & 6204 & 1984 & 1050 \\
\hline 40 a 49 anos & 8320 & 378 & 1262 & 4534 & 1512 & 635 \\
\hline 50 anos ou mais & 6247 & 217 & 845 & 3653 & 1103 & 429 \\
\hline
\end{tabular}

Figura 1.4: Uso da Internet no Brasil por idade e regiões

Na Figura 1.4 é mostrado o número de pessoas que utilizaram a Internet de acordo com a faixa etária e a região do Brasil. Analisando a Figura 1.5 é possível obter uma visão mais clara do percentual de uso da Internet com relação ao número total de usuários do 


\begin{tabular}{|c|c|c|c|c|c|c|}
\hline \multirow{4}{*}{$\begin{array}{c}\text { Sexo } \\
e \\
\text { grupos de idade }\end{array}$} & & & & & & (conclusăo) \\
\hline & \multicolumn{6}{|c|}{$\begin{array}{l}\text { Distribuiçăo das pessoas de } 10 \text { anos ou mais de idade que utilizaram a Internet, } \\
\text { no periodo de referência dos últimos três meses }(\%)\end{array}$} \\
\hline & \multirow{2}{*}{ Brasil } & \multicolumn{5}{|c|}{ Grandes Regióes } \\
\hline & & Norte & Nordeste & Sudeste & Sul & Centro-Oeste \\
\hline \multicolumn{7}{|c|}{2009} \\
\hline Total & 100,0 & 100,0 & 100,0 & 100,0 & 100,0 & 100,0 \\
\hline 10 a 14 anos & 15,1 & 15,7 & 16,9 & 14,2 & 14,9 & 15,8 \\
\hline 15 a 17 anos & 10,9 & 13,6 & 13,3 & 9,5 & 11,0 & 11,2 \\
\hline 18 ou 19 anos & 6,6 & 8,0 & 7,6 & 6,2 & 6,3 & 6,5 \\
\hline 20 a 24 anos & 15,0 & 17,6 & 17,4 & 14,2 & 13,5 & 15,0 \\
\hline 25 a 29 anos & 13,0 & 14,1 & 13,0 & 13,0 & 12,6 & 13,3 \\
\hline 30 a 39 anos & 17,9 & 17,1 & 16,2 & 18,5 & 18,0 & 18,9 \\
\hline 40 a 49 anos & 12,3 & 8,9 & 9,3 & 13,5 & 13,7 & 11,4 \\
\hline 50 anos ou mais & 9,2 & 5,1 & 6,2 & 10,9 & 10,0 & 7,7 \\
\hline
\end{tabular}

Figura 1.5: Uso da Internet no Brasil por idade e regiões em percentuais

Brasil. Por esta figura pode-se constatar que o grupo formado pelos adultos de meia-idade e idosos representa 21,5\% do número total de usuários. Em termos de percentual de uso com relação ao total da população do Brasil no ano de 2009, pode-se observar na Figura 1.6 que do número total da população que se encontra na faixa etária de 40 a 49 anos tem-se 32,7\% de usuários da Internet enquanto que do total da população na faixa etária acima de 50 anos apenas 15,2\% são usuários.

\begin{tabular}{|c|c|c|c|c|c|c|}
\hline \multirow{4}{*}{$\begin{array}{c}\text { Sexo } \\
e \\
\text { grupos de idade }\end{array}$} & & & & & & (conclusăo) \\
\hline & \multicolumn{6}{|c|}{$\begin{array}{l}\text { Percentual das pessoas que utilizaram a Internet, no periodo de referência } \\
\text { dos últimos três meses, na populaçăo de } 10 \text { anos ou mais de idade }(\%)\end{array}$} \\
\hline & \multirow{2}{*}{ Brasil } & \multicolumn{5}{|c|}{ Grandes Regiốes } \\
\hline & & Norte & Nordeste & Sudeste & Sul & Centro-Oeste \\
\hline \multicolumn{7}{|c|}{2009} \\
\hline Total & 41,7 & 34,3 & 30,2 & 48,1 & 45,9 & 47,2 \\
\hline 10 a 14 anos & 58,8 & 39,9 & 41,8 & 71,1 & 70,2 & 70,3 \\
\hline 15 a 17 anos & 71,1 & 60,0 & 55,1 & 82,1 & 80,6 & 79,5 \\
\hline 18 ou 19 anos & 68,7 & 59,0 & 53,6 & 78,3 & 75,6 & 75,2 \\
\hline 20 a 24 anos & 61,8 & 51,4 & 47,3 & 71,8 & 67,5 & 68,3 \\
\hline 25 a 29 anos & 53,7 & 42,2 & 37,5 & 64,0 & 60,8 & 58,6 \\
\hline 30 a 39 anos & 42,1 & 31,0 & 27,8 & 50,5 & 48,5 & 46,0 \\
\hline 40 a 49 anos & 32,7 & 22,5 & 19,6 & 39,7 & 37,0 & 34,7 \\
\hline 50 anos ou mais & 15,2 & 9,5 & 8,3 & 18,8 & 16,7 & 16,2 \\
\hline
\end{tabular}

Figura 1.6: Uso da Internet no Brasil por idade e regiões em percentuais relativos ao total da população

A pesquisa PNAD do ano de 2009 constatou também a têndencia que vem se apresentando desde 1992, que se caracteriza pela redução na população mais jovem e aumento do percentual de pessoas com idade mais avançada. O envelhecimento da população combinado com as taxas de fecundidade em queda irá criar uma população 
brasileira totalmente diferente para o futuro. Diante desse fato surge a preocupação em relação à necessidade que o país, em breve, terá de adaptar muitas das suas políticas públicas para atender ao acelerado envelhecimento da população (IBGE, 2010b).

Dentre as informações já disponibilizadas a respeito do Censo IBGE de 2010 tem-se a pirâmide etária brasileira ${ }^{2}$, representada pela Figura 1.2 cujo percentual de indíviduos de meia-idade compreende $22,6 \%$ e de idosos $11 \%$ (IBGE, 2010a).

Para o ano de 2050 o IBGE (2008b) prevê um perfil demográfico cada vez mais envelhecido. Em 2008, para cada grupo de 100 crianças de 0 a 14 anos existiam 24,7 idosos de 65 anos ou mais. Em 2050, o quadro deve mudar e para cada 100 crianças de 0 a 14 anos existirão 172, 7 idosos. Um exame das estruturas etárias projetadas mostra, também, a transformação nas relações entre pessoas que ingressam (e permanecem) nas idades ativas e aquelas que atingem as chamadas idades potencialmente inativas. Em 2000, para cada pessoa com 65 anos ou mais de idade, aproximadamente 12 estavam na faixa etária chamada de potencialmente ativa (15 a 64 anos). Já em 2050, para cada pessoa com 65 anos ou mais de idade, pouco menos de 3 estarão na faixa etária potencialmente ativa.

Segundo Gonçalves et al. (2011), a idade exerce uma forte influência sobre o uso de tecnologias da informação e comunicação (TICs), no qual pode-se observar uma redução significativa no seu uso após os 45 anos (Minister of Industry, 2005). Nesse sentido, pesquisas na área mostram uma associação negativa entre idade e habilidades de interação com recursos tecnológicos (Hellman, 2007).

A evolução tecnológica tem facilitado a vida das pessoas nos últimos anos, mas quais as tendências que podem ser projetadas para um futuro próximo? Como será a tecnologia daqui a 20 anos?

O dinamismo da evolução tecnológica tende a transformar relações e interações em diversos setores. A convergência das tecnologias em redes de alta velocidade deverá revolucionar o trabalho, o estudo e o lazer. No próximo ano, os telefones celulares deverão ultrapassar os PCs como sendo o dispositivo mais comum de acesso à web em todo o mundo. A ampla adoção da plataforma móvel pelos consumidores forçaram as empresas a apoiar o uso de dispositivos pessoais também para fins profissionais (Gartner, 2012).

Num futuro mais próximo do que se imagina, os aparelhos domésticos deverão conversar entre si. Tudo vai conectar-se à internet, incluindo câmeras, microfones, realidade aumentada, edifícios e sensores embutidos em todos os lugares. Será a chamada Internet das Coisas (Gartner, 2012).

Sistemas de automação comerciais domésticos estão se tornando cada vez mais comuns, proporcionando mecanismos para automatizar casas quase que por inteiras (Mennicken e Huang, 2012)(Aztiria et al., 2012). Por meio de dispositivos eletrônicos programados, as casas poderão controlar a iluminação, abrir e fechar janelas, regar plantas, alimentar

\footnotetext{
${ }^{2}$ Disponível em http://www.ibge.gov.br/censo2010/piramide_etaria/index.php
} 
animais de estimação e até se integrar aos dispositivos eletrônicos portáteis e carros (Fernando Daquino, 2012). Além da comodidade, a tecnologia empregada em casas pode servir para a segurança de crianças e pessoas idosas. Segundo Cook et al. (2012), a intenção é desenvolver tecnologias que forneçam a assistência necessária para suprir limitações cognitivas ou físicas, tais como: dispositivos para ajudar idosos a se levantar, preparar sua comida, fazer chamadas telefônicas com as mãos livres e lembrar-se de tomar suas medicações, etc.

Motivados pela economia nos negócios, empresas não deverão mais executar projetos isolados, mas sim compartilhar serviços, armazenamento e análise de dados (Cloud Computing, Strategic Big Data, Actionable Analytics). A computação em memória poderá permitir que as atividades que consomem horas para serem executadas levem minutos ou apenas segundos. A computação em memória deverá se tornar uma plataforma dominante nos próximos anos, já que cada vez mais os usuários buscam consultas em tempo real (Gartner, 2012).

A nuvem também poderá abrigar todos os aspectos da vida de uma pessoa (Gartner, 2012). Por ser um modelo tão vasto e capaz de empacotar recursos infinitos, nenhuma plataforma, tecnologia ou vendedor deverá dominá-lo. Isso também significa que a tecnologia da informação terá de suportar quase tudo.

A partir desta projeção da evolução da tecnologia surgem dúvidas quanto ao provável futuro para as próximas gerações de usuários de tecnologia. Será que as habilidades atuais se mostrarão adequadas ou suficientes para o uso da tecnologia no futuro?

Hanson (2011) discute se as dificuldades dos adultos mais velhos na utilização das tecnologias permanecerão as mesmas para daqui a 20 anos. Questiona se as perdas das habilidades decorrentes do envelhecimento, principalmente no que diz respeito à capacidade de aprendizado, irão afetar o uso de tecnologias quando os jovens de hoje envelhecerem e argumenta que, as próximas gerações de adultos mais velhos terão um repertório de habilidades tecnológicas maior do que os adultos mais velhos de hoje, o que irá lhes fornecer uma experiência mais específica no uso da Web e consequentemente uma maior capacidade geral de lidar com aplicações informáticas. A tendência em permanecer no mercado de trabalho também poderá contribuir para que estes próximos adultos mais velhos continuem em contato com as mudanças tecnológicas por mais tempo do que as gerações anteriores.

Segundo Hanson (2011), pode ser que num futuro próximo, a incapacidade dos adultos mais velhos em utilizar as tecnologias futuras não sejam decorrentes de um declínio gradual da capacidade em aprender a utilizar a tecnologia, mas pela quebra de paradigma ou pela transformação de usabilidade nos pontos de ruptura das mudanças tecnológicas. Assim, apesar da experiência proveniente do uso da tecnologia atual, pode ser que o usuário não seja capaz de utilizar uma tecnologia recém-desenvolvida. É possível que daqui a 20 anos os computadores possam ter evoluído para um estado em que a experiência de hoje com a 
Web e outras aplicações de computação já não servem para os usuários mais velhos. Como as gerações mais velhas de hoje, as próximas gerações mais velhas podem encontrar novas tecnologias com muitos aspectos desconcertantes.

A preocupação com acessibilidade na Web tem aumentado consideravelmente no cenário brasileiro, visto que a parcela da população idosa está crescendo significativamente com o aumento da expectativa de vida, e as interfaces de usuário não têm atendido de forma satisfatória esse público. Dentre as iniciativas estão o Modelo de Acessibilidade Brasileiro, e-MAG (Brasil, 2011), que já se encontra na terceira versão e um dos "Grandes desafios da pesquisa em computação no Brasil" (SBC, 2006), que trata do "Acessoparticipativoeuniversaldocidadãobrasileiroaoconhecimento", iniciativas essas que visam atender às diferentes necessidades dos usuários e incluir os chamados "analfabetos digitais".

Acessibilidade na Web corresponde a uma característica de qualidade que possibilite que qualquer usuário, utilizando qualquer agente (software ou hardware que recupera e serializa conteúdo Web), possa entender e interagir com o conteúdo de um site (Thatcher e Waddell, 2002) ou que usuários sejam capazes de acessá-la a partir de diferentes situações (W3C, 1999b). Para prover tais características de acessibilidade devem ser observadas as características dos usuários e os recursos tecnológicos necessários para a interação. Assim, páginas Web devem ser implementadas de forma a serem apresentadas e visualizadas independentemente do dispositivo, sistema operacional ou navegador que o usuário estiver utilizando. Por outro lado, as necessidades específicas dos usuários devem ser consideradas por meio da disponibilização de mecanismos que apóiem a interação, promovendo, por exemplo, a adaptação, redundância ou substituição do conteúdo de acordo com as suas deficiências físicas ou cognitivas. Acessibilidade incorpora ainda a ideia de que todas as pessoas têm o direito de ser incluídas na sociedade, independente de deficiências, localização geográfica, barreiras de linguagem ou outro fator (Thatcher e Waddell, 2002).

A acessibilidade na Web se destina a prover meios para que pessoas com dificuldades (usuários inexperientes e idosos), portadoras de necessidades especiais (cegos, daltônicos, baixa visão, surdos, mobilidade reduzida) e usuários de dispositivos móveis sejam capazes de interagir e utilizar a Web de forma natural (Fortes et al., 2005). Embora, muitas vezes, as pessoas mais velhas não possuam qualquer tipo de necessidade especial, elas ainda podem encontrar dificuldades nesse tipo de interação. Uma das principais razões é que, atualmente, os adultos de meia-idade e os idosos são, em grande parte, usuários inexperientes, que não sabem como realizar as atividades que desejam e não têm conhecimento da dimensão dos benefícios que essa interação pode lhes oferecer em sua vida diária. Além dessas razões, existem ainda as barreiras criadas pelos próprios desenvolvedores que, pela busca de produtividade e rapidez no desenvolvimento, acabam por não dar atenção ao aspecto humano e se preocupam apenas em criar ambientes 
tecnologicamente eficientes, deixando de lado as necessidades específicas de certos grupos de usuários.

Quando foi concebida, a WWW (World Wide Web) tinha como principal intuito prover uma tecnologia para disponibilização de conteúdo em um formato padrão simples e flexível, através de informações disponibilizadas em hipertexto utilizando HTML (W3C, 1999a). Desde a concepção da Web, Tim Berners Lee ${ }^{3}$ destacou que "o poder da Web está em sua universalidade. Ser acessada por todos, independente de deficiência, é um aspecto essencial". Mas, com o desenvolvimento e difusão da Web, diversas tecnologias que não seguem padrões foram criadas para estender as possibilidades do HTML e com o intuito de oferecer páginas cada vez mais sofisticadas, grande parte dos criadores de páginas e empresas que desenvolvem navegadores e sites deixaram de seguir os principais padrões que garantiam a universalidade da Web, utilizando-se de recursos técnicos que se transformam em barreiras de acesso para determinados grupos de pessoas, tais como os adultos de meia-idade com pouca experiência no uso de computadores, idosos e os portadores de necessidades especiais.

Embora a Web seja utilizada por adultos de meia-idade e idosos principalmente para a busca de informações e para comunicação com familiares e amigos, é preciso destacar sua grande contribuição para o aumento da produtividade no trabalho e também para a manutenção da independência funcional desses adultos mais velhos, de modo a preservar a autonomia com que eles desempenham as funções do dia-a-dia (Burdick, 2005).

\subsection{Objeto de Estudo}

O trabalho desenvolvido teve como alvo principal os adultos de meia-idade e idosos com pouca experiência no uso da Web, visando a permitir às pessoas com necessidades diferenciadas o acesso às facilidades oriundas da interação com a Web da forma mais independente e natural possível, proporcionando melhorias na qualidade de vida, promovendo sua integração social e também sua inclusão digital. Portanto, as questões relacionadas aos meios de interação com a Web por parte dessa população foi o objeto de estudo desta tese.

Com o objetivo de tornar mais rica a experiência desse público-alvo em interações com a Web, é essencial levar em consideração as necessidades de diferentes perfis de usuários, bem como suas deficiências visuais, auditivas, motoras e cognitivas, as quais vão se tornando mais acentuadas a partir dos 40 anos de idade. A observância dos princípios de usabilidade e das diretrizes de acessibilidades já consagradas pela área de IHC (Interação Humano-Computador) é de fundamental importância para a construção de sistemas usáveis e acessíveis, tanto do ponto de vista tecnológico quanto social.

\footnotetext{
${ }^{3}$ Inventor da Web e diretor do World Wide Web Consortium (W3C)
} 


\subsection{Questão da Pesquisa}

Embora exista um grande esforço por parte de grupos de trabalho do W3C e de vários pesquisadores em definir diretrizes de acessibilidade e usabilidade a serem seguidas durante a elaboração de páginas Web, existe ainda a necessidade de um maior conhecimento, por parte dos desenvolvedores, a respeito dos reais problemas que afetam os usuários mais velhos em suas interações com a Web. Não basta construir um site tecnicamente acessível, mas sim prover meios para que os usuários sejam capazes de compensar suas dificuldades sem a exigência de grandes habilidades técnicas (Sloan, 2006).

A tese está contextualizada na premissa da literatura de que a combinação entre princípios de usabilidade, diretrizes de acessibilidade (WCAG 2.0 e suas extensões) e orientações de design pode enriquecer e/ou melhorar a interação dos adultos de meia-idade e idosos (adultos mais velhos) com a Web, na medida em que favorece a retenção da atenção e diminui a sobrecarga cognitiva, contribuindo assim para a usabilidade e o acesso universal.

Neste contexto, o foco desta tese está na identificação de quais mecanismos de apoio à interação com a Web se mostram mais úteis (bem aceitos) pelo público-alvo da pesquisa, considerando-se que não é possível atender a todos completamente. A pergunta a ser respondida é:

Durante o desenvolvimento de páginas Web, quais mecanismos de usabilidade e acessibilidade devem ser incluídos para que possam executar o apoio necessário à interação e fazer com que usuários mais velhos consigam realizar suas interações da forma mais natural e independente possível?

A abordagem está centrada no conceito de design universal considerando também usabilidade e acessibilidade, e envolve a exploração dos seguintes pontos:

- Como identificar quais as principais dificuldades relativas à interação de adultos de meia-idade e idosos com a Web?

- Com qual prioridade devem ser tratados os aspectos como visualização, reconhecimento de elementos, foco da atenção, estruturação da informação e navegação de modo a influenciar positivamente a interação?

- Quais mecanismos incluir para o apoio apropriado nas páginas sem ser intrusivo o suficiente para interferir negativamente na interação?

A seguir são apresentados os principais elementos que caracterizam essa questão de pesquisa. 


\subsubsection{Questão de Partida}

Para nortear os rumos da pesquisa foi elaborada uma pergunta inicial que serviu como ponto de partida para o objetivo final:

Quais seriam as dificuldades e os mecanismos de apoio necessários para atender as dificuldades na interação de adultos mais velhos com a Web de forma independente?

Vários estudos da literatura seguem a abordagem na qual uma nova interface é criada especialmente para os mais velhos, levando-se em consideração suas deficiências decorrentes do envelhecimento.

Neste trabalho a intenção não é reconstruir interfaces mas incorporar mecanismos de apoio às páginas de modo que auxiliem os adultos mais velhos a interagirem com as páginas em seu formato original, obtendo assim uma experiência satisfatória em suas interações.

\subsubsection{Definição do escopo}

É importante ressaltar que o foco deste trabalho não foi pesquisar em profundidade os declínios consequentes do envelhecimento, mas procurar descobrir, na prática, quais as principais dificuldades enfrentadas pelos usuários mais velhos durante suas interações com a Web, e que muitas vezes, se transformam em barreiras intransponíveis favorecendo o abandono da experiência.

Além disso, foi priorizada a definição de uma abordagem prática, centrada no usuário e orientada pelos dados levantados em cada uma das etapas do trabalho.

Foram realizadas observações de campo, entrevistas e testes presenciais com usuários na cidade de São Carlos. Os questionários on-line foram amplamente divulgados via e-mail, contemplando usuários das mais diversas localidades.

\subsubsection{Justificativas}

Segundo informações publicadas pela Revista IstoÉ (2009), na última década, a População Economicamente Ativa (PEA) de 60 anos ou mais avançou de $56 \%$ e chegou a 770 mil pessoas em 2008 em cinco regiões metropolitanas e no Distrito Federal de acordo com os dados do IBGE. Essa elevação coloca o crescimento do número de trabalhadores idosos $25 \%$ acima do total de pessoas que ingressaram no mercado de trabalho no mesmo período. Em 2008, apenas quatro entre 100 idosos estavam desempregados, segundo levantamento do Departamento Intersindical de Estatística e Estudos Socioeconômicos (Dieese). O IBGE confirma os dados positivos. De 2001 a 2007, houve um crescimento de $43 \%$ no 
número de empregados dessa faixa etária no País, enquanto a população idosa cresceu ao todo $30 \%$.

Os fatores que levam a população da terceira idade a procurar emprego vão desde a ocupação de tempo até a complementação da renda familiar. Em 53\% dos lares brasileiros, os idosos contribuem com pelo menos metade da despesa da família. Segundo a Pesquisa Nacional por Amostra de Domicílios (PNAD) de 2007, 45\% dos idosos viviam com seus filhos na condição de chefe de domicílio. Nesse contexto, é essencial que os adultos mais velhos consigam utilizar a Internet de forma a atender às demandas de seus postos de trabalho. Além das exigências do mercado de trabalho, a população idosa representa também uma parcela economicamente significativa para o comércio eletrônico.

Apesar de todos os avanços na área de IHC, muitas interfaces ainda podem ser difíceis de usar, gerando barreiras para determinados grupos de pessoas, principalmente para os que tem alguma dificuldade motora, visual, de audição ou cognitiva, sendo algumas delas provenientes do processo de envelhecimento. Pessoas que apresentam tais dificuldades podem se sentir desorientadas durante suas interações em um site, ficando impossibilitadas de realizarem um simples envio de mensagem eletrônica, uma tarefa de compra ou até mesmo solicitações de documentos, que algumas vezes, são realizadas exclusivamente por meio da Web.

Apesar das existência de vários estudos de caso envolvendo idosos na área de IHC, muito pouco se sabe sobre as reais necessidades dos adultos de meia-idade na Web. Dessa forma, concluiu-se que o ideal seria iniciar os trabalhos com um levantamento das principais dificuldades e barreiras enfrentadas pelos adultos mais velhos (meia-idade e idosos) durante suas interações com a Web para então ser capaz de identificar um conjunto de mecanismos de apoio para atender a tais necessidades.

\subsection{Objetivos}

\subsubsection{Objetivos Gerais}

O objetivo nesta tese foi: investigar as reais dificuldades e necessidades dos adultos mais velhos em suas interações com a Web para identificar mecanismos de apoio, mais especificamente voltados para as características de design de interfaces, a serem incorporados em páginas Web de modo a melhorar a experiência desse público-alvo com a Web.

Esses mecanismos de design identificados para apoio à interação dos adultos mais velhos com a Web devem endereçar dificuldades como: visualização da informação, retenção de foco da atenção, relembrança de tarefas já executadas, controle de velocidade de execução de elementos da interface, alternativas narrativas para informações importantes 
(textos explicativos, formatação de campos, documentos necessários, etc), guia de opção (o que fazer e como fazer), entre outros.

\subsubsection{Objetivos Específicos}

Os principais objetivos específicos investigados foram:

- Investigar as dificuldades dos adultos mais velhos em suas interações com a Web;

- Investigar possíveis extensões dos príncipios de usabilidade e diretrizes de acessibilidade de forma a acomodar as necessidades reais dos adultos mais velhos;

- Investigar os recursos de design (mecanismos) que devem ser utilizados no desenvolvimento de aplicações Web acessíveis para os adultos mais velhos de modo a compensar suas dificuldades e proporcionar uma experiência satisfatória (conclusão das atividades a que se propõem independentemente do tempo e de auxílios presenciais) sem modificar drasticamente a interface em questão.

\subsection{Procedimentos Metodológicos}

Com a finalidade de investigar inicialmente as principais dificuldades e barreiras dos adultos mais velhos em interações com a Web, foram realizadas observações de campo, por meio do acompanhamento de usuários iniciantes em tecnologias Web em cursos introdutórios. Foram aplicados também questionários a usuários cegos e de baixa visão, bem como questionários para usuários de meia-idade mais experientes com interações na Web (Lara e Fortes, 2009).

Outros procedimentos de investigação foram elaborados: aplicações on-line em forma de questionários, sites e ferramentas de apoio para avaliar o reconhecimento de elementos em páginas Web, protótipo de site de comércio eletrônico, protótipos para a investigação da navegação por meio do uso de menus e a utilização de mecanismo de apoio sensível ao contexto.

A investigação relacionada ao site de comércio eletrônico foi realizada porque esses sites, em especial, podem ser considerados como um meio cômodo e seguro para a realização das compras diárias, especialmente no momento em que o indivíduo passa a apresentar os declínios funcionais decorrentes do envelhecimento, tais como a redução da mobilidade, diminuição da visão, da audição, entre outros. Assim, é de fundamental importância que o indivíduo consiga realizar suas interações com sites de compras on-line de forma satisfatória, apesar de suas dificuldades (Lara et al., 2010a).

A partir dos dados coletados via observações, aplicações de questionários e testes com um protótipo de site de comércio eletrônico, foi então elaborada uma proposta de inclusão de novos critérios de sucesso para as diretrizes da WCAG 2.0 (Lara et al., 2010b). 
Na sequência dos trabalhos, foi investigado o mecanismo de uso de menus, visto que dificuldades relativas ao uso de menus navegacionais desestimulavam a exploração dos sites e favoreciam o abandono da experiência, pois os usuários não conseguiam realizar a tarefa desejada devido a uma série de aspectos relacionados aos menus presentes nas páginas. São várias as características de um menu que podem influenciar na interação dos usuários, tais como: estrutura hierárquica, quantidade de subníveis, apresentação de subopções em colunas, velocidade de apresentação, forma de ativação, entre outras (Santos et al., 2011b)(Santos et al., 2011a).

Com o objetivo de imitar o apoio humano presencial de modo a facilitar a experiência das pessoas com diferentes perfis e necessidades em interações com a Web, bem como levar em consideração suas deficiências visuais e cognitivas, foi desenvolvida uma ferramenta, de apoio sensível ao contexto, para descobrir os elementos de interação presentes na página e ser capaz de fornecer o apoio necessário à sua utilização (Lara et al., 2011a)(Lara et al., 2011b). Essa ferramenta foi implementada por meio de um add-on com o objetivo incrementar as funcionalidades do browser (navegador Web). Constatada a viabilidade da ferramenta por meio de opiniões de usuários coletadas via entrevista, decidiu-se por investigar quais seriam os mecanismos de apoio mais relevantes para o público-alvo em questão.

Com base nas observações e coleta de dados realizadas até então, foram elencados cerca de vinte mecanismos de apoio que seriam de grande auxílio frente às dificuldades encontradas pelos adultos mais velhos. Para coletar o feedback dos usuários, foi elaborado um questionário on-line com demonstrações do funcionamento de cada mecanismo proposto, de modo que o respondente poderia executar a demonstração quantas vezes fosse necessário antes de responder às perguntas.

A Figura 1.7 mostra a sequência de realização dos procedimentos de pesquisa mencionados seguindo a ordem cronológica.

As publicações produzidas no período estão indicadas por quadros numéricos na Figura 1.7 e correspondem aos seguintes trabalhos:

1. FREIRE, A. P.; TANAKA, E. ; LARA, S. M. A.; ROCHA, H.; FORTES, R. P. M. Comparing Accessibility in e-learning Web environments: a metric based approach. In: WebMedia 2007, Gramado, RS. Proceedings of the XIII Brazilian Symposium on Multimedia and the Web (WebMedia'07), v. 1, p. 49-56.

2. LARA, S.M.A. Monografia de Qualificação de Doutorado, ICMC-USP, 2008.

3. LARA, S. M. A.; FORTES, R. P. M. Usabilidade universal para adultos de meia-idade em interações com a Web. In: CLEI 2009, 2009, Pelotas, RS. Proceeding of da XXXV Latin American Informatics Conference (CLEI 2009), v. 1, p. 1-10. 


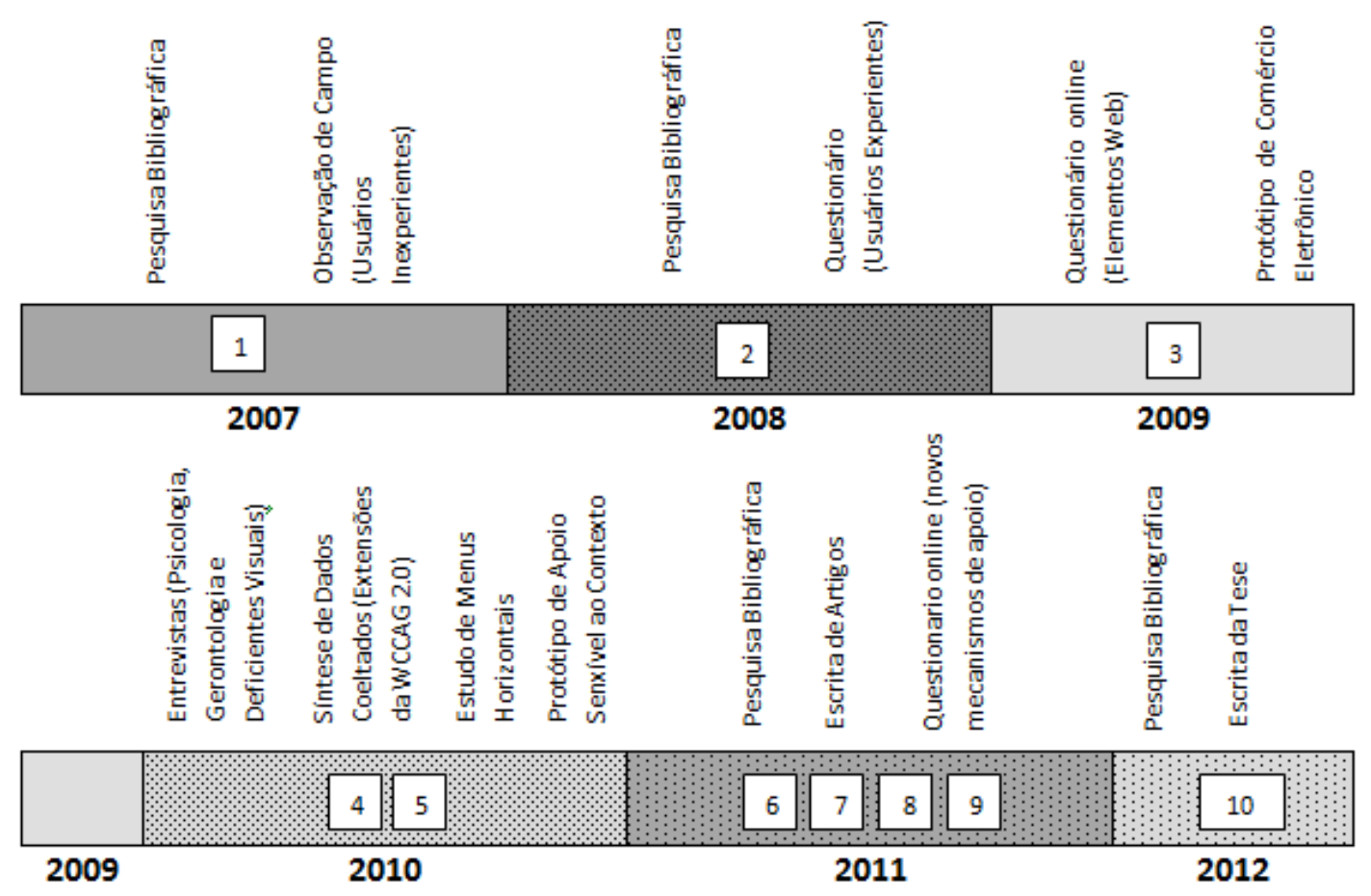

Figura 1.7: Métodos de Pesquisa executados neste trabalho

4. LARA, S. M. A.; PIETROnERO, W. ; FORTES, R. P. M. Acessibilidade para Adultos de Meia-Idade e Idosos em e-Commerce. In: (WebMedia'10), 2010, Belo Horizonte, MG. Anais de Artigos Resumidos e Artigos de Workshops do XVI Simpósio Brasileiro de Sistemas Multimídia e Web, v. II, cd-rom.

5. LARA, S. M. A; WAtanabe, W. M.; SAntos, E. P. B.; FORTES, R. P. M. Improving WCAG for Elderly Web Accessibility. In: ACM SIGDOC'10, 2010, São Carlos, SP. Proceedings of the 28th ACM International Conference on Design of Communication (ACM SIGDOC'10), v. 1, p. 175-182.

6. SANTOS, E. P. B.; LARA, S. M. A.; CASTRO, M.; FORTES, R. P. M. Menus horizontais drop-down: um estudo de caso com prioridade para usuários de meia-idade. In: CLEI 2011, 2011, Quito, Equador. Proceedings of the Centro Latino Americano de Estudios en Informática (CLEI 2011), v. 1, p. 1-10.

7. SANTOS, E. P. B.; LARA, S. M. A.; WATANABE, W. M.; CASTRO, M.; FORTES, R. P. M. Usability evaluation of horizontal navigation bar with drop-down menus by middle aged adults. In: ACM SIGDOC'11, 2011, Pisa, Italy. Proceedings of the 29th ACM International Conference on Design of Communication (ACM SIGDOC'11), v. 1, p. $145-150$.

8. LARA, S. M. A; OLIVEIRA, D.; FORTES, R. P. M. Accessibility Context Sensitive to Middle-Aged Adults and Elderly in Web Systems. In: ACM SIGDOC'11, 2011, 
Pisa, Italy. Proceedings of The 29th ACM International Conference on Design of Communication (ACM SIGDOC'11), v. 1, p. 33-36.

9. LARA, S. M. A.; OliveIRA, D.; FORTES, R. P. M. Acessibilidade Sensível ao Contexto para Adultos Mais Velhos em Sistemas Web. In: IHC+CLIHC 2011, 2011, Porto de Galinhas, PE. Anais do X Simpósio Brasileiro sobre Fatores Humanos em Sistemas Computacionais e V Conferência Latino-Americana de Interação Humano-Computador (IHC+CLIHC 2011), v. 1, p. 353-357.

10. LARA, S.M.A. Tese de Doutorado, ICMC-USP, 2012.

\subsection{Estrutura}

Neste primeiro capítulo foram apresentadas a motivação e objetivos desta pesquisa. O restante da tese está estruturado da seguinte maneira:

- No Capítulo 2 discutem-se os principais conceitos, técnicas e abordagens envolvidos com o tema deste estudo;

- No Capítulo 3 são apresentadas as características e os problemas decorrentes do processo de envelhecimento;

- No Capítulo 4 são apresentados os trabalhos relacionados com esta pesquisa;

- No Capítulo 5 são apresentadas as atividades realizadas para identificar as dificuldades do público-alvo em interações com a Web;

- No Capítulo 6 são apresentadas as propostas e contribuições obtidas com os experimentos realizados;

- No Capítulo 7 são apresentadas as considerações finais, limitações e trabalhos futuros.

Neste trabalho são investigados os potenciais problemas de acessibilidade e usabilidade, considerando-se características e dificuldades dos adultos de meia-idade e idosos nas suas interações com as ferramentas mais comuns da Web. Assim, neste trabalho é efetuadoumlevantamento dos principais problemas enfrentados pelos adultos mais velhos em interações com a Webeidentificados os mecanismos que potencialmente poderiam amenizar tais dificuldades. 


\section{Usabilidade e Acessibilidade}

Para a melhor compreensão do trabalho, serão discutidos a seguir os principais conceitos envolvidos e suas relações com esta pesquisa.

O desenvolvimento de páginas compatíveis com recomendações e diretrizes, por si só, não garantem a usabilidade e a acessibilidade de um site. A heterogeneidade no perfil dos usuários que acessam a Web é um desafio para os desenvolvedores, principalmente quando se considera que esses usuários agem de forma diferente e têm experiências diferentes. Ao se buscar soluções específicas para alguns problemas, pode-se gerar dificuldades de interação para determinados grupos de pessoas.

Os conceitos de acessibilidade e usabilidade são bastante difundidos no escopo de interfaces de software em geral. A acessibilidade pode ser considerada como um atributo de qualidade descrito por meio do desenvolvimento de sistemas de informação flexíveis o suficiente para acomodar as mais variadas necessidades de uma ampla parcela de usuários, independentemente de sua idade, deficiência ou tecnologia. Considera-se como tecnologia não apenas os microcomputadores pessoais, mas também os PDAs (Personal Digital Assistants), os celulares e os equipamentos de tecnologia assistiva, tais como os teclados e mouses alternativos, softwares para leitura de tela, simplificadores de texto, ampliadores de texto, dentre outros.

A pesquisadora entende que a usabilidade se refere à facilidade de uso em sistemas de computação, atendendo aos princípios descritos mais adiante. Já a acessibilidade digital trata da superação de barreiras que normalmente impediriam o acesso aos sistemas de computação a certos grupos de usuários.

Os limites entre usabilidade e acessibilidade são muito tênues, ocorrendo certos casos em que determinadas características que tratam de usabilidade para certos grupos de usuários tornam-se barreiras de acessibilidade para outros grupos de usuários. Um 
exemplo em que a usabilidade se torna uma barreira de acessibilidade é o caso das listas para a entrada de datas, onde o usuário apenas escolhe o dia, o mês e o ano. Esse elemento de interface previne a ocorrência de erros no que se refere à entrada de datas inválidas, quando comparado às simples caixas de texto, mas se torna inviável para a leitura por sistemas de voz para usuários com deficiência visual.

Nesta tese foram tratados conceitos relacionados a usabilidade e acessibilidade na Web, que constituem duas linhas de pesquisa da área de Interação Humano-Computador. Visando esclarecer a abrangência de cada um desses conceitos e os pontos relevantes a esta tese, são apresentados a seguir os tópicos de interesse para esta pesquisa.

\subsection{Usabilidade}

O termo usabilidade tem sido usado com diferentes significados. Um deles é que usabilidade se refere a um conjunto de atributos de qualidade independentes, como desempenho, satisfação, facilidade de aprendizado ou eles todos juntos (Bevan e Curson, 1999). Do ponto de vista de um atributo de qualidade de software, a usabilidade não foi definida de forma consistente pelas organizações que estabelecem padrões e nem pela indústria de desenvolvimento de software. As seguintes definições ilustram como o termo usabilidade tem sido utilizado por três diferentes padrões (Seffah e Metzker, 2004):

- "A capacidade de um produto de software ser entendido, aprendido, fácil de usar, e atrativo para o usuário, quando utilizado em condições específicas" (ISO_9126, 1991);

- "A extensão na qual um produto pode ser utilizado por usuários específicos de forma a atingir seus objetivos de forma efetiva, com eficiência e com satisfação em um contexto de uso específico" (ISO_9241, 2000);

- "A facilidade com que um usuário pode aprender a operar, preparar a entrada e interpretar as saídas de um sistema ou componente" (IEEE_Std_1061, 1998).

A Norma ISO/IEC 9126 (ISO_9126, 1991) foi substituída pela Norma ISO/IEC 25010 (ISO_25010, 2010), que categoriza as propriedades de qualidade do produto de software em oito características: adequação funcional, compatibilidade, eficiência, usabilidade, confiabilidade, segurança, facilidade de manutenção e portabilidade. Cada característica é composta por um conjunto de subcaracterísticas relacionadas. As subcaracterísticas de usabilidade são: possibilidade de reconhecimento adequado, facilidade de aprendizado, operacionalidade, proteção contra erros de usuários, estética da interface do usuário e acessibilidade (ISO_25010, 2010). 
É importante levar em conta que usabilidade não é uma propriedade única e unidimensional de uma interface com usuário; ao contrário, é um conceito relacionado a diversos componentes, sendo tradicionalmente associada a cinco atributos (Nielsen, 1993):

1. Facilidade de Aprendizado: o sistema deve ser fácil para aprender, de forma que um usuário possa começar a utilizá-lo de forma rápida;

2. Eficiência: o sistema deve ser eficiente ao ser utilizado, e, uma vez que o usuário tenha aprendido a utilizá-lo, ele possa ter alta produtividade;

3. Facilidade de memorização: deve ser fácil se lembrar de como utilizar o sistema, de forma que um usuário casual possa ser capaz de voltar a utilizá-lo após um período sem utilização, sem a necessidade de aprender tudo novamente;

4. Erros: o sistema deve apresentar baixa taxa de erros, e quando cometidos pelos usuários, que seja de fácil solução/recuperação. Além disso, erros catastróficos não devem ocorrer;

5. Satisfação: o sistema deve ser de utilização agradável, de forma que os usuários sintam-se subjetivamente satisfeitos enquanto o utilizam.

Para guiar o desenvolvimento de aplicações visando usabilidade, Nielsen (1993) enumera dez heurísticas de usabilidade que endereçam os principais pontos que devem ser verificados durante o desenvolvimento de um sistema de software, que rotulados com Ui, são:

U1. Visibilidade do status do sistema;

U2. Compatibilidade do sistema com o mundo real;

U3. Controle do usuário e liberdade;

U4. Consistência e padrões;

U5. Prevenção de erros;

U6. Reconhecimento ao invés de relembrança;

U7. Flexibilidade e eficiência de uso;

U8. Estética e design minimalista;

U9. Ajudar os usuários a reconhecer, diagnosticar e corrigir erros;

U10. Help e documentação. 
A usabilidade indica o quanto é fácil para o usuário interagir com um sistema computacional. A princípio, pode parecer inviável considerar a diversidade de usuários que acessam um sistema na implementação de suas interfaces, mas quando as diferenças são consideradas desde o início do desenvolvimento de um projeto, sua implementação fica mais ágil, evita esforços desnecessários, diminui custos de manutenção do sistema e apresenta maior probabilidade de garantir a satisfação dos usuários e o sucesso da aplicação (Rocha e Baranauskas, 2003).

Existem diversos princípios e atributos que auxiliam o desenvolvedor a considerar usabilidade em seus projetos, mas a preocupação principal deve ser de que a avaliação das interfaces ocorra continuamente e não apenas no final da implementação. Ainda que sejam considerados princípios de usabilidade no desenvolvimento do projeto, é necessário que o desenvolvedor avalie a interação do usuário com o sistema. Para isso existem testes, métricas e heurísticas de usabilidade (Nielsen, 1993) (Rocha e Baranauskas, 2003).

\subsection{Princípios de usabilidade na Web}

É fundamental para qualquer sistema que a interface tenha boa usabilidade, porém em aplicações Web isso se torna especialmente importante. Na Web, os usuários experimentam a usabilidade dos sites antes de adquirir o produto (Nielsen, 2000). Caso o usuário não encontre aquilo que deseja, ele pode facilmente procurar no concorrente que está a um clique no mouse, diferentemente dos softwares de prateleira que são adquiridos primeiro e a usabilidade testada depois.

Isso posto, se o usuário não encontra a informação que deseja porque não entende como navegar num determinado site, será muito mais simples para ele buscar a informação em um site onde seu esforço cognitivo seja menor. Como existem milhares de opções de páginas, os usuários tendem a buscar aquelas nas quais podem interagir de forma mais eficiente, ou seja, onde conseguem atingir seus objetivos de forma fácil e rápida.

Durante o desenvolvimento de aplicações Web, é necessário considerar diversas características particulares, em especial o fato de que sua interface seja interpretada por diferentes navegadores e acessada em diferentes contextos. Alguns princípios básicos que devem ser considerados durante o design de aplicações Web, apontados por Nielsen (2000), são:

- Clareza na arquitetura da informação: é essencial que o usuário consiga discernir o que é prioritário e o que é secundário em um site da Web. Ou seja, é necessário obter um bom arranjo da informação;

- Facilidade de navegação: uma máxima é que o usuário deveria conseguir acessar a informação desejada em até três cliques. Conseguir organizar a informação dentro disso já é um bom princípio; 
- Simplicidade: a estrutura de um site da Web deve ser simples de forma a tornar fácil o entendimento do conteúdo, sem recursos visuais muito carregados. Cuidados devem ser tomados para que a simplicidade não signifique ausência de informação;

- A relevância do conteúdo: o principal elemento de um site da Web que atrai os usuários é o seu conteúdo. Desta forma, o design de um site da Web deve privilegiar sobretudo o conteúdo da informação disponibilizada;

- Manter a consistência: a consistência é um poderoso princípio de usabilidade na Web. Manter a interface sempre dentro de um mesmo padrão facilita o aprendizado do usuário e aumenta a sua segurança para operar o site na Web;

- Tempo suportável: o tempo de carga das páginas deve ser necessariamente curto. Estudos indicam que 10 segundos é o máximo de tempo antes que as pessoas percam o interesse;

- Foco nos usuários: todos os princípios podem ser sumarizados em um só: o foco deve estar nas atividades dos usuários.

Além dos princípios mais tradicionalmente referenciados na literatura, Goble et al. (2000) argumentam que o design de hipertexto e o estudo de usabilidade na Web estão tradicionalmente concentrados nos princípios de navegação e/ou orientação.

Navegação é um termo amplo. No sentido comum, navegação significa movimentar através do espaço. Na Web, navegação inclui o movimento virtual através de espaços cognitivos formados por informações e pelo conhecimento que daí emerge. Tornar o conteúdo de um site compreensível e navegável não é uma tarefa fácil. A navegação deve ser centrada em objetivos e ações, que são conceitos-chave para a realização de um bom projeto de navegação. De acordo com Fleming (1998), existem dez qualidades comuns que devem estar presentes em um projeto navegacional de sucesso:

1. Ser facilmente aprendida: se os visitantes forem obrigados a gastar muito tempo aprendendo como se utiliza um mecanismo complexo não terão energia para compreender o conteúdo;

2. Ter consistência: a mesma abordagem de navegação deve ser aplicada em todas as páginas;

3. Prover feedback: o usuário deve receber uma resposta a toda ação que é executada no sistema;

4. Oferecer contextualização: para que as pessoas possam tomar decisões sobre movimentos, elas precisam ver rotas, ou seja, os elementos de navegação devem estar sempre visíveis; 
5. Oferecer alternativas: os usuários são diferentes, desde o equipamento que usam até suas preferências e, portanto, o sistema deve oferecer várias alternativas de visualização. Alternativas como diferentes versões de um mesmo site (gráfica e textual), mapas ou mecanismos de busca, por exemplo, são de grande importância;

6. Prover economia de ações: deve-se evitar sites com muitos níveis hierárquicos, nos quais o usuário tem que realizar um número muito grande de passos para alcançar conteúdos importantes;

7. Prover mensagens visuais claras: o design gráfico de um site deve servir como um guia ao usuário, pois a apresentação das opções de navegação está ligada à usabilidade do sistema;

8. Selecionar títulos precisos: na seleção de termos a serem empregados na navegação, deve-se utilizar a terminologia dos usuários e não a linguagem burocrática da organização;

9. A navegação deve ser adequada aos objetivos: a abordagem vai depender muito de qual é o objetivo dos usuários. Um site comercial não deve ter o mesmo tipo de solução que um site de divulgação de informações;

10. Apoiar o comportamento do usuário: o objetivo da navegação é dar suporte às tarefas dos usuários. A compreensão sobre o que as pessoas querem fazer e como se comportam é um dos aspectos mais importantes a serem considerados durante um projeto de navegação.

Questão que continua motivando muitas pesquisas nessa área é que apesar dos esforços concentrados na aplicação dos princípios de usabilidade, na estruturação da informação e na navegação, eles não são suficientes para motivar ou garantir uma interação satisfatória entre usuários e a Web, principalmente quando se trata de usuários mais velhos, que não possuem a "cultura da Web" e apresentam grande resistência ao aprendizado de novas tecnologias, uma vez que nem sempre enxergam o uso dessa tecnologia como meio facilitador para suas atividades cotidianas. Dessa forma, é necessário investigar mais profundamente quais os fatores que realmente influenciam na interação de adultos mais velhos com a Web.

Além dos princípios de usabilidade já citados, outra característica importante que deve ser considerada durante o design de aplicações Web é a acessibilidade, que será descrita na próxima seção. 


\subsection{Acessibilidade}

A World Wide Web (ou simplesmente Web) foi concebida com o intuito principal de prover uma tecnologia para disponibilização de conteúdo em um formato padrão simples e poderoso, através de informações disponibilizadas em hipertexto utilizando HTML (W3C, 1999a). Desde a concepção da Web, Tim Berners Lee ${ }^{1}$ destacou que "o poder da Web está em sua universalidade. Ser acessada por todos, independentemente de deficiência, é um aspecto essencial".

Existem diversos conjuntos de guidelines ou diretrizes, para a elaboração de sites visando à acessibilidade na Web, de forma a possibilitar que qualquer usuário, utilizando qualquer agente (software ou hardware que recupera e serializa conteúdo Web), possa entender e interagir com o conteúdo de um site (Thatcher e Waddell, 2002). Podem ser considerados como diferentes agentes: tecnologias assistivas (TAs) de hardware e software (leitores de tela, browsers braille), dispositivos móveis, TV's digitais, entre outros.

Como será melhor detalhado na próxima seção, os principais documentos que definem diretrizes de acessibilidade são o Section 508 (U.S. Government, 2003), do governo norte-americano, e o WCAG (Web Content Accessibility Guidelines), do W3C, nas versões 1.0 (W3C, 1999b) e 2.0 (W3C, 2008b).

No WCAG 1.0 (W3C, 1999b) é definido um conjunto de 14 diretrizes que trata diversos problemas relacionados à acessibilidade em sites na Web. Cada diretriz possui pontos de verificação, que tem um nível de prioridade baseado no seu impacto na acessibilidade. O conceito de nível de conformidade varia de acordo com a satisfação das diretrizes de acessibilidade. No documento de recomendação das WCAG versão 2.0 (W3C, 2008b), as diretrizes são organizadas em torno de quatro princípios, de forma que as recomendações presentes nas WCAG 1.0 são também atendidas e acrescentadas novas recomendações.

Essas diretrizes ajudam no desenvolvimento de conteúdo mais acessível e usável por indivíduos mais velhos e com melhor usabilidade por usuários em geral. Porém, a heterogeneidade no perfil dos usuários que acessam a Web é um desafio para os desenvolvedores, principalmente quando se considera que os usuários agem e reagem de forma diferente em suas experiências.

Além disso, com o desenvolvimento e difusão da Web, diversas tecnologias, que não seguem padrões, foram criadas para estender as possibilidades da linguagem HTML, e grande parte dos criadores de páginas e empresas que desenvolvem navegadores deixaram de seguir os principais padrões que garantiam a universalidade da Web. Essa "quebra" de padrões e princípios que acompanharam a motivação da criação da Web trouxe diversas consequências para sua evolução, uma vez que a utilização da Web por usuários em situações específicas é dificultada pela falta de padronização, por exemplo, com softwares não convencionais ou em dispositivos móveis.

\footnotetext{
${ }^{1}$ Inventor da Web e diretor do World Wide Web Consortium (W3C)
} 
O avanço das novas tecnologias de computação móvel e ubíqua que utilizam a Web, assim como os avanços sociais para inclusão das pessoas com necessidades especiais têm colocado o tema de acessibilidade na Web em destaque nos ambientes acadêmicos, empresariais e governamentais. Durante o desenvolvimento de um site na Web, é necessário que se leve em consideração não só os usuários que utilizam tecnologias similares às utilizadas pelo desenvolvedor, como também o fato de que a Web pode ser usada em diferentes circunstâncias por pessoas que, por exemplo (W3C, 1999b):

- sejam incapazes de ver, ouvir, se deslocar ou interpretar determinados tipos de informações;

- tenham dificuldade em ler ou compreender textos;

- não tenham um teclado ou mouse, ou não sejam capazes de utilizá-los;

- possuam tela que apresenta apenas texto, ou com dimensões reduzidas, ou ainda com uma conexão lenta com a Internet;

- não falem ou compreendam fluentemente o idioma em que o documento foi escrito;

- estejam com seus olhos, mãos ou ouvidos ocupados (por exemplo, ao volante do carro, a caminho do trabalho ou em um ambiente barulhento);

- possuam uma versão ultrapassada de navegador Web, diferente dos habituais, um navegador por voz, ou um sistema operacional pouco convencional.

A partir desses exemplos, pode-se verificar que o tema "Acessibilidade na Web" não diz respeito somente ao acesso à Web por usuários com deficiências. A utilização dos padrões e recomendações de acessibilidade traz benefícios para diversos grupos de usuários e para a Web como um todo (Hull, 2004) (Melo e Baranauskas, 2005).

Desenvolver páginas acessíveis não significa que não se deva utilizar recursos gráficos e layouts avançados. Não há nada que impeça que um designer crie uma página rica em layout sem barreiras de acessibilidade (Petrie et al., 2003) (Regan, 2004).

O conceito de que o desenvolvimento visando acessibilidade implica em limitações na usabilidade é mal interpretado. Muitos desenvolvedores argumentam que as recomendações de acessibilidade limitam o uso de tecnologias como JavaScript, animações e outras tecnologias que podem ser utilizadas para melhorar a usabilidade de um site. As recomendações não impedem, a priori, o uso dessas tecnologias, mas indicam que elas devem ser utilizadas com parcimônia e cuidado, e que não devem impedir o acesso por usuários que não disponham delas, para que não se tornem barreiras. 


\subsection{Diretrizes de acessibilidade na Web}

Diretrizes (guidelines) ${ }^{2}$ para a criação de interfaces são bastante utilizadas no contexto de Interação Humano-Computador (IHC). Elas consistem em um conjunto de orientações para a solução de problemas conhecidos, com reconhecida eficácia. Para Monk et al. (1993), os princípios são afirmações, bastante amplas, fundamentadas em pesquisas sobre como as pessoas aprendem e trabalham. Desta forma, entende-se que um princípio é apenas um objetivo geral, sem dizer como alcançá-lo. As guidelines representam objetivos mais específicos refinados por especialistas em IHC a partir da pesquisa dos princípios para diferentes contextos. Um princípio pode originar muitas guidelines, e guidelines podem ser diferentes para combinações específicas de usuários, ambientes e tecnologia.

A WAI (Web Accessibility Initiative) é uma organização criada pela W3C, que tem como principal objetivo definir estratégias, diretrizes e recursos para tornar a Web acessível às pessoas com necessidades especiais (W3C, 2012c). Para esse fim, foi estabelecido um modelo de conformidade com três conjuntos de diretrizes consolidadas nos seguintes documentos (Kelly et al., 2005) (Kelly et al., 2007):

- WCAG 1.0 - Web Content Accessibility Guidelines: explicam como tornar o conteúdo Web acessível a indivíduos com deficiências e disponível a todos os usuários, quaisquer que sejam os agentes de usuário que estejam sendo utilizados (navegadores de desktop, navegadores por voz, celulares, entre outros), com quaisquer restrições de operações (ambientes barulhentos, com pouca iluminação, dentre outros) (W3C, 1999b);

- ATAG 1.0 - Authoring Tool Accessibility Guidelines: tem como propósito guiar os desenvolvedores na implementação de ferramentas de autoria de conteúdo Web que seja acessível e na criação de ferramentas de autoria acessíveis (W3C, 2012a);

- UAAG 1.0 - User Agent Accessibility Guidelines: destinado ao desenvolvimento de agentes de usuário que reduzam as barreiras a acessibilidade na Web para pessoas com deficiências (visual, auditiva, física, cognitiva e neurológica). Os navegadores HTML e outros tipos de software que renderizam conteúdo Web também estão incluídos como agentes de usuário (W3C, 2012b).

Para cada diretriz descrita, nesses documentos, são estabelecidos checkpoints que definem etapas ou partes de um projeto que podem apresentar barreiras a usuários com algum tipo de limitação (indivíduos cegos, surdos, com problemas cognitivos, entre outros). A cada um desses checkpoints é determinado um valor de prioridade, de acordo

\footnotetext{
${ }^{2}$ Apesar da tradução oficial do W3C indicar a tradução de guidelines como recomendações, optou-se por utilizar a tradução de "diretrizes", para não gerar confusão com o termo recomendação (recommendation), utilizado para designar a recomendação de tecnologias pelo W3C.
} 
com o seu impacto na acessibilidade e conformidade com os respectivos documentos (W3C, 1999b) (W3C, 2012a) (W3C, 2012b):

- Prioridade 1: o não cumprimento desse checkpoint acarreta que um ou mais grupos de usuários vão ser impossibilitados de acessar a informação desse site;

- Prioridade 2: o não cumprimento desse checkpoint acarreta que um ou mais grupos de usuários vão ter dificuldades para acessar as informações contidas nesse site;

- Prioridade 3: o não cumprimento desse checkpoint acarreta que um ou mais grupos de usuários vão ter um pouco de dificuldade para acessar as informações contidas nesse site.

Especificamente para a ATAG, existem checkpoints de prioridade relativa (Relative Priority) (W3C, 2012a). Esses checkpoints se referem a geração, autoria e verificação de conteúdo Web, ou seja, estão relacionados diretamente a checkpoints da WCAG 1.0. Dessa forma, o nível de importância a eles atribuído depende da prioridade atribuída ao checkpoints correspondente na WCAG 1.0. Por exemplo: o checkpoint 4.1 da ATAG 1.0 indica a importância da verificação e aviso ao autor a respeito de problemas de acessibilidade. A verificação de equivalentes textuais a imagens e audio (checkpoint 1.1 de prioridade 1 da WCAG 1.0) na ferramenta de autoria também é de prioridade 1 . No entanto, a verificação do agrupamento de links no mecanismo de navegação (checkpoint 13.6 de prioridade 3 da WCAG 1.0) é de prioridade 3 .

De acordo com a verificação desses checkpoints na aplicação, a WAI atribui um valor de conformidade com o conjunto de diretrizes entre A e AAA:

- Nível de conformidade "A": todos checkpoints de prioridade 1 são satisfeitos para a WCAG 1.0 e a UAAG 1.0. Para a ATAG 1.0 também é necessária a satisfação de todos os checkpoints de prioridade relativa;

- Nível de conformidade "AA": todos checkpoints de prioridade 1 e 2 são satisfeitos para a WCAG 1.0 e a UAAG 1.0. Para a ATAG 1.0 também é necessária a satisfação de todos os checkpoints de prioridade relativa;

- Nível de conformidade "AAA": todos checkpoints de prioridade 1, 2 e 3 são satisfeitos para a WCAG 1.0 e a UAAG 1.0. Para a ATAG 1.0 também é necessária a satisfação de todos os checkpoints de prioridade relativa.

A relação entre as diretrizes WCAG, ATAG e UAAG está esquematizada na Figura 2.1. É importante destacar que cada uma dessas diretrizes de acessibilidade são destinadas a diferentes componentes e públicos-alvo na Web. A WCAG diz respeito à estrutura e ao conteúdo inserido nas tecnologias de desenvolvimento Web (HTML, CSS, Javascript, entre outras), sendo destinada a autores de páginas Web, Web designers e desenvolvedores de 


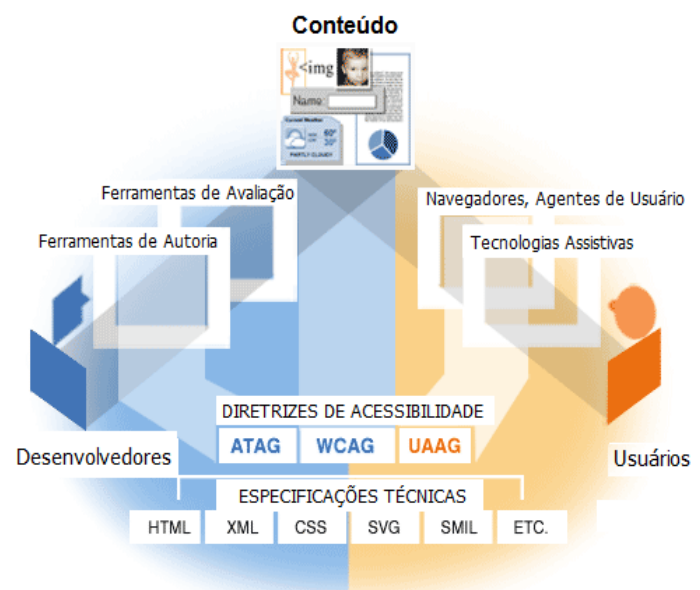

Figura 2.1: Abordagem da WAI. Figura adaptada do site da WAI: http://www.w3.org/WAI/intro/ specs.png

ferramentas de autoria (editores HTML) (W3C, 1999b). ATAG refere-se às características necessárias nas ferramentas de autoria, sendo destinada aos desenvolvedores dessas aplicações (W3C, 2012a). Por fim, a UAAG é dirigida a implementação de navegadores, players multimídia, plug-ins (programas que executam como parte do agente de usuário e não faz parte do conteúdo Web), entre outros (inclusive tecnologias assistivas) (W3C, 2012b).

A primeira versão das Diretrizes para a Acessibilidade do Conteúdo da Web (Web Content Accessibility Guidelines, WCAG 1.0) já foi substituída pela WCAG 2.0 (W3C, 2008b), mas ainda é utilizada como métrica de acessibilidade para muitos sites. No WCAG 1.0 é definido um conjunto de diretrizes que estão relacionadas a dois temas principais:

- Garantir a transformação harmoniosa de páginas: páginas que garantam uma transformação harmoniosa permanecem acessíveis independentemente das restrições do usuário (por exemplo: restrições de percepção visual, auditiva ou motora) ou restrições tecnológicas (por exemplo: dispositivos com restrições de exibição ou restrição de velocidade de conexão);

- Facilitar a compreensão do conteúdo e a navegação através dele: o desenvolvedor deve utilizar uma linguagem simples e clara, como também prover mecanismos para facilitar a navegação dentro de uma página e entre as páginas que compõem o conteúdo.

O documento contendo as diretrizes do WCAG 1.0 é composto por um conjunto de 14 diretrizes de acessibilidade e cada diretriz possui pontos de verificação (checkpoints), que são classificados por níveis de prioridade, sendo que cada um deles demanda uma técnica para implementá-lo. A seguir são descritas as diretrizes do WCAG 1.0:

1. Fornecer alternativas para conteúdo sonoro e visual: esta diretriz indica a necessidade de disponibilizar conteúdo que, ao ser apresentado ao usuário, 
transmita, em essência, as mesmas funções e finalidade que o conteúdo sonoro ou visual;

2. Não recorrer apenas a cor: deve-se garantir a percepção do texto e dos elementos gráficos do documento, mesmo quando são vistos sem cores;

3. Utilizar corretamente marcações e folhas de estilo: esta diretriz indica a necessidade de se utilizar marcação nos documentos com os elementos estruturais adequados e controlar a apresentação por meio de folhas de estilo, em vez de elementos de apresentação e atributos;

4. Indicar claramente qual o idioma utilizado: é imprescindível utilizar marcações que facilitem a pronúncia e a interpretação de abreviaturas ou de texto em língua estrangeira. Deve-se identificar claramente quaisquer mudanças de idioma no texto de um documento, bem como nos equivalentes textuais;

5. Criar tabelas passíveis de transformação harmoniosa: deve-se assegurar que as tabelas têm as marcações necessárias para poderem ser transformadas de forma harmoniosa por navegadores acessíveis e outros agentes do usuário;

6. Assegurar que as páginas dotadas de novas tecnologias sejam transformadas harmoniosamente: as páginas devem ser acessíveis mesmo quando as tecnologias mais recentes não estejam disponíveis ou tenham sido desativadas;

7. Assegurar o controle do usuário sobre as alterações temporais do conteúdo: deve-se possibilitar a interrupção momentânea ou definitiva do movimento, intermitência, transcurso ou atualização automática de objetos e páginas;

8. Assegurar a acessibilidade direta em interfaces integradas pelo usuário: a interface com o usuário deve obedecer a princípios de design para a acessibilidade, tais como: acesso independente de dispositivos, operacionalidade pelo teclado, emissão automática de voz (verbalização);

9. Projetar páginas considerando a independência de dispositivos: é imprescindível utilizar funções que permitam a ativação de elementos de página por meio de uma grande variedade de dispositivos de entrada;

10. Utilizar soluções provisórias ou de transição: deve-se utilizar soluções de acessibilidade transitórias para que as tecnologias de apoio e os navegadores mais antigos funcionem corretamente;

11. Utilizar tecnologias e recomendações do W3C: deve-se utilizar tecnologias do W3C (de acordo com suas especificações) e seguir as recomendações de acessibili- 
dade. Aconselha-se utilizar sempre as últimas versões das recomendações do W3C, quando possível, evitando, assim, a utilização de tecnologias consideradas obsoletas;

12. Fornecer informações de contexto e orientações: o fornecimento de informações de contexto e orientações de navegação é fundamental para auxiliar os usuários a compreender e utilizar o conteúdo de um site;

13. Fornecer mecanismos de navegação claros: deve-se fornecer mecanismos de navegação coerentes e sistematizados de modo a aumentar a probabilidade de uma pessoa encontrar o que procura em um site qualquer;

14. Assegurar a clareza e a simplicidade dos documentos: deve-se assegurar a produção de documentos com linguagem clara e simples para que sejam mais fáceis de compreender.

No documento de recomendação das WCAG versão 2.0 (W3C, 2008b), publicado no final de 2008, as diretrizes são organizadas em torno de quatro princípios (Ai), que incluem aqueles rotulados com Ai.j, conforme a seguir:

A1 O conteúdo deve ser perceptível: usuários devem ser capazes de perceber a informação sendo apresentada, ou seja, o conteúdo não pode ser invisível a todos os seus sentidos

A1.1 Alternativas textuais: disponibilizar alternativas textuais para conteúdos não textuais;

A1.2 Mídias temporais: disponibilizar alternativas para mídias temporais;

A1.3 Adaptabilidade: criar conteúdo que possa ser disponibilizado de diferentes maneiras sem perder a informação ou estrutura;

A1.4 Distinguíveis: facilitar aos usuários ver e ouvir o conteúdo, tendo como foco principal aquilo que está sendo disponibilizado.

A2 Os componentes de interface com o usuário devem ser operáveis: a interface não pode exigir interações com as quais um usuário não possa realizar

A2.1 Acessível pelo teclado: todas as funcionalidades devem ser acessíveis pelo teclado;

A2.2 Tempo suficiente: disponibilizar tempo suficiente de leitura e utilização do conteúdo;

A2.3 Apreensibilidade: não estruturar o site com conteúdos que possam causar apreensão nos usuários; 
A2.4 Navegabilidade: disponibilizar meios que auxiliem a navegação do usuário, busca por conteúdos e localização.

A3 O conteúdo e os controles do usuário devem ser de fácil entendimento: o conteúdo e as operações não podem ir além do conhecimento do usuário

A3.1 Legível e compreensível: disponibilizar o conteúdo de forma legível e compreensível aos usuários;

A3.2 Previsibilidade: os sites devem aparecer e operar por meios previsíveis;

A3.3 Assistência de entrada: auxiliar os usuários a evitar e corrigir erros.

A4 O conteúdo deve ser suficientemente robusto para funcionar com as tecnologias atuais e futuras

A4.1 Compatibilidade: maximizar a compatibilidade com agentes de usuário e tecnologias disponibilizadas atualmente e no futuro.

Os quatro princípios de acessibilidade apontados pelo WCAG 2.0 já estavam de certa forma contidos nas recomendações do WCAG 1.0. Contudo, a classificação, como um princípio, reforça a sua importância e redefine a forma da organização da nova versão da recomendação do W3C.

Segundo Parmanto e Zeng (2005), a maioria dos sites que se auto-intitulam como "acessíveis", violam as guidelines com as quais eles supostamente estariam em conformidade. Somente 8,81\% dos sites, que se dizem AAA (em conformidade com os checkpoints para as prioridades 1, 2 e 3 do WCAG 1.0), estão realmente em conformidade com os três níveis de prioridade.

Garantir acessibilidade na Web de forma geral ainda apresenta desafios, mas para os usuários mais velhos, tornou-se uma grande preocupação para os desenvolvedores. Prover acessibilidade na Web para um público com características tão heterogêneas não significa apenas desenvolver sites compatíveis com as recomendações e diretrizes, mas prover meios para que usuários pouco experientes e com dificuldades de aprendizado possam superar as barreiras com as quais se deparam, e que, muitas vezes, os levam à desistência total desse tipo de experiência.

\subsection{Legislação sobre acessibilidade no Brasil e no mundo}

Os primeiros países que idealizaram parâmetros de acessibilidade na Internet foram Canadá, Estados Unidos e Austrália, em 1997. Nos Estados Unidos, em 1998, entrou em vigor a "Section 508", uma lei determinando que a tecnologia eletrônica e de informação dos órgãos federais fossem acessíveis às pessoas com necessidades especiais. Segundo 
essa lei, a tecnologia inacessível interfere na capacidade individual de adquirir e usar a informação de maneira rápida e fácil. A Section 508 foi decretada com o objetivo de eliminar barreiras na tecnologia da informação, disponibilizando novas oportunidades para as pessoas com necessidades especiais e incentivando o desenvolvimento de tecnologias que as auxiliem a atingir esses objetivos.

Com o objetivo de tornar a Web acessível a um número cada vez maior de pessoas e maximizar a interoperabilidade, o World Wide Web Consortium (W3C) criou a Iniciativa para a Acessibilidade na Web (WAI). Entre outras atribuições, a WAI mantém grupos de trabalho para elaborar conjuntos de recomendações a fim de garantir a acessibilidade do conteúdo da Web às pessoas com necessidades especiais ou que acessam a Web em condições especiais de ambiente, equipamento, navegador e outras ferramentas Web. Como resultado desse trabalho, em 1999, foi publicada a primeira versão das Recomendações para a Acessibilidade do Conteúdo da Web (Web Content Accessibility Guidelines, WCAG 1.0), principal referência mundial em termos de acessibilidade na Web.

Além dessa iniciativa, também em 1999, Portugal regulamentou a adoção de regras de acessibilidade à informação disponibilizada na Internet pela Administração Pública para pessoas com necessidades especiais. Essa iniciativa transformou Portugal no primeiro país da Europa e o quarto no mundo a legislar sobre acessibilidade na Web.

Em 2000, ao aprovar o plano de ação e-Europe 2002 (que inclui o compromisso da adoção das recomendações sobre acessibilidade do W3C nos sites públicos), o Conselho Europeu estendeu a iniciativa portuguesa aos 15 países da União Européia.

No Brasil, na Constituição de 1988, considerada uma das mais avançadas com relação à garantia dos direitos individuais, podem ser destacadas diversas disposições específicas em relação às pessoas portadoras de deficiências. Por exemplo, o art. 227, 1, inciso II da CF dispõe sobre: "a criação de programa de prevenção e atendimento especializado para os portadores de deficiência física, sensorial ou mental, bem como programa de integração social do adolescente portador de deficiência, mediante o treinamento para o trabalho e a convivência, a facilitação do acesso aos bens e serviços coletivos, com a eliminação de preconceitos e obstáculos arquitetônicos".

Diversas leis e decretos foram elaborados para assegurar os direitos das pessoas portadoras de deficiências. A Lei Ordinária 7.853/1989 dispõe sobre o apoio às pessoas com deficiências e sua integração social, dentre outras providências. O Decreto Federal $3.298 / 1999$, que regulamenta a Lei 7.853/1989, dispõe sobre a política nacional para a integração da pessoa com necessidades especiais, consolida as normas de proteção e dá outras providências. A Lei Ordinária 10.048/2000 dá prioridade de atendimento às pessoas com necessidades especiais ou com mobilidade reduzida (idosos, gestantes, lactantes e pessoas acompanhadas por crianças de colo). A Lei Ordinária 10.098/2000 (Lei de Acessibilidade) estabelece normas gerais e critérios básicos para a promoção da acessibilidade e dá outras providências. 
O Decreto Federal 5.296/2004, que regulamenta as Leis n10.048/2000 e n10.098/2000, torna obrigatória a acessibilidade nos portais e sites da administração pública para o uso das pessoas com necessidades especiais a fim de garantir o pleno acesso às informações. $\mathrm{O}$ organismo legalmente constituído para cuidar das normas técnicas no Brasil é a Associação Brasileira de Normas Técnicas $\left(\mathrm{ABNT}^{3}\right)$, que é filiada à International Organization for Standardization (ISO) e atua desde 1940.

A ABNT está dividida em comitês nacionais, entre eles o Comitê Brasileiro de Acessibilidade (ABNT/CB-40), que começou a atuar no ano de 2000. A Comissão de Estudo de Acessibilidade na Comunicação (CE-03) do CB-40 trata o tema da acessibilidade na Web em um dos seus grupos de trabalho e, basicamente, devem ser atendidas as recomendações do W3C. A existência de normas técnicas relacionadas ao tema facilita a adoção de medidas ou ações facilitadoras, uma vez que nelas são estabelecidas as condições de acessibilidade nas diversas situações (Barbosa, 2003).

As normas técnicas definem parâmetros técnicos, estabelecem critérios, imposições ou recomendações, dependendo da questão abordada. A legislação brasileira torna obrigatória a adoção desta ou daquela norma como referência.

O Modelo de Acessibilidade de Governo Eletrônico (e-MAG) (Brasil, 2011) consiste em um conjunto de recomendações que visam orientar os profissionais responsáveis pela disponibilização de informações ou serviços na Internet, a fim de que a incorporação da acessibilidade nos conteúdos do Governo Brasileiro seja conduzida de forma padronizada, de fácil implementação, coerente com as necessidades brasileiras e em conformidade com os padrões internacionais, tornando-os acessíveis ao maior número de pessoas possível.

A primeira versão do e-MAG foi disponibilizada para consulta pública em janeiro de 2005 e a versão 2.0 em dezembro do mesmo ano. Em 2007, a Portaria n 3, de 7 de maio, emitida pelo Ministério do Planejamento, Orçamento e Gestão, institucionalizou o e-MAG no âmbito do Sistema de Administração dos Recursos de Tecnologia da Informação - SISP, tornando sua observância obrigatória nos sites e portais do governo brasileiro. A versão 3.0 do modelo foi desenvolvida por meio da parceria entre o Departamento de Governo Eletrônico, da Secretaria de Logística e Tecnologia da Informação (SLTI) do Ministério do Planejamento, e o Projeto de Acessibilidade Virtual da RENAPI (Rede de Pesquisa e Inovação em Tecnologias Digitais) (Brasil, 2011).

Para a revisão do modelo, foram consideradas as contribuições de especialistas e as novas pesquisas na área de acessibilidade na Web, bem como as Recomendações de Acessibilidade para Conteúdo Web (WCAG) 2.0, da W3C, visando atender as prioridades brasileiras (Brasil, 2011). As recomendações de acessibilidade desse documento referenciam os critérios de sucesso (W3C Working Draft, 2012) e técnicas para as WCAG 2.0 (W3C Working Group Note, 2012). Elas não foram divididas por níveis de prioridade,

\footnotetext{
${ }^{3}$ http://www.abnt.org.br
} 
visto que todas elas são de grande importância e devem ser seguidas. Dessa forma, o e-MAG 3.0 classificou as recomendações nas seguintes seções:

\section{- Marcação}

- Recomendação 1: Respeitar os padrões de desenvolvimento Web;

Ver WCAG 2.0 Critérios de Sucesso 4.1.1 e 4.1.2

- Recomendação 2 Organizar o código HTML de forma lógica e semântica; Ver WCAG 2.0 Critério de Sucesso 1.3.1

- Recomendação 3 Utilizar corretamente os níveis de cabeçalho; Ver WCAG 2.0 Critérios de Sucesso 1.3.1 e 2.4.10

- Recomendação 4 Ordenar de forma lógica e intuitiva a leitura e tabulação; Ver WCAG 2.0 Critérios de Sucesso 1.3.2 e 2.4.3

- Recomendação 5 - Disponibilizar todas as funções da página via teclado; Ver WCAG 2.0 Critérios de Sucesso 2.1.1 e 2.1.2

- Recomendação 6 Fornecer âncoras para ir direto a um bloco de conteúdo; Ver WCAG 2.0 Critério de Sucesso 2.4.1

- Recomendação 7 Não utilizar tabelas para diagramação; Ver WCAG 2.0 Critério de Sucesso 1.3.1 (Técnica H51)

- Recomendação 8 Separar links adjacentes; Ver WCAG 2.0 Critério de Sucesso 1.3.1 (Técnica H48)

- Recomendação 9 Não abrir novas instâncias sem a solicitação do usuário; Ver WCAG 2.0 Critério de Sucesso 3.2.5

\section{- Comportamento (DOM)}

- Recomendação 10 Garantir que os objetos programáveis sejam acessíveis;

Ver WCAG 2.0 Critérios de Sucesso 2.1.1 e 2.1.2

- Recomendação 11- Não criar páginas com atualização automática periódica; Ver WCAG 2.0 Critério de Sucesso 3.2.5 (Técnicas SVR1 e H76)

- Recomendação 12 Não utilizar redirecionamento automático de páginas; Ver WCAG 2.0 Critério de Sucesso 3.2.5 (Técnicas SVR1 e H76)

- Recomendação 13 Fornecer alternativa para modificar limite de tempo;

Ver WCAG 2.0 Critério de Sucesso 2.2.1

- Recomendação 14 Não incluir situações com intermitência de tela;

Ver WCAG 2.0 Critério de Sucesso 2.3.1

- Recomendação 15 Assegurar o controle do usuário sobre as alterações temporais do conteúdo;

Ver WCAG 2.0 Critério de Sucesso 2.2.2 


\section{- Conteúdo/Informação}

- Recomendação 16 Identificar o idioma principal da página;

Ver WCAG 2.0 Critério de Sucesso 3.1.1

- Recomendação 17 Oferecer um título descritivo e informativo à página;

Ver WCAG 2.0 Critério de Sucesso 2.4.2

- Recomendação 18 Disponibilizar informação sobre a localização do usuário na página;

Ver WCAG 2.0 Critério de Sucesso 2.4.8

- Recomendação 19 Descrever links clara e sucintamente;

Ver WCAG 2.0 Critérios de Sucesso 2.4.4 e 2.4.9

- Recomendação 20 Fornecer alternativa em texto para as imagens do site;

Ver WCAG 2.0 Critério de Sucesso 1.1.1 (Técnica G95)

- Recomendação 21 Fornecer alternativa em texto para as zonas ativas de mapa de imagem;

Ver WCAG 2.0 Critério de Sucesso 1.1.1 (Técnica H24)

- Recomendação 22 Disponibilizar documentos em formatos acessíveis;

Sem correspondência a critérios específicos da WCAG 2.0, mas sim como um todo

- Recomendação 23 Em tabelas, utilizar títulos e resumos de forma apropriada; Ver WCAG 2.0 Critério de Sucesso 1.3.1 (Técnicas H39 e H73)

- Recomendação 24 Associar células de dados às celulas de cabeçalho em uma tabela;

Ver WCAG 2.0 Critério de Sucesso 1.3.1 (Técnicas H43 e H63)

- Recomendação 25 Garantir a leitura e compreensão das informações;

Ver WCAG 2.0 Critério de Sucesso 3.1.5

- Recomendação 26 Disponibilizar uma explicação para siglas, abreviaturas e palavras incomuns;

Ver WCAG 2.0 Critérios de Sucesso 3.1 .3 e 3.1 .4

- Recomendação 27 Informar mudança de idioma no conteúdo;

Ver WCAG 2.0 Critério de Sucesso 3.1.2

\section{- Apresentação/Design}

- Recomendação 28 - Oferecer contraste mínimo entre plano de fundo e primeiro plano;

Ver WCAG 2.0 Critério de Sucesso 1.4.3 
- Recomendação 29 Não utilizar apenas cor ou outras características sensoriais para diferenciar elementos;

Ver WCAG 2.0 Critérios de Sucesso 1.3 .3 e 1.4.1

- Recomendação 30 Permitir redimensionamento de texto sem perda de funcionalidade;

Ver WCAG 2.0 Critério de Sucesso 1.4.4

- Recomendação 31 Dividir as áreas de informação;

Ver WCAG 2.0 Critério de Sucesso 3.2.3 (Técnica G61)

- Recomendação 32 Possibilitar que o elemento com foco seja visualmente evidente;

Ver WCAG 2.0 Critério de Sucesso 2.4.7

\section{- Multimídia}

- Recomendação 33 Fornecer alternativa para vídeo;

Ver WCAG 2.0 Critérios de Sucesso 1.2.1, 1.2.2, 1.2.6 e 1.2.8

- Recomendação 34 Fornecer alternativa para áudio;

Ver WCAG 2.0 Critérios de Sucesso 1.2.1, 1.2.2 e 1.2.6

- Recomendação 35 Oferecer audiodescrição para vídeo pré-gravado;

Ver WCAG 2.0 Critério de Sucesso 1.2.3, 1.2.5 e 1.2.7

- Recomendação 36 Fornecer controle de áudio para som;

Ver WCAG 2.0 Critério de Sucesso 1.4.2

- Recomendação 37 Fornecer controle de animação;

Ver WCAG 2.0 Critério de Sucesso 2.2.2

\section{- Formulário}

- Recomendação 38 Fornecer alternativa em texto para os botões de imagem de formulários;

Ver WCAG 2.0 Critério de Sucesso 1.1.1

- Recomendação 39 Associar etiquetas aos seus campos;

Ver WCAG 2.0 Critério de Sucesso 1.3.1 (Técnica H44)

- Recomendação 40 Estabelecer uma ordem lógica de navegação;

Ver WCAG 2.0 Critério de Sucesso 2.4.3

- Recomendação 41 Não provocar automaticamente alteração no contexto;

Ver WCAG 2.0 Critério de Sucesso 3.2.2

- Recomendação 42 Fornecer instruções para entrada de dados;

Ver WCAG 2.0 Critério de Sucesso 3.3.2 
- Recomendação 43 Identificar e descrever erros de entrada de dados;

Ver WCAG 2.0 Critério de Sucesso 3.3.1

- Recomendação 44 Agrupar campos de formulário;

Ver WCAG 2.0 Critério de Sucesso 1.3.1 (Técnicas H71 e H85)

- Recomendação 45 Fornecer captcha humano;

Ver WCAG 2.0 Critério de Sucesso 1.1.1 (Técnicas G143 e G144)

A fim de garantir o desenvolvimento de páginas Web acessíveis para pessoas com deficiência, o e-MAG pretende padronizar alguns elementos de acessibilidade para as páginas do governo federal. Os elementos a serem padronizados, que devem estar presentes em todas as páginas do Governo Federal são (Brasil, 2011):

1. Página com a descrição dos recursos de acessibilidade;

2. Teclas de atalho: para ir ao conteúdo, ao menu principal e à caixa de pesquisa;

3. Barra de acessibilidade: aumentar fonte; diminuir fonte; fonte normal; alto contraste; atalhos (para menu, conteúdo e busca); acessibilidade (link para a página contendo os recursos de acessibilidade do site); Apresentação do mapa do site: deverá ser fornecido um mapa do site para sites que contenham páginas internas que não estão presentes no menu. O mapa do site deve ser disponibilizado em forma de lista, podendo conter quantos níveis forem necessários;

4. Apresentação de formulários. Os formulários deverão estar de acordo com os seguintes itens:

- Sempre utilizar a tag form, mesmo que o formulário possua apenas um elemento, como é o caso de uma caixa para pesquisa;

- Disponibilizar os elementos do formulário no HTML na ordem correta de navegação, sem utilizar o tabindex;

- Associar as etiquetas (label) aos seus campos (input) correspondentes;

- Não deve ocorrer mudança no contexto quando um elemento receber o foco;

- Deve ser fornecido um botão de envio (submit) para enviar os dados. No entanto, é necessário fornecer uma forma de o usuário poder verificar as informações antes que elas sejam enviadas;

- Os erros de entrada de dados devem ser identificados e descritos ao usuário;

- Para cada conjunto de informações, com dois ou mais elementos de entrada de dados, os mesmo deverão ser agrupados através do elemento fieldset/legend, exceto nos casos de formulário de busca simples, pois apresenta apenas um campo de entrada de dados; 
5. Conteúdo alternativo para imagens: deverá ser fornecida uma alternativa textual, pelo atributo alt, para imagens, fotos, gráficos, banners, botões de imagem, áreas ativas de mapa de imagem, CAPTCHA, etc. Além do alt, para imagens mais complexas, que necessitem de uma descrição mais detalhada, deverá ser fornecida uma descrição longa no próprio contexto ou em um link (claramente identificado como descrição da imagem) logo após a imagem;

6. Apresentação de documentos: os documentos em texto deverão ser disponibilizados preferencialmente em HTML. Também podem ser disponibilizados arquivos para download no formato ODF, tomando-se os cuidados para que sejam acessíveis. Se houver necessidade de disponibilizar arquivos em PDF, deverá ser fornecida uma alternativa em HTML ou ODF. É necessário, também, informar a extensão e o tamanho do arquivo no próprio texto do link.

Segundo o e-MAG, os elementos que não devem ser utilizados são:

- Tabelas para fins de diagramação, conforme Recomendação 7;

- Atualizações automáticas periódicas, conforme Recomendação 11;

- Situações com intermitência de tela, conforme Recomendação 14;

- Elementos considerados depreciados pelo W3C, como frame, applet, blink, marquee, basefont, center, dir, align, font, isindex, menu, strike, u, etc.

Finalmente, nota-se que o documento de referência à acessibilidade proposto no Brasil está em conformidade com a WCAG e adequado à realidade brasileira, porém não trata especialmente das necessidades dos adultos mais velhos.

\subsection{Usabilidade $\times$ Acessibilidade}

No estudo realizado por Petrie e Omar (2007) há uma discussão detalhada a respeito dos conceitos de usabilidade e acessibilidade.

Para o conceito de usabilidade, há uma definição fornecida pela ISO 9241 que é amplamente aceita: "trata-se da medida em que um produto ou site pode ser usado por usuários específicos para alcançar objetivos específicos com eficácia, eficiência e satisfação em um determinado contexto de uso" (ISO_9241, 2000). Em relação à acessibilidade, a situação não é tão clara. Segundo o WAI (Web Accessibility Initiative), a definição geral de acessibilidade na Web é que "pessoas com deficiência podem usar a Web, mais especificamente elas devem perceber, compreender, navegar e interagir com a Web" (Henry, 2005). Essa definição pode ser considerada ou chamada de "usabilidade para pessoas com deficiência" ou ainda "acessibilidade usável" (Di Blas, N.; Paolini, P.; Speroni, 
M., 2004) de forma a prover uma definição baseada nas características de uso dos usuários semelhante à fornecida pela ISO 9241.

No entanto, ao invés de buscar uma definição mais precisa para acessibilidade com base em características dos usuários, WAI tem promovido a conformidade com a Web Content Accessibility Guidelines (WCAG) (W3C, 1999b) como o critério para se alcançar e medir a acessibilidade, o que pode ser denominado de "critério técnico de acessibilidade na Web".

A relação entre a definição de "acessibilidade usável" e acessibilidade técnica não é clara. Poucos dados empíricos foram coletados para mostrar que os sites que alcançam maior conformidade com as WCAGs são também mais usáveis por pessoas com deficiência e para levantar quais devem ser os critérios de usabilidade para pessoas com deficiência. Por exemplo, o estudo conduzido pela Disability Rights Commission (2004) em mais de 1000 sites não encontrou relação significativa entre a conformidade com a WCAG e o número de medidas de desempenho e satisfação do usuário para cinco diferentes categorias de pessoas com deficiência.

Segundo Petrie e Omar (2007), os critérios definitivos para a acessibilidade devem ser baseados no usuário e uma possível adaptação da definição dada pela ISO 9241 para esse propósito seria:

"a medida em que um produto/site pode ser usado por usuários específicos com deficiências específicas para alcançar metas específicas com eficácia, eficiência e satisfação em um contexto específico de uso."

No contexto da Web, uma das questões interessantes é a contribuição da acessibilidade técnica para a realização desses critérios.

A usabilidade pode ser definida também em termos da falta de problemas de usabilidade na utilização de um produto ou site; trata-se de uma medição de usabilidade baseada na eficácia, eficiência, etc, ou ainda pode medir os problemas que um usuário encontra ou pode encontrar durante a utilização de um produto/site. Do mesmo modo, a acessibilidade pode ser definida como a falta de problemas de acessibilidade. Mas isto não é o mesmo que dizer que problemas de usabilidade só são encontrados por pessoas sem deficiência e problemas de acessibilidade são encontrados apenas pelos usuários com deficiência. A relação entre acessibilidade e usabilidade e problemas de acessibilidade e de usabilidade são raramente analisados, quer no contexto da Web ou em outros sistemas de informação.

Thatcher e Waddell (2002) defendem que a acessibilidade é um subconjunto da usabilidade, sugerindo que os problemas de acessibilidade são tipos particulares de problemas de usabilidade. No entanto, eles também argumentam que problemas de usabilidade afetam todos os usuários da mesma forma, independentemente da capacidade ou incapacidade; enquanto que problemas de acessibilidade dificultam o acesso para 
pessoas com deficiência e as colocam em situação de desvantagem em relação às pessoas sem deficiência. Estas últimas afirmações sugerem uma relação mais complexa entre acessibilidade e usabilidade do que simplesmente a acessibilidade ser um subconjunto da usabilidade.

Shneiderman (2000) propõe "usabilidade universal" como um termo para abranger tanto a acessibilidade quanto a usabilidade, que ele define como "ter mais de $90 \%$ dos usuários bem-sucedidos no uso da tecnologia de informação e comunicação pelo menos uma vez por semana". Shneiderman (2000) observa que "o acesso não é suficiente para garantir sucesso de uso", sugerindo que a acessibilidade é um começo, mas não o passo suficiente para utilização universal, entretanto ele não analisa a relação entre os dois conceitos.

Se forem considerados os problemas que os deficientes e as pessoas sem deficiência encontram em um site, pode-se supor que haja ou não possíveis relações entre estes dois conjuntos de problemas.

Pode-se supor que os dois tipos de problemas são distintos, dois conjuntos que não se interceptam, significando que não há problemas que tanto os deficientes quanto pessoas sem deficiência encontram. Deste modo, problemas de acessibilidade seriam encontrados apenas por pessoas com deficiência e problemas de usabilidade seriam encontrados apenas por pessoas sem deficiência. De fato, essa é a forma com que são tratados os problemas de acessibilidade e usabilidade na maioria dos sites. Os processos de conceituação, avaliação e remoção dos problemas encontrados por cada grupo de usuários são completamente distintos, provavelmente tratados por diferentes indivíduos dentro de uma organização, em momentos diferentes no processo de desenvolvimento. A ideia de lidar com os dois tipos de problemas em um processo unificado, tanto através do uso de diretrizes ou de testes com usuários, raramente é encontrada na prática, seja na Web ou no desenvolvimento de interfaces.

Como mencionado anteriormente, Thatcher e Waddell (2002) propõem que problemas de acessibilidade (problemas enfrentados por pessoas com deficiência e que sejam relevantes para a sua deficiência e para as tecnologias de apoio utilizadas) podem ser um subconjunto de problemas de usabilidade. Esta definição é relevante na medida em que a acessibilidade pode ser tratada como parte da usabilidade no processo de avaliação. Mas também sugere a possibilidade de que alguns problemas típicos de acessibilidade poderem também afetar usuários sem deficiência. Por exemplo, disponibilizar um conjunto de cabeçalhos informativos pode tornar uma página Web mais útil para as pessoas cegas, que obtem informação por meio de leitores de tela, porém também é bastante útil para pessoas sem deficiência. No entanto, alguns problemas podem afetar apenas as pessoas com deficiências específicas. Por exemplo, ter um botão "enviar", com texto verde em um fundo vermelho, não gera problemas para as pessoas com plena visão de cores e nem para pessoas cegas, mas será um problema intransponível para as pessoas com daltonismo. 
Assim, nem todos os problemas de acessibilidade podem afetar os usuários sem deficiência, e não estão dentro do escopo dos problemas de usabilidade.

Por outro lado, o conceito de "usabilidade universal" de Shneiderman (2000) poderia ser pensado como a extensão do escopo do que tradicionalmente se pensa como usabilidade, incluindo os usuários com deficiência, de modo que, os problemas de usabilidade se tornariam um subconjunto dos problemas de acessibilidade. Isto poderia explicar o fato de que alguns problemas de acessibilidade estão além do escopo da usabilidade, como o problema da visão de cores recém exemplificado. Mas esta formulação sugere que todos os problemas de usabilidade estejam dentro do escopo da acessibilidade, o que significa que pessoas com deficiência devem encontrar problemas idênticos àqueles que as pessoas sem deficiência encontram.

Finalmente, Petrie e Omar (2007) defendem que os problemas de acessibilidade e usabilidade podem ser vistos como dois conjuntos que se sobrepõem, que incluem três categorias:

- Problemas que afetam apenas as pessoas com deficiência; estes podem ser chamados de problemas "puros" de acessibilidade;

- Problemas que afetam apenas as pessoas sem deficiência; estes podem ser chamados de problemas "puros" de usabilidade;

- Problemas que afetam as pessoas com deficiência e sem deficiência, podendo ser chamados de problemas de "usabilidade universal".

Assim sendo, Petrie e Omar (2007) investigaram as relações entre conjuntos de problemas de usabilidade e acessibilidade encontrados por grupos de usuários específicos (separados por tipos de deficiências). Além disso, verificaram se um determinado problema afeta pessoas com deficiência e sem deficiência da mesma forma. Como mencionado, Thatcher e Waddell (2002) define os problemas de usabilidade como sendo aqueles que afetam as pessoas com e sem deficiência de forma igual, enquanto que os problemas de acessibilidade dificultam o acesso a um site somente para pessoas com deficiência. No entanto, tem-se notado, com frequência, que pessoas com deficiência e não deficientes muitas vezes encontram os mesmos problemas, mas são afetados de forma diferente, o que leva a uma análise um tanto diferente: alguns problemas aparecem com menor intensidade para as pessoas sem deficiência, mas representam grandes barreiras para pessoas com deficiência, ou para certos grupos específicos de pessoas com deficiência. Assim, os problemas encontrados por pessoas sem deficiência (problemas de usabilidade) parecem ser intensificados para pessoas com deficiência, o que é um efeito que merece destaque. Os autores sugerem que os problemas de usabilidade poderiam ser detectados mais facilmente por meio da realização de avaliações com pessoas com deficiência, em vez de avaliações com as pessoas sem deficiência, conforme se faz normalmente. 
O estudo desenvolvido por Petrie e Omar (2007) utilizou dois sites de empresas de telefonia móvel como domínio do problema. O público-alvo compreendeu usuários cegos e outros com visão normal. Para ambos os sites, os problemas encontrados pelos participantes cegos e pelos de visão normal constituíram conjuntos que se interceptam, com alguns problemas encontrados somente pelos participantes cegos (mais da metade do número total de problemas encontrados), alguns problemas encontrados somente por pessoas que enxergam, e alguns problemas, embora não muitos (14\%), encontrados por ambos os grupos. Dessa forma foi constatado que os problemas de acessibilidade não constituem um completo sub-conjunto de problemas de usabilidade, como sugerido por Thatcher e Waddell (2002) e nem os problemas de usabilidade constituem um completo sub-conjunto de acessibilidade, como foi inferido por Shneiderman (2000).

A partir dos resultados obtidos, Petrie e Omar (2007) destacam a idéia de que, embora haja pontos de conflito quando se prioriza a acessibilidade em relação à usabilidade e vice-versa, ambos os conceitos devem ser considerados de forma integrada, como um modo de aliar e diminuir o espaço existente entre os princípios de usabilidade e as diretrizes de acessibilidade.

Nesta tese, portanto, as questões de acessibilidade e usabilidade para adultos mais velhos foram investigadas integradamente.

\subsection{Considerações finais}

Neste capítulo foram abordados os principais conceitos relacionados com o desenvolvimento desta pesquisa. Enquanto vários autores buscam definições precisas sobre usabilidade e acessibilidade, discutem seus pontos de intersecção e divergências, a pesquisadora procura aliar as melhores características de cada uma delas de modo a prover orientações baseadas nas dificuldades observadas dos adultos mais velhos em suas interações com a Web.

A expectativa de vida continua aumentando e compreender o processo de envelhecimento é fundamental para que se possa elaborar um conjunto de orientações que permitam contribuir para a melhoria das interações dos adultos mais velhos com a Web.

No próximo capítulo serão apresentadas as principais características dos adultos de meia-idade e idosos e suas principais dificuldades no uso na Web. 


\section{Os Adultos Mais Velhos e a Web}

\subsection{Considerações iniciais}

O crescimento do uso da Web por pessoas de meia-idade, idosas ou com necessidades especiais tem motivado o desenvolvimento de técnicas para produzir páginas Web usáveis e acessíveis. Os governos e a indústria já começaram a perceber o grande aumento no número de adultos "mais velhos" disponíveis no mercado de trabalho. A utilização de tecnologias de informática é parte integrante de muitos postos de trabalho disputados por esse público, criando uma demanda por tecnologia que leve em conta suas capacidades e limitações (Kogan, 2001).

Devido ao acelerado aumento na utilização da Web de modo geral, e devido à sua própria evolução, muitos dos sites, com o intuito de oferecer páginas cada vez mais sofisticadas, utilizam-se de recursos técnicos que se transformam em verdadeiras barreiras de acesso para determinados grupos de pessoas, tais como os adultos de meia-idade e idosos sem experiência no uso da Web.

A acessibilidade é um aspecto fundamental para garantir a inclusão digital dos cidadãos, por isso a preocupação com os "mais velhos" e com os portadores de necessidades especiais vem se ampliando em todos os setores, visto que eles já constituem, atualmente, grande parte da população economicamente ativa e grande parte do mercado de trabalho. Apesar de os adultos de meia-idade e os idosos serem muitas vezes inexperientes com computadores e necessitarem de aulas para utilizá-los, eles constituem um dos grupos de usuários da Internet que cresce com grande velocidade (SeniorNet, 2007).

Apesar de diversas tentativas de desenvolvimento de diretrizes e técnicas que facilitem a interação desse público com a Web, um longo caminho ainda deverá ser percorrido. O grande desafio está no fato de que não existe um fator único que interfira nessa interação, 
mas, sim, um conjunto de fatores (físicos e emocionais) que prejudicam diretamente a interação dos idosos com a Web.

Contudo, nota-se que o grande entrave para a disseminação da cultura de acessibilidade na Web está na conscientização dos desenvolvedores acerca da importância do tema e das consequências trazidas pela utilização de tecnologias que se tornam barreiras para o acesso ao conteúdo disponibilizado na Web.

Nas seções seguintes é descrito o estudo realizado a respeito da situação dos adultos de meia-idade e idosos no Brasil, da qualidade de vida na velhice, dos impactos do envelhecimento, da relação entre os adultos de meia-idade e o mercado de trabalho, bem como da interação dos adultos mais velhos com a Web.

Neste capítulo são caracterizados os fatores que formam a base dos estudos sobre as dificuldades dos idosos, proporcionando uma visão geral do contexto da população que é alvo de investigação nesta tese.

\subsection{Os adultos de meia-idade e idosos no Brasil}

Observa-se na literatura grande dificuldade na definição dos limites entre adultos de meia-idade (idade madura) e a terceira idade (idosos), sendo o critério cronológico o mais amplamente adotado. A divisão da vida em fases define práticas esperadas de cada um, de acordo com o grupo social e cultural em que o indivíduo está inserido (Debert, 1998).

O conceito de idade funcional possui estreita relação com a idade biológica (envelhecimento do organismo), e pode ser definida como sendo o grau de conservação do nível de capacidade adaptativa em comparação com a idade cronológica (Neri, 2005). Segundo Veras (1996), em decorrência das precárias condições de vida nos países em desenvolvimento, o envelhecimento funcional precede o cronológico, fato que é mais evidente nas populações mais carentes.

O conceito de idade psicológica refere-se à relação que existe entre a idade cronológica e as capacidades de percepção, aprendizagem e memória, as quais prenunciam o potencial de funcionamento futuro do indivíduo. Paralelamente, a idade psicológica tem sido relacionada também com o senso subjetivo de idade, isto é, como cada pessoa avalia a presença de marcadores biológicos, sociais e psicológicos do envelhecimento, comparando-se com outros indivíduos de mesma idade (Neri, 2005).

A idade social tem relação com a avaliação da capacidade de adequação de um indivíduo ao desempenho de papéis e comportamentos esperados para as pessoas de sua idade, num dado momento da história de cada sociedade. Dessa forma, as experiências de envelhecimento e velhice podem variar no tempo histórico de uma sociedade, dependendo de circunstâncias econômicas. 
Em suas pesquisas, o IBGE classifica os adultos de meia-idade apenas como indivíduos petencentes à população potencialmente ativa, ou seja, aquela com idades compreendidas entre 15 e 64 anos, disponibilizando poucos dados específicos sobre essa faixa etária. Considera-se, como adultos de meia-idade, para efeitos deste estudo, as pessoas que possuem idade acima de 40 anos e abaixo de 60 anos de idade, uma vez que o interesse desta pesquisa tem como alvo a investigação dos aspectos relacionados com as dificuldades decorrentes do processo de envelhecimento, e que não é notado, normalmente, em adultos com idade entre 15 e 39 anos de idade.

No documento de Indicadores Sociais de 2007 (IBGE, 2007) são apresentados os resultados de pesquisas com relação a duas principais categorias: crianças, adolescentes e jovens (0 a 24 anos), e idosos (acima dos 60 anos). Parece haver uma lacuna de informações específicas a respeito dos indivíduos que compõem a meia-idade. Como a meia-idade e a terceira-idade constituem fases de vida intrinsecamente relacionadas, pesquisas com pessoas na meia-idade podem ser também uma forma de contribuir com os estudos sobre envelhecimento.

Segundo convenções sociodemográficas atuais, idosos são pessoas com mais do que 60 anos nos países em desenvolvimento e com mais do que 65 anos nos países desenvolvidos. No entanto, à medida que o ciclo vital da humanidade se alonga, aumenta substancialmente a heterogeneidade entre os adultos de meia-idade e idosos. Gênero, classe social, saúde, educação, fatores de personalidade, história passada e contexto socio-históricos são elementos importantes que se mesclam com a idade cronológica para determinar diferenças nessa população (Neri, 2005).

Diversos fatores têm contribuído para o envelhecimento populacional, tais como as melhorias das condições nutricionais, de trabalho, de saneamento e de moradia, a redução da taxa de fecundidade, além de novas descobertas da medicina, gerando, por conseguinte, o aumento da expectativa de vida. Segundo os dados da Organização Mundial de Saúde, até 2025, o Brasil será o sexto país do mundo com o maior número de pessoas idosas. Até 2020, 1 em cada 13 brasileiros será idoso. Dessa forma, conclui-se que, atualmente, o número de indivíduos adultos de meia-idade é bastante grande e o governo brasileiro deve se preparar para a necessidade de criar, o mais rápido possível, políticas sociais que preparem a sociedade para essa realidade (IBGE, 2008a).

Segundo o Instituto de Pesquisa e Econômica Aplicada (IPEA, 2007), a preocupação com a população idosa surgiu no final do século passado em função da constatação de que, tanto no mundo desenvolvido, quanto no subdesenvolvido, era esse o segmento populacional que mais crescia. Segundo o IBGE (IBGE, 2006) as estimativas são de que até o ano de 2050, a expectativa de vida nos países desenvolvidos será de 87,5 anos para os homens e 92,5 anos para as mulheres, contra 70,6 e 78,4 anos respectivamente, em 1998. Nos países em desenvolvimento, será de 82 anos para homens e 86 para mulheres. 
É no sentido de facilitar a familiarização com os elementos da interação com a Web que o trabalho desenvolvido nesta tese teve como público-alvo as pessoas "mais velhas", com maior interesse para a faixa etária entre 40 e 60 anos, mas sem excluir os idosos (acima dos 60 anos). O objetivo, foi de que quando essas pessoas da meia-idade e idosos, alcançarem a velhice, possuam conhecimento e familiaridade com a Web de modo a utilizá-la de forma independente.

\subsection{Qualidade de vida na velhice}

A preocupação com a qualidade de vida na velhice ganhou relevância nos últimos 30 anos, na medida em que o crescimento do número de idosos e a expansão da longevidade passaram a ser experiência compartilhada por um número crescente de indivíduos vivendo em muitas sociedades. Cada vez mais as questões que dizem respeito ao bem-estar físico, psicológico e social dos idosos interessam aos planejadores de políticas de saúde, educação, trabalho e seguridade social e aos cientistas.

Segundo Neri (2005), qualidade de vida é um atributo que tem múltiplas dimensões, é multideterminado, diz respeito à adaptação de indivíduos e grupos humanos em diferentes épocas e sociedades, e, assim, sua avaliação consiste em comparar as condições disponíveis com as desejáveis. Os resultados são expressos justamente por índices de desenvolvimento, bem-estar, desejabilidade, prazer ou satisfação.

A Qualidade de Vida em Saúde corresponde à relação custo-benefício inerente à manutenção da vida de enfermos crônicos e terminais, focalizando tanto o ponto de vista do bem-estar e dos direitos individuais, quanto dos interesses e valores da sociedade.

A Qualidade de Vida em Economia está relacionada à renda per capita e ao acesso das populações aos benefícios da Educação, da Medicina e dos Serviços Sociais.

A Qualidade de Vida em Sociologia inclui um conjunto de indicadores econômicos e de desenvolvimento sócio-cultural identificados como nível ou padrão de vida de uma população.

Diante do envelhecimento populacional, o objetivo deixa de ser apenas prolongar a vida, mas, principalmente, prolongar a manutenção da capacidade funcional de cada indivíduo, de forma que ele permaneça autônomo e independente pelo maior tempo possível. Define-se autonomia como a capacidade de decisão e de comando; e independência como a capacidade de realizar algo com seus próprios meios (Neri, 2005). Um indivíduo pode ser autônomo mesmo quando é ou está dependente, por exemplo, uma pessoa com fratura do fêmur, que fica restrita a uma cadeira de rodas, poderá exercer a sua autonomia, apesar de não ser totalmente independente. 


\subsection{Os impactos do envelhecimento}

A meia-idade é um período demarcado por mudanças, em especial por mudanças psicológicas. Nessa fase ocorre a percepção do envelhecimento, a proximidade da fase adulta dos filhos e, geralmente, a competição com pessoas mais jovens e mais bem treinadas no mercado do trabalho. Trata-se de um período de reavaliação e de readaptação pessoal (Neri, 2002).

Como o envelhecimento é uma etapa natural do ciclo de vida, declínios de ordem fisiológica, cognitiva e emocional ocorrem em virtude desse envelhecimento e prejudicam a interação das pessoas mais velhas com os computadores. O envelhecimento não é a mera passagem do tempo; é a manifestação de eventos biológicos que ocorrem ao longo de um período (Hayflick, 1996).

À medida que as pessoas envelhecem, passam a ter algumas necessidades que surgem em função de problemas de ordem sensorial (visão sub-reduzida, acuidade visual, audição, etc.), de ordem física (motricidade fina, locomoção etc.) e cognitivas (redução das capacidades de memória). Acredita-se, em geral, que mudanças ocasionadas pela idade têm muitas causas, algumas das quais podem combinar-se com outras de forma muito complexa. Não existe um delimitador cronológico exato para tais manisfestações, mas sim diversos fatores que podem antecipar ou retardar o processo, tais como: genética, condições de saúde física e mental, hábito e estilo de vida, contexto socioeconômico e sociocultural (Neri, 2005).

Segundo Neri (2005), a definição operacional de capacidade funcional está relacionada com a medida do grau de preservação da capacidade do indivíduo para realizar as atividades da vida diária (AVDs) e do grau de capacidade para desempenhar as atividades instrumentais da vida diária (AIVDs). As AVDs são as atividades que se referem ao autocuidado, ou seja, permitem às pessoas cuidar-se e responder por si só no espaço limitado de seu lar. Essas atividades envolvem, por exemplo, alimentar-se, ter continência, locomover-se, tomar banho, vestir-se, usar o banheiro, andar pela casa, subir e descer escadas e cortar as unhas. Já as AIVDs estão relacionadas com funções mais complexas que permitem vida independente na comunidade, incluindo por exemplo, as atividades de fazer compras, cozinhar, arrumar a casa, telefonar, usar o transporte, lavar roupa, tomar remédio e ter a habilidade de cuidar das próprias finanças. Existem ainda atividades que podem ser consideradas avançadas da vida diária (AAVDs), como dirigir carro, praticar esporte, andar de bicicleta, cantar, viajar, dançar, entre outras. Essas atividades não são fundamentais para uma vida independente, mas, como tendem a ser dependentes de vontade e da motivação, sua presença é indicativa de maior capacidade funcional e melhor saúde física e mental.

As alterações na visão são as mais comuns associadas à idade, dentre elas a formação de catarata, resultante de mudanças normais nas proteínas que aumentam sua opacidade, 
produzindo, então, um desconforto no cristalino dos olhos. O glaucoma e manifestações retinianas provocados pelo diabetes e pela hipertensão arterial também são alterações que podem ocorrer nas pessoas mais velhas (Hayflick, 1996).

As pessoas mais velhas muitas vezes sofrem de deficiências visuais, que podem tornar a leitura de texto em um monitor de computador uma tarefa árdua. Caracteres com tamanho de fontes pequenos, pouco contraste entre cor de fundo e o texto escrito na frente podem comprometer a visualização do conteúdo. Animações na tela também podem distrair os usuários mais velhos, exigindo muito de suas capacidades cognitivas.

Segundo Hayflick (1996), há evidências significativas de declínios cognitivos relacionados ao envelhecimento. Boa parte desses declínios relacionam-se com a capacidade de manter a atenção, com a capacidade da memória de trabalho, com a velocidade de processamento da informação, com a formação de conclusões e também com a interpretação, codificação e compreensão de um discurso. Tais mudanças podem ser acentuadas quando o indivíduo está sujeito a ambientes estressantes, quando lhe falta condicionamento físico, quando está sujeito a uma carga de trabalho excessiva, à depressão, ao stress, ao uso indevido de medicamentos e com problemas de ordem emocional, nutricional, enfermidades, etc.

Alterações cognitivas que não comprometem o cotidiano do indivíduo costumam aparecer por volta da quarta ou quinta década de vida, e evoluem de modo extremamente variável entre os indivíduos, conforme uma variedade de fatores tais como: genética, ambiente, presenças da alteração da hipertensão e diabetes, entre outras. Diferenças podem ser percebidas no indivíduo que envelhece, em seu corpo, em sua mente e na sua vivência. Evidentemente, a idade cronológica não é o agente confiável para prever a aparência ou o comportamento de uma pessoa com mais idade. Alguns fatores de natureza psicológica e cultural fazem com que muitos indivíduos nesta etapa afirmem que não se consideram idosos. No entanto, outros com menos idade agem como velhos.

Meyer et al. (1997) resumiram algumas alterações físicas e psicológicas que podem ser responsáveis pela hesitação que as pessoas mais velhas apresentam quando utilizam a Web. Tais alterações incluem o declínio da memória de trabalho, que foi evidenciado a partir dos problemas que os usuários mais velhos apresentaram, tais como: não se lembrarem de páginas que já haviam visto ou como eles chegaram em tal página. O aumento da idade foi associado também com o aumento da dificuldade motora (ruído motor) e movimentos mais lentos, o que poderia afetar o uso de barras de rolagem ou mapas de imagem.

Segundo um estudo publicado pela revista médica britânica British Medical Journal $(B M J)$, a memória e o raciocínio começam a se deteriorar a partir dos 40 anos de idade, muito antes dos 60 anos, como se acreditava de maneira geral. Um comunicado do Instituto Nacional de Saúde e Pesquisa Médica (INSERM) francês, responsável pelo estudo, revelou que a capacidade de raciocinar e compreender começa a declinar a partir dos 45 anos de idade. Segundo o INSERM, os resultados mostram que o rendimento 
cognitivo (com exceção dos testes de vocabulário) diminui com a idade, e isto ocorre cada vez mais rapidamente na medida que as pessoas envelhecem (British Medical Journal, 2012).

No estudo desenvolvido por especialistas do INSERM francês e da University College de Londres (British Medical Journal, 2012), foi estudada a saúde mental de mais de 7.000 pessoas durante dez anos (1997-2007) e suas funções cognitivas foram medidas três vezes durante esse período. Os participantes possuíam idade entre 45 e 70 anos. O objetivo desse estudo foi avaliar a memória, o vocabulário, a audição e a compreensão. Segundo os resultados observados, o rendimento de raciocínio caiu 3,6\% para os homens de 45 a 49 anos e $9,6 \%$ para os de 65 a 70 anos. Os valores correspondentes para as mulheres foram $3,6 \%$ e 7,4\%, respectivamente (British Medical Journal, 2012).

Segundo Neri (2005), os problemas de memória relatados pelas pessoas mais velhas são, em grande parte, confirmados por investigações de laboratório. No entanto, esses mesmos estudos mostram que a questão é muito complexa e não se pode atribuir todas as diferenças em desempenho de memória encontradas apenas à idade.

De forma simplificada, pode-se usar a analogia com o computador para explicar como é o modelo de processamento de informação no estudo do funcionamento da memória. As informações são recebidas, codificadas, armazenadas e depois são recuperadas mediante o uso de rotinas específicas, compatíveis com a linguagem com que as mensagens foram codificadas. Segundo esse modelo, existem três sistemas de memória e seus subsistemas, que são afetados de diferentes formas pelo envelhecimento (Neri, 2005):

1. Memória sensorial: é responsável pelo armazenamento inicial e breve dos estímulos externos. Uma vez processadas, as informações resultantes são transferidas para a memória de curta duração, sob a forma de imagens, palavras ou números. O funcionamento desse sistema pode sofrer a interferência de deficiências sensoriais e da dilatação no tempo de reação, ocorrências comuns do envelhecimento normal;

2. Memória de curta duração: é dividida em dois subsistemas:

- Memória primária: envolve a retenção de pequenas quantidades de informação por curtíssimos períodos de tempo, por exemplo, reter um número de telefone enquanto é ditado pela operadora, para poder usá-lo em seguida. Para poder ser usada posteriormente, a informação precisa ser processada na memória operacional, sob a forma de conceitos e famílias de conceitos a serem lembrados;

- Memória operacional: permite reter e manipular cada unidade de informação que cai sob o enfoque da atenção durante o processamento da informação, por exemplo, na compreensão de textos, na tomada de decisão e na realização de tarefas concorrentes. Pode ser afetada por perdas sensoriais, medo de fracasso e presença de elementos que causam distração, motivos pelos quais esse subsistema pode ser sensivelmente afetado nos adultos mais velhos. 
3. Memória de longa duração: é responsável pelo armazenamento da informação por um período de tempo mais longo e compreende dois subsistemas:

- Memória declarativa ou explícita: refere-se à memória consciente de experiências prévias. É a que se avalia nos testes de reconhecimento e de evocação livre, que requerem consciência e intencionalidade. É responsável pelos processos de lembrar de experiências passadas com a finalidade de transmitir informações, de organizar a experiência atual e de regular as emoções. É subdividida em dois subsistemas:

- Memória para eventos ou episódica: refere-se à lembrança de coisas e eventos associados a um tempo ou lugar em particular, por exemplo, um compromisso que lembramos ou onde guardamos um livro. Tende a piorar com a idade e está mais associada à dificuldade em atuar no ambiente do que em aprender coisas novas. A oferta de apoio ambiental sistemático pode aprimorá-la à medida que facilita o reconhecimento e a codificação e aciona os esquemas de memória associados à informação a ser utilizada;

- Memória para fatos ou semântica: inclui conteúdos verbais, tais como: nomes, descrições, significados, normas sintáticas, classificações e conceitos abstratos, comumente designados como conhecimento. Fornece um sistema de representações abstratas que funcionam como suportes para o pensamento, a linguagem e a compreensão. É incomum declinar com a idade.

- Memória não declarativa, processual ou implícita: envolve o armazenamento, o encadeamento e a codificação de informações de forma relativamente independente da consciência, da intencionalidade e da linguagem. Revela-se pela facilitação do desempenho a partir de experiências anteriores. Analisada por critérios funcionais, abrange as seguintes categorias:

a. Habilidades, hábitos e condicionamento;

b. Pré-ativação;

c. Condicionamento clássico;

d. Aprendizagem, que é comumente afetada pela idade.

A capacidade de utilizar a Web pode proporcionar aos adultos mais velhos uma melhoria na qualidade de vida à medida que sua capacidade de realização das AIVDs for diminuindo. A utilização de sites de comércio eletrônico e bancos, por exemplo, facilita a realização de tarefas que anteriormente exigiam o uso de transporte ou de deslocamentos. É importante ressaltar que esse aspecto de facilidade proporcionado pela interação com a Web não deve ser encarado como um fator inibidor da realização de atividades externas ou de favorecimento do isolamento, mas apenas como um facilitador para que a pessoa 
debilitada continue tendo a autonomia na realização de suas tarefas, bem como, uma alternativa de lazer, conhecimento e comunicação com seus amigos e familiares.

\subsection{0 adulto de meia-idade e o mercado de trabalho}

Segundo critérios estabelecidos pela Organização das Nações Unidas (ONU), a idade que marca o início da velhice, em países em desenvolvimento, é de 60 anos. De acordo com a legislação brasileira de previdência social atual, os trabalhadores que contribuíram 35 anos com o INSS ${ }^{1}$ e as trabalhadoras que contribuíram 30 anos possuem direito à aposentadoria. Além disso, trabalhadores com mais de 65 anos e trabalhadoras com mais de 60 anos também podem se aposentar. Contudo, muitas vezes, os cidadãos não conseguem adquirir esse direito e continuam no mercado de trabalho (Neri, 2005).

Na prática, em muitos contextos, não é necessário atingir 60 anos para ser considerado velho no mercado de trabalho. Em várias profissões e carreiras, as pessoas já são consideradas velhas quando atingem os 40 anos. Isso ocorre em grande parte por causa de estereótipos tradicionais sobre o envelhecimento, segundo os quais os mais velhos são obsoletos, intelectualmente prejudicados, improdutivos, resistentes à mudança e desmotivados (Neri, 2002).

As práticas vigentes no mercado de trabalho também contribuem para a exclusão das pessoas mais velhas, uma vez que é mais vantajoso financeiramente substituir um trabalhador de mais idade por outro mais jovem, com treinamento mais recente e a custos mais baixos para as empresas. No entanto, existem postos de trabalho onde as práticas dependem muito da experiência acumulada, como nas áreas de direito, da medicina e no meio acadêmico, onde o profissional mais velho é valorizado pelos anos de experiência e sabedoria adquiridos ao longo de sua vida.

Pesquisas do Ministério do Trabalho, realizadas em 2004, apontam para aspectos positivos do mercado de trabalho para trabalhadores e trabalhadoras com mais de 40 anos de idade e com escolaridade mínima de onze anos de estudos. Segundo especialistas, o aumento da procura por trabalhadores e trabalhadoras mais velhos é uma decorrência da retomada do crescimento econômico. O principal critério de recolocação desses profissionais no mercado de trabalho não é propriamente a idade e sim o conhecimento do trabalhador, que precisa satisfazer as exigências no que diz respeito às habilidades, fluência em algum outro idioma e experiência no cargo. Nos dias atuais, devido às rapidas mudanças tecnológicas e organizacionais, a habilidade em operar computadores e interagir com a Web tem sido exigida para a ocupação de diversos postos de trabalho.

A seguir são apresentados aspectos da interação entre os adultos mais velhos e a Web e os reflexos benéficos dessa interação para a velhice.

\footnotetext{
${ }^{1}$ Instituto Nacional do Seguro Social
} 


\subsection{A interação dos "mais velhos" com a Web}

Cada vez mais sites da Web têm sido desenvolvidos para os usuários mais velhos. Dentre os vários benefícios oferecidos pela Web, pode-se citar (Kurniawan e Zaphiris, 2005): socialização, aprendizado de novos conhecimentos, gerenciamento financeiro, compras, contato com amigos e familiares, ajuda a pessoas que não podem sair de casa ou com necessidades especiais.

No Brasil, pode-se observar dois cenários muito distintos quando considerados os adultos de meia-idade e sua interação com a Web. Segundo uma pesquisa publicada pela Revista Veja Vida Digital (2000), existe um grupo de usuários no Brasil que já está entre os mais ativos da Internet. Nesse grupo, estão os profissionais na meia-idade que venceram o medo de usar computadores e se renderam ao uso da Internet em seus escritórios e negócios, e também aqueles que já estão aposentados e descobriram na Web uma fonte de lazer e facilidades.

Segundo essa mesma pesquisa, o público da meia-idade era o que se mostrava mais fiel à Internet. Dentre as 2064 pessoas pesquisadas, o grupo da meia-idade foi o único em que $100 \%$ dos internautas se conectavam diariamente à rede. A maioria desse público, $70 \%$, acessava a rede várias vezes ao dia. Uma frequência maior que a observada entre os jovens e adultos de até 24 anos. Desses, $94 \%$ acessavam a rede todo dia e $6 \%$ só o faziam uma vez por semana. A justificativa desse intenso uso da Internet era de as pessoas mais velhas possuírem um estilo de vida mais caseiro e uma rotina mais definida, facilitando a assiduidade na Web.

Por possuírem situação econômica normalmente mais favorável, os adultos de meia-idade pesquisam preços, compram em lojas virtuais, realizam transações bancárias pela rede, consultam agências de turismo e reúnem a família para conversar por meio de programas de mensagens instantâneas. Constituem um público atraente porque tem renda disponível e a maioria não está mais comprometida com a educação dos filhos ou com a prestação da casa própria.

Segundo o Instituto de Pesquisa Marplan (Marplan, 2008), 80\% dos internautas de meia-idade são das classes A e B e possuem nível de escolaridade acima da média. Nessas duas faixas, a população com mais de 50 anos revela uma saúde econômica muito boa: $89 \%$ têm casa própria e $82 \%$ possuem carro. Os dados fazem parte do estudo "Good-Agers e sua potencialidade de consumo", realizado pela Marplan nos nove principais mercados do Brasil para mapear os consumidores com mais de 50 anos. Por estarem bem de vida, são chamados de goodagers (os que estão na boa idade) para contrastar com o termo inglês teenagers (adolescentes).

Em contrapartida, existe outro grupo de adultos de meia-idade com uma realidade bem diferente da descrita acima, que são os indivíduos pouco escolarizados, com pouca 
ou nenhuma experiência no uso de computadores e Internet, que muitas vezes perderam seu emprego e sentem-se excluídos tanto digitalmente, quanto socialmente.

Atualmente, as pessoas de 40 anos ou mais, uma vez fora do mercado de trabalho e com pouca qualificação, dificilmente voltam a ele e, quando conseguem trabalho, é geralmente em função inferior à que exerciam e recebem um salário menor. Dessa forma, muitas delas, buscam os cursos de informática como meio para tentarem obter recolocação profissional, uma vez que, diante das novas expectativas de vida, com 40 e poucos anos, o profissional ainda tem pela frente, em termos estatísticos, um tempo praticamente igual ao período que já trabalhou até então.

Existe também o aspecto geracional relacionado ao uso de tecnologias que deve ser levado em conta. Um estudo realizado pela empresa de pesquisa norte-americana Pew Internet, o projeto "Generation and the gadgets" (Kathryn Zickuhr, 2011), entrevistou mais de 3 mil americanos adultos (com idades acima de 18 anos) no ano de 2010. Foram realizadas entrevistas em inglês e espanhol, e a pesquisa incluiu 1.000 entrevistas por telefone celular. Neste estudo as gerações foram classificadas conforme a Figura 3.1

\begin{tabular}{|c|c|c|c|c|c|}
\hline Millennials & Gen $X$ & $\begin{array}{c}\text { Younger } \\
\text { Boomers }\end{array}$ & $\begin{array}{c}\text { Older } \\
\text { Boomers }\end{array}$ & $\begin{array}{c}\text { Silent } \\
\text { Gen. }\end{array}$ & G.I. Gen. \\
AGES 18-34 & AGES 35-46 & AGES 47-56 & AGES 57-65 & AGES 66-74 & AGE 75+ \\
\hline
\end{tabular}

Figura 3.1: Classificação de gerações segundo o projeto "Generation and the gadgets" (Kathryn Zickuhr, 2011)

Muitos dispositivos tornaram-se populares entre as gerações, e os mais adotados atualmente são os telefones celulares, laptops e computadores de mesa. Os adultos mais jovens contribuem cada vez mais para o aumento da mobilidade, preferindo laptops e usando seus telefones celulares para uma variedade de funções, incluindo internet, e-mail, música, jogos e vídeos (Kathryn Zickuhr, 2011) (Figura 3.2).

$\mathrm{O}$ avanço da tecnologia e as dificuldades de acesso às novas técnicas causam impacto em todas as gerações e, em especial, às pessoas mais velhas. Uma das razões mais frequentemente citadas como a causa do afastamento desse público da Web decorre da incompreensão dos desenvolvedores de que as pessoas mais velhas têm necessidades diferentes em relação às pessoas mais jovens. Os declínios provenientes do envelhecimento prejudicam a sua interação com os computadores, e em especial, com a Web.

Levando-se em consideração as principais dificuldades encontradas pelos idosos, algumas soluções podem ser adotadas (Hanson, 2004):

- Soluções de hardware: há grande variedade de soluções de hardware que podem ser utilizadas. Monitores grandes auxiliam os idosos com os problemas de leitura de fontes pequenas e ajustes do ângulo dos óculos bifocais. Mouses diferenciados podem facilitar a realização de duplos cliques e controle da rolagem. Microfones e fones de ouvidos podem ser utilizados para melhorar o material de áudio. Além disso, 


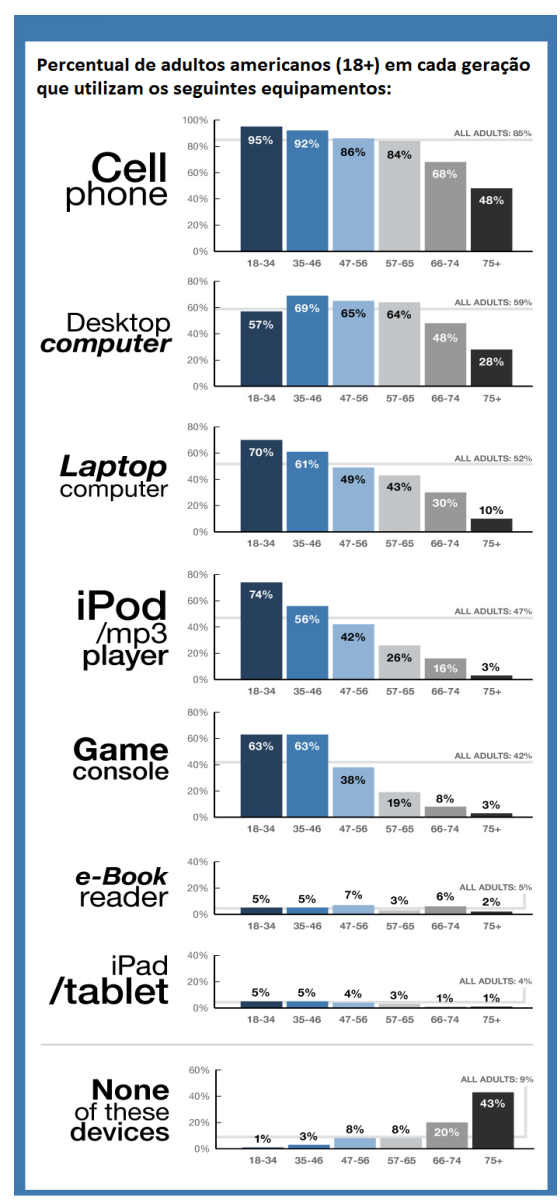

Figura 3.2: Percentual de uso de equipamentos pelas gerações (Kathryn Zickuhr, 2011)

tecnologias assistivas projetadas para deficiências específicas, como teclados e telas especiais para usuários com baixa visão podem ser extremamente úteis (Paciello, 2000);

- Soluções via softwares-clientes: há também grande variedade de softwares que rodam do lado do cliente e que possibilitam mudanças em sua configuração tornando as páginas mais acessíveis. Por exemplo, as alterações de configurações de tamanhos de fonte e cores melhoram a acessibilidade. Animações e texto piscando podem ser eliminados. Ajustes no teclado também ajudam a eliminar os erros causados por usuários com tremores e artrite;

- Soluções via desenvolvedores de software: outra abordagem para minimizar os problemas enfrentados pelos idosos é a utilização de guidelines e ferramentas que auxiliem na criação de página acessíveis. Ou ainda, a utilização de implementações de software que reformatam páginas Web e apresentam uma versão mais acessível ao usuário idoso ou ao portador de necessidades especiais.

A dificuldade óbvia com as duas primeiras soluções, no entanto, é que a responsabilidade de atualizações é colocada nas mãos dos usuários, que devem estar sempre atentos 
para manter as soluções atualizadas e/ou comprarem os acessórios necessários. A maioria das soluções via software requerem que o usuário esteja ciente delas, sendo que algumas funções requerem a interação do usuário com uma sequência de mensagens (diálogo longo) para configurar fontes de letras, cores e opções de acessibilidade em determinados navegadores.

A dificuldade com abordagens que deixam a responsabilidade com os desenvolvedores é que eles não têm consciência das barreiras de acessibilidade que geram por não seguirem as guidelines, haja vista que nem mesmo a simples inclusão de tags, contendo texto descritivo para imagens, é utilizada.

As pessoas mais velhas são as mais penalizadas com os avanços de grande variedade de tecnologias que não lhes são familiares. No que se refere aos idosos, equipamentos assistivos normalmente atuam para minimizar um certo tipo de deficiência, embora esse público geralmente apresente uma combinação de várias delas.

Considera-se que os adultos de meia-idade têm potencial para se inserir no processo de aprendizagem, tal como ocorre nas demais faixas etárias. Porém, no caso da informática, há uma defasagem muito acentuada entre o conhecimento acumulado pelos jovens, já nascidos e socializados com a utilização de ícones, teclas, botões e mouse, e a quase nenhuma familiaridade da maioria das pessoas mais velhas, o que vai requerer estratégias e mecanismos de apoios específicos para que elas possam vencer os obstáculos tecnológicos e se tornarem aptas a utilizar a Internet com independência e autonomia antes de atingirem a idade idosa, favorecendo assim uma melhor qualidade de vida na velhice.

\subsection{Considerações finais}

Acessibilidade na Web tem se tornado um importante tópico no contexto da interação entre as pessoas mais velhas e a Web. Os governos e as indústrias têm começado a se preocupar em oferecer-lhes treinamento apropriado, devido ao grande aumento no número de idosos disponíveis no mercado de trabalho.

Neste capítulo, foram levantados os principais problemas causados pelo envelhecimento e que prejudicam a interação entre as pessoas mais velhas e a Web, estudados na literatura.

O perfil demográfico da população do Brasil passa por grandes transformações. Em face do continuado declínio da fecundidade e do aumento da longevidade de sua população, o país caminhará rapidamente rumo a um padrão etário cada vez mais envelhecido, o que, seguramente, implicará em avaliações permanentes das políticas sociais voltadas para o atendimento das demandas de um contingente de adultos de meia-idade e idosos que crescerá velozmente.

O avanço das novas tecnologias, ao mesmo tempo em que promove melhorias para a população, traz à tona uma nova forma de exclusão: a digital, que atinge todos aqueles que não têm acesso ao equipamento e/ou aos procedimentos técnicos para fazer funcionar 
computadores, centrais eletrônicas, caixas de bancos, celulares, controles remotos, fornos de microondas e demais máquinas eletrônicas, sendo que um dos segmentos mais atingidos pela exclusão digital é o das pessoas mais velhas.

Por outro lado, embora haja a necessidade de políticas públicas mais eficientes, há também uma parcela de pessoas de meia-idade e idosas que não frequenta os cursos de informática oferecidos gratuitamente e que não se sente motivada a se incluir no mundo digital. Tais pessoas acreditam que essa inclusão seja um desafio maior do que suas possibilidades, haja vista que o acesso à informática parece ser um obstáculo intransponível para os mais velhos, principalmente por não entenderem o alcance da inclusão digital. Há, portanto, falta de políticas públicas que possam esclarecer e motivar os adultos mais velhos a se incluírem no mundo digitalizado.

Há, ainda, o preconceito, assumido por todas as faixas etárias, e principalmente pelas pessoas mais velhas, de que o processo de aprendizagem é incompatível com a velhice. Várias pesquisas comprovam que a dificuldade de aprendizagem resulta mais da insegurança do que da deterioração da faculdade de aprender e que, muito além da idade, o que mais influencia a interação de um indivíduo com a Web é o seu nível de escolaridade. 


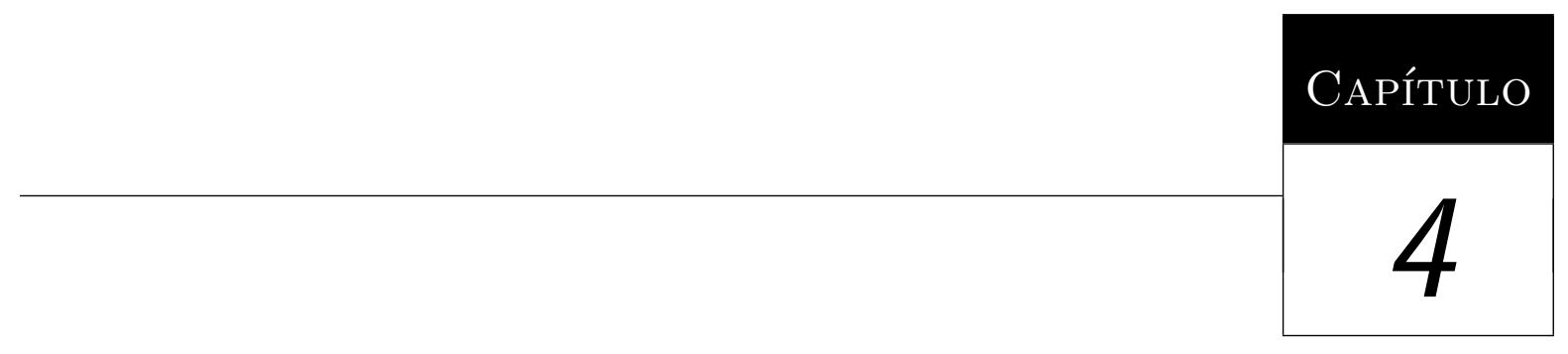

\section{Trabalhos Relacionados}

Estudos sobre os impactos do envelhecimento e suas implicações na interação dos idosos com diversos tipos de tecnologias têm recebido maior atenção do meio acadêmico nos últimos anos, embora não se possa dizer o mesmo com relação aos estudos sobre adultos de meia-idade.

A maior parte das pesquisas sobre as diferenças de desempenho no uso de tecnologias relacionadas com a idade comparam adultos de no máximo 30 anos e idosos com idade superior a 60 anos. Nesse contexto, os adultos de meia-idade têm recebido bem menos atenção, embora constituam grande parte da força de trabalho e estejam amplamente expostos à tecnologia em sua vida diária.

Grande parte da preocupação especial com os idosos se deve ao crescimento acelerado dessa população, que em 2020 deve exceder 1 bilhão no mundo todo (Zaphiris et al., 2005). Mas, o que não se discute é que, se a população de idosos vai atingir tais níveis daqui a aproximadamente 8 anos, existe, hoje, um contingente muito grande de adultos de meia-idade que deve ser preparado para alcançar a velhice com melhor qualidade de vida.

De acordo com estatísticas da OCDE (Organização para a Cooperação e Desenvolvimento Econômico), da República da Coréia em 2006, a proporção de adultos de meia idade (45-59 anos de idade) era de 28,5 \% do total da população. Essa proporção foi maior do que a dos jovens adultos com idades compreendidas entre os 20-29 anos (19,8 $\%$ ), e das pessoas com mais de 60 anos de idade (19,7\%). Além disso, 30,2\% de todos os postos de trabalho são preenchidos por adultos de meia-idade, comparativamente a 17,5 $\%$ dos postos de trabalho preenchidos por jovens adultos, e apenas 10,8 \% de postos de trabalho ocupados por pessoas idosas. Do mesmo modo, nos Estados Unidos, no Reino Unido e na União Européia, adultos de meia idade compreendem 31,5 \%, 30,5 \%, e 30,4 
$\%$ do total de trabalhadores adultos e ocupam $32,3 \%, 31,9 \%$, e $32,5 \%$ dos postos de trabalho, respectivamente.

Estudos mostram que as habilidades físicas, sensoriais e cognitivas dos adultos de meia-idade são geralmente mais reduzidas do que as dos adultos mais jovens (Hawthorn, 2000). Conforme já mencionado anteriormente, as pessoas de meia-idade, de forma geral, têm menos conhecimento sobre tecnologia em comparação com os adultos mais jovens. Assim, estudos sobre a interação de adultos de meia-idade com diversos tipos de tecnologias, revelando as principais diferenças observadas de acordo com a idade, são muito importantes.

A seguir são mostrados os estudos realizados a respeito da interação de adultos de meia-idade com tecnologias diversas, bem como estudos que foram direcionados ao público idoso mas que também favorecem a interação de adultos de meia-idade com necessidades especiais ou pouca experiência no uso de tais tecnologias.

Neste capítulo são apresentados e discutidos também trabalhos que se relacionam com o propósito da pesquisa em questão e abordagens para o desenvolvimento de aplicações Web acessíveis. São apresentados trabalhos que tratam do apoio aos adultos de meia-idade e idosos em suas interações com a Web, seja por meio da customização total da interface quanto de apoios contextuais.

\subsection{O Uso de Redes Sociais por Adultos Mais Velhos}

Embora ainda sejam poucos os estudos da literatura voltados especificamente para o uso da Web por adultos de meia-idade, o estudo desenvolvido por Hogeboom et al. (2010) teve por objetivo verificar se o uso da Internet por este público está ou não associado às redes sociais. O estudo utilizou uma amostra nacionalmente representativa (Health and Retirement Survey) e manteve o foco nos adultos de meia-idade com idade superior a 50 anos.

Segundo Hogeboom et al. (2010), a literatura é contraditória a respeito do impacto do uso da Internet nas redes sociais, uma vez que alguns estudos sugerem que a Internet tira o foco dos usuários de suas reais redes sociais, enfraquecendo esses laços, enquanto que outros estudos sugerem que a Internet ajuda o fortalecimento das redes sociais, visto que conecta pessoas e aumentam o apoio social. Várias teorias sugerem que a participação em redes sociais afeta positivamente o estado de saúde e bem-estar psicológico dos usuários, ajudando a reduzir a susceptibilidade dos indivíduos a doenças relacionadas com estresse.

O estudo desenvolvido por Hogeboom et al. (2010) abordou três questões. Em primeiro lugar, buscou investigar se há diferenças entre os usuários e os não usuários de Internet quanto ao número de laços estreitos com a família, amigos e confidentes, e quanto ao número de contatos com esses laços. Em segundo lugar, se eles diferem na frequência dos contatos sociais face-a-face com amigos e familiares e na frequência de participação em 
organizações e serviços religiosos. Terceiro, dado que os idosos têm mais tempo livre do que adultos de meia-idade e diferentes padrões de uso da Internet, a idade poderia ser um fator importante das associações de uso social na Internet?

$\mathrm{Na}$ análise deste estudo não foram encontradas diferenças no número de relacionamentos próximos ou de confidentes entre usuários e não usuários de Internet por meio de modelos de regressão. No entanto, foram constatadas diferenças estatísticas significativas entre os usuários da Internet e não-usuários no que se refere à frequência de contatos com amigos e família. Os resultados mostraram uma associação positiva entre o uso da Internet e frequência de contato com amigos e familiares para adultos com mais de 50 anos da idade. Os resultados mostraram também que os usuários da Internet eram mais propensos a participar de organizações ou clubes (excluindo serviços religiosos) do que os não-usuários, sugerindo uma influência positiva sobre o envolvimento do adulto de meia-idade com a comunidade. E por fim, foi observado que usuários de Internet reuniram-se pessoalmente menos vezes com outros membros da família quando comparados aos não-usuários, embora não tenha ficado claro, se este comportamento ocorreu devido ao uso da rede ou se os entrevistados se encontraram com menos frequência devido a outros fatores, tais como a falta de mobilidade ou distância física.

Esses resultados apóiam a teoria de que a Internet pode ajudar a fortalecer as redes sociais e, por sua vez, ajudar a controlar o estresse, reduzir a depressão e melhorar os resultados de saúde para adultos com mais de 50 anos.

Outro trabalho, envolvendo redes sociais e idosos, foi desenvolvido por Páscoa e Gil (2012) e teve por objetivo compreender a contribuição do Facebook no processo de envelhecimento ativo. O conceito de envelhecimento ativo é entendido como um processo de otimização de oportunidades para a saúde, participação e segurança no sentido de aumentar a qualidade de vida durante o envelhecimento (Páscoa e Gil, 2012).

O estudo consistiu na observação não participante de idosos de uma turma de informática da Universidade Sénior Albicastrense (USALBI), na realização de entrevistas semiestruturadas aos idosos e à professora de informática, e também na aplicação de uma sequência de tarefas de exploração cronológica baseada nas funcionalidades do Facebook. Em particular, o estudo com o Facebook foi escolhido porque despertou grande atenção por parte dos idosos, no qual foi possível verificar uma evolução positiva na aprendizagem deste software ao longo do ano letivo, salientando-se a colaboração, o compartilhamento de informação, a participação ativa e o trabalho colaborativo.

Segundo Páscoa e Gil (2012), os motivos que levaram os alunos a frequentarem as aulas de informática foram essencialmente para a manutenção da atividade intelectual, para aumentar o conhecimento e para melhorar o contato social. A maioria dos alunos utilizava o computador diariamente com a finalidade principal de acessar a Internet, enviar e receber e-mails, realizar buscas por meio do Google, carregar celulares e realizar compras on-line. Em relação ao Facebook, os alunos relataram que se tratava de uma 
ferramenta digital que combate o isolamento, promove a socialização, sendo também um complemento de lazer e entretenimento que aproxima gerações, em que avós e netos falam a mesma linguagem. Segundo os alunos, as principais vantagens do Facebook são: o intercâmbio de comunicação e informação, o compartilhamento de conhecimentos, eventos e a possibilidade de reencontrar pessoas com as quais tinham perdido contato, tornando o idoso mais ativo e participativo, aumentando sua autoestima e a sua sensação de inclusão. As principais desvantagens relacionam-se com a ilusão de ter muitos amigos, uma vez que o conceito de amizade no Facebook não possui o mesmo significado de amizade offline (real), ser amigo neste espaço é sinônimo de ter uma rede de contatos e esta situação não é bem vista pelos alunos. Outra desvantagem do Facebook relatada pelos alunos e, confirmada pela professora, é a exposição da vida pessoal, que pode originar algumas desilusões e problemas (Páscoa e Gil, 2012).

Os resultados desses estudos a respeito de redes sociais relatam apenas impressões sobre a utilização e utilidade das ferramentas no contexto social, sendo que nenhum deles investigou mais aprofundadamente com qual facilidade ocorrem as interações com as ferramentas na Web. Em particular, no segundo estudo de caso, foi relatado que houve um extenso período de aprendizagem da ferramenta por parte dos alunos, possibilitando a realização das atividades práticas e o registro das impressões.

Sob a perspectiva da investigação nesta tese, os estudos descritos reforçam a relevância de apoios melhores na interação com ferramentas Web que viabilizam o uso de redes sociais virtuais para adultos mais velhos, visto que esse tipo de interação se apresenta como uma tendência da sociedade atual.

\subsection{Trabalhos relacionados à interação com tecnologias diversas}

Os trabalhos apresentados a seguir não possuem relação direta com a utilização da Web, mas descrevem resultados de estudos a respeito da interação de adultos de meia-idade e idosos com computadores e outros dispositivos eletrônicos, como PMPs (Portable Multimedia Players), leitores de MP3 e celulares (Figura 4.1). Tais características são relevantes e servem como indícios do que poderá ser observado na interação desse mesmo público-alvo com a Web.

O estudo conduzido por Chou e Hsiao (2007) teve como principal objetivo analisar a usabilidade da interface homem-computador para alunos de meia-idade em Taiwan

e consistiu de duas fases: (1) uma tarefa elementar de treinamento básico para a utilização de computadores, e (2) uma tarefa de análise de usabilidade de interface homem-computador. 


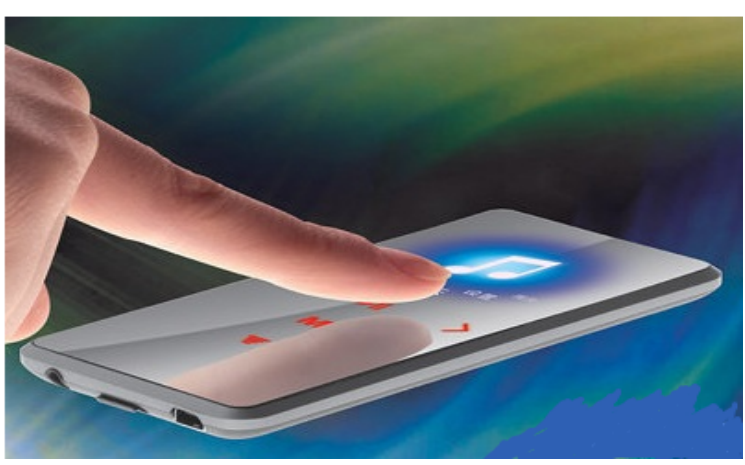

(a)

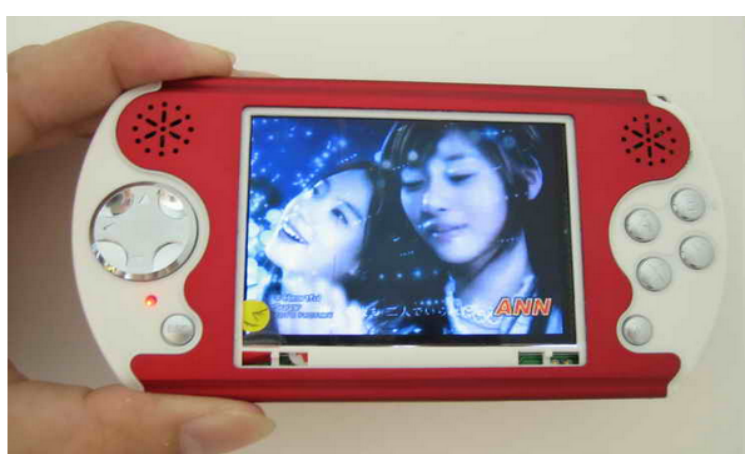

(b)

Figura 4.1: Exemplos de Portable Multimedia Players

No total, 216 indivíduos foram selecionados e divididos em 12 turmas para o treinamento em um programa de computador. Os participantes foram classificados de acordo com suas idades, que variou de 45 a 54 anos, e se eram desempregados ou não. O sexo e o nível de escolaridade também foram considerados no estudo. Nenhum dos participantes tinha experiência prévia no uso de computadores. Por meio da utilização de questionário, análise de correlação, e pela técnica Grey Relational Model (Chou e Hsiao, 2007), foram derivadas algumas características dos usuários e seu comportamento com relação à aprendizagem do uso de computadores e da interface de software.

Dentre as principais características observadas com relação ao comportamento dos alunos de meia-idade na interação com os computadores, pode-se citar (Chou e Hsiao, 2007):

- o teclado é o dispositivo de hardware tido como o mais difícil de usar pelos alunos de meia-idade, pois a maioria deles não consegue manter uma postura neutra para o punho enquanto digitam. Essa é uma característica que independe de fatores como sexo, idade ou nível educacional;

- com relação ao uso do mouse, os alunos do sexo masculino, na faixa etária de 50-54 anos ou com menor nível educacional apresentam mais dificuldades. Outra dificuldade observada tanto em homens quanto em mulheres é a dificuldade em apontar um alvo com exatidão por meio do cursor do mouse;

- a maior parte dos alunos de meia-idade apresentam dificuldades de leitura de informações no monitor, bem como de memorização e compreensão do conteúdo da informação. No entanto, os alunos que possuem médio ou alto grau de escolaridade se preocupam mais em compreender coerentemente o contexto da informação do que memorizar todo o conteúdo apresentado na tela;

- a maior parte dos alunos de meia-idade, particularmente os que possuem nível de instrução mais baixo, não conseguem manter uma postura estática durante um longo período de tempo de trabalho; 
- a familiaridade com o uso de interface de software é bastante problemática, uma vez que o design é considerado como funcionalmente incompreensível para os alunos de meia-idade, particularmente para os alunos do sexo masculino ou com baixo nível de instrução;

- com relação às mensagens de erro, a maioria dos alunos com menor nível de instrução tendem a solicitar ajuda dos mais experientes com maior rapidez, enquanto que os alunos com maior nível de instrução tentam ler o conteúdo da mensagem de erro atentamente para resolver o problema que gerou o erro;

- no que se refere à atitude para com o uso de novos softwares para computadores, a maioria dos alunos de meia-idade gostaria de tentar usá-los mesmo sem saber como utilizá-los. Os alunos com menos idade ou maior nível de escolaridade apresentam atitudes mais positivas em relação ao aprendizado de novos softwares antes de utilizá-los.

Para este estudo, os resultados mostraram que o nível educacional é o principal fator que influencia os alunos de meia-idade na interação com interfaces. A maior parte dos alunos de meia-idade com nível de instrução baixo entendem que o aprendizado no uso de computadores, embora não seja fácil, irá favorecer sua competitividade no mercado de trabalho, enquanto que as pessoas de meia-idade com maior nível de instrução consideram que o uso dos computadores se tornou uma necessidade básica diante da sociedade de informação.

Em outro estudo, realizado por Kang e Yoon (2008), o objetivo foi identificar as diferenças de comportamento relacionadas à idade e ao nível de conhecimento entre jovens adultos (20-29 anos) e adultos de meia-idade (46-59 anos) durante a interação com interfaces de dispositivos eletrônicos complexos. Os equipamentos selecionados para o estudo foram dois dispositivos multi-funcionais: PMPs e leitores de MP3.

Participaram do experimento 60 participantes, incluindo 30 jovens adultos e 30 adultos de meia-idade. Todos os participantes eram cidadãos da República da Coréia e tinham várias profissões: estudantes, professores, engenheiros, advogados, mecânicos, empresários, domésticas, entre outros. Todos os participantes tinham acuidade visual normal ou totalmente corrigida por meio de óculos. Todos tinham nível superior de ensino e não possuíam nenhuma experiência prévia no uso dos dispositivos utilizados no experimento.

Os resultados revelaram que as diferenças de idade afetam principalmente o número de interações, a frequência de mensagens de erro recebidas, a rigidez na exploração, o sucesso e o desempenho para a conclusão de uma tarefa. Por outro lado, comportamentos de tentativa e erro, bem como o grau de frustações, foram mais influenciados pelo nível de conhecimento do que pela idade. 
Outro estudo significativo foi realizado por Gonçalves et al. (2011), que observou a interação de idosos com telefones celulares inteligentes (smartphones) com o objetivo de identificar problemas de usabilidade e acessibilidade durante as interações. Para esse fim, foi realizada uma atividade prática de observação com um conjunto de 10 idosos com idades entre 60 e 84 anos, escolaridade entre nenhuma e nível superior e diferentes experiências com o uso de tecnologias.

O objetivo da atividade era o cadastramento de um contato na agenda do celular e a realização de uma ligação para o mesmo na sequência. Foram observados desde os aspectos relacionados à questão física do dispositivo, até o impacto dessa interação com o mundo real e o comportamento ajustável de um sistema de celular para atender aos requisitos de interação dos idosos. Os idosos foram organizados em duplas, considerando-se idade e escolaridade, e durante a interação cada indivíduo da dupla recebeu um telefone celular (smartphone) Samsung Galaxy 5 com sistema operacional Android na versão 2.2.

Em paralelo à execução da tarefa no celular pelos idosos, os pesquisadores preenchiam um formulário de observação com questões do tipo: Precisou de ajuda para começar a tarefa? O tamanho da tela está adequado para os itens? A sequência de ações para salvar o contato: Contatos $>$ Novo contato $>$ Salvar no telefone $>$ Inserir dados $>$ Salvar. Está adequada? Caso fosse necessário, os idosos poderiam auxiliar ou pedir ajuda ao amigo da dupla. O número discado era de um telefone fixo, que direcionava para a secretária eletrônica, onde estava gravada uma mensagem de agradecimento pela participação.

Após a conclusão das tarefas, os pesquisadores conversavam com a dupla, levantando questões relacionadas à interação e às dificuldades enfrentadas durante a interação com o celular. As principais dificuldades observadas foram:

- tela muito sensível ao toque, gerando muitos erros involuntários;

- caminho muito longo para executar a tarefa solicitada;

- tamanho da tela inadequado, sendo o espaço para o cadastro do contato muito pequeno, dificultando assim a noção geral da tela de cadastro;

- falta de padronização da posição dos botões;

- teclas muito pequenas;

- cores de pouco destaque nos botões de ação;

- uso de termos não familiares aos idosos.

Finalmente, pode-se perceber, pelos estados descritos, que apesar da diminuição das funções motora ou cognitiva decorrentes do envelhecimento, um dos principais fatores de influência na interação de adultos de meia-idade e idosos com equipamentos tecnológicos é o nível de conhecimento ou o nível educacional. 
Trata-se de informações importantes que fornecem novos elementos a respeito da interação entre diferentes grupos etários e tecnologias diversas, podendo facilitar a concepção de interfaces mais adequadas e que atendam aos diferentes requisitos de interação desse público-alvo. Assim, os fatores: não familiaridade com novas tecnologias, diferenças de nível educacional, inabilidades físicas e cognitivas devem ser consideradas no projetos de design de interfaces de modo a acomodar a diversidade de necessidades que interfere nas interações dos adultos de meia-idade e idosos com as TICs.

\subsection{Trabalhos relacionados à especialização de diretrizes para adultos mais velhos}

No caso específico da Web, a maioria dos trabalhos se dedicam a avaliar a interação e as dificuldades enfrentadas pelo público idoso (com idade superior a 60 anos) com a Internet, mas não realizaram pesquisas com os adultos de meia-idade.

Pesquisas relacionadas à interação de adultos mais velhos com a Web procuram identificar possíveis adaptações das diretrizes de usabilidade e acessibilidade para diferentes grupos etários como meio de facilitar o acesso das pessoas mais velhas ao conteúdo Web e tornar essa experiência a mais agradável e proveitosa possível (Zaphiris et al., 2005).

Zaphiris et al. (2005) procuraram identificar um conjunto de guidelines de usabilidade para desenvolvimento de página Web fundamentado nas diferenças de idade. O conjunto inicial de 52 guidelines foi obtido a partir de revisões da literatura sobre IHC e sobre o envelhecimento. Essas guidelines atendiam às seguintes necessidades:

- visão: declínio na acuidade, sensibilidade ao contraste, sensibilidade a cor, sensibilidade a luminosidade, diminuição do campo visual, diminuição no processamento de informações visuais;

- psicomotora e habilidades de atenção: declínios na atenção seletiva e na divisão da atenção;

- memória e aprendizagem;

- inteligência e conhecimentos especializados.

Após o levantamento do conjunto inicial, foi realizado o exercício de Card Sorting, no qual os participantes deveriam agrupar/classificar as guidelines em categorias distintas, nas quais as guidelines similares ou relacionadas poderiam ser unificadas. O resultado desse exercício serviu como dados de entrada para a realização do Focus Group, no qual especialistas no domínio de HCI usaram a técnica do diagrama de afinidades para discutirem e revisarem as posições das guidelines e chegarem ao resultado final denominado "38 Senior Friendly guidelines", agrupadas em 11 categorias distintas. 
As categorias e suas respectivas guidelines são as seguintes:

1. Design de alvos de interação

- Projetar alvos de interação maiores, tais como ícones, links, imagens clicáveis, entre outros;

- Deixar claro qual é o alvo/objetivo de captura no momento, o qual deve estar bem visível para as pessoas mais velhas, que normalmente não reconhecem pequenas mudanças na interface;

- Não projetar alvos de interação com duplos cliques;

2. Uso de Gráficos

- Não utilizar gráficos como elementos de decoração, ou seja, eles devem ser relevantes;

- Não utizar animações;

- Colocar texto alternativo para as imagens (tags ALT);

- Utilizar ícones simples e significativos;

3. Navegação

- Fornecer sinalizadores extras e fortes para a navegação;

- Prover navegação clara;

- Apresentar a localização da página atual;

- Evitar menus suspensos;

- Evitar hierarquias profundas e agrupar informações em categorias significativas;

4. Características do Navegador

- Evitar barras de rolagem;

- Fornecer apenas uma janela aberta. Pop-ups, propagandas animadas ou múltiplas janelas sobrepostas devem ser evitadas;

5. Projeto de exibição do conteúdo

- A linguagem deve ser simples e clara;

- Evitar a apresentação de informações irrelevantes na tela;

- Destacar as informações importantes;

- A disposição da informação deve estar concentrada principalmente no centro da tela; 
- Layout da tela, navegação e terminologia utilizadas no projeto da interface devem ser simples, claras e consistentes;

6. Elos de ligação (Links)

- Deve haver diferenciação entre os links visitados e os não visitados;

- As ligações devem ser claramente identificadas e todos os links de mesma denominação devem ir sempre para a mesma página;

- Os links devem estar em uma lista de itens;

7. Projeto com prioridade para o aspecto cognitivo do usuário

- Dar tempo suficiente para o usuário ler informações;

- Reduzir a demanda pela memória de trabalho, por meio de apoio ao reconhecimento ao invés da recordação;

- Prover menos opções de escolha para o usuário;

8. Uso de Cores

- As cores devem ser usadas de forma conservadora;

- Tons de azul e verde devem ser evitados;

- As telas de fundo não devem ser totalmente brancas e nem mudar rapidamente o brilho;

- Deve existir um grande contraste entre as cores de frente e de fundo da tela;

- Evitar textos coloridos em fundo de tela também colorido;

- O conteúdo todo não deve estar escrito em uma única cor;

9. Apresentação do Texto

- Evitar movimentações com o texto;

- Os textos devem ser justificados à esquerda e as linhas de texto devem ser curtas;

- Deve haver espaçamento entre as linhas;

- Usar letras maiúsculas apenas em início de frases, e não em todas as letras;

- Texto deverá ter cabeçalhos grandes e claros;

- Usar fontes sem serifa como Helvetica, Arial, Verdana, entre outras e com tamanhos de 12-14 pontos;

10. Mecanismos de busca 
- Os mecanismos de pesquisa devem reconhecer erros ortográficos;

11. Resposta aos usuários e Apoio

- Apresentar mapa do site;

- Disponibilizar tutorial de ajuda on-line;

- Fornecer apoio à liberdade e controle do usuário;

- Mensagens de erro devem ser simples e fáceis de entender.

Para validar essas guidelines foi realizada uma avaliação heurística usando os dois conjuntos de guidelines (as 52 iniciais e o conjunto das 38 propostas). Foram escolhidos 6 participantes para realizarem a avaliação por meio da revisão de dois sites da Web: http://www.nsclc.org e http://www.elderhostel.org/welcome/home.asp, com o objetivo de verificar suas respectivas aderências aos dois conjuntos de guidelines. Cada site foi pontuado em termos da satisfação de guidelines, recebendo 1 ponto por guideline satisfeita. Caso a guideline não fosse satisfeita receberia 0 pontos e se não fosse aplicável, seria marcada como NA (não aplicável).

O objetivo do teste era mostrar que, quando o conjunto de guidelines é muito grande, os desenvolvedores se sentem desestimulados a utilizá-lo. O resultado final demonstrou que o conjunto menor de guidelines se mostrou mais robusto e generalizado (Zaphiris et al., 2005).

Outro trabalho relacionado às diretrizes foi realizado por Sales e Cybis (2003) e propôs a extensão das diretrizes para a Acessibilidade do Conteúdo da Web (W3C, 1999b) de modo a atender às necessidades de acessibilidade das pessoas mais velhas. Segundo Sales e Cybis (2003), as fontes de recomendações mais utilizadas para esse estudo foram: W3C WAI (Iniciativa de Acessilidade na Web); GUIA (Grupo Português pelas Iniciativas em Acessibilidade) da UTAD Universidade de Trás-os-Montes e Alto Douro; Institute National Aging do Canadá e IBM Web Accessibility for Special Needs.

A partir das recomendações selecionadas, foi gerada a primeira versão de um checklist, o qual passou por três ciclos de elaboração e testes de versões evolutivas até se chegar à sua versão final. Esse checklist detalha e estende as diretrizes para que sejam aplicadas na verificação de acessibilidade de páginas Web para idosos.

O sistema IMP (Internet Messaging Program http://horde.org/imp), aplicativo de correio eletrônico na Internet, foi o sistema escolhido para a realização das oficinas de validação em função dos seguintes fatores: ser de domínio público; ser o sistema utilizado pelo departamento de informática da UFSC (Universidade Federal de Santa Catarina) e por possibilitar aos usuários idosos a execução de tarefas sobre as quais eles têm um conhecimento conceitual (todos sabem quais são os objetivos finais da tarefa). A seguir são apresentados exemplos dessas adaptações: 
- Diretriz 1: Verifique se legendas e descrições sonoras aparecem sincronizadas às passagens a que estão associadas nas apresentações multimídia (ex.: legenda para uma entrevista em um filme, texto associado a animação visual, etc.).

Relevância: Idosos com problemas visuais e/ou auditivos e com dificuldades de concentração/manutenção da atenção irão se beneficiar de representações alternativas sincronizadas. Assim, eventuais dificuldades com um canal perceptivo serão compensadas por apresentações que explorem outro canal, no momento mais adequado e de forma oportuna.

- Diretriz 2: Verifique se há contraste favorável entre as cores do texto e as cores do fundo, no qual o texto se encontra.

Relevância: Discriminação entre cores de mesmo matiz (tom), principalmente para azul, verde e amarelo que são cores difíceis de serem diferenciadas. Esse tipo de dificuldade é ainda maior para idosos com dificuldades visuais, para pessoas daltônicas e para pessoas com dificuldades de concentração e de manter a atenção. É recomendado, portanto, o emprego de texto com letras brancas em fundo escuro.

- Diretriz 12: Verifique se os blocos de informação e documentos que sejam extensos encontram-se subdivididos em sessões curtas.

Relevância: Muitas pessoas têm dificuldade para encontrar e compreender a informação contida em blocos extensos (grande quantidade de informação) e desorganizados, devido a sobrecarga de trabalho necessária para percorrer, identificar e classificar mentalmente os conteúdos desses blocos. Estas tarefas cognitivas podem exigir uma elaboração mais complexa e que normalmente requerem o emprego constante da memória de curto prazo. Na medida em que os idosos têm essas habilidades prejudicadas em função da idade, eles irão beneficiar-se de blocos de informação organizadas em subdivisões lógicas.

Além das extensões das diretrizes do W3C, outras recomendações foram obtidas a partir das outras fontes anteriormente citadas e da observação dos idosos em oficinas (Sales e Cybis, 2003), tais como:

- Verifique se o texto está escrito na voz ativa (ex. "é necessário que você se cadastre" em vez de "é necessário que você seja cadastrado").

Relevância: a habilidade de executar algumas operações mentais diminui com a idade, e essas operações incluem a habilidade de compreender um texto. Embora essas mudanças não sejam geralmente dramáticas, sua presença pode interferir com o desempenho de suas tarefas. Neste sentido as frases de um texto devem ser escritas da maneira mais clara, direta e objetiva possível, o que exclui o emprego da voz passiva. 
- Verifique se existem opções de ajuda facilmente acessíveis que auxiliem um visitante a utilizar o site.

Relevância: operações como as realizadas por sites de bancos, de comércio eletrônico, de empresas do setor de serviços, etc são muito complexas para o entendimento das pessoas mais velhas. Para esses tipos de operações, os guias de ajuda representam um importante recurso para a orientação de usuários em geral e de idosos com dificuldades de aprendizado, em particular.

- Verifique se o texto está escrito em linguagem simples, clara, familiar, no idioma do usuário.

Relevância: com o passar da idade existe a perda de habilidades de recordar e processar simultaneamente informações novas pelos idosos. Neste sentido, linguagem simples, clara e familiar e um glossário fácil de ser consultado pode ser de grande valia.

Esses exemplos mostram as especializações das diretrizes de usabilidade e acessibilidade para o público idoso, mas nada impede que algumas delas possam ser utilizadas também pelos adultos de meia-idade, uma vez sua utilização pode propiciar mais conforto e segurança na utilização de sites da Web.

\subsection{Trabalhos relacionados às deficiências cognitivas}

Apesar da evidente necessidade de atenção especial a determinados grupos de usuários, tais como os idosos, os usuários inexperientes ou os portadores de necessidades especiais, a maioria dos sites da Web continuam a ser desenvolvidos com base em parâmetros de design artístico e oferecem um grau de usabilidade muito limitado para as pessoas com deficiências cognitivas.

No trabalho realizado por Small et al. (2005), foi verificado, por meio de experimentos e avaliação de usabilidade, que a maioria dos usuários com deficiências cognitivas eram capazes de acessar a Web, mas incapazes de utilizar os sites compatíveis com as diretrizes de acessibilidade presentes no documento das WCAGs (W3C, 1999b). Nesses experimentos foram verificados problemas com a navegação e com o nível de percepção e de satisfação dos usuários.

O estudo realizado se fundamentou na investigação exploratória que analisou a forma de navegação na Web, em sites compatíveis com as diretrizes do WCAG (W3C, 1999b), por usuários com deficiências cognitivas (nível baixo a moderado) e idade acima dos 18 anos. Os sites escolhidos para a realização do experimento foram: ADD-Up (www.addup.org) e MedlinePlus (www.medlineplus.gov). Ambos foram selecionados por estarem em conformidade com as guidelines de acessibilidade da versão 1.0 do 
WCAG (W3C, 1999b). Quatro componentes cognitivos determinantes do desempenho na navegação foram observados: percepção da situação, percepção espacial, alternância de tarefas e previsão de resposta do sistema.

A percepção da situação está relacionada com a conscientização do usuário, a compreensão e a projeção dos requisitos da tarefa. Requer estratégias que encapsulem os dados para evitar a sobrecarga de informação. A capacidade espacial está relacionada com a habilidade de resolver problemas mentalmente e com o tempo gasto para realizar uma tarefa na Web. A alternância de tarefas corresponde à habilidade de mudar de uma tarefa para outra e está diretamente relacionada com a navegação eficaz. A previsão ou antecipação da resposta do sistema se refere à percepção de como os usuários acham que o sistema deve responder à sua consulta (Neerincx e Lindenberg, 1999)(Neerincx et al., 2001).

Durante o experimento, foi observado o desempenho dos usuários na realização de tarefas, como o número de vezes que o usuário utilizou o botão "Voltar" voluntariamente e principalmente as atitutes de cada um. Atitude corresponde à percepção subjetiva de "se perder" nos sites da Web ou quando o usuário solicita ajuda. Foram levadas em conta também as informações sobre o sexo, o nível de comprometimento cognitivo e a idade.

Cada participante deveria realizar as seguintes tarefas: (1) localizar e clicar no cabeçalho do site; (2) usar o botão direito do mouse e as setas para cima e para baixo para deslocar o conteúdo da página da Web; (3) clicar com o botão esquerdo do mouse e sublinhar uma frase na página da Web, e (4a) encontrar uma área de interesse na página Web e ler esta área, ou, uma vez que a legibilidade de muitos Web sites é um obstáculo para indivíduos com deficiências cognitivas, (4b) encontrar um espaço na página da Web, de seu interesse e descrever o que ela contém.

Verificou-se que a capacidade de navegar nos sites escolhidos foi prejudicada pelos seguintes fatores: falta de certeza para onde navegar, navegação inconsistente, técnicas de interação não-padronizadas, falta de percepção da possibilidade de clique, problemas para rolar as páginas utilizando a barra de rolagem, falta de capacidade ou de vontade de ler instruções.

Com esse estudo, foi demonstrado que as diretrizes de acessibilidade não são suficientes para atender às necessidades de pessoas com deficiências cognitivas e que novas pesquisas são necessárias para compreender como as deficiências cognitivas afetam o uso de aplicações Web.

O trabalho de Dickinson et al. (2007) apresenta outro tipo de abordagem para prover acessibilidade na navegação Web para usuários idosos e novatos. O trabalho desenvolvido teve como principal objetivo investigar formas de apresentar a Web para usuários idosos e/ou inexperientes, de modo a habilitá-los a explorar e se beneficiar com o que a Web tem a lhes oferecer sem sustos e nem confusões, facilitando assim o aprendizado e a progressão do uso. 
Foi elaborado um projeto denominado "Proof of Concept (P-of-C) Project", no qual uma interface especial foi desenvolvida especialmente para esse grupo de usuários e teve a preocupação em oferecer uma interação inicial positiva para os usuários, evitando que eles fossem sobrecarregados com a enorme diversidade de conteúdo que a Web oferece.

O sistema de pesquisa e navegação foi concebido para proporcionar um ambiente seguro para os usuários aprenderem sobre como interagir com a Web, e, ao mesmo tempo, orientá-los através de um processo que resultaria no uso autônomo de navegadores e portais convencionais da Web.

O sistema conduzia o usuário, de forma gradativa, à interação com um número cada vez maior de funcionalidades e de variedades de conteúdo, capacitando-os a acessar a Web por meio das interfaces mais gerais e convencionais.

Para a boa utilização foi fundamental que a aparência do sistema não fosse confusa ou intimidadora. Os usuários foram inicialmente introduzidos no sistema por meio de uma página inicial (Figura 4.2), que continha uma breve descrição do ambiente e a orientação de sempre olhar para ela quando se sentissem desorientados. Em seguida, entravam em contato com a página contendo as funcionalidades básicas e outra com um número maior de opções (Figura 4.3).

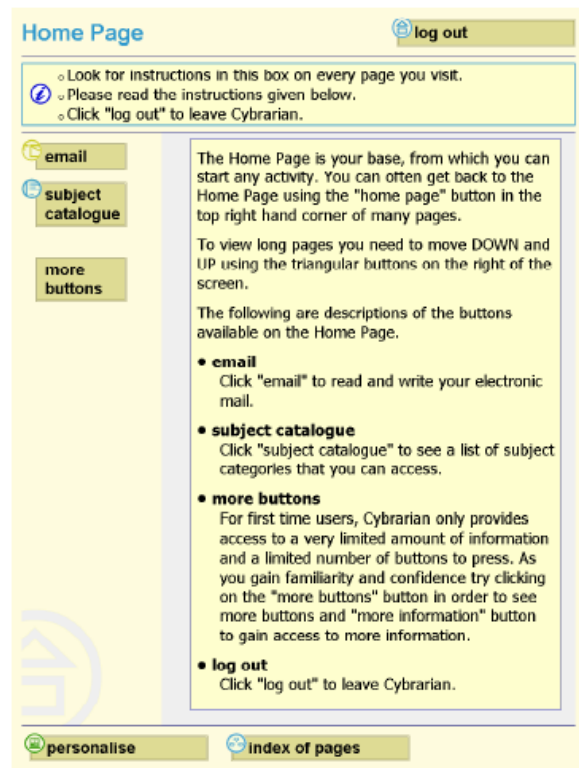

Figura 4.2: Página inicial

A avaliação realizada por um pequeno grupo de pessoas idosas revelou que o sistema experimental era usável e acessível pelas pessoas idosas que possuíam alguma experiência com o uso de computadores e nenhuma experiência na utilização da Web, mas que poderia também ser utilizado com um mínimo de treinamento pelas outras pessoas. 

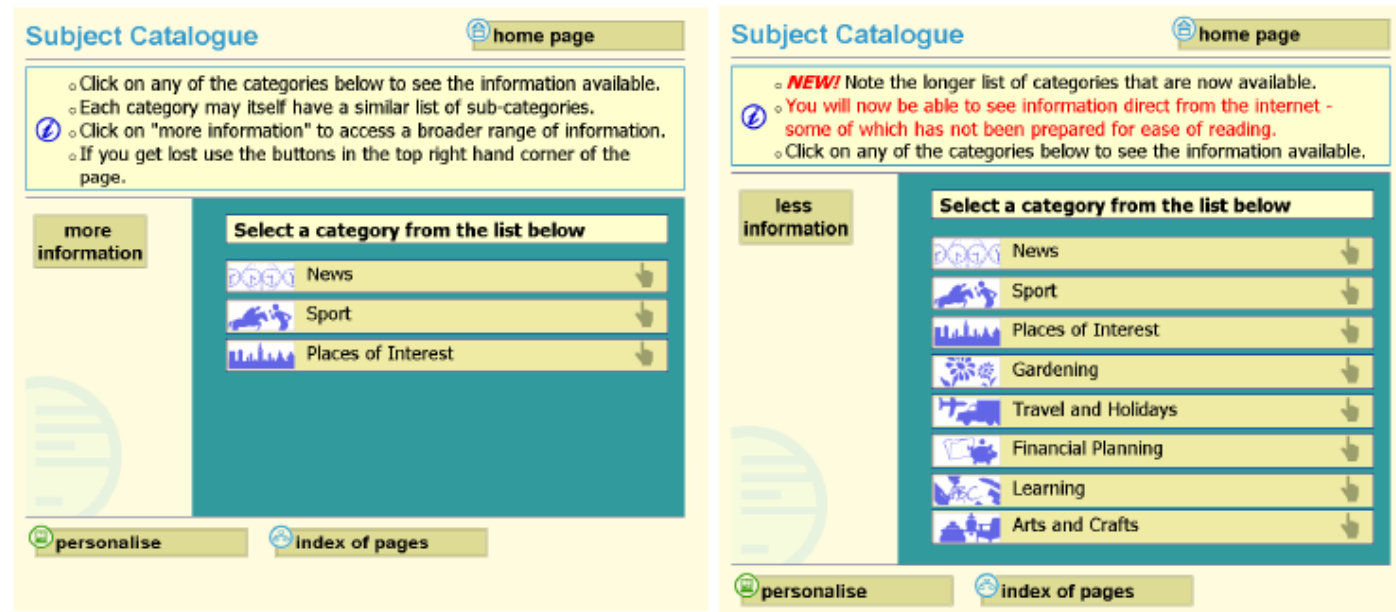

Figura 4.3: (a) Apresentação das funcionalidades básicas (nível 1) e (b) Aumento no número de funcionalidades apresentadas (nível 2)

\subsection{Trabalhos relacionados a customizações de interfaces}

Uma necessidade importante, citada pela literatura, é a customização ${ }^{1}$ de aplicações computacionais em graus distintos, dependendo das diferentes necessidades especiais de cada usuário, pois no caso da interação de usuários mais velhos com a Web, nem sempre a correta implementação das especificações e guidelines para acessibilidade garantem que o sistema seja usável ou que satisfaça às expectativas de um usuário com necessidades especiais.

Pesquisas se dedicam a estudar quais aspectos deveriam direcionar o desenvolvimento de aplicações para os idosos, de modo a melhorar a interação humano-computador e tornar os sistemas mais flexíveis, mais amigáveis e também mais acessíveis. Dentre as facilidades julgadas mais importantes a serem oferecidas estão: sintetizador de voz, entrada via voz, amplificador de som, ampliação de texto, pontos grandes e discretos para acionamento via mouse, variação de layouts de teclado, possibilidade de ajuste da velocidade dos cliques do mouse, possibilidade de ajuste do delay do teclado, entre outros (WUAUC, 2001).

Hanson (2004) constatou, por meio de estudos, que muitos usuários idosos gostariam de ver o conteúdo oferecido por uma página Web em um formato maior, ou ainda, de forma menos "confusa" . Para atender a esse tipo de solicitação, navegadores e várias aplicações fornecem uma variedade de possibilidades para apresentação das páginas, embora, muitas vezes, essas transformações possam gerar consequências inesperadas.

Um exemplo relacionado com transformações no modo de visualização, proposto por Hanson (2004), apresenta uma aplicação que permite ao usuário controlar os aspectos de apresentação de uma página Web. Com essa abordagem, as páginas Web podem ser alteradas "on the fly", com o objetivo de se tornarem mais usáveis por pessoas com

\footnotetext{
${ }^{1}$ Customização significa personalização, modificações para atender a necessidades específicas;
} 
diversos tipos de necessidades especiais. Esse tipo de aplicação não atende às pessoas cegas, mas atendem a vários outros tipos de usuários.

Outro fator limitante ao uso da Web é a restrição da visão, ou seja, existem muitas pessoas que não são cegas, mas que possuem algum tipo de limitação. Para a realização de seu trabalho, Hanson entrevistou os instrutores de uma escola de computação para idosos e os principais questionamentos foram com relação a quais os principais problemas que os usuários tinham com a Web e quais as intervenções dos instrutores para minimizar esses problemas.

O principal problema relatado foi com relação a leitura, pois muitos idosos usavam lentes bifocais e perdiam muito tempo para ajustar suas lentes a um ângulo que permitisse uma boa leitura. Outros problemas estavam relacionados a design complexos ou animações que desviavam a atenção dos idosos.

A aplicação desenvolvida para atender a algumas dessas necessidades foi a "Web Adaptation Technology" (Hanson, 2004). Originalmente, essa aplicação foi projetada para pessoas idosas, mas acabou sendo usada por muitas organizações para atender às necessidades de idosos e pessoas com dificuldades de acesso à Web, abrangendo grande variedade de limitações.

O protótipo do software permite que os usuários ajustem a apresentação das páginas Web de acordo com suas necessidades individuais. O protótipo trabalha com o Windows Internet Explorer e transforma o conteúdo de requisições HTTP numa versão mais acessível para o usuário. As transformações são aplicadas apenas nas visões das páginas, pois nenhuma alteração é realizada no código fonte. Na Figura 4.4 é mostrada uma página em seu formato normal, sem nenhuma alteração.

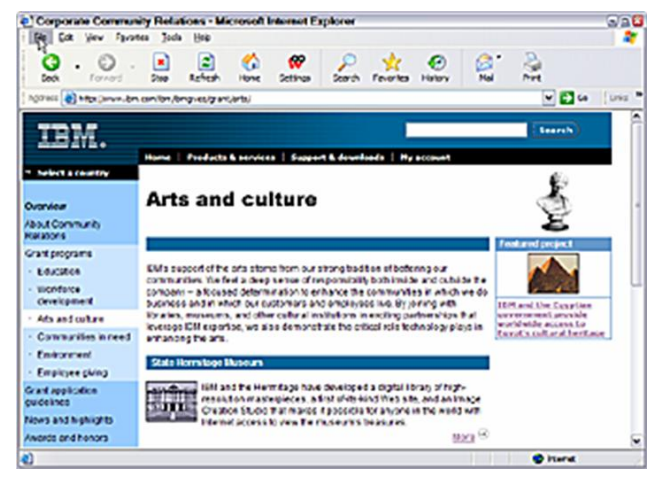

Figura 4.4: Página Normal (Hanson, 2004)

As principais transformações realizadas pela aplicação são (Hanson, 2004): colocação do texto em faixas largas (banner), ampliação do tamanho do texto, ampliação dos controles do navegador, ampliação do tamanho de uma imagem, ampliação da página em escala percentual, aumento do espaçamento entre letras, aumento do espaçamento entre linhas, mudanças no estilo do texto, mudanças de cores para melhorar o contraste, 
ocultação de backgrounds e imagens, interrupção de animações GIF e realização da leitura de partes de texto via voz, entre outras.

Alguns exemplos dessas transformações podem ser visualizados nas figuras a seguir. Na Figura 4.5(a) foi realizada a ampliação do texto em faixas largas (banner) e na Figura 4.5(b) a ampliação do texto explicativo da imagem. Na Figura 4.6(a) é realizada a transformação do menu do navegador em letras bem maiores e na Figura 4.6(b) a imagem é mostrada em destaque.

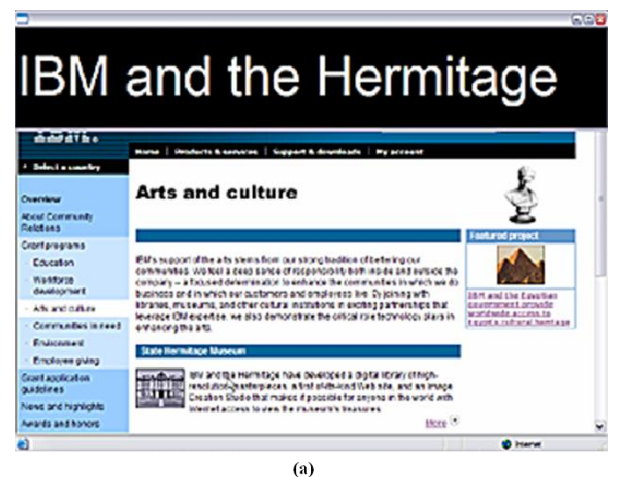

(a)

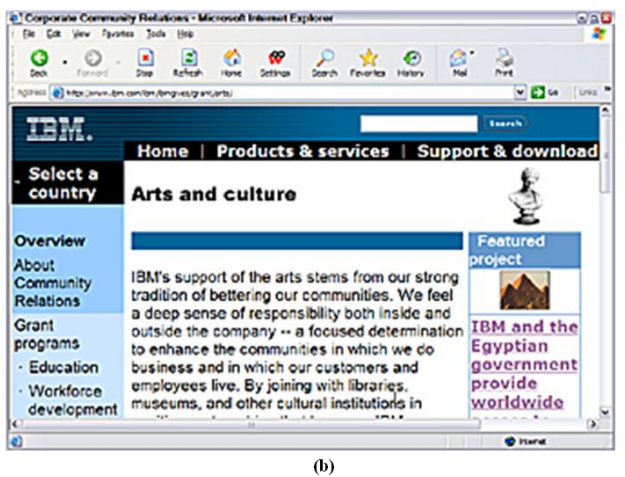

(b)

Figura 4.5: (a) Ampliação do texto em banner (b) Ampliação do texto da imagem (Hanson, 2004)

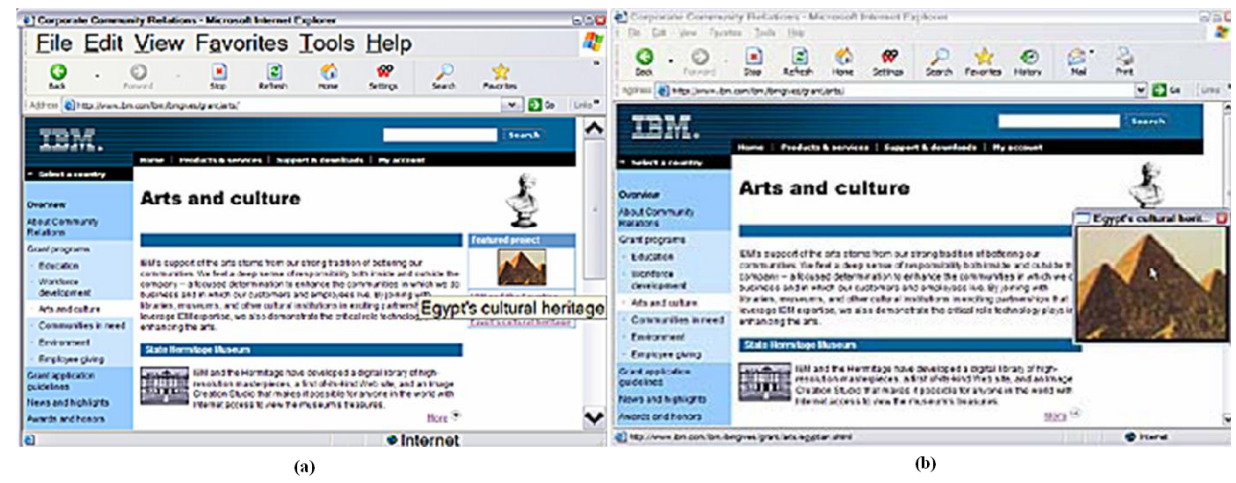

Figura 4.6: (a) Ampliação do menu do navegador (b) Ampliação da Imagem (Hanson, 2004)

Há ainda outras opções de transformações para facilitar a leitura, tais como a linearização do texto, a configuração do espaçamento entre as linhas e a alteração de cores e contrastes (Figura 4.7).

Finalmente, para atender pessoas com grandes dificuldades visuais, a aplicação oferece ainda a opção de leitura de texto via voz, como pode ser observado na Figura 4.8.

Embora os padrões de acessibilidade forneçam as diretrizes que devem ser incorporadas às páginas para que estas sejam acessíveis, tais padrões não garantem uma boa experiência de interação a todos os usuários Web.

A abordagem utilizada nesse trabalho teve como objetivo prover uma experiência melhor de interação entre usuários com necessidades especiais e as páginas Web. Ao invés 

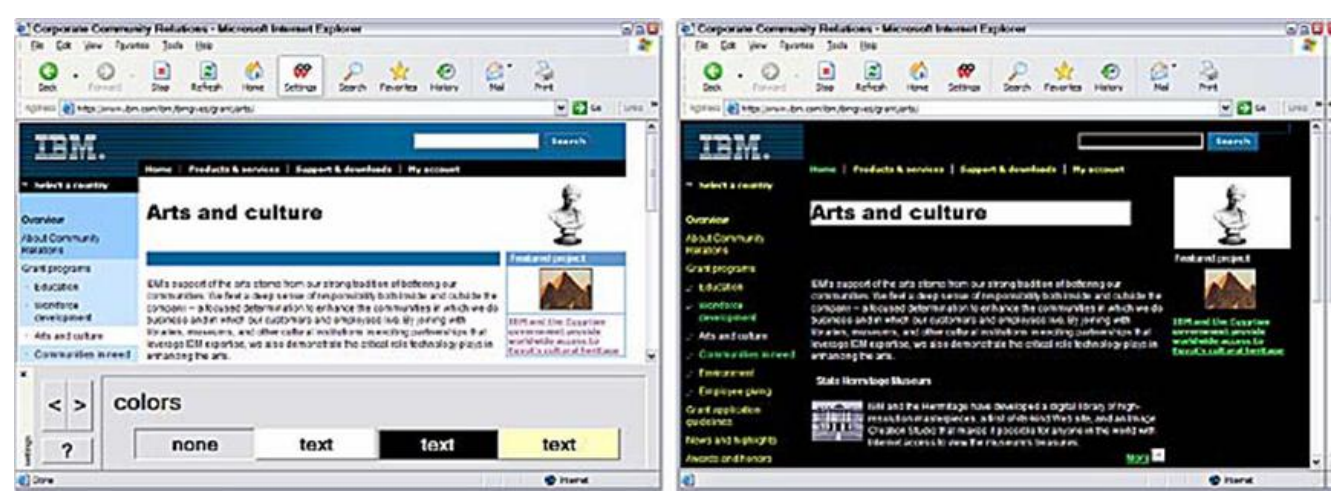

Figura 4.7: Configuração de cores e contraste (Hanson, 2004)

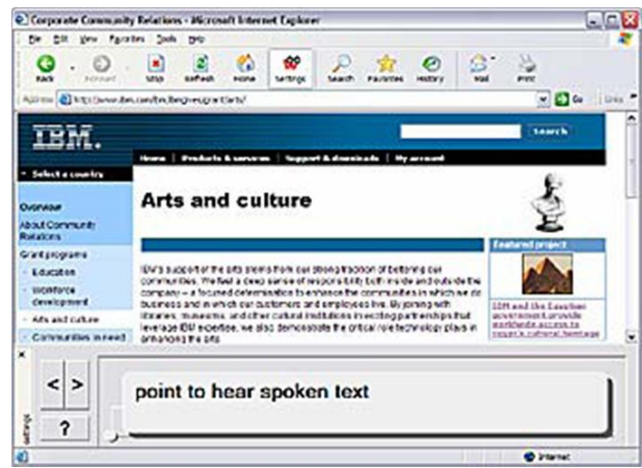

Figura 4.8: Leitura de texto via voz (Hanson, 2004)

de apresentar páginas acessíveis baseadas apenas em texto, procurou-se alterar a aplicação de modo a apresentar um bom design para a interação entre os idosos e a Web.

Hawthorn (2003), em seu trabalho, argumenta que para fazer um bom design para usuários idosos não basta seguir as guidelines, mas sim, envolvê-los no processo de design. Após a realização do trabalho, as conclusões a respeito de design de interface para usuários idosos foram as seguintes:

- o projeto de interface para usuários idosos deve explorar o conhecimento dos usuários e suas ideias ao invés de seguir uma receita pré-definida;

- um bom projeto de interface para usuários idosos normalmente gera problemas de interface para os demais usuários em geral.

O trabalho de Hawthorn (2003) teve como foco o desenvolvimento de uma aplicação de e-mail, denominada SeniorMail, que foi construída com a participação de um grupo de idosos. Durante o período de desenvolvimento, o grupo envolvido no trabalho rejeitava qualquer funcionalidade do sistema que não fosse básica, com seguinte justificativa: "mantenha a aplicação simples para que possamos entendê-la".

Assim sendo, o sistema tentou simplificar o aprendizado e o uso da aplicação de e-mail por meio da simplificação do design da tela, oferecendo ao usuário um design linear muito simples com poucas opções, aumentando o tamanho das fontes e controles, tentando 
reduzir as tarefas de gerenciamento da janela e as barras de rolagem. Os menus do MS Windows foram rejeitados e substituídos por grandes botões de comando. As Figuras 4.9 a 4.13 ilustram as principais decisões relativas ao projeto de interface da aplicação SeniorMail.

Na Figura 4.9 pode-se observar a ausência de menus e a apresentação das opções da aplicação de forma linear, em botões grandes com texto e figuras correspondentes.

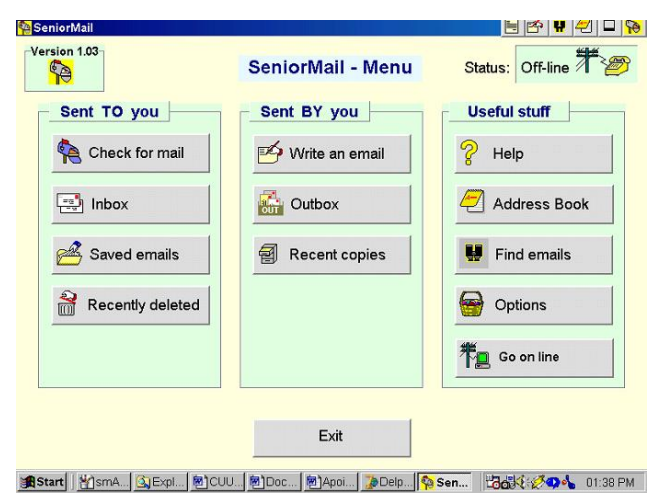

Figura 4.9: Tela inicial da ferramenta de e-mail (Hawthorn, 2003)

Na Figura 4.10 é apresentada a caixa de entrada da aplicação de e-mails cujas opções também estão dispostas em formato de botões.

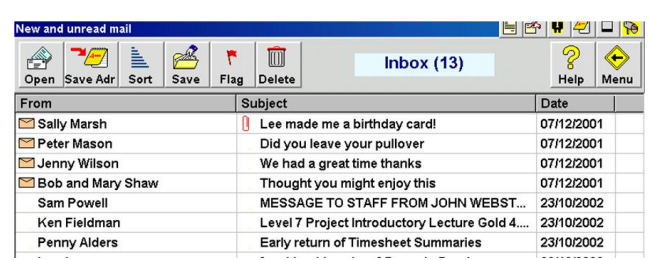

Figura 4.10: Caixa de entrada de e-mails (Hawthorn, 2003)

Outra decisão de projeto interessante foi a adição explícita de setas para facilitar a rolagem do texto (Figura 4.11), pois a barra de rolagem do browser costuma confundir os usuários mais velhos.

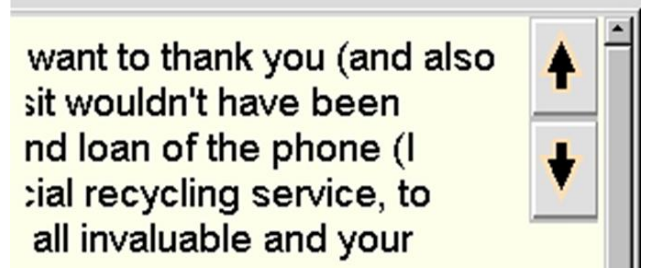

Figura 4.11: Setas auxiliares para rolagem de texto (Hawthorn, 2003)

Para que o usuário não tivesse que memorizar os passos para anexar um arquivo na mensagem optou-se por colocar a explicação textual para cada um dos passos da operação como é mostrado na Figura 4.12. 


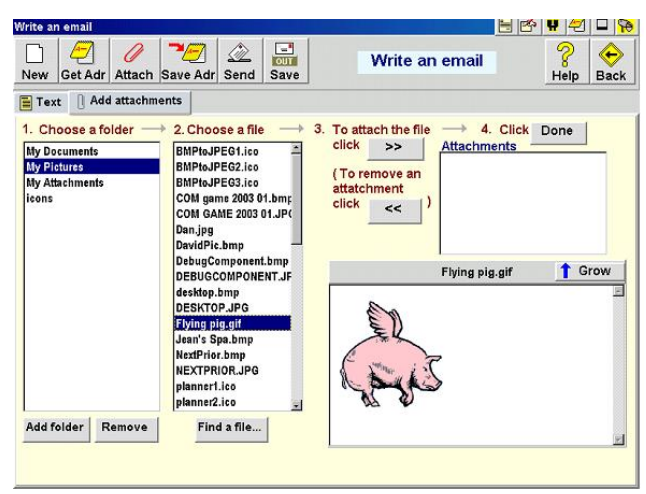

Figura 4.12: Seleção de arquivo anexo (Hawthorn, 2003)

Do mesmo modo, na página referente à classificação de e-mails em determinada ordem são oferecidas dicas de utilização (Figura 4.13).

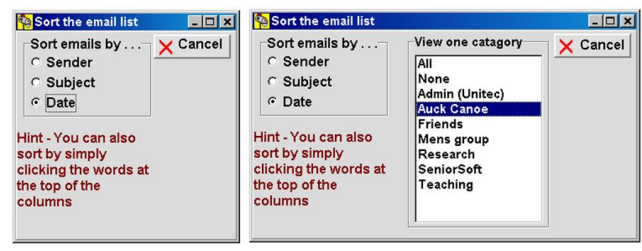

Figura 4.13: Classificação de e-mails (Hawthorn, 2003)

A navegação foi simplificada e requereu um progresso linear através de uma série de tarefas até atingir o objetivo e, também, para retornar ao menu principal. Algumas tarefas como as que envolviam transações com o sistema operacional também foram simplificadas, de modo que o usuário pudesse fazer uma pré-seleção de quais eram os seus diretórios preferidos para salvar e buscar documentos em caso de anexo, por exemplo.

A cada teste de usabilidade realizado, a aplicação era modificada. O teste de usabilidade era visto como uma oportunidade para tentar interpretar como os impactos da idade influenciavam a interação dos idosos com a Web.

As principais dificuldades encontradas foram:

- gerenciamento de arquivos anexos, que necessita de transações com o sistema operacional, mas muitos usuários acham complicado o conceito e o uso da árvore hierárquica de diretórios;

- outra dificuldade está na organização e busca de um e-mail, pois envolve tarefas como criar novos diretórios, fazer drag and drop, lembrar ou encontrar onde os itens foram armazenados, entre outras.

A navegação, que constitui outra característica complexa, também foi considerada. Um típico sistema de e-mail oferece rápido acesso aos usuários e apresenta grande variedade de tarefas, ferramentas e diretórios. Mas as pessoas com alguma restrição, 
devido à idade, não conseguem ter boa visão a respeito de interfaces complexas e acabam abandonando a interação.

As principais soluções encontradas foram: uso de botões em toolbars ao invés de menus; manipulação de barras de rolagem; uso de Hints ou Tooltips com fontes grandes e maior tempo de exibição; gerenciamento de janelas e navegação (uso da tela em modo full screen), entre outras.

Os trabalhos apresentados nesta seção tiveram como foco principal as alterações de design, que são necessárias para favorecer a interação entre os usuários idosos e a Web, mas não trataram dos problemas relacionados às deficiências de aprendizado e de memorização, que são também, muito comuns aos idosos.

\subsection{Trabalhos relacionados ao Apoio Contextual}

Zajicek (2001) destaca em seu trabalho que, além das dificuldades de ordem motora, visual e auditiva consequentes do envelhecimento, as mudanças relacionadas à memória afetam muito o aprendizado e a interação dos idosos com a Web. Problemas de memória interferem em atividades exploratórias na Web, pois envolvem a recordação de combinações entre ações e resultados. Os idosos encontram dificuldades para lembrar das sequências de ações que realizaram em determinada interação e apresentam dificuldades para a construção de modelos conceituais, o que os deixam confusos e frustrados. Com o objetivo de amenizar problemas relacionados com a perda de memória e a deficiência visual durante as interações, foi desenvolvido um prótotipo especial de navegador Web com auxílio de voz para adultos mais velhos, denominado BrookesTalk.

O sistema BrookesTalk foi distribuído gratuitamente para mais de 200 cegos e deficientes visuais em todo o mundo, e avaliado por meio de um questionário on-line. $\mathrm{O}$ fato mais significativo dessa avaliação foi que o aproveitamento pelos idosos com deficiência visual, na primeira vez que interagiram com o navegador, foi extraordinariamente baixo: $82 \%$ dos idosos não foram capazes de interagir com a Web, mesmo com o apoio de familiares. Por exemplo, usuários ficaram inseguros quanto à funcionalidade de um link. Mesmo sendo esclarecidos a respeito de como funcionava um link e incentivados a seguir o link para ter acesso a outras páginas e conteúdos, rapidamente eles voltavam para a posição inicial. Entrevistas revelaram que além de não entenderem exatamente como funcionava a aplicação, eles não conseguiram relacionar botões, teclas e menus às funções que executavam e ainda ficaram com medo de "quebrar" o software caso fizessem alguma coisa errada (Zajicek, 2001).

Para tentar acomodar a perda de memória e deficiência visual, um outro tipo de apoio foi construído no Brookes Talk para ajudar o usuário na construção de modelos conceituais. Para cada possível estado do navegador BrookesTalk, uma saída falada era fornecida. Em cada ponto na interação, o usuário era informado onde estava e o que poderia fazer a 
seguir, incluindo detalhes que descreviam as consequências de cada ação. Depois de ouvir a mensagem, o usuário escolhia uma opção e então recebia outra mensagem descrevendo o novo estado do sistema. Um novo experimento foi realizado com oito usuários que não haviam conseguido utilizar o navegador inicialmente e foi observado que, com esse novo apoio, quatro desses usuários conseguiram utilizar o navegador com êxito.

O objetivo de incorporar ajuda por voz no navegador Brookes Talk foi para familiarizar o usuário com os passos necessários para atingir as metas de interação da Web, e esperava-se que, gradativamente as instruções de voz se tornariam supérfluas a partir do momento que o usuário "soubesse" a tecla que deveria ser pressionada para obter o resultado desejado.

Finalmente, Zajicek (2001) destaca em seu trabalho que, devido à maior variabilidade na capacidade dos adultos mais velhos, os desenvolvedores de software não podem admitir a homogeneidade desse grupo e nem um conjunto relativamente fixo de requisitos para atender às suas necessidades. Ao projetar para adultos mais velhos, deve-se considerar a diversidade de aspectos que os torna muito diferente do grupo dos jovens. Ressalta ainda que, o método padrão para o desenvolvimento de interfaces, o "projeto centrado no usuário", não atende às necessidades do grupo de adultos mais velhos, pois assume um conjunto estático de requisitos do usuário, que é obtido por meio de um ciclo de protótipo e avaliação. Os adultos mais velhos não possuem um conjunto estático de requisitos de usuário. Esses requisitos diferem entre os indivíduos e ao longo do tempo, uma vez que suas habilidades tendem a diminuir durante o processo de envelhecimento. Assim sendo, propõe um novo paradigma de design, que não busca mais um conjunto de requisitos estático, mas que leva em consideração a natureza dinâmica de alguns dos parâmetros da interação, introduzindo o conceito de Design para a Diversidade Dinâmica (DDD).

Apesar do trabalho desenvolvido por Grossman e Fitzmaurice (2010) não estar relacionado ao uso da Web, foi investigado um tipo de auxílio que pode ser aplicado para interações na Web de forma similar. Nesse estudo, foi investigado o uso de um tipo de assistência on-line, o vídeo contextual, para melhorar a capacidade de aprendizado das funcionalidades de softwares. Essa forma de assistência, denominada de ToolClips, tem por objetivo aumentar as dicas tradicionais, fornecendo assistência textual e por vídeo, de modo contextual, como meio de facilitar o acesso para os usuários.

ToolClips estendem as tradicionais dicas (Tooltips) (Farkas, 1993), integrando videoclipes com narrações explicativas do contexto e documentação em formato texto em maior profundidade. Um novo modelo de interação progressiva (vídeos contextuais segmentados) foi utilizado para assegurar que o mecanismo não se tornasse intrusivo. Trata-se de uma solução simples, mas ainda inexplorada, que pode ser incorporada em muitos programas que possuem interface gráfica e que já disponibilizam os tooltips.

Durante o projeto do recurso foram estabelecidos os seguintes objetivos de design: 
1. On-line: como os usuários normalmente não lêem manuais o principal objetivo foi atender os usuários que enfrentam desafios no uso da interface durante o uso da ferramenta;

2. Contextual: a ajuda deveria ser fornecida dentro do contexto, quando os elementos da interface são acessados por meio da interface;

3. Detalhada: a assistência deverá conter o máximo de informações relevantes quanto for possível.

4. Segmentada: evidências demonstram que quando os usuários estão envolvidos no seu fluxo de tarefa eles só vão querer adquirir o mínimo de informações que eles precisam;

5. Custos Baixos de Transação: usuários não devem precisar se preocupar com codecs, plug-ins, e velocidades de download;

6. Não intrusivo: um sistema de ajuda contextual não deve interromper frequentemente a ponto de interferir no bom andamento do seu próprio trabalho.

O recurso foi implementado dentro da ferramenta Paint.NET, uma aplicação de edição de imagem de código aberto. A visualização do recurso na ferramenta pode ser observada na Figura 4.14.

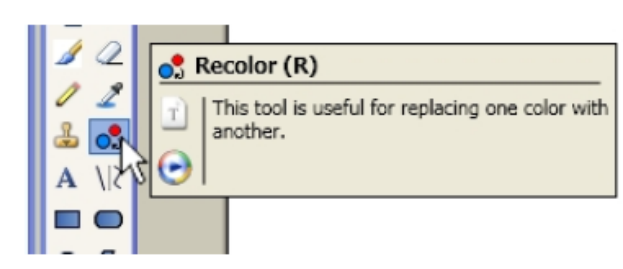

Figura 4.14: Apresentação do Toolclips na ferramenta Paint.NET (Grossman e Fitzmaurice, 2010)

Caso o usuário acione o auxílio por texto uma página semelhante à mostrada na Figura 4.15 (a) lhe é apresentada dentro da ferramenta, mostrando um exemplo da execução da opção da ferramenta. O mesmo ocorre se o usuário escolher a opção de vídeo (Figura $4.15(\mathrm{~b})$ ).

Foram conduzidos dois estudos para comparar ToolClips com o apoio do Help tradicional. No primeiro estudo foram realizadas tarefas de alto nível, que requerem o uso de múltiplas ferramentas, de modo a obter feedbacks e dados de uso do projeto. O segundo estudo concentrou as tarefas numa ferramenta isolada de modo a compreender sua efetiva ajuda na capacidade de aprendizado.

Para o primeiro estudo foram recrutados 16 (10 homens, 6 mulheres) participantes pagos, com idade variando de 17 a 32 anos. A característica principal para a 


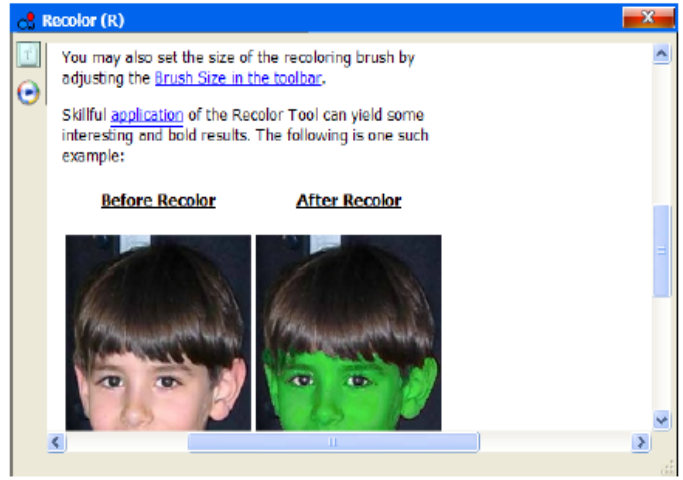

(a) Auxílio em formato texto

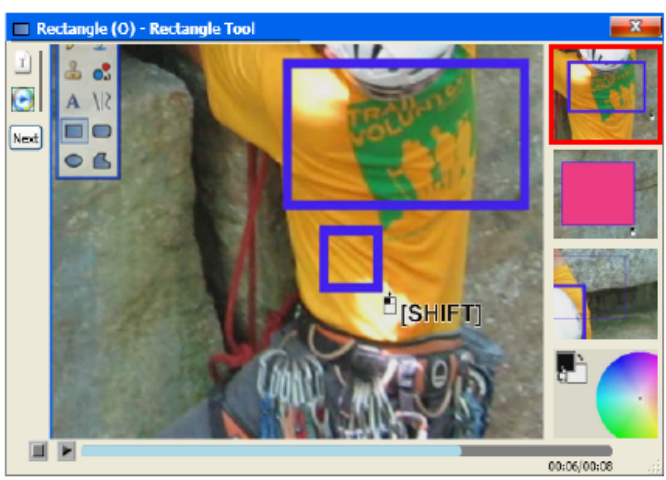

(b) Auxílio por meio de vídeo

Figura 4.15: Execução dos recursos de texto e vídeo oferecidos pelo Toolclips

escolha dos participantes foi a pouca ou nenhuma experiência com a aplicação Paint.NET, uma vez que o interesse estava em usuários que precisassem aprender a utilizar as ferramentas da aplicação. Foram estipuladas oito tarefas que progrediam gradativamente em complexidade, e utilizavam as 22 ferramentas disponíveis na paleta de ferramentas principal Paint.NET.

Cada participante completou as oito tarefas na mesma ordem. As tarefas geralmente envolviam a utilização de 2 a 5 ferramentas cada. Para cada tarefa, os usuários recebiam um arquivo com um modelo diferente e uma cópia impressa da imagem final, que eles precisavam criar. No estado inicial, tooltips estavam disponíveis para cada um dos ícones na paleta de ferramentas, fornecendo o nome e uma curta descrição da ferramenta. Quando uma dica de ferramenta fosse exibida, os usuários poderiam digitar F1 para ir direto para a ajuda Paint.NET existente (help da ferramenta). ToolClips foram fornecidos para todas as 22 ferramentas na paleta principal da ferramenta. O conteúdo de vídeo integrado fornecia as mesmas informaçõs do help on-line, mas em formato de vídeo. Um ícone animado foi sobreposto aos vídeos para indicar a posição do cursor e o botão que deveria ser pressionado.

Os Toolclips foram acessados na média de 2,08 vezes por tarefa, ou um total de 118 vezes, 46 vezes através do ícone de texto e 72 vezes através do ícone da mídia. Um efeito interessante foi que a maioria dos usuários preferiu tanto o conteúdo texto ou o conteúdo de vídeo, e poucos invocaram ambos, o que indica que esses usuários escolheram o meio a partir do qual obtiveram uma aprendizagem mais confortável, o que validou a decisão para incluir tanto o texto quanto o conteúdo de vídeo dentro dos ToolClips.

Como resultado desse primeiro estudo pôde-se observar que o design da interface do usuário foi bem recebido pelos participantes e os usuários foram capazes de utilizar ToolClips com sucesso dentro do fluxo de suas tarefas. Enquanto alguns 
participantes preferiram a documentação integrada já existente (help tradicional), a maioria preferiu utilizar o conteúdo do vídeo.

Para verificar se os Toolclips eram realmente efetivos na redução dos problemas de aprendizado de uma nova ferramenta foi realizado um estudo no qual os participantes deveriam completar tarefas de nível mais baixo. Para garantir que os participantes precisariam aprender a usar as ferramentas, e não tentar supor como as mesmas funcionavam, o estudo utilizou a ferramenta AutoCAD, cujo design e arquitetura da aplicação é notoriamente difícil de aprender. Para implementar ToolClips no AutoCAD foi realizada uma modificação na aplicação Paint.NET de modo que o aplicativo fosse executado em segundo plano, e exibisse os ToolClips quando o cursor estivesse sobre ícones do AutoCAD.

Participaram desse segundo estudo dez voluntários pagos (4 homens, 6 mulheres), com idade variando de 18 e 40 anos. Foram recrutados usuários com experiência no uso de computadores mas sem experiência no uso do AutoCAD. Foram escolhidas seis ferramentas de nível básico em AutoCAD e cada tarefa requerida utilizava de 1 a 3 ferramentas. Os usuários receberam um modelo de arquivo para iniciar cada tarefa e uma cópia impressa do imagem final que deveriam obter.

Os resultados deste segundo estudo mostraram que o uso dos ToolClips proporcionou uma vantagem significativa em comparação com o sistema de ajuda tradicional do AutoCAD, aumentando taxa de conclusão de $10 \%$ para $70 \%$. Além disso, foi constatado que com os vídeos, os usuários puderam entender rapidamente a qual objeto uma instrução se referia. Na ajuda estática, os usuários, muitas vezes, interpretavam erroneamente o objeto de referência de uma instrução, mesmo quando as imagens eram fornecidas. Foi observado também que os usuários pareciam ter mais "confiança" nos vídeos do que na ajuda estática.

Outro fator importante observado foi com relação à retenção da informação, visto que uma semana mais tarde outra rodada do experimento foi executada e os participantes conseguiram executar as tarefas de forma significativamente mais rápida, diminuindo em média o tempo de conclusão das atividades de 306 segundos para 166 segundos.

Uma desvantagem observada no uso dos ToolClips foi que, algumas vezes, os usuários queriam trabalhar com o vídeo em reprodução, fato que gerava um descompasso entre o trabalho e o andamento do vídeo. Como consequência, eles tiveram que voltar e ir para frente, pausar e reproduzir o vídeo, de modo que pudessem reproduzir os mesmos passos mostrados pelo vídeo. Este tipo de estratégia fica mais fácil de ser realizada com a ajuda estática, visto que as etapas geralmente aparecem em uma visão única. 
Com este trabalho pode-se observar que a ajuda dinâmica que "imita o apoio presencial" e acionada diretamente sob demanda no próprio contexto de trabalho se mostra bastante eficaz, no entanto, ao se tentar fazer um paralelo com a interação na Web surge uma questão importante: qual a escalabilidade de vídeos para atender a todos os tipos de interação na Web?

\subsection{Considerações finais}

A literatura na área de Interação Humano-Computador é relativamente rica em trabalhos que exploram os diversos aspectos da interação de usuários com a Web, mas ainda existe espaço para contribuições que resultem da investigação do que realmente é relevante para que a interação envolvendo os adultos mais velhos seja satisfatória.

Neste capítulo foram destacados trabalhos que investigaram diferentes aspectos da interação entre os adultos mais velhos e a Web, e que de alguma forma contribuíram para o desenvolvimento desta pesquisa. Assim, os trabalhos relacionados, suas principais contribuições e os itens correspondentes aos tratados nesta tese foram:

- Trabalhos: uso de Redes Sociais (Hogeboom et al., 2010) (Páscoa e Gil, 2012)

- Contribuições: destacam a importância da participação dos adultos mais velhos em redes sociais durante o processo de envelhecimento. Os principais benefícios relatados foram o contato com familiares e amigos, aquisição de conhecimento e informações, etc.

- Itens tratados nesta tese: reconhecimento de elementos da Web nas interfaces de ferramentas de apoio ao contato social (e-mail e chat), verificando a familiaridade dos usuários com os elementos mais comuns das interfaces Web. Ver Seção 5.4.

- Trabalhos: uso de Tecnologias Diversas (Chou e Hsiao, 2007) (Kang e Yoon, 2008) (Gonçalves et al., 2011)

- Contribuições: registro das principais dificuldades observadas na interação com computadores, PMPs, MP3, celulares, por exemplo, manuseio de teclado e mouse, foco de leitura, mensagens de erros, tela pequena, teclas muito próximas, erros involuntários, contraste entre cores, etc.

- Itens tratados nesta tese: o protótipo de site de comércio eletrônico trata do uso de cores, conteúdo centralizado, divisão da tarefa em várias telas, formatação de campos, etc. O protótipo de menus horizontais trata da visualização de pontos de ativação, quantidade de níveis, velocidade de apresentação, etc. Ver Seções 5.5 e 5.6. 
- Trabalhos: adaptação das Diretrizes (Zaphiris et al., 2005) (Sales e Cybis, 2003)

- Contribuições: criação de 11 categorias de diretrizes que tratam de alvos de interação, uso de gráficos, navegação, características do navegador, exibição do conteúdo, elos de ligação, prioridade para o aspecto cognitivo do usuário, uso de cores, apresentação do texto, reconhecimento de erros ortográficos em mecanismos de pesquisa, resposta aos usuários e apoio. Outras adaptações propostas foram o sincronismo entre legendas e descrições sonoras, blocos de informações subdivididos em seções curtas, etc.

- Itens tratados nesta tese: sugestão para extensão dos critérios de sucesso para as diretrizes do WCAG 2.0 e sugestões de solução para os principais problemas identificados a partir dos dados coletados. Ver Seções 6.1 e 6.2.

- Trabalhos: deficiências cognitivas (Small et al., 2005) (Dickinson et al., 2007)

- Contribuições: identificação de dificuldades relacionadas às deficiências cognitivas - incerteza para onde navegar, navegação inconsistente, falta da percepção da capacidade de clique, problemas para ler o conteúdo total das páginas utilizando a barra de rolagem, falta de capacidade ou de vontade de ler instruções, etc.

- Itens tratados nesta tese: proposta de mecanismos para apoio à memorizacão e à redução da sobrecarga cognitiva. Ver Seção 6.3.

- Trabalhos: customização de interfaces (Hanson, 2004) (Hawthorn, 2003)

- Contribuições: apresentam possibilidades de modificações na interface para atender a necessidades específicas - ampliação de texto, pontos grandes e distantes para acionamento via mouse (cliques), uso de botões ao invés de links, configuração de espaçamento entre linhas de texto, etc.

- Itens tratados nesta tese: elaboração de um protótipo de site de comércio eletrônico especialmente para os adultos mais velhos. Ver Seção 5.5.

- Trabalhos: apoio contextual (Zajicek, 2001) (Grossman e Fitzmaurice, 2010)

- Contribuições: mostram como ampliar o apoio tradicional de modo sensível ao contexto.

- Itens tratados nesta tese: proposta de mecanismos para apoio à interação, que tentam imitar o apoio presencial. Ver Seção 6.3.

Neste capítulo foram apresentados os trabalhos da literatura relacionados com esta pesquisa. Foram discutidos trabalhos que não estão diretamente associados à interação com a Web, mas que, de alguma forma, contribuem para o desenvolvimento 
da pesquisa, uma vez que revelam indícios de problemas a serem encontrados também na interação de adultos mais velhos com as interfaces de páginas na Web. 


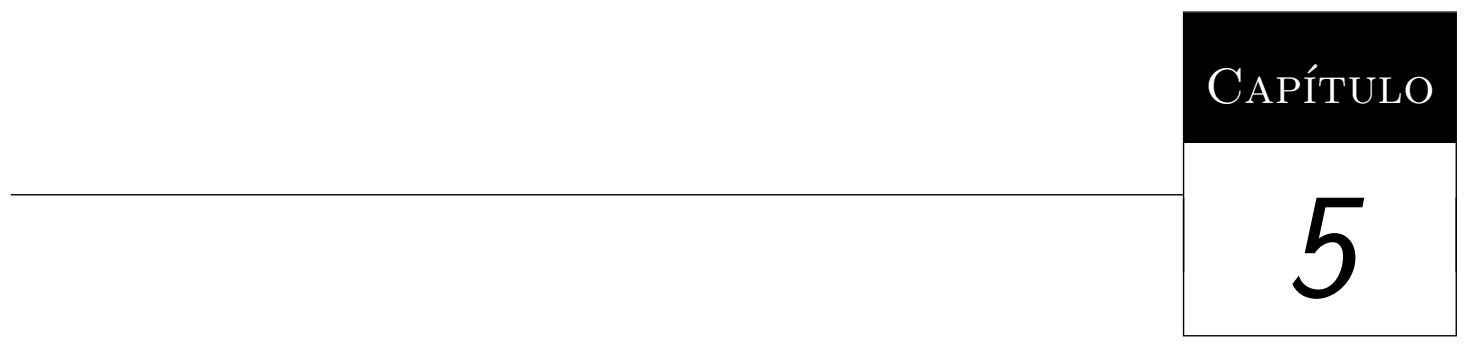

\section{Identificação das Dificuldades}

Neste capítulo são apresentadas as características técnicas adotadas com relação à natureza da pesquisa realizada nesta tese, seus delineamentos, procedimentos, técnicas de coleta e análise de dados.

Trata-se de um estudo principalmente de natureza qualitativa, visto que procura identificar quais as principais dificuldades e barreiras enfrentadas pelos adultos mais velhos em suas interações com a Web, os "porquês" que ocasionam tais problemas e propor as possíveis formas de "como" resolver ou minimizar tais problemas. A principal característica da pesquisa qualitativa é tentar entender os fenômenos ao invés de mensurá-los. Normalmente, a pesquisa qualitativa analisa pequenas amostras, não necessariamente representativas da população, mas que apresentam um amplo foco de interesse (Lakatos e Marconi, 2007) (Lakatos e Marconi, 2008).

Neste estudo pretende-se identificar quais as reais dificuldades, de qualquer ordem, enfrentadas pelos adultos mais velhos durante suas interações com páginas e ferramentas disponíveis na Web. A pesquisa qualitativa é utilizada quando se possui pouca informação, em situações em que o fenômeno deve ser observado ou em que se deseja conhecer um processo, sem muitos dados de partida. A pesquisa qualitativa costuma ser direcionada por um objetivo, ao longo de seu desenvolvimento e inclui a obtenção de dados descritivos mediante contato direto e interativo do pesquisador com o objeto de estudo (Neves, 1999).

Quanto aos objetivos específicos, as pesquisas científicas podem ser classificadas em três modalidades: exploratória, descritiva e explicativa. Cada uma trata o problema de maneira peculiar. A pesquisa exploratória tem "como objetivo 
proporcionar maior familiaridade com o problema". A descritiva adota "como objetivo primordial a descrição das características de determinada população ou fenômeno". Já a pesquisa explicativa tem "como preocupação central identificar os fatores que determinam ou que contribuem para a ocorrência dos fenômenos" (Gil, 2008).

A modalidade de pesquisa adotada foi a pesquisa descritiva. As pesquisas descritivas caracterizam-se frequentemente como estudos que procuram determinar status, opiniões ou projeções futuras nas respostas obtidas. A sua valorização está baseada na premissa de que os problemas podem ser resolvidos e as práticas podem ser melhoradas por meio de descrição e análise de observações objetivas e diretas. As técnicas utilizadas para a obtenção de informações são bastante diversas, destacando-se os questionários, as entrevistas e as observações. Esse tipo de pesquisa apoia-se na estatística descritiva para realizar as descrições da população (mediante amostra probabilística) ou do fenômeno, ou relacionar variáveis. Assim, a pesquisa descritiva pura tem natureza quantitativa, mas pode ser quantitativa e qualitativa ao mesmo tempo, se representar descrição de amostra não-probabilística.

Durante o planejamento da pesquisa, foram escolhidos os principais recursos técnicos a serem utilizados na investigação. A classificação das pesquisas quanto aos seus objetivos pode compreender diversos tipos, sendo os mais conhecidos: a pesquisa documental, a pesquisa bibliográfica, o levantamento, a pesquisa experimental, a pesquisa expost-facto, o estudo de caso e a pesquisa-ação. Nesta pesquisa foram utilizados a pesquisa bibliográfica (síntese narrativa), o levantamento (questionários, entrevistas e observações) e o estudo de caso.

A pesquisa bibliográfica representa o contato do pesquisador com as informações disponibilizadas na literatura, sobre determinado assunto, sejam elas obtidas por meio de livros, periódicos científicos, artigos de conferências, teses ou relatórios científicos, cuja autoria é conhecida e que foi publicado ou registrado de alguma forma. Nesse caso, o pesquisador deve avaliar criticamente a produção científica sobre o assunto em questão, de modo a extrair conclusões relevantes a respeito dos resultados das pesquisas realizadas até o momento (estado da arte).

O levantamento tem como característica principal a coleta de informações diretamente das pessoas, para se conhecer o comportamento de determinado grupo. Essas informações são captadas por meio de instrumentos que possibilitam a realização de análise quantitativa, cujas conclusões podem ser projetadas para um universo mais amplo. O levantamento ou Survey é o tipo de pesquisa que visa determinar informações sobre práticas ou opiniões atuais de uma população específica.

O estudo de caso é o tipo de pesquisa no qual um caso (fenômeno ou situação) individual é estudado em profundidade para obter uma compreensão ampliada sobre 
outros casos (fenômenos ou situações) similares. Os estudos de caso descritivos procuram apenas apresentar um quadro detalhado de um fenômeno para facilitar a sua compreensão, pois não há a tentativa de testar ou construir modelos teóricos. $\mathrm{Na}$ verdade, esses estudos constituem um passo inicial ou uma base de dados para pesquisas comparativas subsequentes e construção de teorias. Os estudos de caso interpretativos também utilizam a descrição, mas o enfoque principal é interpretar os dados num esforço para classificar e contextualizar a informação e talvez teorizar sobre o fenômeno. Os estudos de caso avaliativos envolvem tanto a descrição quanto a interpretação, mas o objetivo principal é usar os dados para avaliar o mérito de alguma prática, programa, movimento ou evento. O estudo de caso é a pesquisa preferida quando predominam questões dos tipos "como?" e "por quê?", ou quando o pesquisador detém pouco controle sobre os eventos e ainda quando o foco se concentra em fenômenos da vida real. O estudo de caso é um modo de pesquisa empírica que investiga fenômenos contemporâneos em seu ambiente real, quando os limites entre o fenômeno e o contexto não são claramente definidos; quando se baseia em várias fontes de evidências; e quando há proposições teóricas para conduzir a coleta e a análise dos dados.

Os trabalhos foram iniciados com a revisão da literatura apresentada nos capítulos 2, 3 e 4. A seguir, os procedimentos realizados foram: observação de campo (Seção 5.1 ), aplicação de questionário para usuários experientes (Seção 5.2), entrevista com deficientes visuais (Seção 5.3), aplicação de questionários on-line em várias fases distintas (Seção 5.4 e Seção 6.4), testes com protótipo de comércio eletrônico (Seção 5.5), menus (Seção 5.6) e uma prova de conceito do mecanismo de apoio contextual (Seção 6.3). Devido à interdisciplinaridade contemplada pela pesquisa foram realizadas entrevistas com profissionais das áreas de psicologia e gerontologia, que resultaram em indicações bibliográficas importantes.

Vale destacar que em todas as técnicas de coleta de dados aplicadas, houve, por parte dos respondentes, o consentimento para a utilização de suas respostas para a realização deste trabalho de pesquisa e por parte da pesquisadora, a garantia de que os dados não seriam utilizados para nenhum outro fim. Segundo Singer et al. (1995), as garantias de confidencialidade somente importam para respondentes quando o conteúdo do levantamento é considerado sensível e portanto, pode haver casos em que os indivíduos não necessariamente se preocupem que a sua informação seja divulgada. As descrições de cada uma das etapas do trabalho e seus respectivos resultados são apresentadas a seguir. 


\subsection{Observação em Campo}

Com o objetivo inicial de mapear o perfil dos usuários inexperientes no uso da Web, foi realizado o acompanhamento presencial de um curso de treinamento, intitulado "Internet Avançada" destinado aos adultos de meia-idade e idosos, oferecido pela FESC (Fundação Educacional de São Carlos), instituição mantida pela Prefeitura Municipal de São Carlos. O requisito exigido para que um indivíduo pudesse frequentar o curso era que tivesse apenas noções básicas do uso de computadores e idade superior a 40 anos.

Houve o contato direto da pesquisadora com os alunos do curso durante aproximadamente 4 meses (agosto a dezembro de 2007). Esse contato foi importante na medida em que auxiliou a pesquisadora a compreender as dificuldades segundo a perspectiva dos alunos participantes e a realizar reflexões sobre o que poderia ser melhorado no desenvolvimento das interfaces Web, de modo a proporcionar avanços na forma de interação desse público-alvo com a Internet.

O grupo de sete alunos era formado por seis mulheres e um homem. A idade média do grupo era de 57 anos, sendo que duas alunas possuíam idade superior a 60 anos. Em termos socioeconômicos, foi observado que todos os alunos possuíam computador em casa e bom nível intelectual, o que lhes permitia acompanhar as instruções de treinamento sem dificuldades acentuadas. Inicialmente havia mais três pessoas no grupo, que desistiram por motivo de doença ou falta do computador em casa, e consequentemente a impossibilidade de treinamento com regularidade ou com a frequência mínima esperada.

A maior parte deles procurou o curso com o objetivo de aprender a utilizar a Web de modo a obter informações, comunicação e entretenimento. Poucos vislumbravam a possibilidade de usufruir de serviços que pudessem facilitar sua rotina diária, tais como compras, bancos e serviços governamentais.

As aulas, ministradas por uma instrutora, eram expositivas e sem material de apoio. Cada aluno utilizava um microcomputador contendo Windows XP e o navegador Internet Explorer. Todos os passos executados pela instrutora eram reproduzidos pelos alunos, os quais frequentemente solicitavam ajuda, inclusive desta pesquisadora, para concluirem suas tarefas. Devido a esse fato, ficou clara a dificuldade dos alunos em processar informações simultâneas, ou seja, prestar atenção na instrução e reproduzí-la em seu computador. Percebeu-se que os alunos não conseguiam fixar na memória uma instrução completa, tendo a instrutora e até mesmo esta pesquisadora, que repetir a instrução e acompanhar a execução com cada um dos alunos de forma individual. 
Foram registradas observações e relatos dos alunos a respeito das dificuldades encontradas durante suas interações na Web. Uma reclamação recorrente era de que em casa, utilizando seus próprios computadores, eles não conseguiam reproduzir individualmente o que lhes era ensinado em aula, pois não conseguiam se lembrar de todos os passos executados. Uma manifestação desse fato foi de uma senhora de aproximadamente 70 anos de idade:

“...durante a aula eu faço tudo, mas em casa eu tento e não consigo..."

Outra observação recorrente, segundo depoimentos colhidos, foi:

"...no meu computador as telas são diferentes ..."

Constatou-se também que qualquer detalhe ou algo diferente na localização das informações já se apresentava como uma barreira de acesso aos alunos, fato este relacionado às diferentes versões de navegadores utilizados.

A partir do levantamento das dificuldades realizado, observou-se o relacionamento entre os princípios de usabilidade (Seção 2.2) e diretrizes de acessibilidade da WCAG 2.0 (W3C, 2008b) (Seção 2.4) já apresentados no Capítulo 2, proporcionando uma visão agregada que deve ser considerado nas tendências das evoluções das tecnologias das interações com a Web, dado o contínuo avanço da faixa etária de seus usuários (Lara e Fortes, 2009). As dificuldades observadas, resumidas com seus respectivos princípios de usabilidade e diretrizes de acessibilidade foram:

- problemas no manuseio do mouse (U7 - A2.1);

- problemas na digitação de URLs e nos campos de entrada (U2, U5 - A3.3);

- problemas na compreensão de mensagens de erros (U9 - A3.1, A3.3);

- problemas na ativação de links em listas quando há muita proximidade entre os mesmos (U5 - A2.4, A3.1);

- problemas na ativação de foco em campos de entrada (U1,U6 - A3.2, A3.3);

- problemas no acionamento da tecla <ENTER $>$ (U1,U6 - A3.2, A3.3);

- falta de atenção e esquecimento (U6 - A2.4, A3.1, A3.2, A3.3);

- problemas para localização de campos de entrada de dados (U8 - A3.2, A3.3);

- problemas para localização da informação desejada (U8 - A2.4);

- problemas para reprodução de números e letras contidos em imagens (U5 $\mathrm{A} 1.1, \mathrm{~A} 1.4)$

- não percepção de feedbacks na barra inferior do navegador (U1 - A3.1);

- problemas na visualização de informações com cores (frente e fundo) semelhantes (U8 - A1.4); 
- problemas na visualização de informações com letras pequenas (U8 - A1.4).

As dificuldades observadas nas interações dos membros do grupo em uma sala de bate-papo ${ }^{1}$, que é uma ferramenta síncrona, foram:

- não acompanhamento da dinâmica da troca de mensagens (U7 - A1.3, A2.2);

- problemas no uso da barra de rolagem (U2,U6 - A2.1);

- problemas na identificação das metáforas (U2 - A1.1, A3.1);

- problemas para a configuração dos elementos que compõem a mensagem (destinatário, reservado, emoticon, etc) (U2,U6 - A3.1);

- problemas para a compreensão sobre a funcionalidade dos emoticons (associam a figura à pessoa) (U2,U6 - A3.1);

- problemas para a identificação de qual mensagem é destinada para eles (U7 A1.4).

Para o aprendizado sobre troca de mensagens via e-mail foi utilizada uma ferramenta popular de e-mail ${ }^{2}$ e as dificuldades observadas foram:

- problemas de memorização de senha de acesso (U6 - A3.1, A3.3);

- problemas na digitação de endereços eletrônicos (U5 - A3.3);

- problemas na visualização do link para acessar o anexo (U2,U8 - A1.1, A1.4, A3.1);

- problemas na realização de todos os passos para o download do anexo (U5,U6 - A3.1, A3.2);

- problemas na criação de mensagem contendo anexo (U2,U5,U6 - A3.1, A3.2).

A partir das observações descritas foi possível verificar os princípios de usabilidade que foram mais recorrentes nesse contexto específico, conforme mostrado na Figura 5.1 .

As diretrizes de acessibilidade mais recorrentes podem ser observadas na Figura 5.2. Verificou-se que os princípios de reconhecimento ao invés de relembrança (U6), prevenção de erros (U5) e, estética e design minimalista (U8) estão fortemente relacionados às diretrizes de previsibilidade (A3.2), assistência de entrada (A3.3) e, legibilidade e compreensibilidade (A3.1) respectivamente. O princípio de usabilidade que trata da estética e design minimalista (U8) tem também forte correspondência com as diretrizes de conteúdo perceptível e de

\footnotetext{
${ }^{1}$ http://chat.terra.com.br

${ }^{2}$ http://www.yahoo.com.br
} 


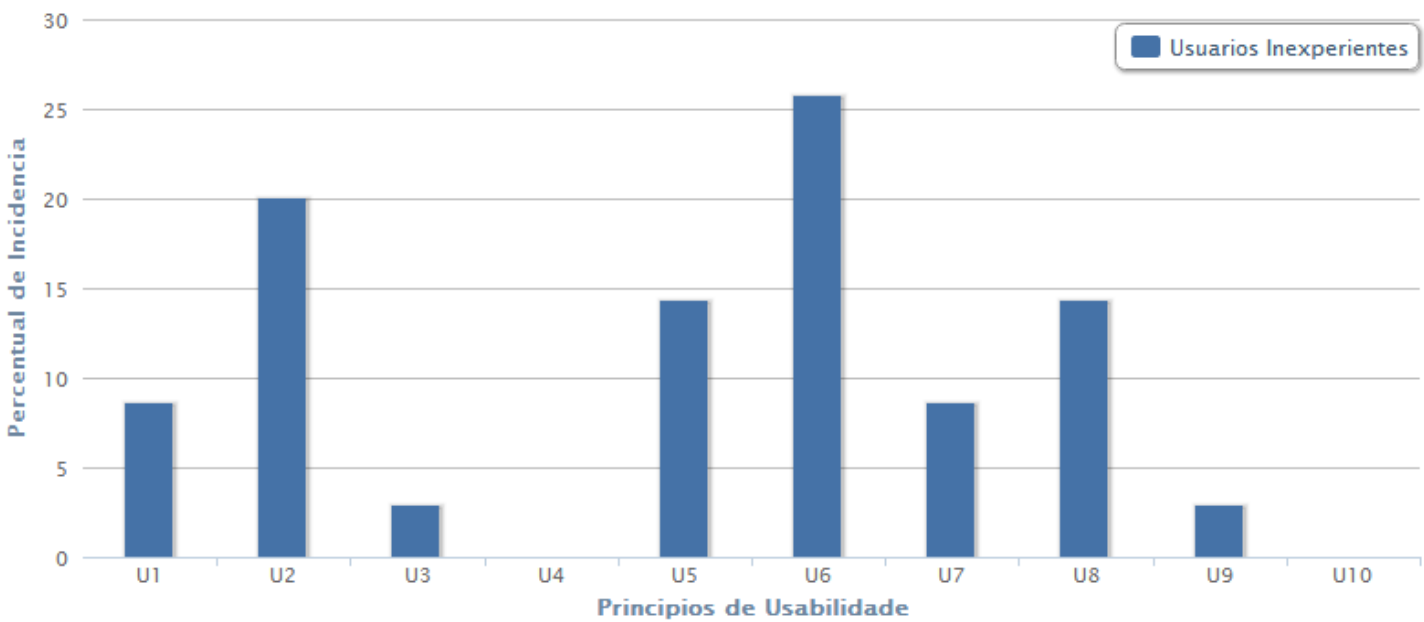

Figura 5.1: Percentual de Incidência dos Princípios de Usabilidade entre Usuários Inexperientes

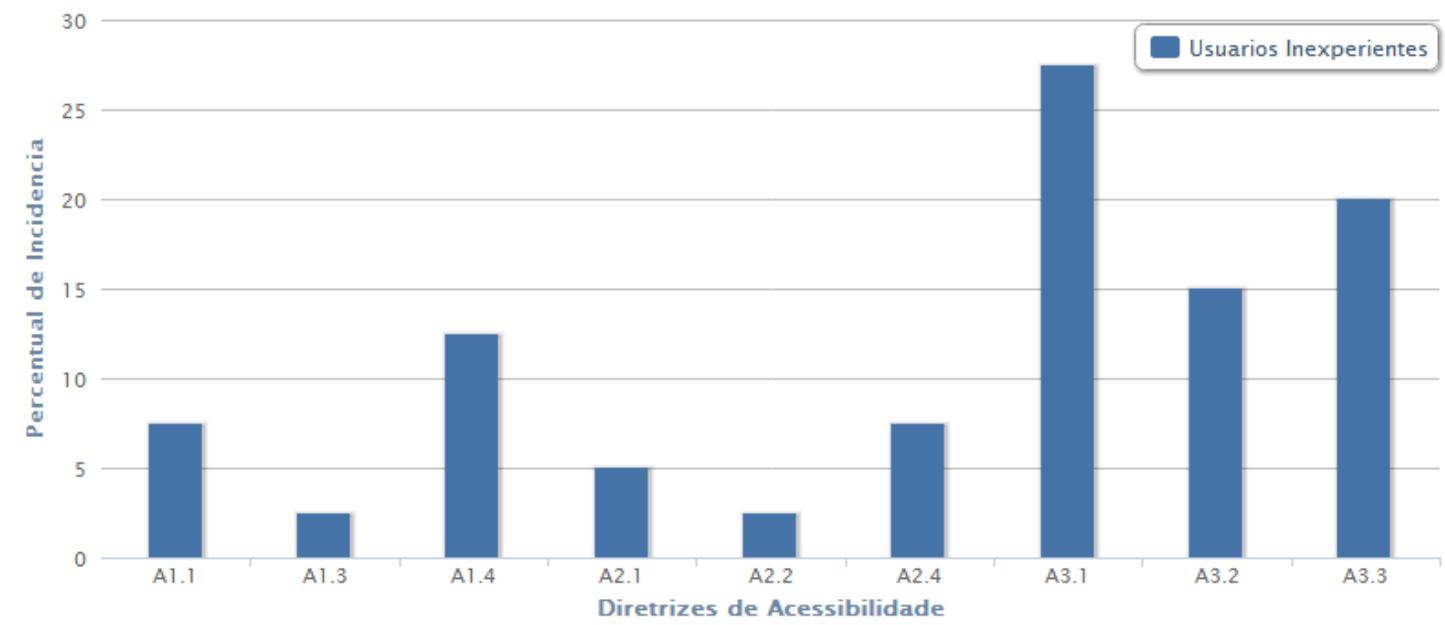

Figura 5.2: Percentual de Incidência das Diretrizes de Acessibilidade entre Usuários Inexperientes

navegabilidade, em que se deve disponibilizar meios que auxiliem a busca por conteúdo e localização.

O princípio de usabilidade que trata da compatibilidade do sistema com o mundo real (U2), que também foi um dos princípios de maior incidência nos problemas apresentadados pelos usuários não experientes, pode ser associado à diretriz de legibilidade e compreensibilidade (A3.1).

O princípio de usabilidade mais recorrente dentre os problemas apresentados por esse grupo de usuários foi o princípio que trata do "reconhecimento de objetos e operações" (U6), evidenciando que os problemas relacionados à memória e sobrecarga cognitiva são os que mais afetam esse grupo de usuários.

Portanto, nesta tese, foi priorizado um dos problemas mais identificados durante a observação em campo: legibilidade e compreensibilidade do conteúdo (A3) (Figura 
5.2). O levantamento foi realizado no início desta pequisa (segundo semestre de 2007), porém havia indícios de que problemas relacionados às diretrizes de acessibilidade A1 e A2 também deveriam ser mais investigados.

\subsection{Questionário para adultos com experiência (Survey)}

Além da observação dos usuários menos experientes, em cursos que envolviam interações com a Web, mencionados na seção anterior, se fez necessário saber mais a respeito do perfil e das dificuldades apresentadas também pelos adultos mais velhos que já possuíam experiência no uso da Web. Para tanto, foi elaborado um questionário (survey) (Apêndice A) que foi enviado para pessoas diversas, procurando atingir usuários da Web com mais de 40 anos de idade. A elaboração desse questionário foi concluída em 15 dias e coincidiu com a escrita da monografia de qualificação, no final do primeiro semestre de 2008.

O questionário (Apêndice A) para a coleta de dados continha 18 questões, além das informações do perfil, e abordava os seguintes aspectos:

(a) informações pessoais: idade, sexo, estado civil, nível de escolaridade, profissão;

(b) uso da Web: tempo de experiência, frequência de uso, motivo do não uso, sentimentos e ações durante o uso, navegadores utilizados;

(c) sites mais utilizados: busca, e-mail, redes sociais, bancos, compras, etc;

(d) quais principais dificuldades encontradas na navegação e na realização de alguma operação específica;

(e) sugestões de melhorias para a interação com a Web;

(f) percepção sobre comprometimentos relacionados à memória: memorização de senhas, uso de medicamentos, entre outros.

Como nesta tese foi adotada a modalidade de pesquisa descritiva, o procedimento de Survey foi realizado visando obter dados detalhados das práticas, opiniões e eventuais anseios dos usuários mais experientes.

\subsubsection{Coleta de Dados}

Embora tenha sido realizado o controle sobre quantas pessoas receberam o convite para responder ao questionário, apenas o número de usuários que enviaram as respostas e que satisfaziam as condições de idade e experiência com a Web foi 
contabilizado. O questionário foi enviado, via e-mail, para diversos grupos de indivíduos no período entre julho e agosto de 2008. No total, foram recebidos 47 questionários respondidos, dos quais 34 satisfaziam o critério de idade igual ou superior a 40 anos $(72 \%)$.

Dentre as respostas válidas, apenas uma pessoa possuía nível de escolaridade médio e as demais, todas possuíam nível superior, especialização, mestrado ou doutorado. A idade média dos usuários considerados foi de 47,3 anos de idade. A participação das mulheres totalizou $59 \%$ dos questionários respondidos contra $41 \%$ dos homens. As pessoas que responderam ao questionário são profissionais de diversas àreas: professores do ensino superior, analistas técnicos, analistas de informática, secretárias, arquitetos, advogados, engenheiros, entre outros. O tempo de experiência dos usuários na utilização da Web foi bastante elevado: $91 \%$ dos respondentes disseram que a utilizavam há mais de 10 anos, e 97\% deles, a utilizam pelo menos uma vez por dia.

Para cada dificuldade mencionada ou sugestão dada, foi realizada a correspondência com os princípios de usabilidade e diretrizes de acessibilidade da WCAG 2.0 (W3C, 2008b) já apresentadas no Capítulo 2.

\subsubsection{Resultados}

Quanto às dificuldades com operações específicas como compras, pagamento de contas, dentre outras, as dificuldades citadas são mostradas a seguir, juntamente com a análise de princípio de usabilidade e diretriz de acessibilidade com que se relacionam. As principais dificuldades relatadas foram:

- necessidade de ter em mãos todas as informações que são solicitadas durante o preenchimento de formulários (U10 - A3.2, A3.3);

- problemas ao digitar os números do código de barras para o pagamento de contas (U5 - A3.3);

- problemas ao realizar pagamentos com cartão de crédito (U10 - A3.1, A3.3);

- problemas para encontrar a opção adequada dentre as possibilidades oferecidas pelos sites de busca (U6 - A3.1, A2.4);

- problemas ao preencher campos de entrada onde não há avisos sobre a formatação, como tirar os espaços ou não colocar hífens (U10 - A3.3);

- problemas para saber a sequência correta de passos ou procedimentos que devem ser executados para concluir uma operação (U6, U10 - A3.2, A3.3).

Com relação à interação e navegação na Web, os itens mais citados foram: 
- problemas para localizar a informação desejada (U8 - A2.4, A3.1);

- sites com estrutura lógica sem sentido e sem uma metáfora adequada para as tarefas (U2,U6 - A2.4, A3.1);

- excesso de informações e de links (U4,U8 - A2.4, A3.1);

- problemas para visualizar os botões que realizam funções importantes e que são apresentados sem destaque (U4,U8 - A1.4);

- problemas para visualizar informações em sites cujas cores, de fundo e letras, são muito parecidas (U8,U4 - A1.4, A3.1);

- não poder configurar o tamanho e a fonte das letras (U8,U4 - A1.3);

- não saber para onde vai o link (U10 - A3.1, A3.2);

- demora no carregamento de páginas, gerando insegurança (U1 - A3.1);

- necessidade de fechar todas as janelas pop-ups e propagandas (U8 - A1.2).

Foram solicitadas sugestões, de qualquer tipo, sobre o que poderia ser modificado nos sites para que as experiências na utilização da Web fossem melhores. As principais contribuições dadas foram:

- ter um visual mais limpo (U8 - A1.4, A3.1);

- ter os resultados de uma pesquisa organizados de forma mais adequada para a apresentação (U6,U8 - A2.4);

- ter páginas enxutas com cores agradáveis e contrastantes (U4,U8 - A2.4, 3.1);

- eliminar as janelas pop-ups (U7 - A1.2);

- visualizar os botões de funções importantes com destaque (U4,U8 - A1.4, A3.1);

- ver claramente as informações da situação do navegador (U1 - A1.1, A3.1);

- ter ajuda em formatação em campos de entrada (U10 - A3.3);

- receber indicações para a navegação quando os resultados de uma pesquisa, por exemplo, não forem muito específicos, ou seja, receber caminhos alternativos de forma a obter a informação desejada (U10 - A2.4);

- fornecer ajuda mais detalhada para iniciantes (U10 - A1.4, A2.2, A3.1, A3.3).

Para os indivíduos mais experientes, que responderam ao questionário, os princípios de usabilidade mais recorrentes que foram observados são mostrados na Figura 5.3, que foram U8 (Estética e design minimalista) e U10 (Help e documentação).

Realizando um comparativo entre os princípios de usabilidade mais recorrentes entre os usuários inexperientes (Seção 5.1) e os usuários experientes com a Web, pode-se 


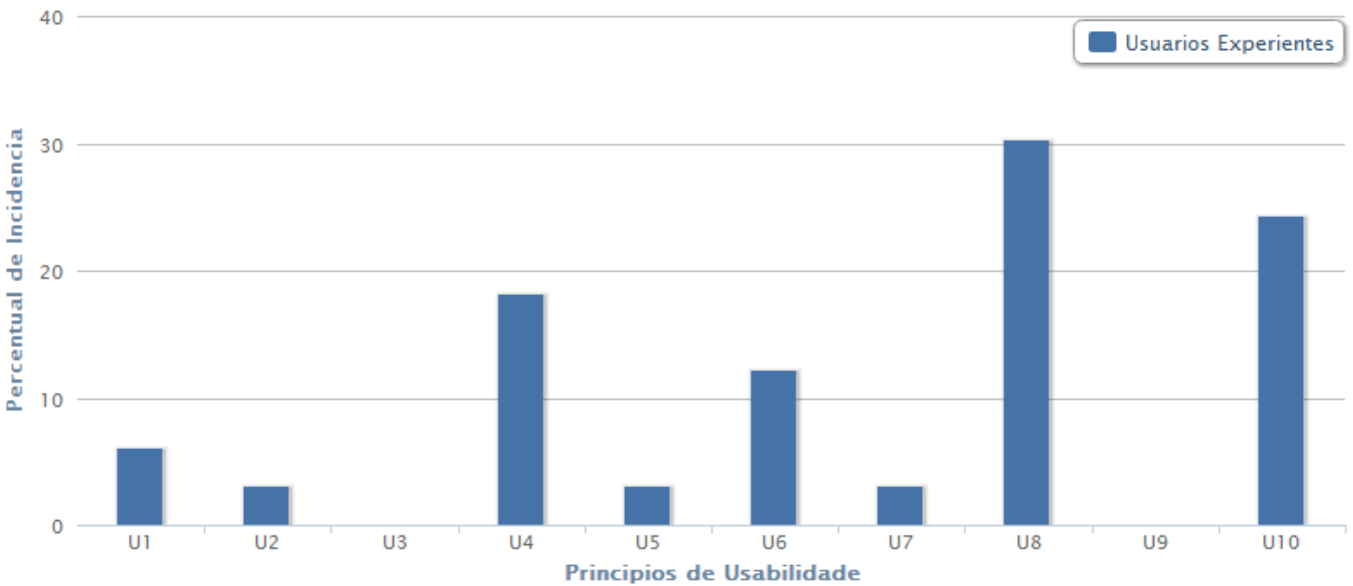

Figura 5.3: Percentual de Incidência dos Princípios de Usabilidade entre Usuários Experientes

observar que os resultados que mais se aproximam são quanto ao princípio de usabilidade U1 (visibilidade do status do sistema), sendo que nos demais princípios a diferença é bastante significativa, conforme observado na Figura 5.4. Observa-se ainda que os princípios que tiveram mais problemas incidentes foram o U6 (para os inexperientes) e U8 (para os experientes) no total das respostas de ambos os grupos.

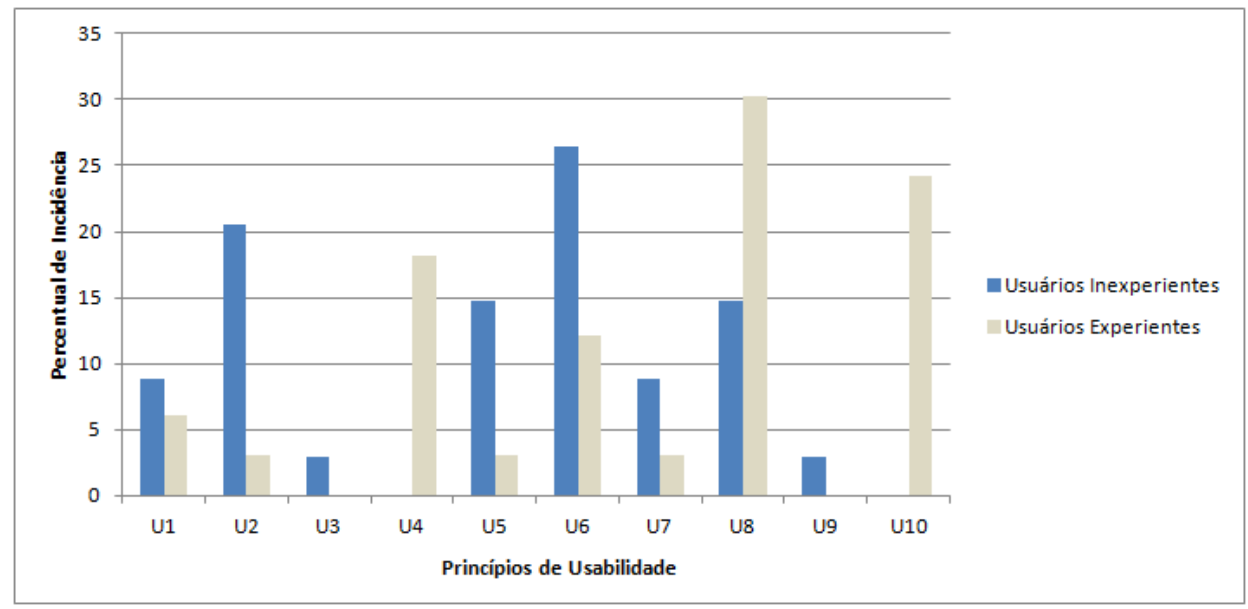

Figura 5.4: Comparativo do Percentual de Incidência dos Princípios de Usabilidade entre Usuários Inexperientes e Experientes

Quanto às diretrizes de acessibilidade observadas, as mais recorrentes podem ser verificadas na Figura 5.5.

Ao realizar um comparativo entre as diretrizes de acessibilidade mais recorrentes entre os usuários inexperientes e os usuários experientes (Figura 5.6), pode-se observar que os resultados mostram-se muito próximos para as diretrizes A1.3 (conteúdo adaptável), A1.4 (conteúdo distinguível), A2.2 (tempo suficiente). As dificuldades dos usuários experientes que prevalecem sobre a dos usuários inexperientes estão associadas às diretrizes A2.4 (navegabilidade) e A3.1 (legibilidade e compreensibi- 


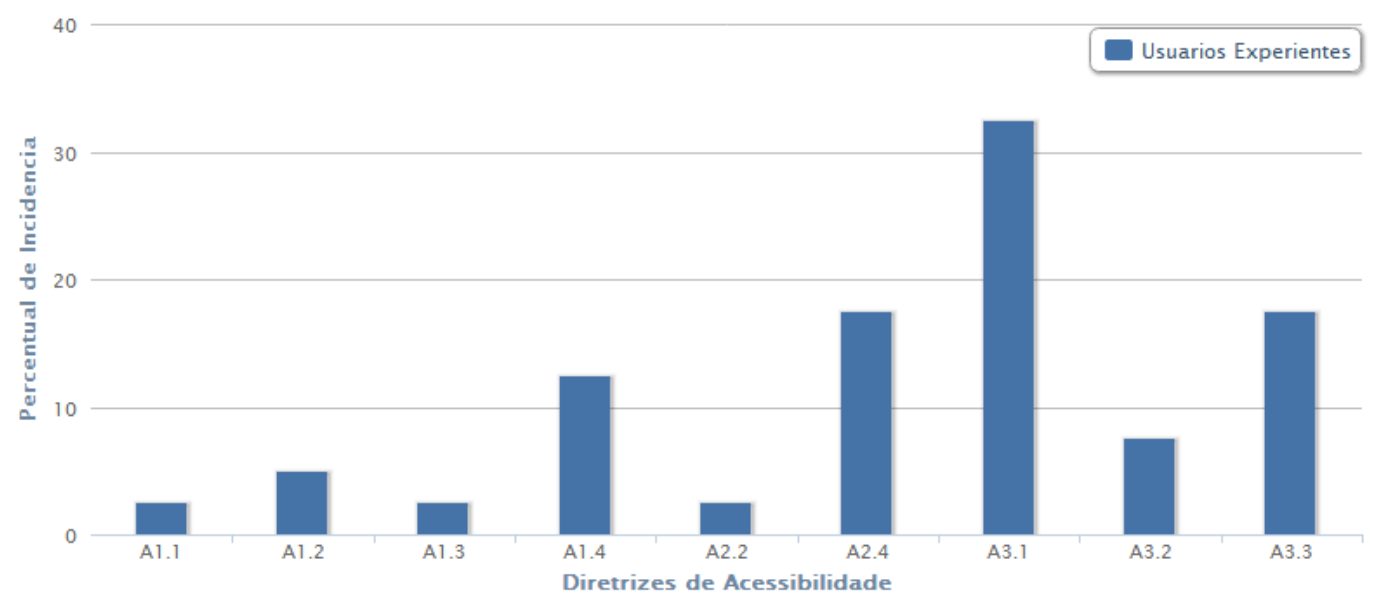

Figura 5.5: Percentual de Incidência das Diretrizes de Acessibilidade entre Usuários Experientes

lidade). Essas dificuldades motivaram uma investigação mais detalhada a respeito da navegabilidade, que foi tratada nesta tese com os testes sobre uso de menus horizontais (Seção 5.6), bem como das questões de legibilidade e compreensibilidade, as quais foram tratadas nesta tese com a proposta de mecanismos de apoio para usabilidade e acessibilidade na interação de adultos mais velhos na Web (Seções 6.3 e 6.4$)$.

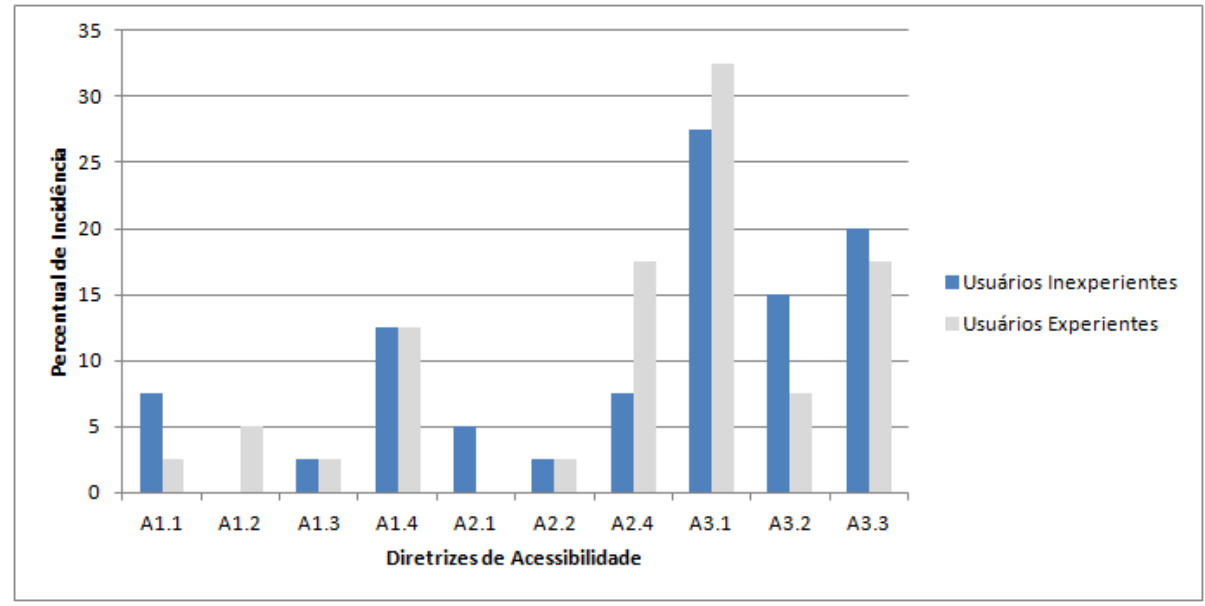

Figura 5.6: Comparativo do Percentual de Incidência das Diretrizes de Acessibilidade entre Usuários Inexperientes e Experientes

O questionário verificou também outros aspectos, como: os navegadores Web mais utilizados, a frequência de desorientação, solicitação de auxílio, compreensão de mensagens de erro e esquecimento de senhas. Foram elencados os sites mais utilizados para e-mail, compras, informação, sites governamentais, educação, lazer, entre outros. A contagem de incidências apresentada para os elementos a seguir não representa uma única opção por pessoa, mas sim, quantas vezes o elemento foi citado entre os respondentes. 
Dentre os navegadores, foram citados apenas o Internet Explorer (20 citações de uso) e o Mozilla Firefox (15 citações de uso), havendo indivíduos que citaram ambos.

Os respondentes foram questionados se sentiam medo ou insegurança ao utilizarem a Web, e dos 34 respondentes, 7 deles responderam positivamente (20,6\%), sendo que os principais comentários acerca dos motivos foram:

- "tenho medo em lidar com dados sigilosos";

- "tenho medo de pegar vírus no meu computador";

- "insegurança em fornecer informações de cartões de crédito, senhas de banco";

- "não confio no sistema de segurança de bancos";

- "não confio em conexões wireless... porque sei dos perigos";

- "nunca sei ao certo se meu procedimento trará algum prejuízo para meu computador, por exemplo";

- "não acho confiável efetuar pagamentos via Internet".

Outras questões investigadas foram: a frequência de desorientação durante a navegação, a necessidade de solicitação de ajuda de outras pessoas, a dificuldade na compreensão de mensagens de erro e o esquecimento de senhas. Os totais computados são apresentados na Tabela 5.1. Observa-se que a dificuldade na compreensão de mensagens de erros foi o problema que mais se apresentou como barreira para os respondentes.

Tabela 5.1: Totais de incidências por característica

\begin{tabular}{|l|l|l|l|l|}
\hline Característica & Sempre & $\grave{\text { As vezes }}$ & Raramente & Nunca \\
\hline Desorientação & 1 & 5 & 18 & 10 \\
\hline Solicitação de ajuda & 0 & 9 & 18 & 7 \\
\hline Compreensão de mensagens de erro & 9 & 20 & 5 & 0 \\
\hline Esquecimento de senhas & 5 & 9 & 14 & 6 \\
\hline
\end{tabular}

Os mecanismos utilizados mais citados para evitar o esquecimento de senhas foram: memória, anotação, utilização da mesma senha em vários sites, códigos mneumônicos e regras de associação.

$\mathrm{Na}$ análise do aspecto que buscava identificar quais os tipos de sites mais utilizados com sua respectiva ordem de frequência, optou-se por descartar a ordem de frequência, pois a grande maioria dos respondentes não conseguiu compreender que além de especificar os sites que eles utilizavam, eles deveriam também classificá-los de acordo com sua frequência de uso. Os sites mais citados, dentro de sua respectiva categoria, revelaram que a ferramenta de busca Google foi a mais mencionada, seguida de jornais de notícias como Folha de São Paulo e O Estadão. Para comunicação, as ferramentas Skype e MSN foram as mais mencionadas. 
Os respondentes foram questionados a respeito das principais dificuldades enfrentadas durante a navegação ou a realização de uma tarefa específica, e os comentários foram classificados nas seguintes categorias:

\section{- Relacionados a conexão:}

- "conexão instável, demora nas buscas";

- "em alguns sites a consulta é muito lenta";

- "lentidão de alguns sites e dificuldade na obtenção da informação desejada";

- "rede wireless não confiável".

\section{- Relacionados a confiança:}

- "não confio na maioria dos sites de pagamento de compras, não confio em repassar informações sigilosas";

- "no envio de e-mail: saber se o destinatário efetivamente recebeu a mensagem".

\section{- Relacionados aos campos de entrada:}

- "dificuldade em relação a pagamento com cartão";

- "no pagamento de contas: digitar os números de código de barra, uma vez que a maioria dos micros não têm leitura ótica";

- "ter em mãos as informações que solicitam".

\section{- Relacionados a apresentação do conteúdo:}

- "acho que deveriam diminuir aquelas propagandas que costumam aparecer quando estamos vendo alguma notícia (temos que ficar fechando a todo momento a propaganda para podermos continuar a ler as notícias)";

- "o excesso de informações e links me desestimula e estressa";

- "me atrapalho com sites cujas cores são muito parecidas (fundo e letras) são muito cansativos";

- "algumas páginas exibem texto com tamanho de fonte muito pequeno";

- "algumas vezes os botões de funções importantes (enviar, cancelar, pesquisar, etc) não são exibidos em destaque".

\section{- Relacionados a localização da informação:}

- "encontrar a opção adequada nas possibilidades apresentadas pelos sites";

- "site com estrutura lógica sem sentido, sem uma metáfora adequada a tarefa";

- "localizar exatamente o que eu desejo"; 
- "saber que existe a informação mas não encontrar o caminho. Quando tem disponível, a saída é utilizar o mapa do site";

- "às vezes em encontrar determinada informação";

- "localizar o que quero num site de busca: eles retornam muitas informações";

- "muitas vezes encontra-se muito lixo quando utilizo buscadores como o Google";

- "a navegação no site. Depende do site. Alguns são confusos e não se encontra o que quer";

- "as maiores falhas, são de segurança e dificuldade em encontrar o que se está procurando (indicações de navegação com falhas)".

\section{- Relacionados a implementação do site:}

- "bugs nas páginas";

- "sites que nao funcionam direito (no firefox) ou sites mal feitos de modo geral.

As impressões registradas apontaram que os maiores problemas estão relacionados à apresentação do conteúdo e à localização da informação. Dessa forma é reforçada a necessidade de apoio para os adultos mais velhos e experientes, que tratem das questões de legibilidade e compreensibilidade (A3.1).

Dentre as poucas sugestões de melhorias fornecidas, os principais comentários foram:

- "Acho que precisa melhorar programas de tradução on-line para que se possa ter acesso a sites em russo, árabe, chinês, japonês, etc";

- "menos senhas nos sites de bancos";

- "ter um visual mais limpo a fim de facilitar a navegação e principalmente encontrar os links desejados. Têm muitos sites que carregam demais a página principal com muita informação";

- "páginas enxutas e com cores agradáveis e contrastantes - tirar pop-ups que fazem perder a paciência";

- "as buscas dentro do site poderiam ser melhoradas";

- "opção para reportar erros para webmaster de forma padronizada e de fácil acesso";

- "fora spam, fora pop-up";

- "há um excesso de páginas sobre um mesmo assunto, muitas vezes repetidos, dificultando a pesquisa"; 
- "evitar a propaganda indesejada e popups".

Apenas três pessoas comentaram a respeito de problemas que afetam a sua coordenação motora ou a sua memória, e os comentários foram:

- "Perda branda da lembrança de certas palavras causada por profundo estresse diário";

- "Passei dos 40";

- "Memória, devido à idade e ao excesso de informações com que somos obrigados a lidar".

A partir dos indicativos obtidos com esse estudo foi possível observar que as principais dificuldades dos adultos mais velhos, mesmo com sua experiência, se concentram na localização da informação desejada, esteja ela inserida no conteúdo de uma página Web ou no resultado de uma busca específica. No caso específico das buscas, resta uma dúvida: o problema está em localizar a informação desejada em uma lista de resultados obtida a partir de uma busca realizada de forma correta (utilizando os mecanismos e sintaxes corretas do buscador em questão) ou a dificuldade surge porque a busca não foi executada corretamente devido ao desconhecimento do usuário em como realizar o procedimento?

No primeiro caso, a dificuldade poderia surgir devido ao visual poluído e ao excesso de informações apresentado na tela, aumentando assim a sobrecarga cognitiva do usuário que teria que filtrar quais informações realmente interessam. No segundo caso, o usuário poderia sentir-se desorientado devido ao fato de que as opções dos resultados apresentados não correspondem ao que ele imaginava receber como resultado, devido à utilização incorreta do mecanismo de busca.

O problema evidenciado no segundo caso, serviu de motivação para a proposta do mecanismo de auxílio ao preenchimento do campo de busca (ver Seção 6.4.1).

\subsection{Entrevistas com Deficientes Visuais}

Na fase inicial dos trabalhos, a pesquisadora buscou também conhecer as necessidades dos deficientes visuais em seus acessos à Web. No final de 2008, foi realizada uma visita a Associação Mulher Unimed (AMU), que desenvolve um trabalho de responsabilidade social junto à Unimed na cidade de São Carlos, local onde os deficientes visuais se reúnem para estudos de Braille, Internet, entre outros. 
Na sede da associação havia um computador onde estavam disponíveis os softwares de tecnologia assistiva, Jaws ${ }^{3}$ e Virtual Vision ${ }^{4}$, para o auxílio a navegação na Internet. Ambos permitem ao usuário trabalhar com o sistema operacional Windows e com seus aplicativos, por meio da leitura dos menus e telas desses programas por um sintetizador de voz. O Jaws, apesar de ser um produto americano, é capaz de sintetizar o texto apresentado na tela em nove idiomas, inclusive no português do Brasil. É o leitor de tela mais caro do mercado, mas também um dos mais utilizados pelas pessoas com deficiência visual fora do Brasil (SENAI, 2012).

Foi realizada uma entrevista com os deficientes visuais que se encontravam presentes no local, que durou aproximadamente 2 horas, com o intuito de verificar quais suas principais dificuldades. Havia 3 indivíduos com deficiência visual total e 2 com baixa visão (R2 e R3). O perfil dos entrevistados pode ser visualizado na Tabela 5.2.

Tabela 5.2: Perfis dos Deficientes Visuais

\begin{tabular}{|l|l|l|l|l|}
\hline ID & Data de Nascimento & Sexo & Ocupação & Escolaridade \\
\hline R1 & $07 / 02 / 1984$ & $\mathrm{~F}$ & Estudante & ensino superior completo \\
\hline R2 & $15 / 09 / 1990$ & $\mathrm{M}$ & Estudante & ensino médio completo \\
\hline R3 & $26 / 07 / 1968$ & $\mathrm{M}$ & Estudante & mestrado \\
\hline R4 & $09 / 02 / 1988$ & $\mathrm{M}$ & Estudante & ensino médio completo \\
\hline R5 & $18 / 02 / 1954$ & $\mathrm{~F}$ & $\begin{array}{l}\text { Professora } \\
\text { Aposentada }\end{array}$ & ensino superior completo \\
\hline
\end{tabular}

No que se refere à experiência de uso da Internet, frequência de uso e finalidades, os dados coletados podem ser visualizados na Tabela 5.3.

Tabela 5.3: Experiência, frequência e finalidades de uso da Internet pelos deficientes visuais

\begin{tabular}{|l|l|l|l|}
\hline ID & Experiência & Frequência & Finalidades \\
\hline R1 & mais que 10 anos & pelo menos 1 vez por dia & estudo, entretenimento e outras \\
\hline R2 & entre 5 e 10 anos & pelo menos 1 vez por dia & $\begin{array}{l}\text { estudo, comunicação com outras } \\
\text { pessoas e entretenimento }\end{array}$ \\
\hline R3 & entre 5 e 10 anos & pelo menos 1 vez por dia & trabalho, estudo, compras e outras \\
\hline R4 & mais que 10 anos & pelo menos 1 vez por dia & estudo, entretenimento e outras \\
\hline R5 & iniciante & não utilizo a Internet & $\begin{array}{l}\text { comunicação com outras pessoas e } \\
\text { entretenimento }\end{array}$ \\
\hline
\end{tabular}

Quando os deficientes foram indagados sobre quais tipos de tecnologia assistiva que utilizavam em seu dia-a-dia, as respostas foram:

- R1: Virtual Vision, relógios e calculadoras sonoras;

- R2: Sistema de voz e lupa (ampliação de letras);

- R3: Lente de aumento e leitor de tela Virtual Vision;

\footnotetext{
${ }^{3}$ http://en.wikipedia.org/wiki/JAWS_(screen_reader)

${ }^{4}$ http://www.virtualvision.com.br/index.html
} 
- R4: Software de acessibilidade Virtual Vision, relógio sonoro e calculadoras sonoras;

- R5: Relógio sonoro, programas Virtual Vision e Dos-Vox, quando acessado por acompanhante no treinamento que estou realizando.

Quando foram questionados se o apoio recebido pela tecnologia assistiva (TA) era suficiente para compreender, navegar e realizar atividades como compras e serviços de banco pela Web, as respostas foram:

- R1: Os problemas não estão nas TAs, mas sim nas páginas da Internet;

- R2: Eu acho que não, acho que deveria ser criado algo novo que ajudasse as necessidades de quem precisa;

- R3: Sim;

- R4: Os problemas estão nas páginas da Internet que não são construídas sobre o padrão de acessibilidade e não nas TAs;

- R5: Não.

Quando lhes foi solicitada alguma sugestão de mecanismo de auxílio para apoiar as suas interações na Internet, seja para enviar mensagens, fazer compras, utilizar bancos on-line ou qualquer outro tipo de atividade na Web, as sugestões dadas foram:

- R1: Nenhuma;

- R2: Nenhuma;

- R3: Todas as imagens deveriam ter audio-descrição;

- R4: Nenhuma;

- R5: Não fazia ideia.

Finalmente, o último questionamento foi em termos de conteúdos e serviços disponibilizados na Internet, o que eles achavam que poderia ser melhorado:

- R1: Seguir as normas de acessibilidade;

- R2: Nada;

- R3: As páginas da Internet deveriam ser construídas com base no desenho universal;

- R4: Seguir as normas de acessibilidade;

- R5: Não respondeu. 
Pelas dificuldades relatadas pôde-se observar que o principal problema ainda está relacionado mais à construção de páginas Web do que com o uso da tecnologia assistiva, que nesses casos, ficaram restritas aos leitores de tela para os deficientes visuais. Essa entrevista foi relevante porque ressaltou a importância da responsabilidade dos profissionais de desenvolvimento no atendimento aos padrões e diretrizes de desenvolvimento Web, visto que os adultos mais velhos, em especial os idosos, também necessitam utilizar-se de tecnologias assistivas para realizar interação na Web.

\subsection{Reconhecimento de Elementos}

Para propor mecanismos de apoio à interação dos adultos mais velhos com a Web sentiu-se a necessidade de investigar a familiaridade desse público com os elementos de interface normalmente encontrados em páginas e ferramentas da Web. Para realizar tal verificação, foi desenvolvido um questionário on-line, que abordou desde os conceitos mais simples, como URL, imagens, menus e links, como também elementos de ferramentas de e-mail e chat, por se tratarem de ferramentas comumente utilizadas pelo público-alvo durante as observações de campo e questionários já mencionados anteriormente (Seções 5.1 e 5.2).

O questionário (Apêndice B), elaborado e implementado pela pesquisadora durante o primeiro semestre de 2009, foi colocado no ar em julho do mesmo ano. Vale observar que a coleta de dados não presencial está sujeita a algumas limitações, tais como: não se ter certeza se a pessoa que está respondendo corresponde exatamente ao perfil registrado, ausência de esclarecimentos de dúvidas sobre o questionário, entre outras.

\subsubsection{Coleta de Dados}

O pedido de colaboração na pesquisa foi realizado por meio de mensagens de e-mail para pessoas diversas, cujo requisito considerado foi a idade superior a 40 anos. $\mathrm{O}$ questionário ficou disponível no período de julho a outubro de 2009. Devido ao fato de ser uma aplicação on-line na Web e da propagação, algumas vezes, indiscriminada do pedido de colaboração via e-mail, este questionário foi respondido por pessoas com idade entre 18 e 67 anos, apesar de ter como público-alvo principalmente pessoas com idade acima dos 40 anos, totalizando 118 respondentes, sendo que destes, 59 possuíam idade entre 40 e 67 anos (50\%) (Tabela 5.4). 
Tabela 5.4: Quantidade de respondentes por faixa etária

\begin{tabular}{|l|l|}
\hline Faixa Etária & Quantidade \\
\hline jovens & 59 \\
\hline adultos de meia-idade & 56 \\
\hline idosos (acima de 60 anos) & 3 \\
\hline
\end{tabular}

Para que fosse possível traçar o perfil das pessoas que colaboraram respondendo às questões propostas foram coletadas as seguintes informações: e-mail, idade, ocupação, escolaridade, experiência no uso da Web e sua frequência de uso.

Analisando o perfil dos respondentes cadastrados foi observado que dos 59 participantes considerados, mais de $80 \%$ deles tinham pelo menos o nível superior completo de escolaridade, como é mostrado na Tabela 5.5.

Tabela 5.5: Escolaridade dos Respondentes das Faixas Etárias de Meia-idade e Idosos

\begin{tabular}{|l|l|l|}
\hline Escolaridade & Quantidade & Percentual \\
\hline Não especificada & 3 & $5 \%$ \\
\hline Ensino médio incompleto & 1 & $1,7 \%$ \\
\hline Ensino médio completo & 4 & $6,7 \%$ \\
\hline Ensino superior incompleto & 2 & $3,4 \%$ \\
\hline Ensino superior completo & 20 & $34 \%$ \\
\hline Especialização & 4 & $6,7 \%$ \\
\hline Mestrado & 5 & $8,5 \%$ \\
\hline Doutorado & 20 & $34 \%$ \\
\hline
\end{tabular}

Quanto à experiência do grupo de adultos mais velhos na utilização da Web, pela distribuição que pode ser verificada na Tabela 5.6, pode-se dizer que pelo menos $84 \%$ dos respondentes possuíam mais de 5 anos de experiência de uso, resultado obtido somando-se as duas últimas linhas da Tabela 5.6.

Tabela 5.6: Experiência no Uso dos Respondentes das Faixas Etárias de Meia-idade e Idosos

\begin{tabular}{|l|l|l|}
\hline Experiência de Uso & Quantidade & Percentual \\
\hline Não especificada & 2 & $3,4 \%$ \\
\hline Menos de 6 meses & 1 & $1,7 \%$ \\
\hline Entre 6 meses e 1 ano & 1 & $1,7 \%$ \\
\hline Entre 1 e 5 anos & 5 & $8,5 \%$ \\
\hline Entre 5 e 10 anos & 11 & $18,7 \%$ \\
\hline Mais que 10 anos & 39 & $66 \%$ \\
\hline
\end{tabular}

A frequência de uso indicada pela grande maioria, cerca de 86,5\% dos participantes (Tabela 5.7), é de que utilizam a Web pelo menos uma vez por dia, o que juntamente com a experiência informada deveriam indicar um bom nível de experiência na interação desse público-alvo com a Web.

Ao contrário do esperado, das 59 pessoas que constituíram o conjunto relativo ao adultos mais velhos, 3 delas não responderam a nenhuma das questões propostas, 
Tabela 5.7: Frequência de Uso dos Respondentes das Faixas Etárias de Meia-idade e Idosos

\begin{tabular}{|l|l|l|}
\hline Frequência de Uso & Quantidade & Percentual \\
\hline Não especificada & 5 & $8,5 \%$ \\
\hline Pelo menos 1 vez por dia & 51 & $86,5 \%$ \\
\hline Pelo menos 1 vez por semana & 3 & $5 \%$ \\
\hline
\end{tabular}

e dos 56 restantes nem todos chegaram ao final do questionário, de modo que o número total de respondentes válidos varia de questão para questão. Na subseção a seguir são apresentados os resultados considerando apenas os respondentes com idade igual ou maior que 40 anos e posteriormente uma comparação com o público jovem.

O questionário disponibilizado continha 20 questões que abordavam conhecimentos relativos a URL, abas, menus, imagens, links, características de ferramentas de e-mail e chat, dentre outras. O questionário completo pode ser visualizado no Apêndice B.

Todos os dados do perfil dos usuários e das respostas do questionário foram armazenados em base de dados e a confidencialidade para sua utilização nesta pesquisa foi expresso na primeira página on-line apresentada ao respondente, na qual era informado que todas as respostas fornecidas seriam confidenciais e somente utilizadas para os fins desta pesquisa, de modo que os pesquisadores responsáveis asseguravam que as mesmas não seriam utilizadas para nenhum outro fim.

\subsubsection{Resultados}

Inicialmente foram analisados os dados dos respondentes que satisfaziam o critério da idade ser maior ou igual a 40 anos. Como já mencionado anteriormente, alguns respondentes não chegaram a concluir o questionário, de modo que o número de respostas válidas varia entre as questões, conforme pode ser observado na Tabela 5.8 .

Considerando que a taxa de $20 \%$ ou mais de erros representa uma taxa significativa, as questões que mais apresentaram erros foram: 1, 2, 4, 5, 7, 11, 14 e 18. A seguir, considerações sobre essas questões com maior índice de erros são discutidas.

A Questão 1 abordava o conhecimento do respondente sobre a entrada de dados para URL e se apresentou conforme a Figura 5.7.

Nesta Questão 1, cuja resposta esperada era "o endereço da Web que localiza um site", a proporção de respostas erradas pode ser observada na Tabela 5.9. Com relação a essa questão, vale observar que durante as pesquisas e acompanhamentos em campo foi muito comum constatar a confusão entre o campo para a entrada 
Tabela 5.8: Quantidade e percentual de respostas erradas por questão

\begin{tabular}{|l|l|l|l|l|}
\hline Questão & $\begin{array}{l}\text { Quantidade } \\
\text { de } \\
\text { Respondentes } \\
\text { Válidos }\end{array}$ & $\begin{array}{l}\text { Quantidade } \\
\text { de Respostas } \\
\text { Erradas }\end{array}$ & Percentual & Elemento Web \\
\hline 1 & 56 & 14 & $25 \%$ & URL \\
\hline 2 & 54 & 19 & $35 \%$ & Menus \\
\hline 3 & 54 & 8 & $15 \%$ & Abas \\
\hline 4 & 52 & 15 & $29 \%$ & Links \\
\hline 5 & 52 & 25 & $48 \%$ & Links Visitados \\
\hline 6 & 52 & 7 & $13 \%$ & Busca Interna \\
\hline 7 & 52 & 10 & $20 \%$ & Link Textual \\
\hline 8 & 52 & 9 & $17 \%$ & Imagem \\
\hline 9 & 51 & 5 & $10 \%$ & Icone \\
\hline 10 & 51 & 4 & $8 \%$ & Lista \\
\hline 11 & 50 & 15 & $30 \%$ & Alteração do Tamanho da Fonte \\
\hline 12 & 50 & 8 & $16 \%$ & E-mail - Download \\
\hline 13 & 50 & 6 & $12 \%$ & E-mail - Menu \\
\hline 14 & 50 & 10 & $20 \%$ & E-mail - Remetente \\
\hline 15 & 50 & 9 & $18 \%$ & E-mail - Encaminhamento de \\
& & 7 & $14 \%$ & Eensagem \\
\hline 16 & 50 & 2 & $4 \%$ & E-mail - Acesso à leitura \\
\hline 17 & 50 & 11 & $22 \%$ & Chat - Ações \\
\hline 18 & 50 & 6 & $12 \%$ & Chat - Emoticon \\
\hline 19 & 50 & 1 & $2 \%$ & Formatação de Texto \\
\hline 20 & 50 & & & \\
\hline & & & & \\
\hline
\end{tabular}

de URLs e campos de busca para a digitação de palavras-chave. Grande parte dos adultos mais velhos sentiam-se inseguros sobre onde digitar o endereço ou a palavra-chave para obter o resultado desejado; tal fato se deve à não existência de correspondência com conceitos do mundo real. Dessa forma, o princípio de usabilidade que trata da compatibilidade do sistema com o mundo real (U2) não foi atendido, fato que também pode ser associado ao não atendimento da diretriz de legibilidade e compreensibilidade (A3.1). Vale observar que, em navegadores como Chrome e Firefox já é possível digitar palavras-chaves nessa caixa de texto de URLs,

Questão 1: 0 que deve ser digitado nessa caixa de texto?
W. http://pt.wikipedia.orgi'wikijPágina_principal
b. O nome de um site
c. Seu nome
d. Sua senha
e. Nenhum dos anteriores
f. Não sei

Figura 5.7: Enunciado e alternativas da Questão 1 
como um recurso mais recente que disponibiliza esse espaço no navegador, atuando como uma caixa de texto para busca.

Tabela 5.9: Respostas erradas para a Questão 1

\begin{tabular}{|l|l|l|}
\hline Alternativa & Quantidade & Percentual \\
\hline Nome do site & 5 & $35,7 \%$ \\
\hline Seu nome & 2 & $14,3 \%$ \\
\hline Sua senha & 0 & $0 \%$ \\
\hline Nenhum dos anteriores & 4 & $28,6 \%$ \\
\hline Não sei & 3 & $21,4 \%$ \\
\hline
\end{tabular}

Na Questão 2, cujo objetivo era o reconhecimento de um menu de opções, ficou evidenciado um outro problema que também já havia sido observado em campo, que é a dificuldade que os adultos mais velhos apresentam em reconhecer a existência de um menu na página Web. Por considerar essa dificuldade muito relevante, bem como a dificuldade em operar menus, foi conduzido outro estudo específico sobre menus, detalhado mais adiante, na Seção 5.6.

As Questões 4, 5 e 7, que tratam do reconhecimento de links (visitados, não visitados e link textual), também apresentaram uma quantidade significativa de erros em relação às demais questões. Na Questão 4, os links ativos foram confundidos com passos de tarefas e índices. Na Questão 5 foi constatada a dificuldade de diferenciação entre links visitados e não visitados. Na Questão 7, os usuários não reconhecem um link textual como um símbolo passível de navegação. Essa dificuldade pode ser considerada como um problema de reconhecimento de detalhes técnicos, ou mesmo de dificuldade na precisão e observação do detalhe, que possui semântica distinta.

Na Questão 11 foi verificado o reconhecimento de um recurso de acessibilidade presente em vários sites, que possibilita o aumento e diminuição do tamanho da fonte do texto, constatando-se que $30 \%$ dos adultos mais velhos não conheciam a função do recurso.

A Questão 14, que trata da identificação do remetente de e-mails também apresentou uma quantidade significativa de erros, provavelmente devido à não existência de uma metáfora adequada com a troca de correspondências do mundo real.

Apesar da Questão 18 também ter apresentado uma quantidade de erros significativa $(22 \%)$, ela serviu para mostrar a não familiaridade dos adultos mais velhos com ferramentas de chat. Em pesquisas de campo, foi observado que grande parcela desse público-alvo apresentava resistência e insegurança para conversar com pessoas desconhecidas, devido a não credibilidade na troca de informações e ao medo de serem lesados de alguma forma, preferindo conversar com pessoas identificadas via ferramentas como MSN e Skype. 
Posteriormente foram realizadas outras análises, separando-se os adultos de meia-idade e idosos e considerando também o público jovem para efeito de comparação. O percentual de erros por questão para cada uma das três faixas etárias pode ser observado na Figura 5.8.

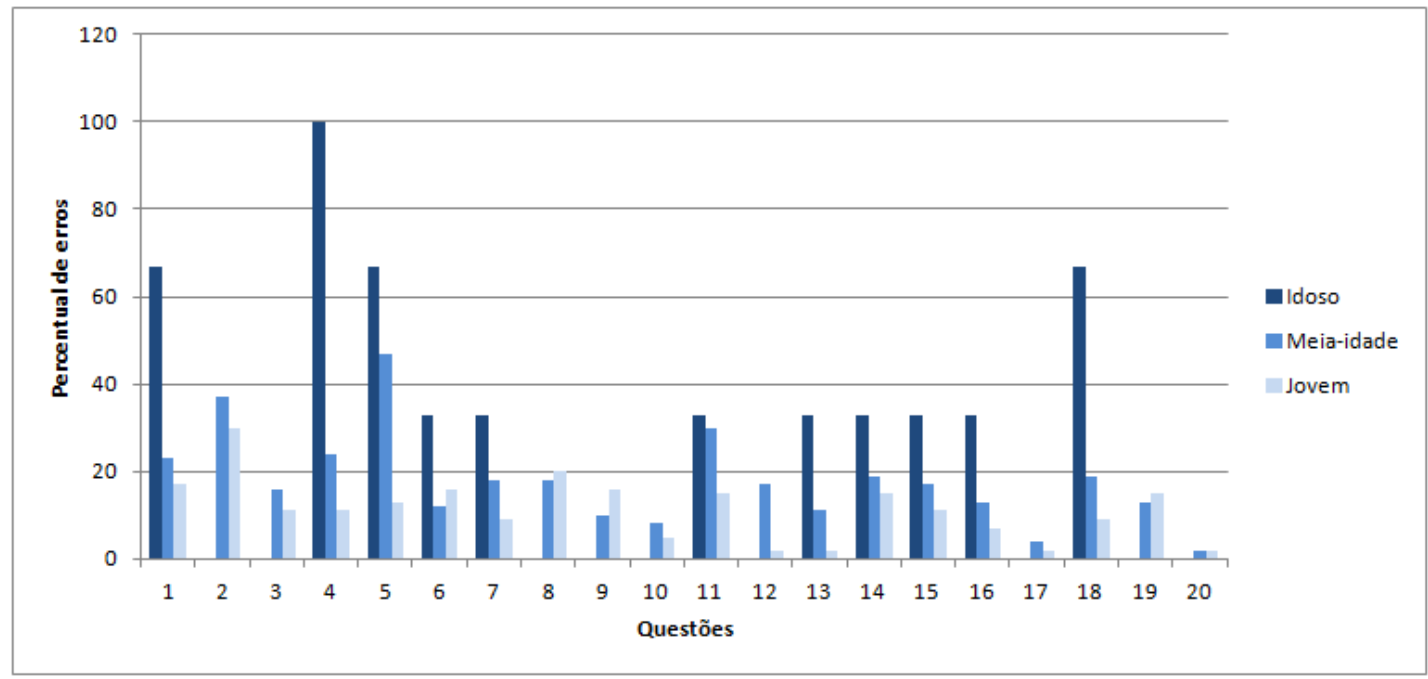

Figura 5.8: Percentual de Erros por Questões para Idosos, Adultos de Meia-Idade e Jovens

A dificuldade no reconhecimento de elementos comuns presentes nas páginas Web, tais como URLs, links, menus, etc, foi uma característica já identificada durante toda a observação em campo, descrita na Seção 5.1. Os usuários apresentavam-se confusos e inseguros ao manipular elementos como listas, caixas de texto com formatação específica, links em geral, entre outras, e ficavam grande parte do tempo olhando para a tela e aguardando o apoio presencial.

No decorrer daquela observação em campo, foi observado também que as pessoas que evoluíram mais rapidamente e que conseguiam navegar e realizar atividades na Web eram aquelas que mais treinavam em casa, de forma que pode-se concluir que a frequência de uso ou a familiaridade foi um fator essencial para facilitar o aprendizado.

Neste estudo, separando-se os respondentes por categorias de uso, pode-se observar que as pessoas que utilizavam a Web apenas uma vez por semana foram as que apresentaram percentuais de erros acima de $30 \%$ para a maioria das questões (Figura $5.9)$.

\subsection{Comportamento em Comércio Eletrônico}

A utilização de sites de comércio eletrônico tem se tornado uma atividade cada vez mais comum no cotidiano de usuários com experiência na utilização da Web. 


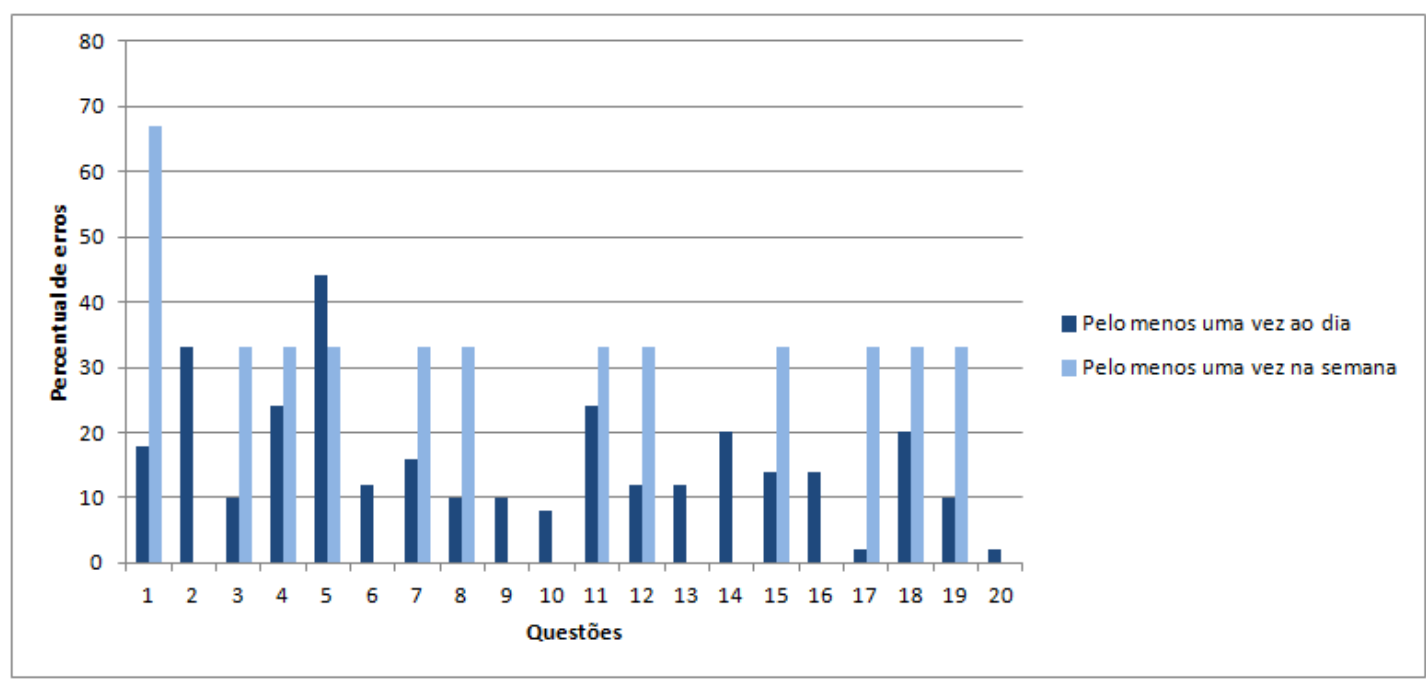

Figura 5.9: Percentual de Erros por Questões por Categorias de Frequência de Uso

A inclusão do público mais velho nesse tipo de atividade se tornou motivo de grande preocupação para empresas e desenvolvedores, pois a elaboração de interfaces acessíveis para um público com características tão heterogêneas ainda constitui um grande desafio.

Apesar da comodidade oferecida pelos sites de comércio eletrônico e da possibilidade da busca por melhores preços sem a necessidade de grande esforço físico e deslocamentos, observa-se que apenas uma parcela de adultos mais velhos, já mais experientes em interações na Web, é que realizam compras por meio da Internet.

Criar meios para facilitar a interação desse público com a Web significa que, além de desenvolver sites consistentes com as recomendações de acessibilidade e usabilidade, deve-se também prover condições para que os usuários menos experientes consigam superar as barreiras com que se deparam em suas experiências, proporcionando assim melhorias na qualidade de vida, promovendo a integração social e também a inclusão digital desse público tão economicamente importante quanto o público mais jovem.

Segundo estudos realizados por N/N Group (Coyne e Nielsen, 2002), as principais dificuldades encontradas pelos adultos mais velhos são:

- exigência de login para efetuar a compra;

- ausência de preço na oferta do produto;

- categorização do produto de forma errada, prejudicando sua localização pelo usuário;

- má definição da imagem do produto, que não é clara o suficiente para o usuário ter absoluta certeza de que é o produto que ele está procurando;

- links que não ativam a compra; 
- problemas para a adição do produto no carrinho de compras;

- pouca visualização dos itens selecionados;

- apresentação do valor total comprado com pouco destaque.

Com o objetivo de realizar testes de interação com os adultos mais velhos em um site de comércio eletrônico que atendesse as suas dificuldades e limitações foi elaborado o site de compras denominado Accessible Souk (Lara et al., 2010a).

Para o desenvolvimento da interface, foram observados vários aspectos relacionados às dificuldades dos adultos mais velhos apontados pela literatura e verificadas em observações de campo. A seguir são apresentados os recursos utilizados e sua respectiva aderência aos princípios de usabilidade e às diretrizes da WCAG 2.0 (W3C, 2008b), as quais se encontram entre parênteses:

(a) possibilidade de aumento do tamanho da fonte das páginas por meio de botões (U8, A1.4.4);

(b) para cada página foi criado um título claro o suficiente para indicar o propósito da mesma (U6, A2.4.2);

(c) possibilidade de alteração da cor de apresentação: colorido ou preto e branco, para melhorar o contraste (U8, A1.4.8);

(d) possibilidade de acesso aos campos de entrada por meio do teclado, pois foi implementada a navegação entre os elementos por meio da tecla $<\mathrm{TAB}>$ seguindo a ordem correta de preenchimento (U7, A2.4.3);

(e) mensagens de erros apresentadas abaixo do campos de entrada onde ocorreu o erro, com fonte e cor em destaque (U9, A3.3.3);

(f) apresentação da barra de navegação/localização no foco de visão do usuário, com a apresentação da seção de compra em que o usuário se encontra (U6, A2.4.8);

(g) apresentação de forma distinta dos links visitados e dos links não visitados (U5, A1.4.1).

Além da observação das diretrizes, foram levados em consideração os seguintes aspectos observados em campo:

- utilização de margens laterais para centralização do conteúdo no foco de visão do usuário;

- utilização de abas para separação de categorias de produtos com destaque;

- divisão da tarefa em vários passos; 
- apresentação antecipada das informações a serem providenciadas para o preenchimento de formulário;

- apresentação automática de dicas de preenchimento de campos de entrada no formulário;

- apresentação dos produtos em todas as categorias onde poderiam ser enquadrados de modo a facilitar sua localização pelo usuário;

- apresentação do acesso ao carrinho de compras em todas as fases intermediárias do processo, com a apresentação de todos os itens selecionados, suas respectivas quantidades, preço unitário, preço por itens, fotos, bem como a possibilidade de exclusão desses itens e o valor total da compra.

As fases de projeto, implementação e testes do protótipo foram realizados no período entre setembro/2009 a maio/2010. No mês de junho de 2010 foram realizados os testes com os usuários, síntese dos dados coletados entre todos os procedimentos executados até então e a redação de artigo relacionado ao trabalho (Lara et al., 2010a). A seguir é apresentado o projeto inicial da interface do site Accessible Souk com destaques para os recursos mencionados anteriormente.

\subsubsection{Interface}

Como o objetivo principal da elaboração deste projeto foi o registro da realização de uma atividade de compra na Web por usuários reais, inicialmente, para cada participante foi realizado o registro de informações necessárias para a posterior elaboração do seu perfil, tais como idade, ocupação e nível de escolaridade.

Na sequência da interação é apresentada ao usuário a tela inicial do site contendo as opções de aumento e diminuição do tamanho da fonte (botões A+ e A-) e modificação da cor (colorido/preto e branco), como pode ser observado no destaque da Figura 5.10. Além desses recursos, vale ressaltar que o conteúdo principal encontra-se centralizado entre margens laterais e possui abas e botões com cores em destaque, facilitando assim a visualização e a navegação por outras categorias (Figura 5.10). Antes de iniciar o cadastramento propriamente dito, é apresentada uma tela contendo todas as informações que serão requisitadas durante os passos do processo, para que o usuário possa providenciá-las antecipadamente e evitar que a sessão se expire devido à lentidão no preenchimento dos campos de entrada da página (Figura 5.11). A atividade de cadastramento dos dados do usuário foi dividida em três passos, a fim de evitar a sobrecarga de informações e o uso de barras de rolagem, como é mostrado na Figura 5.12. 


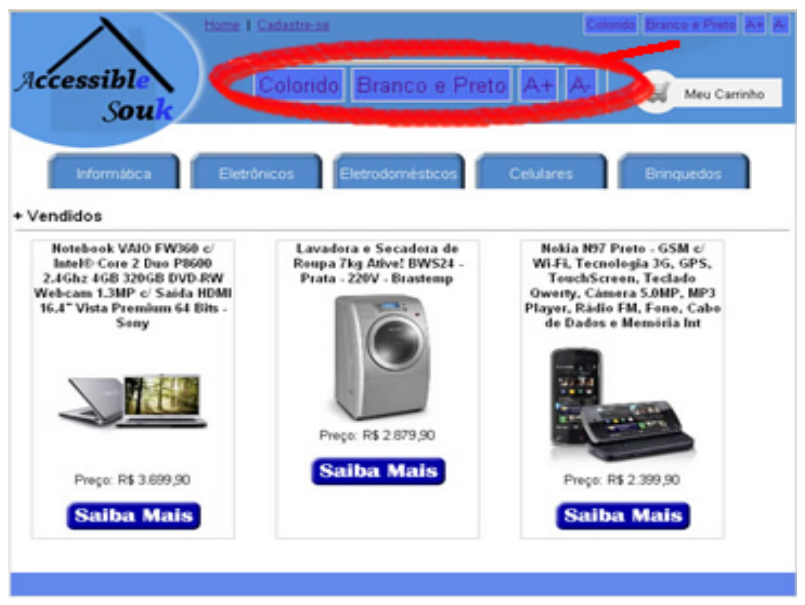

Figura 5.10: Tela Inicial

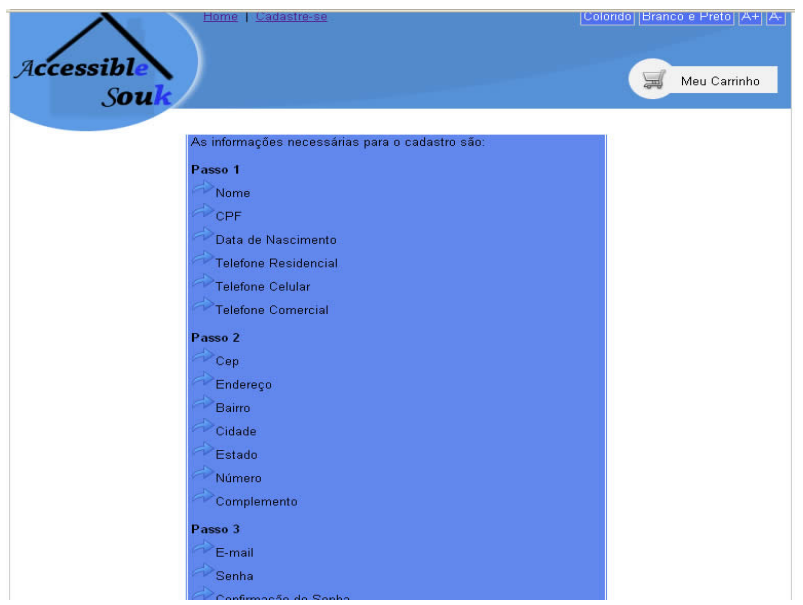

Figura 5.11: Informações necessárias para o cadastramento

Vale destacar a apresentação das dicas de preenchimento ao lado do campo que está para ser preenchido no momento. A dica apresentada varia de acordo com o posicionamento do mouse (Figura 5.12).

Após a conclusão de todos os passos do cadastramento de informações, o usuário pode realizar a visualização e compra de produtos de diversas categorias. Ao selecionar um determinado item é apresentada ao usuário uma tela contendo todas as informações a respeito do produto, tais como preço, parcelamento, desconto e informações técnicas (Figura 5.13 (a)). Ao acionar o carrinho de compras é apresentada uma tela contendo os produtos escolhidos para a compra. Para facilitar a visualização e relembrar o que já foi selecionado, é mostrada a foto do produto, seu nome completo, seu preço unitário, a quantidade comprada, preço total com base na quantidade e também o botão que possibilita ao usuário eliminar o produto caso não o deseje mais. Além dessas informações o usuário tem a opção de "Continuar comprando" ou "Finalizar a compra", por meio de botões em destaque (tamanhos 


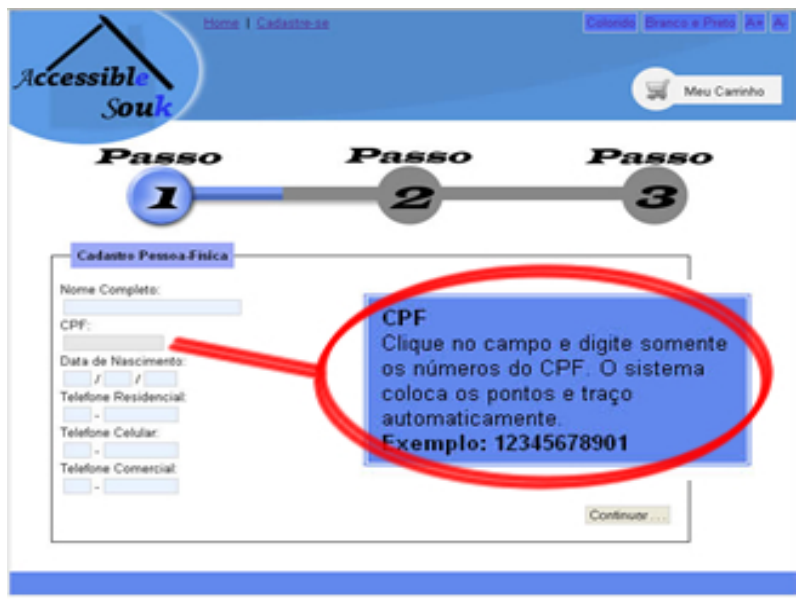

Figura 5.12: Primeiro Passo do Cadastramento

maiores) ao invés de links, que são comumente usados em sites de compras (Figura $5.13(\mathrm{~b}))$.

Em todas as telas do site existem links para a página inicial e para o carrinho de compras do usuário, como forma de orientar a navegação e permitir que o usuário volte para a página principal sempre que desejar.

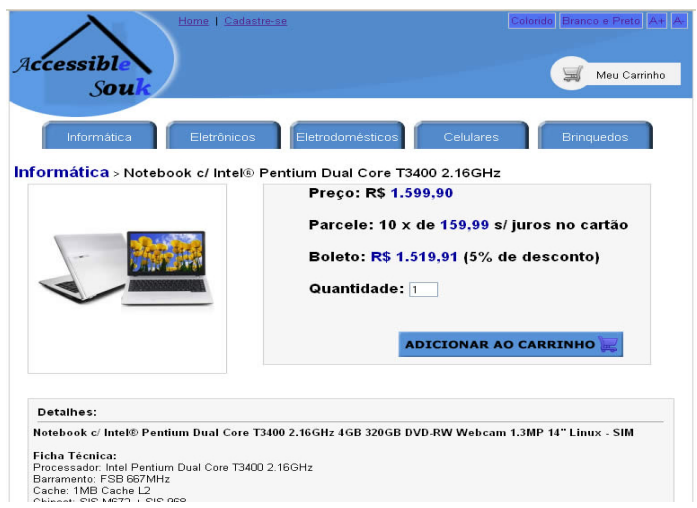

(a) Apresentação dos Detalhes do Produto

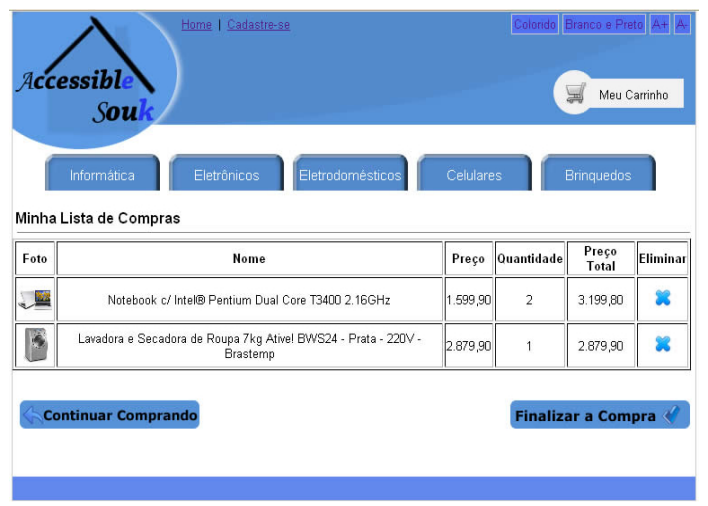

(b) Carrinho de Compras e Botões em Destaque

Figura 5.13: Telas intermediárias do processo de compra on-line

Caso o usuário acione o botão de finalização da compra, é apresentada a tela contendo as informações do carrinho e os campos para digitação do endereço de entrega e do pagamento (Figura 5.14). Propositalmente, nesta tela não foi incluído o preenchimento automático dos campos com os dados do usuário, nem o auxílio das dicas de preenchimento de campos, decisões essas que serão discutidas na seção a seguir. 


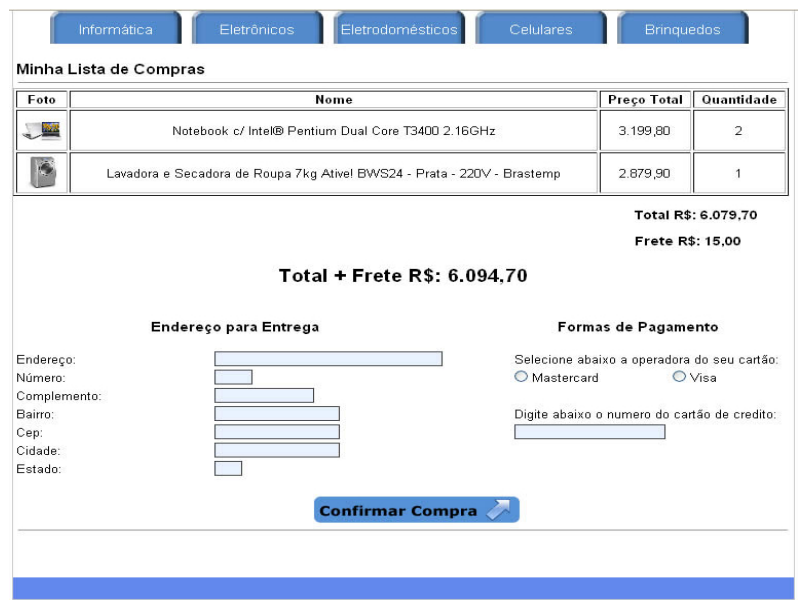

Figura 5.14: Tela de inclusão dos dados finais da compra

\subsubsection{Coleta de Dados}

Para a realização dos testes foram selecionados 30 participantes que apresentam como característica principal o fato de não realizarem compras pela Web, mas a utilizarem frequentemente para trocas de mensagens, e-mails e leitura de informações. Todos consentiram em participar do teste e permitiram a disponibilização dos resultados para esta pesquisa.

Os participantes foram distribuídos igualmente em três grupos de acordo com sua faixa etária:

- Grupo 1: 10 indivíduos com idades entre 18 e 39 anos;

- Grupo 2: 10 indivíduos com idades entre 40 e 59 anos;

- Grupo 3: 10 indivíduos com idades a partir de 60 anos.

Os testes foram aplicados de forma individual para todos os participantes. Inicialmente foi explicado o propósito do teste e os recursos de usabilidade e acessibilidade disponíveis, como também as tarefas que deveriam ser concluídas, respectivamente: o cadastramento de informações pessoais em três passos e a realização da compra de pelo menos um item de produto.

Em um arquivo de log foram armazenados registros de todos os dados das sessões dos usuários. Esses dados contêm um código para cada usuário, seu nome, idade, escolaridade, e para cada interação realizada é registrado o elemento acionado pelo usuário, a data e a hora. A partir desses dados foi possível realizar o rastreamento da interação de cada usuário, recuperando passo a passo os detalhes da sua navegação e da efetivação das tarefas de cadastramento e compras. A seguir são apresentadas a análise e as conclusões obtidas a partir do teste realizado. 


\subsubsection{Resultados}

Para todos os grupos foram realizados os cálculos de média do tempo utilizado para concluir a atividade de cadastramento (Passos 1, 2 e 3) e a atividade efetiva de compra como pode-se observar na Tabela 5.10.

Tabela 5.10: Tempo Médio de Conclusão das Tarefas por Grupos

\begin{tabular}{|l|l|l|l|l|}
\hline Grupo & $\begin{array}{l}\text { Cadastro } \\
\text { Passo 1 }\end{array}$ & $\begin{array}{l}\text { Cadastro } \\
\text { Passo 2 }\end{array}$ & $\begin{array}{l}\text { Cadastro } \\
\text { Passo 3 }\end{array}$ & Realização da Compra \\
\hline \hline Grupo 1 & $49,3 \mathrm{seg}$ & $54,2 \mathrm{seg}$ & $51,1 \mathrm{seg}$ & $84 \mathrm{seg}$ \\
\hline Grupo 2 & $57,1 \mathrm{seg}$ & $44,6 \mathrm{seg}$ & $49,6 \mathrm{seg}$ & $78 \mathrm{seg}$ \\
\hline Grupo 3 & $63 \mathrm{seg}$ & $55,3 \mathrm{seg}$ & $62 \mathrm{seg}$ & $80 \mathrm{seg}$ \\
\hline
\end{tabular}

Todos os usuários completaram suas tarefas com sucesso e a partir desses resultados pode-se concluir que houve uma variação pouco significativa no desempenho entre os grupos com relação ao tempo de execução, de modo que fica evidente que, com a utilização de recursos adequados, a realização de uma atividade de compra em um site de comércio eletrônico não sofre grande impacto com a variação da idade. Quando os participantes foram questionados se fariam compras pela Web, os resultados foram:

- Grupo 1: Sim para 7/10 participantes (70\%);

- Grupo 2: Sim para 5/10 participantes (50\%);

- Grupo 3: Sim para 3/10 participantes (30\%);

O principal motivo apontado para a não realização desse tipo de atividade nos sites reais foi falta de confiança que os usuários apresentam com relação à segurança na Web.

Por meio da observação dos testes foi possível verificar também o grau de utilidade das dicas durante os passos do cadastramento das informações pessoais: no Grupo 1 foram acionadas por 7 entre os 10 participantes; no Grupo 2 por 8 participantes e no Grupo 3 por 9 participantes.

Dentre as sugestões registradas, as mais importantes foram: colocação das dicas de preenchimento de campos de entrada também nas telas de compra (que não foram colocadas propositalmente) e a inclusão, nas telas de compra, da indicação de qual é o passo correspondente, para que fique claro ao usuário o quanto falta para concluir a atividade. 
Observamos assim que a diminuição da complexidade da tarefa e o apoio em situações específicas podem minimizar as dificuldades decorrentes da falta de experiência desse público, que utiliza a Web principalmente com um meio de informação e comunicação. A utilização dos princípios de usabilidade, de diretrizes de acessibilidade e de outros mecanismos de apoio apresentaram um impacto significativo na forma como eles interagiram na realização da atividade, de modo que os resultados de desempenho para conclusão da atividade entre as faixas etárias foram bastante próximos.

\subsection{Menus Horizontais}

Conforme mencionado nas seções anteriores, observou-se que os adultos mais velhos apresentam dificuldades tanto no reconhecimento de menus presentes em páginas da Web quanto na operação dos mesmos, fato este observado durante os acompanhamentos de cursos presenciais.

Devido à importância da navegação no projeto de sites Web e do aumento da complexidade de seu projeto à medida que aumentam a quantidade de informações e os serviços disponibilizados, foi realizada uma investigação mais profunda sobre o uso de menus, uma vez que os menus constituem o principal meio de navegação em páginas Web, e que sem eles, os usuários dependeriam dos elementos de navegação dos browsers para executarem suas ações.

Menus fornecem modelos estruturais e contextuais para a organização lógica e a interface funcional, bem como provêm comunicação entre os usuários e os sistemas (Lai e Waugh, 1994), (Laverson et al., 1987), (Norman e Chin, 1988) e (Oliveira et al., 1999). Os menus em páginas Web exercem três papéis de grande importância, que são: navegação por meio dos links, o apoio estrutural e o apoio contextual para a busca de informação (Yu e Roh, 2002).

Assim sendo, optou-se por realizar um estudo mais aprofundado a respeito dos menus horizontais situados no topo das páginas Web. Esse estudo foi conduzido de forma colaborativa com um trabalho de mestrado, sendo que o aluno de mestrado foi quem realizou a codificação e os testes (Santos, 2012). A pesquisadora desta tese esteve envolvida nas fases de identificação dos requisitos do protótipo, escolha dos menus, elaboração das tarefas, análise dos dados e redação de artigos relacionados ao teste (Santos et al., 2011b)(Santos et al., 2011a); atividades que ocorreram no período de agosto de 2010 a fevereiro de 2011.

A ideia foi investigar, dentre algumas opções de implementações de menus horizontais, qual o modelo mais apropriado, na visão dos adultos mais velhos, para apoiar 
efetivamente a busca de informações e auxiliar a navegação de forma a evitar a desorientação e a sobrecarga cognitiva.

\subsubsection{Coleta de Dados}

Diante da motivação apresentada e com o objetivo de investigar quais tipos de menus ofereciam melhores condições de navegação e realização de tarefas para os adultos mais velhos, foi realizado um estudo de caso para analisar os efeitos de oito tipos diferentes de menus horizontais na interação de adultos de meia-idade e idosos com páginas Web.

O público-alvo para esse experimento foram pessoas com idade acima dos 40 anos e que possuíam alguma experiência no uso da Internet. Em cada sessão foram medidos os tempos para a realização das tarefas e o número de erros por meio do registro de logs. Os resultados mostraram diferentes efeitos na velocidade da conclusão das tarefas, na quantidade de erros registrados e também na satisfação do usuário com relação aos menus.

Os participantes receberam o convite para colaborar com a pesquisa por meio de uma mensagem via e-mail, a qual solicitava que realizassem o teste por meio do acesso ao servidor no qual as páginas contendo os menus estavam disponíveis. Ao acessar o endereço Web informado, o participante deveria ler um esclarecimento sobre os objetivos do teste e em seguida lhes era apresentada uma página contendo um formulário para o cadastramento das informações do seu perfil, bem como um comprometimento de privacidade das informações coletadas.

Após a realização do cadastro inicial, cujas informações fornecidas eram data de nascimento, grau de escolaridade, frequência de uso da Internet e as principais finalidades de seu uso, o participante era conduzido a iniciar o seu teste com os menus.

O estudo de caso consistiu na realização de 2 tarefas pré-determinadas para cada um dos oito tipos de menus horizontais implementados, totalizando 16 tarefas para cada participante. O conteúdo da página que continha os menus de navegação era sempre o mesmo e apresentava textos relativos a viagens. O participante deveria então cumprir a tarefa de localizar um item específico dentre as várias opções do menu e clicá-la. Caso o usuário errasse o item ele seria direcionado para uma página de erro contendo o botão "Voltar", para que fosse possível refazer a tarefa. Após a conclusão das duas tarefas, o usuário deveria responder um pequeno questionário para deixar registrada suas impressões a respeito do menu que ele acabara de utilizar. Para prevenir os efeitos da aprendizagem na utilização entre um tipo de menu e outro, a ordem de apresentação dos oitos menus utilizados foi gerada randomi- 
camente para cada sessão do teste. Desta forma, caso existisse um participante passivo visualizando o teste de outro participante ativo, no momento em que esse participante passivo fosse realizar o teste, ele visualizaria uma nova ordem de apresentação dos oito menus.

Os mockups e as imagens dos oito menus selecionados estão apresentados na Figura 5.15. A descrição das principais características dos menus implementados pode ser visualizada no Apêndice $\mathrm{C}$.

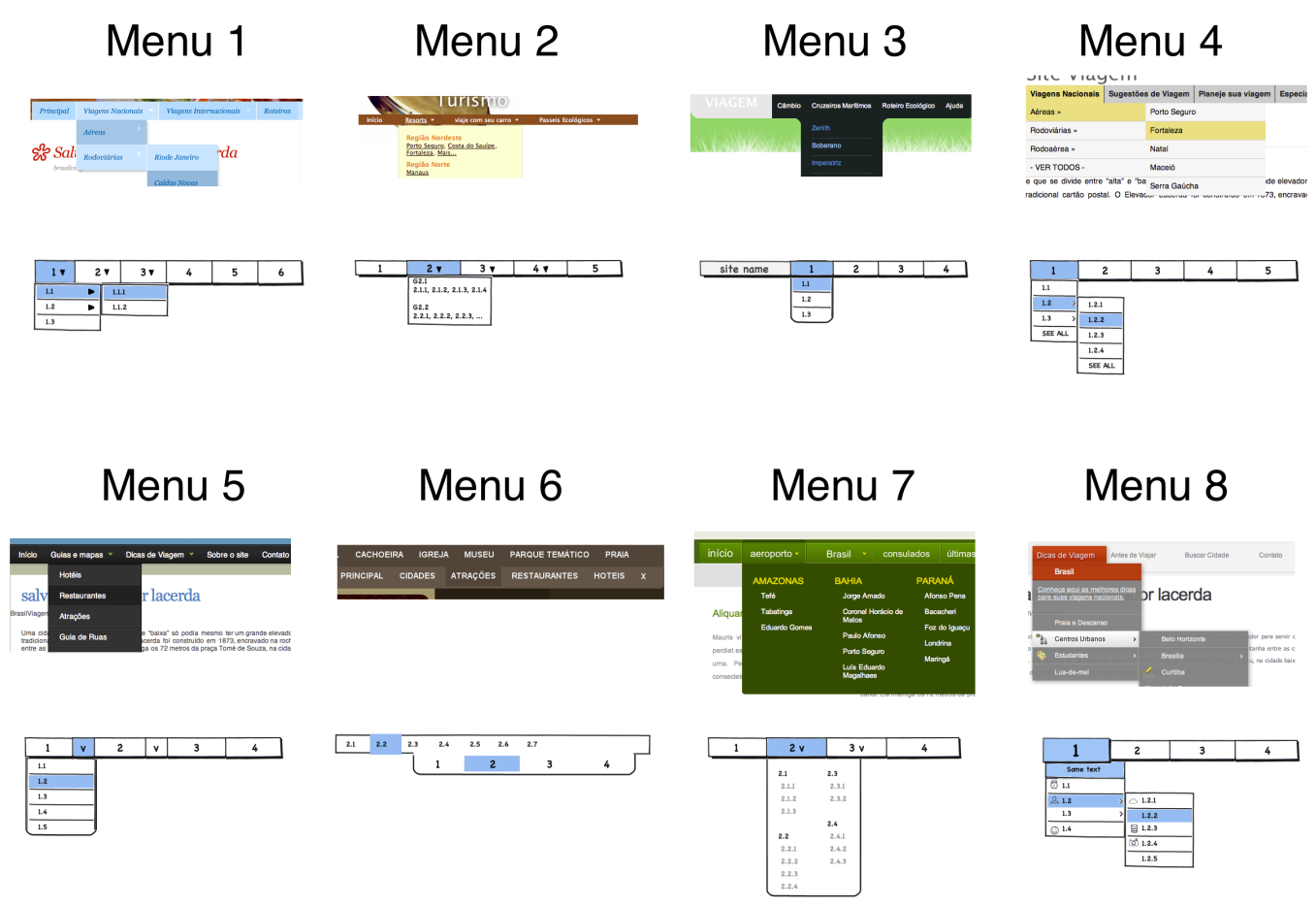

Figura 5.15: Representação gráfica dos oito menus e os mockups

Os oito menus apresentados no estudo de caso foram desenvolvidos utilizando as marcações HTML para gerenciar a hierarquia das opções. Para os oito menus apresentados foram consideradas sete propriedades principais (Santos et al., 2011b)(Santos et al., 2011a):

1. Disposição: descreve em qual posição os submenus serão apresentados. A disposição pode variar dependendo do nível do submenu, sendo seus valores: Abaixo ( $\mathbf{\nabla})$, Acima ( $\mathbf{\Delta})$ e Direita $(\boldsymbol{-})$;

2. Velocidade: é a propriedade que representa o tempo para a apresentação do submenu. Essa propriedade foi classificada em três valores: rápido, com tempo de apresentação do submenu menor ou igual a 0,3 segundos; médio, com tempo de apresentação entre 0,4 a 0,6 segundos; lento, com tempo de apresentação maior que 0,6 segundos. Esses intervalos de tempo foram obtidos a partir dos estudos 
de Card et al. (1983), as representações dos seus valores são: Rápido (o), Médio (ब), Lento (в);

3. Necessidade de clique: descreve a necessidade de realizar um clique com o mouse para ativar o submenu. Caso não seja necessário o clique, a ativação é realizada apenas com o posicionamento do ponteiro na região de ativação do submenu, seus valores são: $\operatorname{Sim}(\boldsymbol{v})$ e Não $(\boldsymbol{x})$;

4. Identificação de continuidade: descreve a existência de algum elemento visual para mostrar a existência de submenus para uma determinada subopção do menu, seus valores são: $\operatorname{Sim}(\boldsymbol{v})$ e Não $(\mathbf{x})$;

5. Contraste de cores na seleção: ativa-se no momento em que o ponteiro está sobre a área de ativação e apresenta a troca de cores ou tamanho da fonte para melhorar a identificação do menu a ser acionado. As principais mudanças normalmente são a troca suave da cor de fundo da área referente à área de ativação, o sublinhado do texto ou uma troca de cor do fundo e da fonte do texto, seus valores são: $\operatorname{Sim}(\boldsymbol{v})$ e Não $(\mathbf{x})$;

6. Apresentação da hierarquia: descreve a forma que é apresentada a hierarquia inerente ao menu. A hierarquia pode ser dividida com os níveis dos submenus ou com espaçamento em um mesmo bloco de conteúdo, seus valores são: Níveis (I) ou Bloco (匹);

7. Presença de dica: descreve a presença de texto informativo no início do submenu, seus valores são: $\operatorname{Sim}(\boldsymbol{v})$ e Não $(\boldsymbol{x})$.

No Quadro 1 são resumidas as sete características consideradas para os oito tipos de menus selecionados (Santos et al., 2011b)(Santos et al., 2011a), identificados por $\mathrm{M}[\mathrm{i}]$, onde i varia de 1 a 8 , representando cada menu $\mathbf{i}$.

\begin{tabular}{lcccccccc}
\hline Propriedades & M1 & M2 & M3 & M4 & M5 & M6 & M7 & M8 \\
\hline 1 Disposição & $\boldsymbol{\nabla}$ & $\boldsymbol{\nabla}$ & $\boldsymbol{\nabla}$ & $\boldsymbol{\nabla}$ & $\boldsymbol{\nabla}$ & $\mathbf{A}$ & $\boldsymbol{\nabla}$ & $\boldsymbol{\nabla}$ \\
2 Velocidade & $\mathbf{2}$ & $\mathbf{3}$ & $\mathbf{1}$ & $\mathbf{1}$ & $\mathbf{2}$ & $\mathbf{2}$ & $\mathbf{2}$ & $\mathbf{1}$ \\
3 Necessidade de clique & $\mathbf{x}$ & $\mathbf{x}$ & $\mathbf{x}$ & $\mathbf{x}$ & $\boldsymbol{V}$ & $\mathbf{x}$ & $\mathbf{x}$ & $\boldsymbol{\checkmark}$ \\
4 Continuidade & $\boldsymbol{V}$ & $\boldsymbol{V}$ & $\mathbf{x}$ & $\mathbf{x}$ & $\boldsymbol{V}$ & $\mathbf{x}$ & $\boldsymbol{V}$ & $\mathbf{x}$ \\
5 Contraste de cores & $\boldsymbol{V}$ & $\boldsymbol{V}$ & $\boldsymbol{V}$ & $\boldsymbol{V}$ & $\boldsymbol{V}$ & $\boldsymbol{V}$ & $\boldsymbol{V}$ & $\boldsymbol{V}$ \\
6 Apresentação da hierarquia & $\mathbf{I}$ & $\mathbf{v}$ & $\mathbf{I}$ & $\mathbf{I}$ & $\mathbf{I}$ & $\mathbf{I}$ & $\mathbf{\square}$ & $\mathbf{I}$ \\
7 Presença de dica & $\mathbf{x}$ & $\mathbf{x}$ & $\mathbf{x}$ & $\mathbf{x}$ & $\mathbf{x}$ & $\mathbf{x}$ & $\mathbf{x}$ & $\boldsymbol{V}$ \\
\hline
\end{tabular}

Quadro 1: Propriedades dos oitos menus 


\subsubsection{Resultados}

A partir dos dados coletados e armazenados em banco de dados foram elaboradas com base nos perfis dos usuários, análises relativas às opiniões dos usuários sobre os menus, a quantidade de erros, estimativas do tempo de realização das tarefas por faixa etária e gráficos de análise de sobrevivência para avaliar o aprendizado.

Com os dados dos participantes coletados no momento inicial da realização do teste, foi possível identificar os seguintes perfis (Santos et al., 2011b)(Santos et al., 2011a):

- A faixa etária dos participantes variou entre os 18 anos até os 69 anos de idade, sendo que o maior número de pessoas se concentrou na faixa classificada como meia-idade, que engloba as pessoas de 40 a 59 anos de idade, com 68 pessoas (50,3\%); o segundo maior grupo classificado como jovem foi da faixa etária de 18 a 39, com 59 pessoas $(43,7 \%)$ e o terceiro grupo, classificado como idoso, pertencendo a faixa etária dos 60 a 74 anos, com 8 pessoas $(6 \%)$;

- Das 135 pessoas que finalizaram o teste, 57 (42\%) eram do sexo feminino e 78 $(58 \%)$ do sexo masculino;

- 48 pessoas (36\%) possuíam nível superior completo de escolaridade e 39 pessoas $(29 \%)$ haviam concluído doutorado;

- Pessoas de 10 diferentes estados brasileiros $^{5}$ realizaram o teste, sendo que a maior representatividade foi do estado de São Paulo com 92 pessoas (68\%), seguido do estado do Paraná com 25 pessoas (19\%).

Na Figura 5.16 são mostradas as opiniões fornecidas por todos os usuários ao término de cada uma das duas tarefas realizadas sobre cada um dos oito menus, o que possibilita uma classificação subjetiva, que varia de acordo com a percepção do usuário. Para cada tarefa concluída em um determinado menu, o usuário deveria classificá-lo em: "Muito Fácil", "Fácil", "Difícil" e "Muito difícil".

Como as duas tarefas foram realizadas consecutivamente sobre o mesmo menu, foi possível verificar, nessa classificação, o aprendizado com o menu. O aprendizado é verificado pelo aumento das classificações "Muito fácil" e "Fácil" ao se comparar as impressões da Tarefa $1 \mathrm{com}$ as da Tarefa 2 para o mesmo menu. Pode-se verificar também que os menus 1 e 3 tiveram melhores classificações, e os menus 2 e 5 tiveram os maiores índices de classificações "Difícil" e "Muito difícil".

Outra medida importante verificada para os menus foi a quantidade de erros cometidos por todos os usuários ao realizar as tarefas solicitadas, conforme mostra a Figura 5.17 (Santos et al., 2011b)(Santos et al., 2011a).

\footnotetext{
${ }^{5}$ São eles: SP, PR, RJ, MG, PE, BA, MS, MT, RS e SC.
} 


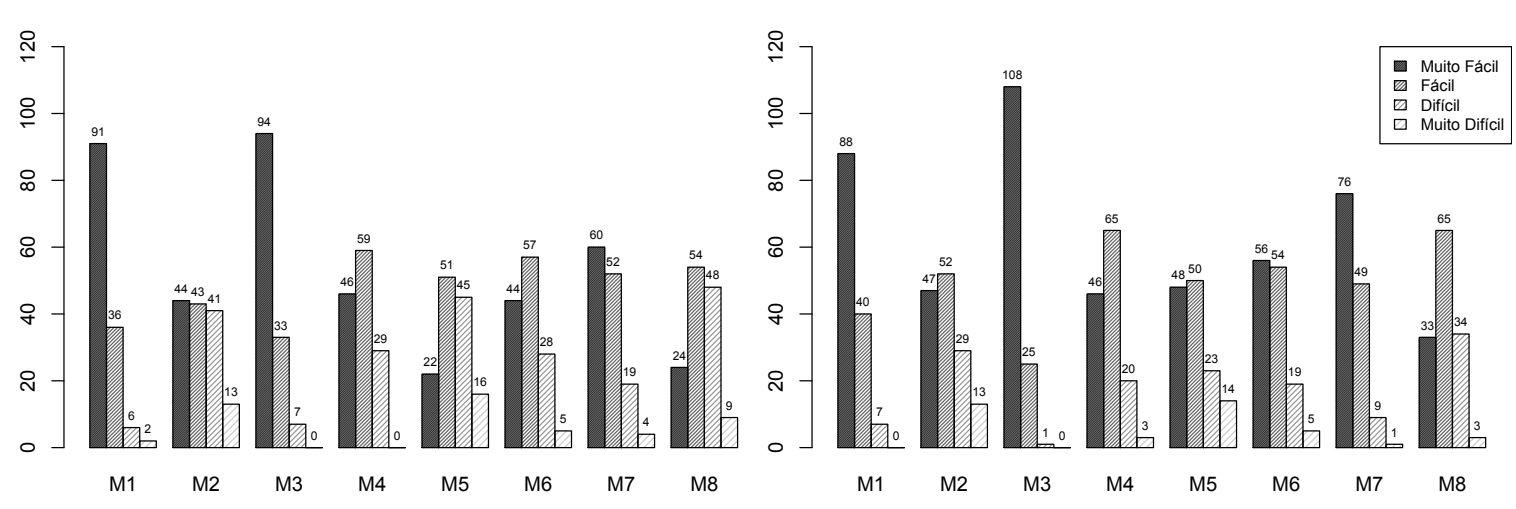

Figura 5.16: Classificação para a Tarefa 1 (esquerda) e para a Tarefa 2 (direita) para cada menu

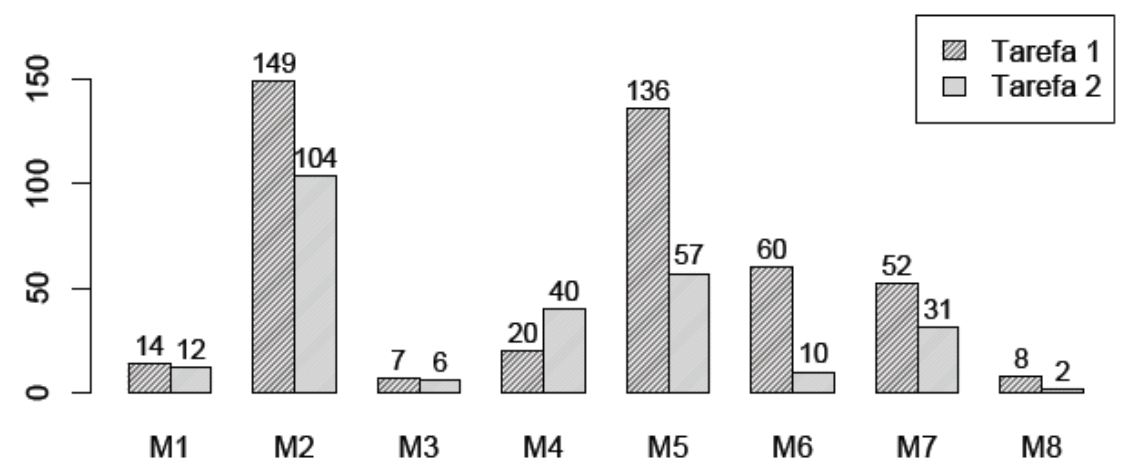

Figura 5.17: Número de erros cometidos por tarefa em cada menu

O fator "aprendizagem do usuário" pode ser observado também na Figura 5.17, pois na maioria dos testes, o número de erros cometidos na Tarefa 2 é menor que o número de erros cometidos na Tarefa 1, fato que só não se comprova no menu 4. Os menores números de erros foram observados nos menus 1, 3 e 8.

Optou-se pela técnica estatística de análise de sobrevivência (Bastos e Rocha, 2006)(Colosimo e Giolo, 2006) para avaliar os tempos de conclusão das tarefas no teste.

Análise de sobrevivência é a expressão utilizada para designar a análise estatística de dados quando a variável em estudo representa o tempo desde um instante inicial bem definido até a ocorrência de determinado acontecimento de interesse. Para a aplicação da análise de sobrevivência nos tempos coletados via o mecanismo de log, foi utilizada a linguagem estatística R (R Development Core Team, 2010).

A mediana dos tempos para cada grupo de usuários auxiliou na identificação de quais menus apresentam o melhor desempenho perante as faixas etárias. A Figura 5.18 mostra a mediana em segundos para a conclusão de cada tarefa para cada menu testado (Santos et al., 2011b)(Santos et al., 2011a). 


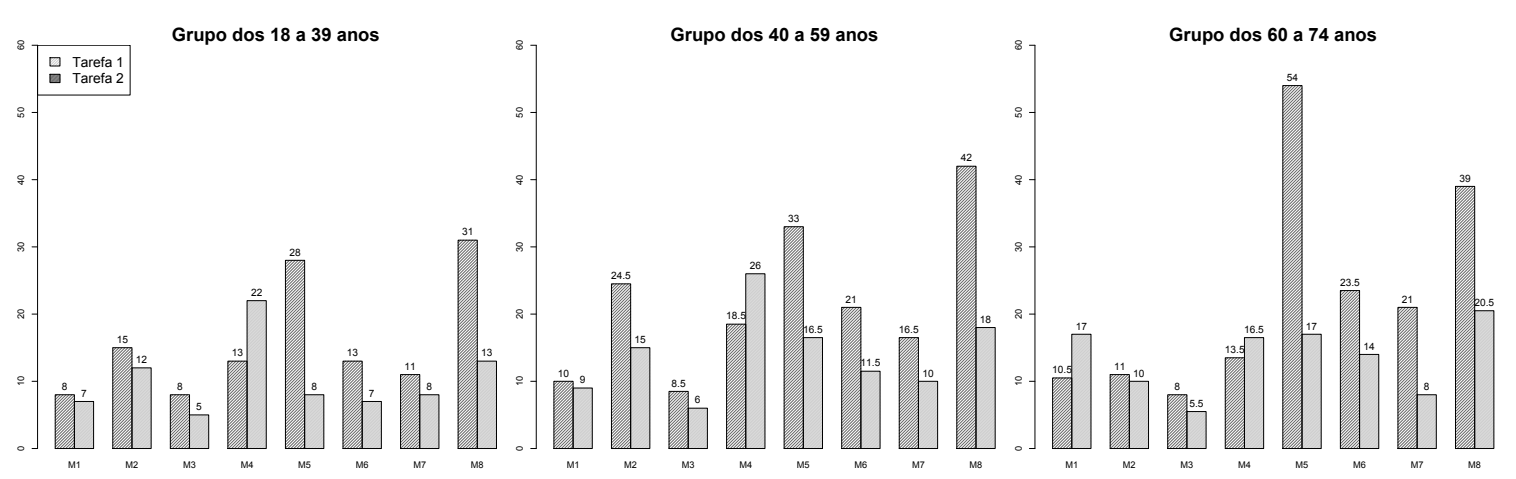

Figura 5.18: Mediana dos tempos por classificação de idade dos usuários

Observa-se que os menus M5 e M8 foram os que ocasionaram maior demora na conclusão das tarefas pelos três grupos etários. Ao analisar a mediana de tempo do menu 5 para os adultos de meia-idade, observa-se que este ficou próximo ao tempo do grupo jovem para a Tarefa 1, sendo 33 segundos e 28 segundos, respectivamente. Para o menu 8, a mediana do tempo para os adultos de meia-idade se aproximou, e superou, o tempo registrado para os idosos na Tarefa 1, sendo de 42 segundos e 39 segundos, respectivamente.

A Figura 5.19 apresenta a análise de sobrevivência para os tempos das dezesseis tarefas realizadas pelo grupo de usuários classificados como jovens, a Figura 5.20 apresenta os resultados da aplicação da técnica estatística para o grupo de usuários classificados como meia-idade e a Figura 5.21 apresenta os resultados para o grupo classificado como idoso. Pode-se verificar que as curvas que decaem mais rapidamente representam as tarefas que foram realizadas mais rapidamente, em média, pelos usuários.
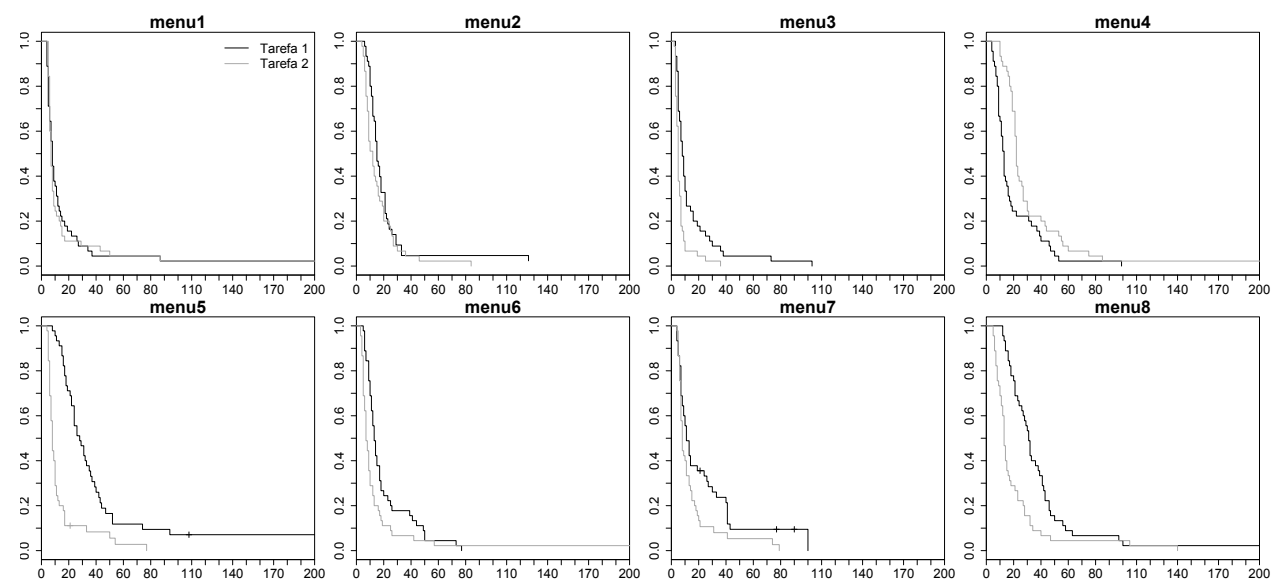

Figura 5.19: Estimativas de Kaplan-Meier do tempo de realização das tarefas pelo grupo jovem 

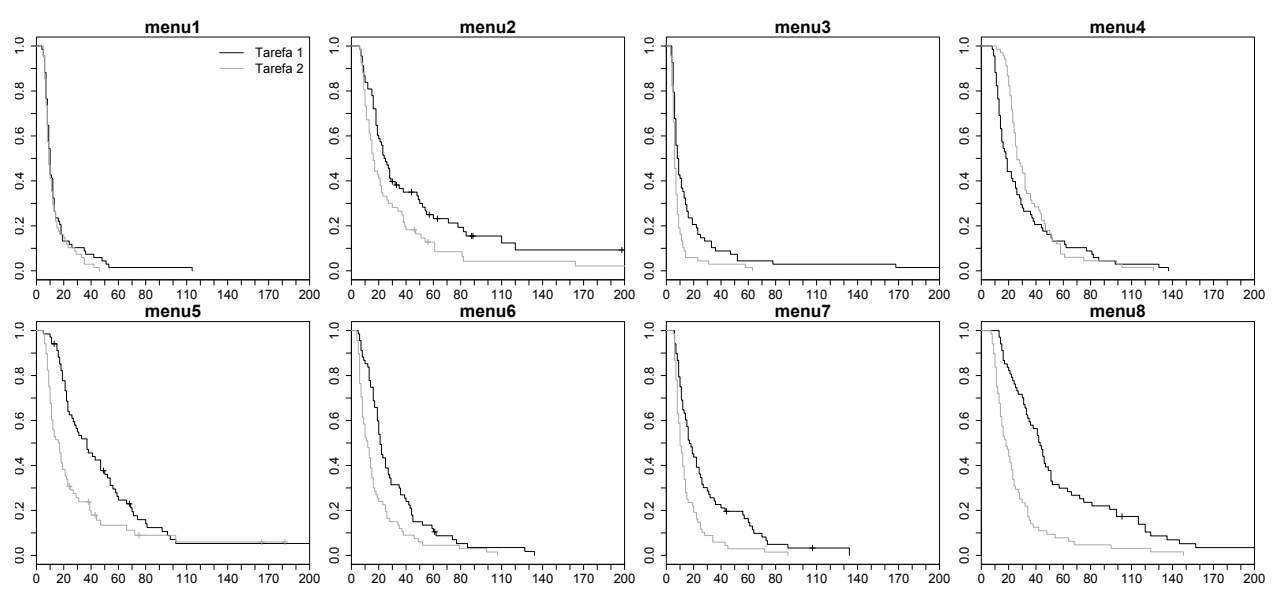

Figura 5.20: Estimativas de Kaplan-Meier do tempo de realização das tarefas pelo grupo meia-idade
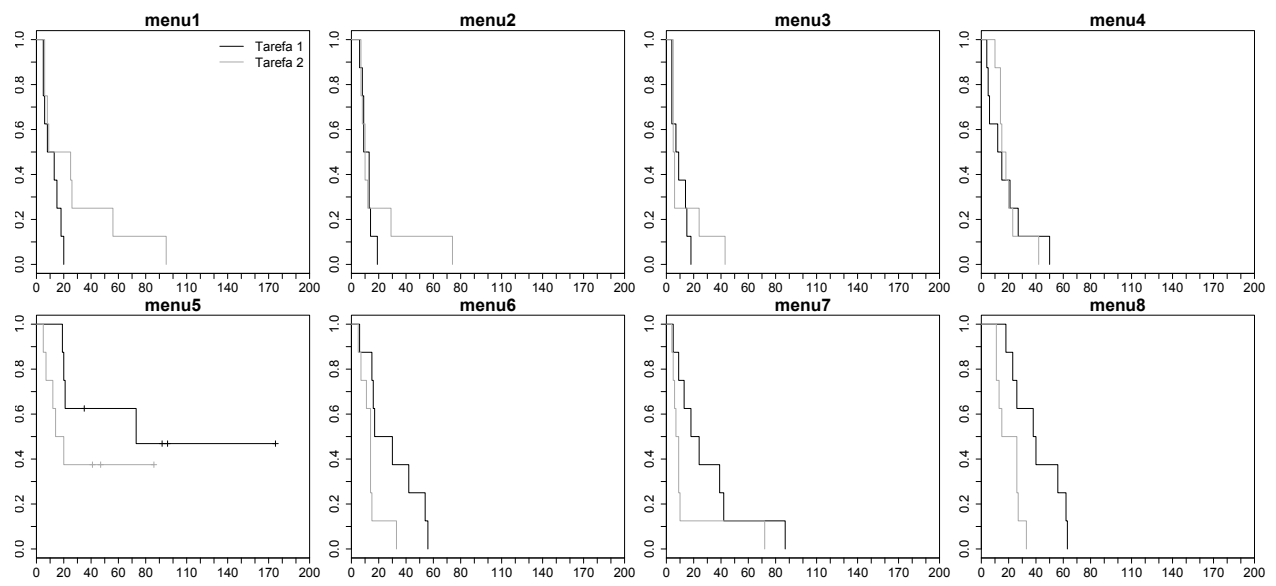

Figura 5.21: Estimativas de Kaplan-Meier do tempo de realização das tarefas pelo grupo idoso

Nos resultados anteriores contendo as informações de todos os usuários, verifica-se a preferência pelos menus 1 e 3. Após observar as curvas de sobrevivência, separando os usuários pela faixa etária, os menus com melhores resultados, para os grupos jovem e meia-idade, foram os menus 1 e 3. A diferença entre esses dois menus, verificando os valores da análise de sobrevivência, é que o menu 3 apresenta maior grau de aprendizagem, sendo o menu com o menor tempo para a realização da Tarefa 2. O menu 1 foi o único menu a apresentar uma execução próxima na realização das duas tarefas e apresentando um bom desempenho. Para o grupo dos idosos observou-se que os menus 1, 2 e 3 apresentaram menor tempo de conclusão para a Tarefa 1 e maior para a Tarefa 2. Para os menus 4, 5, 6, 7, 8 foi observado um maior grau de aprendizagem após a execução da Tarefa 2. 
Assim sendo, pode-se concluir que os menus 1 e 3 são os mais apropriados para os adultos mais velhos e apresentam excelente desempenho também para o grupo jovem.

\subsection{Considerações finais}

Neste capítulo os procedimentos científicos da investigação realizados nesta tese foram descritos. Foram realizadas as seguintes atividades: revisão bibliográfica, observação de campo, entrevistas, questionários (Surveys) e testes com protótipos funcionais.

Inicialmente foi realizado um estudo de observação de campo por meio do acompanhamento de cursos relacionados ao uso da Web. Além do acompanhamento presencial foram elaborados questionários on-line, sendo um deles destinado a pessoas com grande experiência no uso da Web (mais de 5 anos de experiência e uso diário) e outro destinado ao público em geral. Nesse segundo caso, o objetivo principal era verificar o reconhecimento dos principais elementos que compõem uma página Web, tais como: URLs, links (visitados e não visitados), imagens, entre outros.

A partir do levantamento das principais dificuldades encontradas pelo público-alvo e dos resultados do questionário de reconhecimento dos elementos, foi definida uma abordagem de testes com protótipos, cujos aspectos priorizados foram a interação com site de comércio eletrônico e com menus horizontais. Foram realizadas também entrevistas com profissionais da área de psicologia e gerontologia e um encontro com deficientes visuais da AMU-São Carlos.

A partir desses levantamentos mencionados foi elaborada uma proposta dos mecanismos de apoio aos adultos mais velhos por meio de sugestão de extensão dos critérios de sucesso para as diretrizes de acessibilidade da WCAG 2.0 (W3C, 2008b) e também foi proposto um conjunto de mecanismos de apoio, que deu origem a um questionário on-line para verificar a aceitação dos mesmos pelo público-alvo, que serão descritos no próximo capítulo.

O conjunto de resultados obtidos da pesquisa descritiva, apresentado neste capítulo, possibilitou a identificação das principais dificuldades e barreiras dos adultos mais velhos em suas interações com a Web. Quanto à natureza da pesquisa, ela se caracteriza por ter sido qualitativa pois analisou pequenas amostras e obteve dados, em certos casos, mediante o contato direto e interativo da pesquisadora com os usuários. 


\section{Mecanismos para Interação de Adultos Mais Velhos na Web}

A partir dos resultados dos experimentos realizados, foi possível analisar os principais problemas enfrentados pelos adultos mais velhos nas interações Web e evidenciar mecanismos que possam auxiliar a reduzir esses problemas. Para o entendimento e desenvolvimento dos recursos que devem compor esses mecanismos, neste capítulo são apresentadas contribuições e propostas na forma de: sugestões de critérios de sucesso, sugestões de soluções para minimizar os principais problemas, um apoio sensível ao contexto e mecanismos de apoio para a interação de adultos mais velhos na Web.

\subsection{Sugestões de Critérios de Sucesso para Interação}

Enquanto os movimentos a favor da padronização da Web (Web Standards) defendem o uso da WCAG, a existência de outras diretrizes derivadas de trabalhos vistos na literatura demonstra a insatisfação com a WCAG, devido à insuficiência de orientações para guiar o desenvolvimento voltado para o público mais velho. É evidente que existe uma desconexão entre os pesquisadores que consideram a WCAG insuficiente no apoio à concepção de sites Web que possam ser acessados e usados por pessoas mais velhas, e o movimento Web Standards, que prontamente adota WCAG e não considera as alternativas de pesquisa derivadas das diretrizes (Sloan, 2006). 
Por outro lado, as diretrizes derivadas de trabalhos que buscam complementar as diretrizes da WCAG identificam e reconhecem os reais problemas enfrentados pelos usuários mais velhos em suas interações com a Web. Em geral, essas diretrizes prescrevem aspectos da aparência que, se aplicados, podem minimizar os potenciais problemas decorrentes da incapacidade de um usuário mais velho para alterar a aparência de uma página para adaptá-la de acordo com suas necessidades, dado que não possui as habilidades técnicas necessárias para realizar a otimização da acessibilidade nos sites que visita.

Dessa forma, deve-se reconhecer a WCAG como referência preeminente para a acessibilidade na Web e investigar quais diretrizes de design adicionais podem ser combinadas com ela, a fim de superar os desafios específicos enfrentados pelos usuários mais velhos na Web.

A partir das observações de campo sobre as interações de adultos mais velhos com a Web (Lara e Fortes, 2009), das respostas obtidas por meio da aplicação do questionário sobre o reconhecimento de elementos utilizados na composição da maioria das páginas Web, de testes de usabilidade com menus e testes com uma aplicação de comércio eletrônico (Lara et al., 2010a) voltados para esse público-alvo, foi proposto um conjunto de sugestões específicas de design para a WCAG 2.0, visando atender as dificuldades observadas.

As sugestões propostas podem ser integradas e vir a estender os critérios de sucesso que compõem as atuais diretrizes de acessibilidade da Web (Lara et al., 2010b). Essa adaptação deve ser realizada de modo a manter a consistência com as soluções previamente descritas no documento da WCAG 2.0 e manter a neutralidade da solução tecnológica a ser empregada. Assim, a abordagem é ilustrada na Figura 6.1.

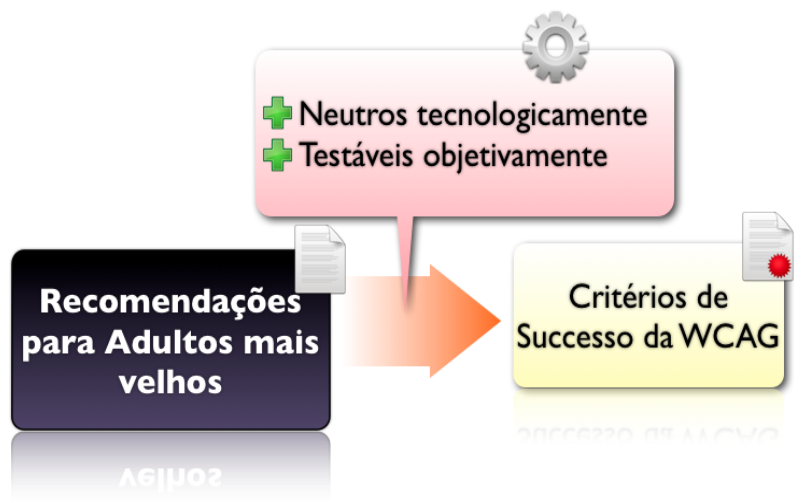

Figura 6.1: Adaptação das propostas de acessibilidade para integrar a WCAG 2.0

A proposta é que as sugestões sejam acrescentadas aos Critérios de Sucesso da WCAG 2.0 como ilustrado na Figura 6.2.

Por se tratarem de sugestões fundamentadas em experimentos com indivíduos mais velhos e sem o objetivo de aprofundar sobre seus detalhes técnicos, não foram 


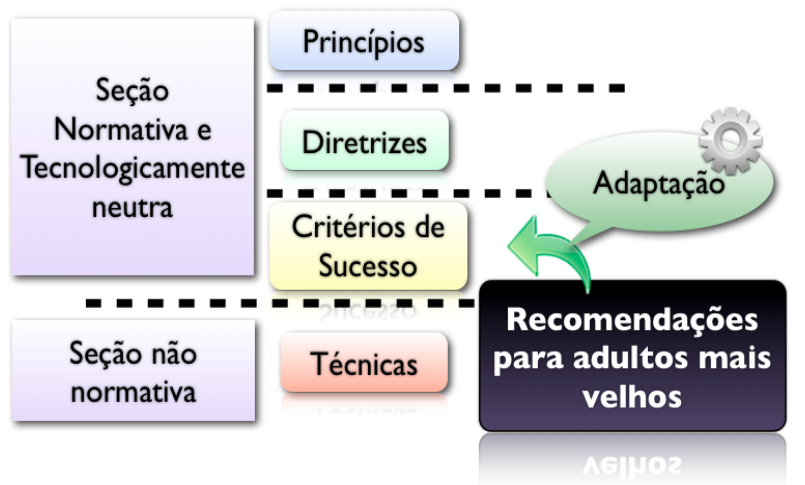

Figura 6.2: Proposta de integração das recomendações aos Critérios de Sucesso da WCAG 2.0.

especificadas as técnicas relacionadas e nem a aplicabilidade que se associam ao cumprimento dos critérios de sucesso. A seguir são descritos os critérios de sucesso propostos, que deveriam ser acrescentados em função das demandas dos adultos mais velhos e estão organizados de acordo com os princípios da WCAG 2.0 (W3C, $2008 b)$.

\subsubsection{Perceptível}

- Critério de Sucesso 1.3.4: A página Web deve oferecer uma funcionalidade que leia o conteúdo por meio de sintetizador de voz.

Motivação: reduzir o esforço visual e manter o foco da atenção no conteúdo da página.

Integração: diretriz 1.3 - Adaptável.

- Critério de Sucesso 1.4.11: Os principais elementos que compõem a página Web devem ser visualizados em destaque, tais como links, menus, botões e outros.

Motivação: adultos mais velhos apresentam dificuldades para identificar e distinguir os componentes da interface de uma aplicação Web e portanto é necessário que seja oferecido algum meio de destacá-los. Além disso, adultos mais velhos apresentam dificuldades para diferenciar elementos navegacionais do conteúdo da página.

Integração: diretriz 1.4 - Discernível. 


\subsubsection{Operável}

- Critério de Sucesso 2.1.4: A página Web não deve depender do recurso de barras de rolagem.

Motivação: adultos mais velhos apresentam dificuldades para perceber a existência de barras de rolagem e geralmente não completam a tarefa que requer o uso desse componente da interface.

Integração: diretriz 2.1 - Acessível por teclado

- Critério de Sucesso 2.1.5: A página Web deve evitar o uso de janelas do tipo pop-up.

Motivação: adultos mais velhos tendem a apresentar uma reação de resistência e confusão quando uma janela pop-up aparece no meio da tela pois normalmente acreditam que causaram algum erro no sistema.

Integração: diretriz 2.1 - Acessível por teclado

- Critério de Sucesso 2.2.6: Menus do tipo drop-down devem ser apresentados com velocidade reduzida o suficiente para serem ativados por usuários que apresentam pouca coordenação motora.

Motivação: adultos mais velhos apresentam dificuldades na manipulação de menus móveis rápidos e geralmente acabam selecionando a opção errada.

Integração: diretriz 2.2 - Tempo suficiente

- Critério de Sucesso 2.2.7: Conteúdo multimídia deve disponibilizar opções para controlar a sua execução e a velocidade de apresentação.

Motivação: conteúdo multimídia afeta o foco de atenção dos adultos mais velhos desviando-a da execução da tarefa e frequentemente não é bem compreendido devido à alta velocidade de execução.

Integração: diretriz 2.2 - Tempo suficiente

- Critério de Sucesso 2.4.11: Não utilizar nomes idênticos para referenciar URLs distintas.

Motivação: adultos mais velhos se acostumam com a interface apresentada e qualquer renomeação de referências deve ser evitada.

Integração: diretriz 2.4 - Navegável

- Critério de Sucesso 2.4.12: Links adjacentes devem ser apresentados na interface com espaço suficiente entre eles para evitar erros involuntários. 
Motivação: adultos mais velhos, em especial os idosos, apresentam dificuldades de precisão ao clicar em pequenas áreas de links.

Integração: diretriz 2.4 - Navegável

- Critério de Sucesso 2.4.13: Icones ou imagens adjacentes devem fazer parte da área de ativação dos links.

Motivação: Imagens pequenas ou ícones adjacentes aos links confundem os adultos mais velhos, visto que eles tendem a clicar nas imagens ao invés do links.

Integração: diretriz 2.4 - Navegável

- Critério de Sucesso 2.4.14: A página Web deve diferenciar os links visitados dos links não visitados.

Motivação: adultos mais velhos tendem a esquecer os links que eles já visitaram, devido às deficiências cognitivas.

Integração: diretriz 2.4 - Navegável

- Critério de Sucesso 2.4.15: A página Web deve apresentar de forma distinta as opções de menu que já foram visitadas daquelas que ainda não foram selecionadas.

Motivação: adultos mais velhos tendem a esquecer quais opções de menu eles já visitaram.

Integração: diretriz 2.4 - Navegável

- Critério de Sucesso 2.4.16: Os menus do tipo drop-down devem apresentar apenas um nível de opções.

Motivação: adultos mais velhos apresentam grande dificuldade ao interagir com vários níveis de menus do tipo drop-down, acionando as opções erradas frequentemente.

Integração: diretriz 2.4 - Navegável

- Critério de Sucesso 2.4.17: As opções intermediárias do menu, quando selecionadas, devem apresentar uma página contendo suas opções subsequentes e elementos alternativos para o seu acionamento, tais como botões e links.

Motivação: é comum adultos mais velhos acionarem as opções intermediárias dos menus quando estão tentando alcançar uma opção do último nível.

Integração: diretriz 2.4 - Navegável 
- Critério de Sucesso 2.4.18: Icones devem ser facilmente associados com objetos do mundo real.

Motivação: adultos mais velhos tendem a relacionar as informações que visualizam com objetos do mundo real na tentativa de construção de um modelo mental que os façam relembrar a informação ou tarefa em momentos posteriores.

Integração: diretriz 2.4 - Navegável

- Critério de Sucesso 2.4.19: A página deve apresentar meios que permitam ao usuário visualizar um resumo de suas interações anteriores.

Motivação: é importante que os usuários possam rever suas experiências de sucesso como forma de incentivá-los a realizar novas interações, reduzindo a insegurança e a quantidade de erros durante a navegação ou execução de uma tarefa.

Integração: diretriz 2.4 - Navegável

\subsubsection{Compreensível}

- Critério de Sucesso 3.2.6: A página inicial deve identificar claramente quais partes da aplicação Web podem ser acessadas com ou sem autenticação. Motivação: adultos mais velhos tendem a apresentar dificuldades de compreensão do estado do sistema e normalmente confundem mensagens de erro do sistema com as mensagens a respeito da necessidade de autenticação.

Integração: diretriz 3.2 - Previsível

- Critério de Sucesso 3.2.7: A página Web não deve apresentar funcionalidades distintas com descrições e títulos já utilizados em contextos diferentes.

Motivação: adultos mais velhos podem encontrar dificuldades para identificar e distinguir corretamente as funcionalidades do sistema.

Integração: diretriz 3.2 - Previsivel

- Critério de Sucesso 3.2.8: A página Web não deve ter a mesma forma de apresentação para links e outros componentes da interface que não aceitem ativação.

Motivação: adultos mais velhos tendem a apresentar dificuldades na distinção entre componentes que possibilitam e os que não possibilitam interação. 
Integração: diretriz 3.2 - Previsível

- Critério de Sucesso 3.3.7: Na página Web que contem campos para a entrada de dados devem ser explicitadas informaçôes sobre o formato de dado e seu domínio, ou seja, informações de como o usuário deve preencher o campo.

Motivação: adultos mais velhos apresentam dificuldades no preenchimento de campos de formulário e necessitam de visualização de exemplos e explicações de como completar a tarefa.

Integração: diretriz 3.3 - Assistência de entrada

- Critério de Sucesso 3.3.8: A página Web deve fornecer todas as informações necessárias para a conclusão de tarefas específicas.

Motivação: adultos mais velhos tendem a necessitar de mais tempo que os jovens para realizar uma tarefa complexa, tais como o preenchimento de formulários, confirmações de pagamentos, entre outras, o que acaba gerando a expiração da sessão da aplicação. Dessa forma a página Web deve apresentar as explicações de como completar a tarefa previamente.

Integração: diretriz 3.3 - Assistência de entrada

- Critério de Sucesso 3.3.9: A página Web deve fornecer recursos interativos para auxiliar o preenchimento de campos de formulário.

Motivação: adultos mais velhos geralmente apresentam mais erros durante o preenchimento de formulários, de forma que a página Web deve ser capaz de prever suas dificuldades e então auxiliá-los por meio de apresentação de mensagens de texto e voz.

Integração: diretriz 3.3 - Assistência de entrada

- Critério de Sucesso 3.3.10: A página Web deve disponibilizar diferentes meios de preenchimento de informações em campos de formulários além do teclado.

Motivação: adultos mais velhos tendem a apresentar grandes dificuldades na digitação de sequências de números pelo teclado.

Integração: diretriz 3.3 - Assistência de entrada

- Critério de Sucesso 3.3.11: A página Web deve fornecer um canal simples e pragmático para que o usuário informe sobre erros verificados na página.

Motivação: adultos mais velhos precisam se sentir confiantes para reportarem 
suas experiências e dificuldades para o desenvolvedor Web.

Integração: diretriz 3.3 - Assistência de entrada

No decorrer da elaboração da proposta de extensão dos critérios de sucesso foram identificadas sugestões que já haviam sido endereçadas por princípios de usabilidade e também pelo Projeto WAI-AGE (W3C, 2008a), tais como:

7. Critério de Sucesso para Diretriz 1.4: O conteúdo principal da página Web deve ser apresentado no campo visual central do usuário, $15 \%$ de margens esquerda e direita, e $20 \%$ abaixo do topo

Motivação: em observações de campo foi verificado que adultos mais velhos focam sua atenção no centro da tela, ignorando as informações apresentadas em menus laterais, cabeçalhos e rodapés.

Integração: diretriz 1.4 - Discernível.

8. Critério de Sucesso para Diretriz 2.4: Não apresentar links com referências inválidas na interface.

Motivação: Links quebrados frustram as expectativas dos adultos mais velhos.

Integração: diretriz 2.4 - Navegável

9. Critério de Sucesso para Diretriz 2.4: Links devem referenciar o tópico exato referenciado pelo seu nome.

Motivação: adultos mais velhos apresentam grande dificuldade para localizar informações. Normalmente esses usuários abandonam sua busca pelo tópico desejado quando eles são redirecionados para a página inicial do site ao invés do tópico descrito pelo seu nome.

Integração: diretriz 2.4 - Navegável

10. Critério de Sucesso para Diretriz 2.4: As opções de menu apresentadas devem direcionar para a tarefa ou página correta.

Motivação: devido à dificuldade para identificar a informação ou a tarefa correta na interface, os adultos mais velhos se sentem frustrados quando são redirecionados para páginas que não se referem a ação que eles esperavam.

Integração: diretriz 2.4 - Navegável

11. Critério de Sucesso para Diretriz 2.4: Deve haver a opção de apresentação da página inicial do site em todas as suas páginas secundárias.

Motivação: adultos mais velhos se confundem facilmente e normalmente desejam 
retomar o ponto inicial para buscarem novamente seu objetivo.

Integração: diretriz 2.4 - Navegável

12. Critério de Sucesso para Diretriz 3.1: A interface da Web não deve apresentar grande volume de informação de modo a não provocar sobrecarga cognitiva nos adultos mais velhos.

Motivação: dentre as consequências do envelhecimento está a diminuição da capacidade cognitiva, de modo que se deve priorizar o design simples e minimalista. Integração: diretriz 3.1 - Legível

Segundo David Sloan et al. Sloan (2006), os desenvolvedores de Web têm muito a ganhar com a adoção em suas práticas, do material obtido em pesquisas baseadas em diretrizes. Existe ainda a necessidade de um maior reconhecimento por parte dos desenvolvedores a respeito dos reais problemas que afetam os usuários mais velhos em suas interações com a Web e essa é uma questão que não pode ser superada simplesmente por meio da apresentação de um site tecnicamente acessível. É preciso encontrar meios para que os usuários sejam capazes de personalizar a interface de forma a compensar seus problemas de acessibilidade, sem que para isso grandes habilidades técnicas sejam exigidas.

\subsection{Sugestões de Solução para os Principais Proble- mas}

Tendo por base as dificuldades observadas nos experimentos descritos no Capítulo 5 foram elencadas sugestões de desenvolvimento visando a superação de tais barreiras. Algumas dificuldades, obtidas por meio de observação de grupos de usuários, não podem ser classificadas como sendo de usabilidade ou de acessibilidade de aplicações de software, visto que envolvem características de ordem socioeconômicas e socioculturais, tais como:

- Falta de computador em casa: impossibilidade de treinar o que aprendeu e progredir no uso da Web;

- Medo e insegurança: temor em danificar os programas devido ao manuseio incorreto do mouse e/ou do teclado;

- Medo ou insegurança ao utilizar a Internet e redes wireless;

- Falta de confiança nos sistemas de segurança dos bancos on-line ou de sistemas que necessitem de dados sigilosos; 
- Medo de adquirir vírus;

- Não familiaridade com instruções e mensagens: a falta de hábito de leitura e os termos estrangeiros geram resistências, tornando as instruções menos acessíveis;

- Falta de atenção e esquecimento: característica muito comum devido às perdas cognitivas observadas durante o envelhecimento.

Outras dificuldades, também observadas, estão relacionadas com a interface dos sites da Web e foram agrupadas nos sete seguintes grupos descritos a seguir:

1. Dificuldade de leitura e compreensão de textos;

2. Dificuldade de reconhecimento e acesso aos links;

3. Dificuldade de navegação;

4. Dificuldade na realização de tarefas específicas;

5. Dificuldade na realização de compras e lojas on-line;

6. Dificuldade na busca e localização da informação;

7. Dificuldade na comunicação com os responsáveis pelo site.

A definição desses grupos de problemas com suas respectivas sugestões de solução estão descritas a seguir, relacionando-as aos critérios de sucesso da WCAG 2.0 (identificados por "A"), aos critérios estendidos (identificados por "A" e representados por “*”) (Lara et al., 2010b), bem como aos princípios de usabilidade (identificados por "U").

\subsubsection{Dificuldade de leitura e compreensão de textos}

A legibilidade ainda é um problema que os adultos mais velhos encontram em grande parte dos sites da Web, independentemente da qualidade visual dos mesmos. Ocorre tanto nos textos disponibilizados quanto em mensagens provenientes do sistema e opções de menus. Texto com letras pequenas ou desfocado não é um problema apenas para os adultos mais velhos, pois mesmo as pessoas que não apresentam problemas visuais preferem ler conteúdos sem esforços. No Quadro 2 são apresentadas as principais dificuldades e as respectivas sugestões (rotulados por "L") para a minimização desses problemas. 


\begin{tabular}{|c|c|c|c|}
\hline Índice & Problema & Sugestão de Ajustes & Critério \\
\hline L1 & Tamanho de fonte pequeno & $\begin{array}{l}\text { Utilizar fonte com tamanho } \\
\text { mínimo de } 12 \text { pontos }\end{array}$ & $\overline{\mathrm{A} 1.4 .4}$ \\
\hline L2 & $\begin{array}{l}\text { Tamanho do texto não é re- } \\
\text { dimensionável }\end{array}$ & $\begin{array}{llr}\text { Possibilitar } & \text { o } & \text { au- } \\
\text { mento/diminuição } & \text { do } & \text { tamanho } \\
\text { do texto } & & \end{array}$ & A1.4.4 \\
\hline L3 & $\begin{array}{l}\text { Linguagem técnica no texto } \\
\text { e em mensagens de erro }\end{array}$ & $\begin{array}{l}\text { Utilizar linguagem mais próxima } \\
\text { da realidade do usuário }\end{array}$ & A3.1.1 \\
\hline L4 & $\begin{array}{l}\text { Pouco contraste entre a cor } \\
\text { do texto e a cor de fundo }\end{array}$ & $\begin{array}{l}\text { Possibilitar alteração entre cor de } \\
\text { texto e cor do fundo }\end{array}$ & A1.4.8 \\
\hline L5 & Excesso de informação & $\begin{array}{l}\text { Disponibilizar somente as in- } \\
\text { formações mais importantes }\end{array}$ & A3.1.7* \\
\hline L6 & $\begin{array}{l}\text { Dispersão de informações } \\
\text { relacionadas }\end{array}$ & $\begin{array}{l}\text { Agrupar as informações relacio- } \\
\text { nadas }\end{array}$ & $\overline{\mathrm{U} 4, \mathrm{U} 8}$ \\
\hline L7 & $\begin{array}{l}\text { Falta de centralização da in- } \\
\text { formação }\end{array}$ & $\begin{array}{l}\text { Centralizar a informação essen- } \\
\text { cial com o uso de bordas laterais }\end{array}$ & $\mathrm{A} 1.4 .10^{*}$ \\
\hline L8 & Barra de rolagem & $\begin{array}{l}\text { Dividir o conteúdo em páginas } \\
\text { curtas que não necessitem da } \\
\text { barra de rolagem }\end{array}$ & $\mathrm{A} 2.1 .4^{*}$ \\
\hline L9 & $\begin{array}{l}\text { Mensagens de erro e avi- } \\
\text { sos exibidos no rodapé da } \\
\text { página }\end{array}$ & $\begin{array}{l}\text { Apresentar as mensagens do sis- } \\
\text { tema no foco de visão do usuário, } \\
\text { geralmente na parte central da } \\
\text { tela }\end{array}$ & $\mathrm{A} 1.4 .10^{*}$ \\
\hline L10 & $\begin{array}{l}\text { Elementos de layout deixam } \\
\text { o texto em segundo plano }\end{array}$ & $\begin{array}{l}\text { Evitar o uso de texto com todas } \\
\text { as letras maiúsculas e textos em } \\
\text { movimentos }\end{array}$ & A1.3.1 \\
\hline L11 & $\begin{array}{l}\text { Atualização automática } \\
\text { do texto em intervalos de } \\
\text { tempo pré-determinados }\end{array}$ & $\begin{array}{l}\text { Deixar a atualização da página ao } \\
\text { controle do usuário }\end{array}$ & A3.2.5 \\
\hline
\end{tabular}

Quadro 2: Problemas e sugestões de ajustes para a legibilidade 


\subsubsection{Dificuldade de reconhecimento e acesso aos links}

Uma dificuldade ocorre quando o usuário não consegue diferenciar um texto comum de um link. Usuários inexperientes não percebem a distinção do formato do apontador quando varre a área do link, ou seja, o apontador em formato de seta ou em formato de mão representam a mesma coisa. Outra característica que deve ser considerada é o esquecimento ou a distração das pessoas mais velhas com relação aos links já visitados. Dessa forma, é importante considerar o uso dos seguintes recursos (rotulados por "RL"):

- RL1 - utilizar recursos visuais e/ou sonoros que destaquem links em imagens, cabeçalhos e textos em negrito (A1.4.11*);

- RL2 - diferenciar com recursos visuais e/ou sonoros os links não visitados e já visitados, incluindo as opções de menus (A2.4.16*);

- RL3 - utilizar área de ativação dos links suficiente para acomodar difuldades motoras como tremores ou a falta de exatidão por parte dos usuários $\left(\mathrm{A} 2.4 .15^{*}\right)$;

- RL4 - incorporar ao link as imagens ou gráficos que se encontram muito próximos da sua área de ativação (A2.4.15*);

- RL5 - utilizar recursos visuais que destaquem a área em que o usuário pode clicar (A1.4.11).

\subsubsection{Dificuldade de navegação}

Segundo Nielsen \& Loranger (Nielsen e Loranger, 2007), os sites mais eficazes em direcionar as pessoas ao lugar correto são aqueles que correspondem às expectativas dos usuários. Quando os usuários não conseguem atingir seus objetivos utilizando os elementos de navegação presentes num site, é comum que eles suponham que as informações procuradas não se encontram lá e visitem outros sites. Os principais problemas de navegação observados e as correspondentes correções sugeridas para sua melhoria são apresentados no Quadro 3, e estão rotulados por "N".

A elaboração de uma estrutura navegacional consistente e adequada faz com que os usuários se sintam confiantes em explorar o site, visto que percebem que podem retornar facilmente às páginas acessadas anteriormente, sem dificuldades. 


\begin{tabular}{|c|c|c|c|}
\hline Índice & Problema & Sugestão de Ajustes & Critério \\
\hline N1 & $\begin{array}{l}\text { Uso de links quebrados ou } \\
\text { links que possuem rótulos } \\
\text { sobre assuntos específicos } \\
\text { mas que endereçam home- } \\
\text { pages de sites }\end{array}$ & $\begin{array}{l}\text { Verificar a disponibilidade de to- } \\
\text { dos os links utilizados e se re- } \\
\text { almente direcionam o link para } \\
\text { a página que trata do assunto } \\
\text { especificado pelo rótulo }\end{array}$ & $\begin{array}{l}\mathrm{A} 2.4 .12^{*}, \\
\mathrm{~A} 2.4 .13^{*}\end{array}$ \\
\hline N2 & $\begin{array}{l}\text { Uso de elementos de na- } \\
\text { vegação movéis e rápidos } \\
\text { tais como os menus suspen- } \\
\text { sos (pull-down e drop-down) }\end{array}$ & $\begin{array}{l}\text { Utilizar elementos de navegação } \\
\text { estáticos ou com velocidade lenta } \\
\text { o suficiente para acomodar as di- } \\
\text { ficuldades motoras dos usuários, } \\
\text { tais como: tremores e dificuldades } \\
\text { de precisão }\end{array}$ & $\mathrm{A} 2.2 .6^{*}$ \\
\hline N3 & $\begin{array}{l}\text { Falta de informação para } \\
\text { onde vai o link }\end{array}$ & $\begin{array}{l}\text { Mostrar o assunto principal ou } \\
\text { pelo menos o endereço Web que } \\
\text { será acessado por meio do link }\end{array}$ & $\mathrm{A} 2.4 .4$ \\
\hline $\mathrm{N} 4$ & Uso de janelas pop-up & $\begin{array}{l}\text { Evitar ao máximo o uso de jane- } \\
\text { las pop-up, mas se for necessário, } \\
\text { deve-se garantir que ela tenha o } \\
\text { tamanho suficiente para transmi- } \\
\text { tir a mensagem ao usuário sem } \\
\text { a necessidade de uso da barra de } \\
\text { rolagem e que sua aparência seja } \\
\text { diferente das caixas de diálogo } \\
\text { utilizadas pelo ambiente operaci- } \\
\text { onal }\end{array}$ & $\mathrm{A} 2.1 .15^{*}$ \\
\hline N5 & $\begin{array}{l}\text { Uso de recursos pouco } \\
\text { visíveis para a realização de } \\
\text { tarefas importantes dentro } \\
\text { do site }\end{array}$ & $\begin{array}{l}\text { Destacar os elementos de design } \\
\text { que são fundamentais para a na- } \\
\text { vegação, colocando-os no foco de } \\
\text { visão do usuário }\end{array}$ & $\begin{array}{l}\text { A1.4.10*, } \\
\text { A } 1.4 .11^{*}\end{array}$ \\
\hline N6 & $\begin{array}{l}\text { Nomes confusos para as ca- } \\
\text { tegorias }\end{array}$ & $\begin{array}{l}\text { Os nomes das categorias devem } \\
\text { fazer sentido aos usuários e não } \\
\text { aos projetistas }\end{array}$ & A3.1.2 \\
\hline N7 & $\begin{array}{l}\text { Arquitetura da informação } \\
\text { inadequada }\end{array}$ & $\begin{array}{l}\text { Nomes, layouts e relacionamentos } \\
\text { entre páginas individuais devem } \\
\text { ser apresentados claramente }\end{array}$ & $\mathrm{U} 4, \mathrm{U} 8$ \\
\hline
\end{tabular}

Quadro 3: Problemas e sugestões de ajustes para a navegação 


\subsubsection{Dificuldade na realização de tarefas específicas}

Uma dificuldade ocorre quando o usuário não consegue realizar tarefas que facilitariam sua vida diária por meio de interação na Web. Os principais problemas observados são mostrados no Quadro 4 (rotulados por "RT"), bem como as respectivas sugestões para minimizar tais problemas.

\subsubsection{Dificuldade na realização de compras em lojas on-line}

Fazer compras on-line é muito conveniente dado que apresenta várias vantagens, tais como: economia de tempo, possibilidade de comparação de preço em várias lojas, flexibilidade de horário, liberdade em desistir da compra em qualquer momento sem a pressão da venda por parte de vendedores, entre outros. Mas, apesar das vantagens, é comum observar a resistência dos usuários, principalmente dos mais velhos, ao comércio eletrônico. Nos Quadros 5 e 6 são mostrados os principais obstáculos encontrados pelos usuários e as respectivas sugestões de ajuste para os problemas (rotulados por "CO").

\subsubsection{Dificuldade na busca e localização da informação}

O mecanismo de busca de um site da Web é um facilitador para o acesso ao conteúdo. É normalmente muito útil e utilizado por usuários que sabem realmente o que querem. A principal dificuldade reportada pelos adultos mais velhos observados, está em localizar a informação desejada em meio ao excesso de informações e links que normalmente são apresentados, como resultados da busca, na forma de listas ou menus. No Quadro 7 (rotulados por "B") são apresentadas as principais dificuldades relativas ao mecanismo de busca e sugestões de como minimizar tais problemas.

\subsubsection{Dificuldade de comunicação com os responsáveis pelo site}

Esse tipo de dificuldade ocorre quando o usuário não consegue utilizar o site e deseja se comunicar com os seus responsáveis. Na maioria dos casos não há opção para a 


\begin{tabular}{|c|c|c|c|}
\hline Índice & Problema & Sugestão de Ajustes & Critério \\
\hline$\overline{\mathrm{RT1}}$ & $\begin{array}{l}\text { Exigência de grande número } \\
\text { de interações para a con- } \\
\text { clusão da tarefa }\end{array}$ & $\begin{array}{l}\text { Dividir a tarefa em passos meno- } \\
\text { res, seguindo um processo linear, } \\
\text { para que a tela não necessite de } \\
\text { barra de rolagem e nem o tempo } \\
\text { para sua conclusão expire }\end{array}$ & $\begin{array}{l}\mathrm{A} 2.1 .4 \\
\mathrm{~A} 2.2 .1\end{array}$ \\
\hline RT2 & $\begin{array}{l}\text { Falta de informação anteci- } \\
\text { pada sobre como realizar a } \\
\text { tarefa }\end{array}$ & $\begin{array}{l}\text { Utilizar um sinalizador que indi- } \\
\text { que o quanto da tarefa já foi con- } \\
\text { cluído e disponibilizar um vídeo } \\
\text { mostrando todos os passos da in- } \\
\text { teração para que os usuários se } \\
\text { sintam mais seguros e confiantes }\end{array}$ & A2.4.8 \\
\hline RT3 & $\begin{array}{l}\text { Ausência das informações } \\
\text { necessárias para a conclusão } \\
\text { da tarefa }\end{array}$ & $\begin{array}{l}\text { Indicar em cada passo da ta- } \\
\text { refa quais informações serão ne- } \\
\text { cessárias, de modo que o usuário } \\
\text { já possa tê-las em mãos antes do } \\
\text { início do processo }\end{array}$ & $\begin{array}{l}\text { A1.3.3 } \\
\text { A3.3.8* }\end{array}$ \\
\hline RT4 & $\begin{array}{l}\text { Ausência de avisos a res- } \\
\text { peito da formatação de } \\
\text { campos de formulários }\end{array}$ & $\begin{array}{l}\text { Descrever o tipo de formatação de } \\
\text { cada campo e incluir um exemplo }\end{array}$ & A3.3.2 \\
\hline RT5 & $\begin{array}{l}\text { Necessidade de } \\
\text { memorização de usernames } \\
\text { para autenticações diversas }\end{array}$ & $\begin{array}{l}\text { Disponibilizar outros tipos de au- } \\
\text { tenticações tais como: perguntas } \\
\text { pessoais, reconhecimento de face, } \\
\text { dentre outros }\end{array}$ & A3.2.6* \\
\hline RT6 & $\begin{array}{l}\text { Digitação de senhas em te- } \\
\text { clados virtuais de difícil pre- } \\
\text { cisão }\end{array}$ & $\begin{array}{l}\text { Disponibilizar a entrada de dados } \\
\text { por diversos dispositivos de en- } \\
\text { trada, tais como: teclado, mouse, } \\
\text { microfone (via voz), dentre outros }\end{array}$ & $\begin{array}{l}\text { A2.1.1, } \\
\text { A2.1.6* } \\
\text { A3.3.10 }\end{array}$ \\
\hline RT7 & $\begin{array}{l}\text { Digitação dos números do } \\
\text { código de barras/cartão de } \\
\text { crédito para o pagamento de } \\
\text { contas }\end{array}$ & $\begin{array}{l}\text { Disponibilizar a entrada de dados } \\
\text { por diversos dispositivos de en- } \\
\text { trada, tais como: teclado, mouse, } \\
\text { microfone (via voz), dentre outros }\end{array}$ & $\begin{array}{l}\text { A2.1.1, } \\
\text { A2.1.6* } \\
\text { A3.3.10 }\end{array}$ \\
\hline RT8 & $\begin{array}{l}\text { Falta de destaque a botões } \\
\text { ou links que realizem } \\
\text { funções importantes }\end{array}$ & $\begin{array}{l}\text { Destacar os elementos de design } \\
\text { que necessitem de interação de } \\
\text { forma visual ou sonora }\end{array}$ & $\mathrm{A} 1.4 .11^{*}$ \\
\hline RT9 & $\begin{array}{l}\text { Memorização e retenção do } \\
\text { aprendizado }\end{array}$ & $\begin{array}{l}\text { Disponibilizar a visualização de } \\
\text { histórico de operações realizadas } \\
\text { e experiências anteriores passo a } \\
\text { passo }\end{array}$ & $\mathrm{A} 2.4 .23^{*}$ \\
\hline
\end{tabular}

Quadro 4: Problemas e sugestões de ajustes para a realização de tarefas específicas 


\begin{tabular}{|c|c|c|c|}
\hline Índice & Problema & Sugestão de Ajustes & Critério \\
\hline$\overline{\mathrm{CO} 1}$ & Falta de confiança no site & $\begin{array}{l}\text { Descrever a empresa objetiva- } \\
\text { mente, como são realizadas os } \\
\text { procedimentos de compra, formas } \\
\text { de pagamento, taxas, descontos, } \\
\text { entrega e devolução de produtos, } \\
\text { segurança da informação, bem } \\
\text { como possibilitar que usuários do } \\
\text { site registrem sua opinião sobre } \\
\text { a empresa e sobre os produtos } \\
\text { adquiridos }\end{array}$ & $\overline{\mathrm{U} 2}$ \\
\hline $\mathrm{CO} 2$ & $\begin{array}{l}\text { Descrição resumida do pro- } \\
\text { duto }\end{array}$ & 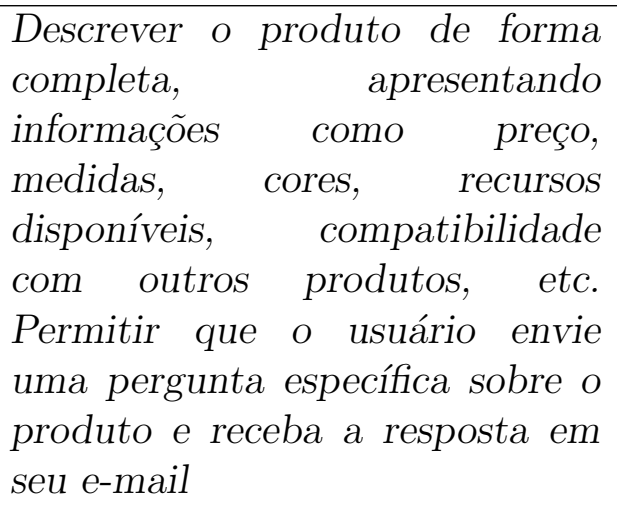 & $\begin{array}{l}\mathrm{U} 2, \\
\mathrm{~A} 3.3 .11\end{array}$ \\
\hline CO3 & $\begin{array}{l}\text { Demora no carregamento da } \\
\text { página }\end{array}$ & $\begin{array}{l}\text { Verificar o tempo de carrega- } \\
\text { mento da página Web em uma co- } \\
\text { nexão de Internet média e compa- } \\
\text { rar com o tempo de carregamento } \\
\text { das páginas de empresas concor- } \\
\text { rentes, visto que se a página ti- } \\
\text { ver um carregamento lento ela } \\
\text { pode frustar os usuários fazendo } \\
\text { com que eles desistam do acesso, } \\
\text { como pode também obter um } \\
\text { posicionamento ruim em retor- } \\
\text { nos de busca que utilizam esse } \\
\text { parâmetro para sua classificação }\end{array}$ & U1 \\
\hline $\mathrm{CO} 4$ & $\begin{array}{l}\text { Links que não ativam a } \\
\text { compra }\end{array}$ & $\begin{array}{l}\text { Verificar a disponibilidade de to- } \\
\text { dos os links utilizados e se real- } \\
\text { mente direcionam o link para a } \\
\text { compra, pois caso contrário po- } \\
\text { dem gerar incredibilidade na em- } \\
\text { presa }\end{array}$ & $\begin{array}{l}\mathrm{A} 2.4 .12^{*}, \\
\mathrm{~A} 2.4 .13^{*}\end{array}$ \\
\hline
\end{tabular}

Quadro 5: Problemas e sugestões de ajustes para sistemas de compras on-line 


\begin{tabular}{|c|c|c|c|}
\hline Índice & Problema & Sugestão de Ajustes & Critério \\
\hline$\overline{\mathrm{CO} 5}$ & $\begin{array}{l}\text { Exigência de autenticação } \\
\text { para efetuar a compra }\end{array}$ & $\begin{array}{l}\text { Permitir que os dados obri- } \\
\text { gatórios sejam fornecidos no mo- } \\
\text { mento da conclusão da compra e } \\
\text { também disponibilizar uma forma } \\
\text { prática de recuperação dos dados } \\
\text { de pessoas credenciadas no site }\end{array}$ & A3.2.6* \\
\hline $\mathrm{CO} 6$ & $\begin{array}{l}\text { Categorização do produto } \\
\text { de forma errada }\end{array}$ & $\begin{array}{l}\text { Disponibilizar o produto em to- } \\
\text { das as categorias nas quais ele } \\
\text { possa se enquadrar }\end{array}$ & $\mathrm{U} 2$ \\
\hline $\mathrm{CO} 7$ & $\begin{array}{l}\text { Ausência de preço do pro- } \\
\text { duto }\end{array}$ & $\begin{array}{l}\text { Disponibilizar um preço aproxi- } \\
\text { mado do produto é melhor do } \\
\text { que não mostrar nada, visto que } \\
\text { se nenhum preço é mostrado, as } \\
\text { pessoas podem supor que ele seja } \\
\text { caro. O preço já deve ser mos- } \\
\text { trado na página das categorias e } \\
\text { não somente na página interna de } \\
\text { descrição do produto }\end{array}$ & $\mathrm{U} 2$ \\
\hline $\mathrm{CO} 8$ & $\begin{array}{l}\text { Ausência ou má definição da } \\
\text { imagem do produto }\end{array}$ & $\begin{array}{l}\text { Disponibilizar a imagem do pro- } \\
\text { duto e permitir que a mesma } \\
\text { seja ampliada. Para produtos } \\
\text { não convencionais, disponibilizar } \\
\text { imagens que descrevam sua forma } \\
\text { de utilização para que o usuário } \\
\text { possa ter absoluta certeza de que } \\
\text { é o produto que ele está procu- } \\
\text { rando }\end{array}$ & $\mathrm{U} 2, \mathrm{U} 8$ \\
\hline CO9 & $\begin{array}{l}\text { Visualização dos dados dos } \\
\text { itens do carrinho de com- } \\
\text { pras }\end{array}$ & $\begin{array}{l}\text { Disponibilizar imagem, descrição, } \\
\text { tamanho, quantidade, valor } \\
\text { unitário e preço total para } \\
\text { item do carrinho de compras. } \\
\text { Possibilitar que nessa mesma } \\
\text { página o usuário possa alterar } \\
\text { dados, como quantidade e } \\
\text { tamanho, por exemplo }\end{array}$ & U1, U3 \\
\hline $\mathrm{C} 10$ & $\begin{array}{l}\text { Apresentação do valor total } \\
\text { comprado com pouco desta- } \\
\text { que }\end{array}$ & $\begin{array}{l}\text { Disponibilizar com clareza to- } \\
\text { dos os valores envolvidos na } \\
\text { transação: preços, descontos, ta- } \\
\text { xas extras, fretes, etc. }\end{array}$ & $\mathrm{U} 1, \mathrm{U} 8$ \\
\hline
\end{tabular}

Quadro 6: Problemas e sugestões de ajustes para sistemas de compras on-line - continuação 


\begin{tabular}{|c|c|c|c|}
\hline Índice & Problema & Sugestão de Ajustes & Critério \\
\hline B1 & $\begin{array}{l}\text { O link do resultado da pes- } \\
\text { quisa direciona para páginas } \\
\text { iniciais dos sites }\end{array}$ & $\begin{array}{l}\text { Direcionar os links para o tópico } \\
\text { de consulta desejado e não para } \\
\text { páginas iniciais do site }\end{array}$ & A2.4.13* \\
\hline$\overline{\mathrm{B} 2}$ & $\begin{array}{l}\text { Palavras digitadas erradas } \\
\text { pelos usuários }\end{array}$ & $\begin{array}{l}\text { Eliminar caracteres indesejados } \\
\text { que prejudicam as pesquisas, uti- } \\
\text { lizar sinônimos, corrigir erros de } \\
\text { ortografia, utilizar metadados e } \\
\text { outras variantes que podem faci- } \\
\text { litar a busca ao documento dese- } \\
\text { jado }\end{array}$ & A3.3.1 \\
\hline B3 & $\begin{array}{l}\text { O trecho de descrição do } \\
\text { resultado não é suficiente- } \\
\text { mente claro }\end{array}$ & $\begin{array}{l}\text { Prover um visual mais limpo e } \\
\text { bons resumos na apresentação dos } \\
\text { resultados para que o usuário } \\
\text { possa identificar o que deseja }\end{array}$ & $\mathrm{U} 4, \mathrm{U} 8$ \\
\hline $\mathrm{B} 4$ & $\begin{array}{l}\text { Não existe uma ordem } \\
\text { lógica para a apresentação } \\
\text { dos resultados }\end{array}$ & $\begin{array}{l}\text { Categorizar os resultados de } \\
\text { forma semântica (tipos de texto, } \\
\text { gênero, necessidades pessoais) }\end{array}$ & $\mathrm{U} 4, \mathrm{U} 8$ \\
\hline B5 & $\begin{array}{l}\text { Inserção de palavras } \\
\text { genéricas }\end{array}$ & $\begin{array}{l}\text { Prover orientações e caminhos al- } \\
\text { ternativos quando os resultados } \\
\text { de uma pesquisa não forem es- } \\
\text { pecíficos }\end{array}$ & U7 \\
\hline $\mathrm{B} 6$ & $\begin{array}{l}\text { O usuário não sabe quais } \\
\text { palavras inserir em uma } \\
\text { caixa de busca }\end{array}$ & $\begin{array}{l}\text { Apoiar o usuário no preenchi- } \\
\text { mento da caixa de busca ou in- } \\
\text { centivá-lo a explorar o site por } \\
\text { meio dos elementos navegacionais } \\
\text { de forma que ele identifique o que } \\
\text { está procurando }\end{array}$ & A3.3.1 \\
\hline
\end{tabular}

Quadro 7: Problemas e sugestões de ajustes para a busca de informações 
realização do contato ou quando existe, exige o preenchimento de diversos campos de entrada além do campo destinado à mensagem propriamente dita.

Um possível ajuste seria a apresentação da opção de envio de mensagens de erros para o webmaster de forma simples e padronizada, sem a necessidade de preenchimento de muitas informações pessoais ou somente as essenciais.

\subsection{Um Apoio Sensível ao Contexto}

Durante todo o processo tanto de observação em campo, quanto das análises dos dados coletados via questionários, percebeu-se a necessidade do desenvolvimento de mecanismos que proporcionassem uma ajuda efetiva aos usuários com dificuldades na interação com a Web. Mas o que seria uma ajuda efetiva?

A abordagem tradicional para atender a essa demanda é usualmente realizada ao disponibilizar documentação, ou o Help, como é mais comumente conhecida. Mas, muitas vezes a ajuda baseada em texto torna-se difícil de ser seguida, fazendo com que os usuários relutem em utilizá-la (Goodall, 1992) (Rettig, 1991).

Nos últimos anos, os tutoriais em vídeo tornaram-se uma fonte de informações para os usuários, embora este tipo de recurso geralmente deva ser acessado fora do contexto da interface do usuário, em sites externos (Plaisant e Shneiderman, 2005). Embora já existam as formas contextuais de assistência, tais como as Tooltips (Farkas, 1993), raramente elas possuem o nível de detalhe que seria necessário para o usuário entender como usar uma ferramenta complexa, por exemplo. Seria desejável que mecanismos mais apropriados de auxílio fossem fornecidos no contexto da aplicação.

Foi constatado em campo que quando um usuário apresenta dificuldades relativas à falta de cultura de uso da Web, ele fica "paralisado" diante das opções oferecidas pela página e demora muito para encontrar a opção que realmente deseja, ou chega a abandonar a experiência sem nem sequer rolar a página e verificar a completude de seu conteúdo. A busca por auxílio via "Help" é praticamente impraticável para esse usuário.

Após a realização dos procedimentos de pesquisa descritos no Capítulo 5, ficou evidente para esta pesquisadora que certos grupos de usuários mais velhos são incapazes de usar a Web sem ajuda e para os quais o apoio que "imite" o suporte presencial é essencial. Optou-se por identificar quais aspectos do apoio pessoal eram mais valiosos e quais mecanismos deveriam ser incorporados às páginas Web para prover a ajuda efetiva. 
Segundo Fisk et al. (2009), no que se refere à atenção, tanto a atenção visual seletiva (varredura em um display visual) quanto a atenção visual dinâmica (reorientação do foco de atenção) mostram declínios durante o processo de envelhecimento, sendo que os adultos mais velhos tendem a se beneficiar de sugestões para orientar e captar sua atenção.

Seguindo essa abordagem e visando reduzir as demandas da memória de trabalho do público-alvo estudado, foi elaborado, como prova de conceito, um mecanismo de apoio à interação que tem por objetivos facilitar e estimular a interação de adultos de meia-idade e idosos com a Web.

Um sistema que implemente este mecanismo deve ser projetado com a finalidade de ser um programa leve, agradável ao usuário, e adicionar funções de usabilidade e acessibilidade durante a interação do usuário com a página Web, provendo maior integração entre os mesmos.

Para criar um mecanismo capaz de fornecer estímulos adequados ao contexto durante a interação foi necessário realizar, em primeiro lugar, a identificação do tipo das páginas Web, cuja etapa foi denominada de "categorização". A categorização consistiu na identificação automática dos principais elementos presentes em páginas Web e a sua classificação em uma determinada categoria, de acordo com sua funcionalidade principal. A partir dessa classificação foi elaborado um conjunto de mensagens e dicas de utilização apropriadas para o usuário.

A classificação de páginas da Web, também conhecida como categorização de páginas Web, é o processo de atribuição de uma página Web para uma ou mais categorias pré-definidas (Qi e Davison, 2009). A classificação do conteúdo de páginas Web é essencial para o rastreamento de conteúdo automático (crawling), o desenvolvimento assistido de diretórios da Web, a análise de links por tópicos específicos e para a publicidade contextual. A classificação de páginas da Web também pode ajudar a melhorar a qualidade das pesquisas na Internet (Qi e Davison, 2009).

O problema da classificação geral de páginas Web pode ser dividido em problemas de classificação mais específicos, como a classificação por assunto, a classificação funcional, a classificação por sentimento e outros tipos de classificação. A classificação por assunto tem como foco o assunto ou tema de uma página da Web. Por exemplo, julgar se uma página é relativa a "artes", "negócios" ou "esportes" é uma instância de classificação por assunto. A classificação funcional investiga o papel que a página Web exerce. Por exemplo, decidir se uma página é uma "página pessoal", "página de curso" ou "página de admissão" é uma instância de classificação funcional. A classificação por sentimento concentra-se na opinião que é apresentada em uma página da Web, isto é, na atitude do autor sobre algum tema em particular (Qi e Davison, 2009). 
Nesta pesquisa, após a classificação da página Web, o mecanismo deve identificar os elementos da página por meio do objeto DOM (Document Object Model) e destacar os elementos passíveis de interação, instruindo o usuário, via mensagem de voz ou texto, como proceder para interagir com tais elementos, bem como explicando sobre meios de acesso alternativos, tais como teclas de atalho, entre outras.

Um requisito importante a ser considerado é que o usuário pode interromper o funcionamento do mecanismo sempre que desejar, porém ao reativá-lo ele receberá os estímulos visuais e as instruções orais desde o início, podendo repetí-los quantas vezes quiser.

A plataforma de desenvolvimento a ser escolhida para a construção do protótipo deve considerar o potencial da ferramenta em relação à interatividade com páginas Web e a facilidade de implementação, ou seja, deve ser priorizada a utilização de linguagens de programação Web já conhecidas e que viabilizem a utilização de padrões sugeridos pela W3C.

\subsubsection{Projeto Tuki: um protótipo para apoio sensível ao con- texto}

A Web, além de oferecer aplicações para a comunicação, o entretenimento e a prestação de serviços on-line, deve oferecer também apoio para a realização da interação entre os usuários e os recursos disponíveis. Assim sendo, foi proposto um mecanismo de apoio à interação Web por meio de um add-on, de modo a incrementar as funcionalidades do navegador, permitindo às pessoas com mais idade o acesso às facilidades da interação com a Web da forma mais natural possível, promovendo sua integração social e sua inclusão digital, sempre visando reduzir as demandas de memória de trabalho e o conhecimento prévio.

O mecanismo, denominado Tuki, visa fornecer estímulos visuais e sonoros de forma a incentivar e apoiar a interação de adultos mais velhos com a Web, desempenhando o papel de um recurso de tecnologia assistiva. A ideia inicial é ilustrada na Figura 6.3 .

A versão inicial do mecanismo Tuki foi construída como um add-on do navegador Mozilla Firefox, que após ter sido instalada ficava em execução no navegador por todo o tempo e a partir do momento que o mecanismo era ativado, realizava a classificação da página corrente e fornecia mensagens de apoio à interação do usuário, conforme esquematizado na Figura 6.4.

Durante o desenvolvimento desse protótipo optou-se por realizar uma classificação funcional simples da página Web corrente, por meio de duas formas distintas. 


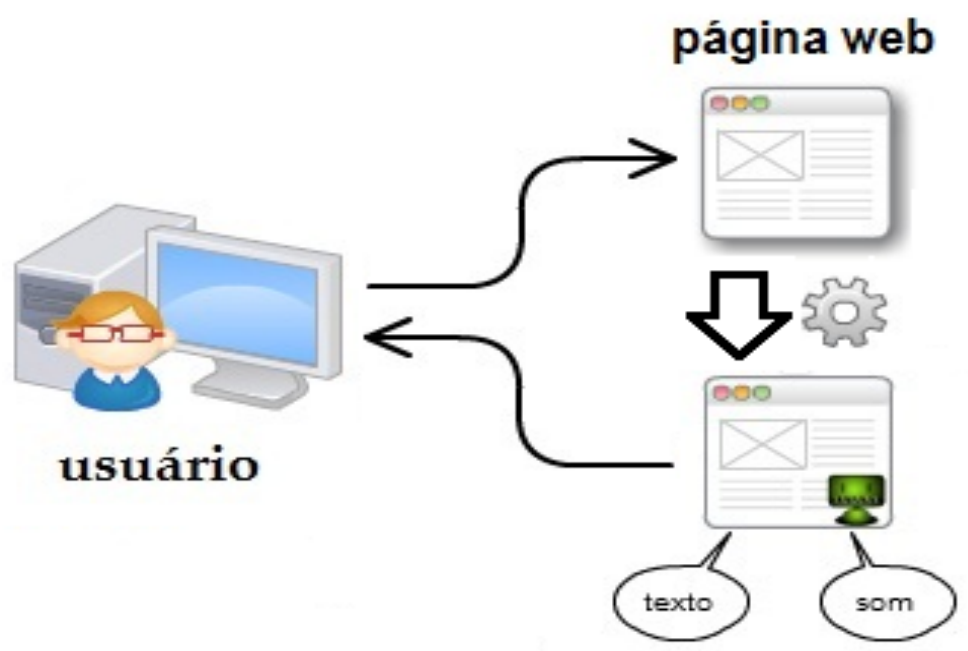

Figura 6.3: Ideia inicial da funcionalidade do mecanismo de auxílio Tuki

Além do processamento automático realizado pelo próprio mecanismo Tuki e com o objetivo de construir uma base de dados de páginas (URLs) com suas respectivas categorias, foi disponibilizado outro plug-in para o navegador Mozilla Firefox denominado de "mecanismo categorizador", que possibilitava o envio da classificação da página Web corrente de acordo com a percepção que os usuários possuíam da página. Optou-se por realizar essa coleta visto que uma ferramenta de livre acesso na Web é uma tecnologia viável para criação de um maior corpus de páginas Web categorizadas de forma bastante rápida.

Após a instalação do mecanismo classificador, a cada nova página Web que o usuário acessava lhe era apresentado um formulário de classificação, no qual o usuário informava sua idade, selecionava a categoria mais adequada à página em questão e a enviava para uma página receptora, que totalizava a quantidade de classificações por URL/Categoria. Foram disponibilizadas as categorias mais simples, tais como: informativo, bancário, vendas/compras, vídeos e cadastro, como mostrado na Figura $6.5(\mathrm{a})$.

Devido à necessidade de se obter a classificação absoluta/real das páginas para a criação da base de dados, o público-alvo utilizado para essa categorização foi, principalmente, composta por estudantes de nível superior em áreas relacionadas à computação, por se tratar de um público que apresenta maior experiência na utilização de recursos Web. Na Figura 6.5 (b) é apresentado um exemplo de execução do mecanismo classificador.

O mecanismo Tuki, ao ser ativado, realizava uma busca na base de dados para verificar se tal URL já havia sido categorizada (classificação livre coletada via participação de usuários Web) e caso não encontrasse a sua categoria, realizava a classificação automática da página Web corrente via a extração de itens de 


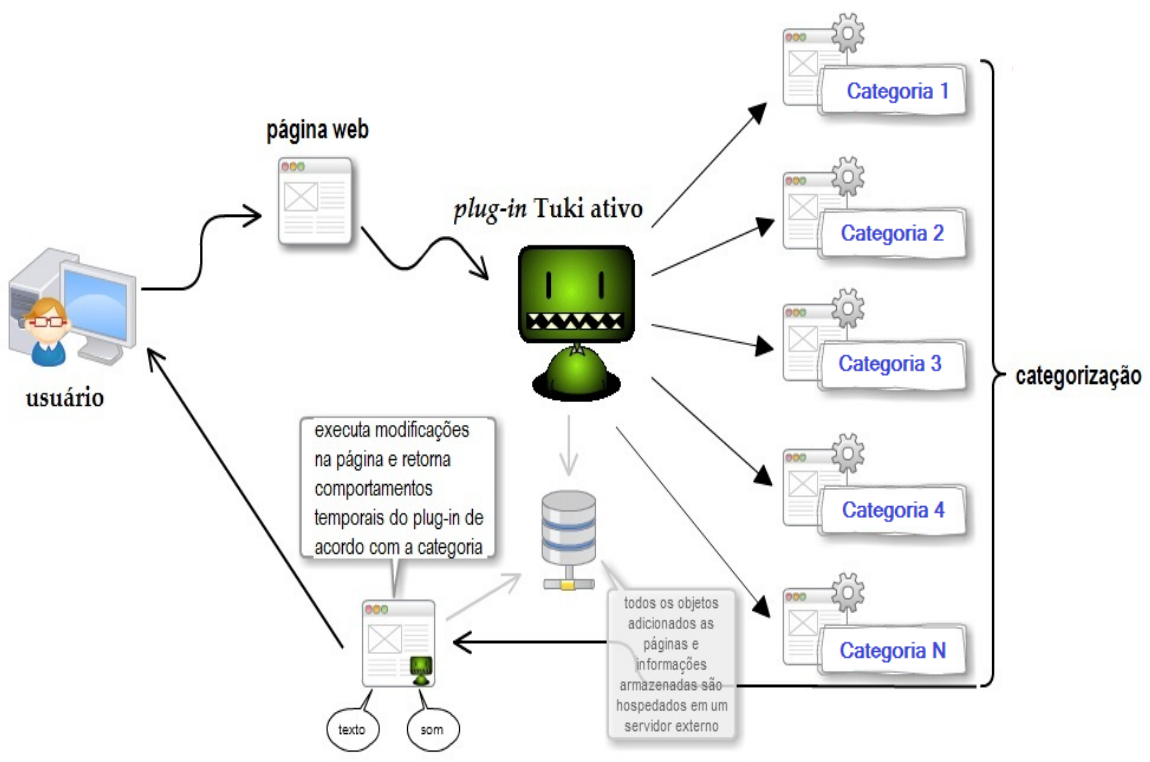

Figura 6.4: Mecanismo de auxílio Tuki

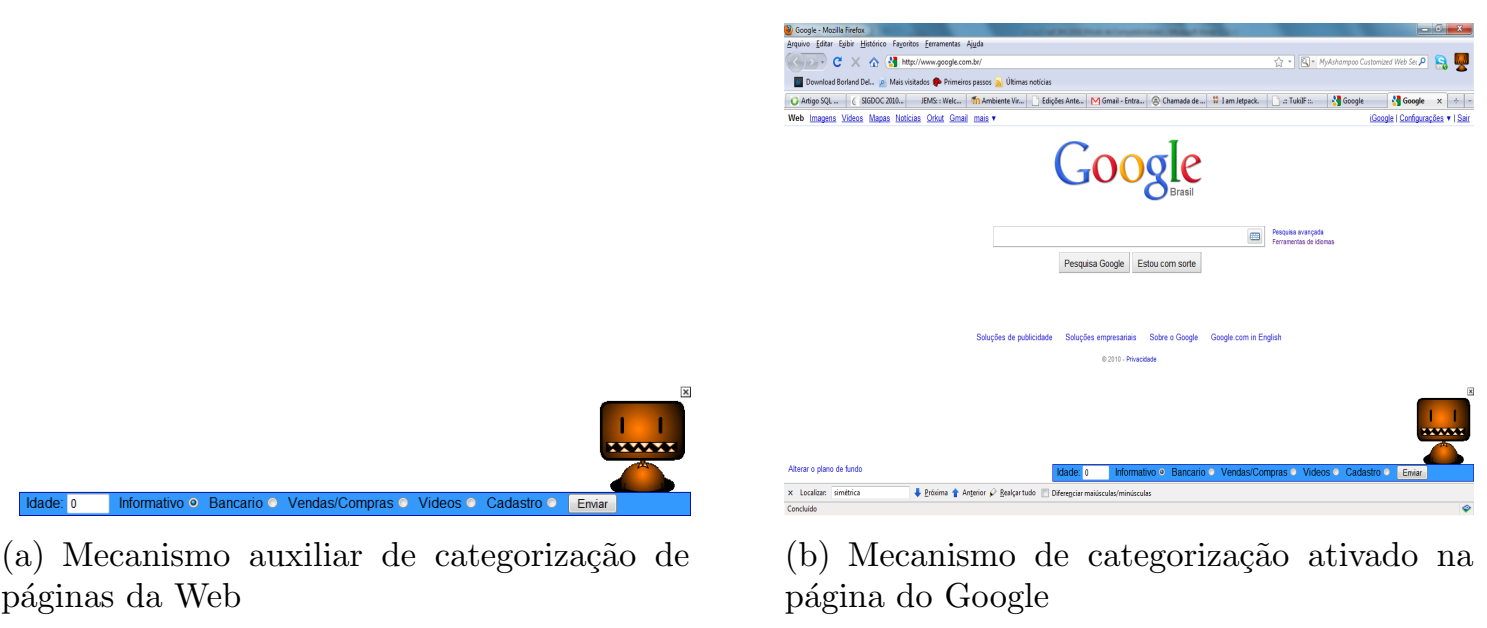

Figura 6.5: Mecanismo categorizador para páginas Web

informação do código-fonte da página, tais como: análise da própria URL da página, metadados, títulos, quantificação de links, parágrafos, imagens e objetos em Flash, dentre outros. Um peso era atribuído a cada item encontrado, totalizando um valor final para a classificação propriamente dita (Figura 6.6).

A definição dos pesos foi realizada de forma empírica, ou seja, de acordo com valores que representam a graduação do tipo de relevância observada nas pesquisas preliminares. Os valores de pesos utilizados foram:

- item de mínima relevância (2);

- item de baixa relevância (5);

- item relevante (10);

- item de máxima relevância (50). 
O item de maior relevância é o que melhor descreve a categoria, por exemplo, o peso 50 é atribuído a URLs de determinadas categorias ou devido à presença de metadados, por exemplo, \%tube\% em uma URL da categoria de vídeo.

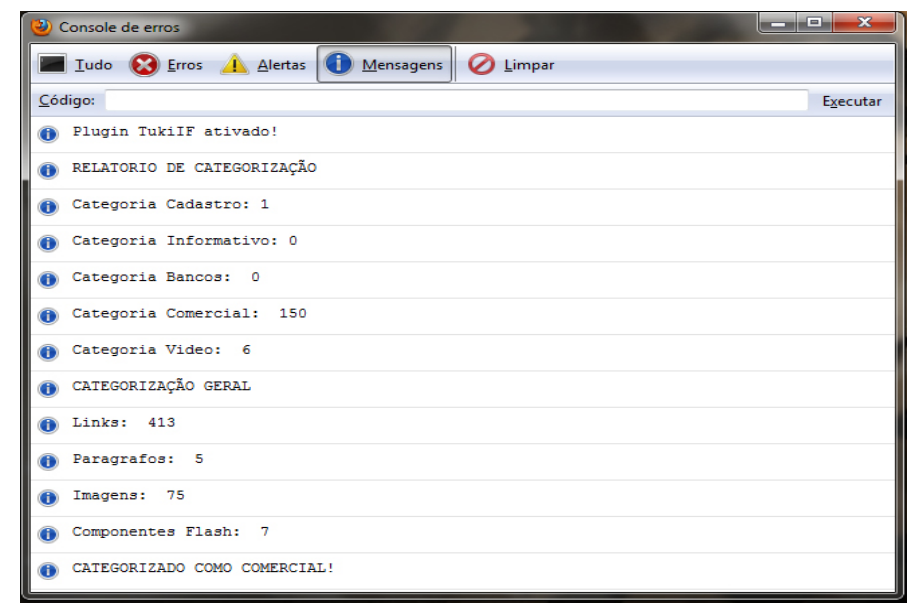

Figura 6.6: Relatório de classificação do mecanismo Tuki

Após a finalização da classificação da página Web, ações "comportamentais" eram executadas pelo mecanismo, ou seja, diversas funcionalidades transformavam a página visando fornecer um apoio acessível no contexto do conteúdo daquela página. A primeira ação consistia em realizar modificações no layout da página, eliminando pop-ups, banners e outros elementos que comprovadamente prejudicam a interação do público-alvo com as páginas Web, e em seguida oferecia estímulos visuais e instruções orais de acordo com a categoria da página.

A definição do comportamento do mecanismo Tuki depende diretamente dos elementos presentes na própria página Web em questão. Como prova de conceito, as páginas categorizadas no projeto Tuki foram as Wikis e páginas contendo formulário para cadastro.

Suponha, por exemplo, que a página Web corrente fosse uma página da Wikipédia (Figura 6.7). Inicialmente, ela será categorizada como uma página Wiki. A partir daí, elementos presentes em seu código-fonte são extraídos, para que o mecanismo consiga instruir o usuário sobre como e quais opções ele pode acessar.

O mecanismo de apoio para páginas Wiki destaca as principais opções de interação da página colocando uma borda ao redor da opção ao mesmo tempo em que reproduz um texto explicativo via voz. Para a opção de criação de contas (Figura 6.8) o usuário ouve: "Caso queira criar uma conta de usuário ou entrar em uma conta já existente clique com o mouse nesta região". Ao destacar o menu lateral esquerdo (Figura 6.9) é reproduzida a seguinte instrução: "Ao lado esquerdo da tela temos o menu de navegação, clique com o mouse em um dos itens para acessá-lo". 


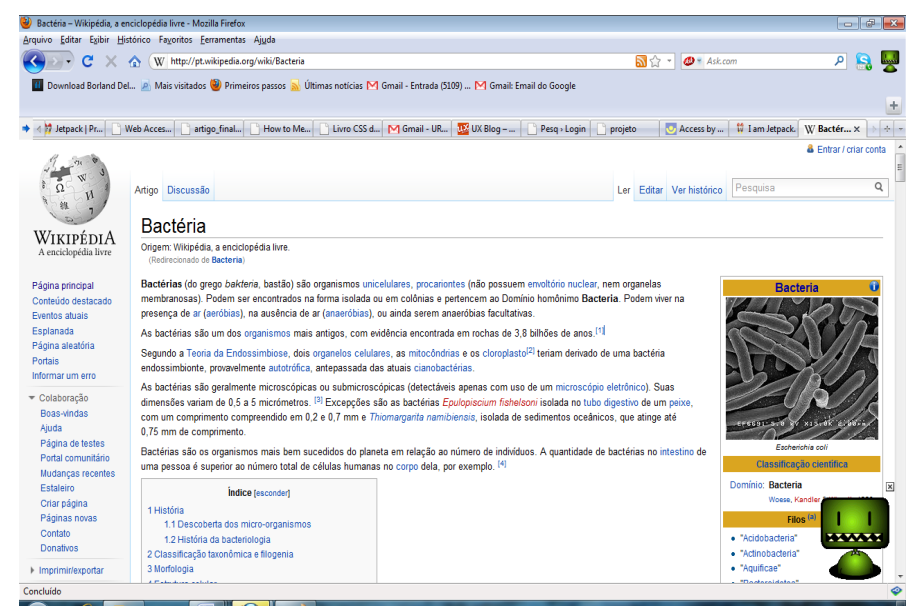

Figura 6.7: Mecanismo Tuki ativo na página da Wikipédia

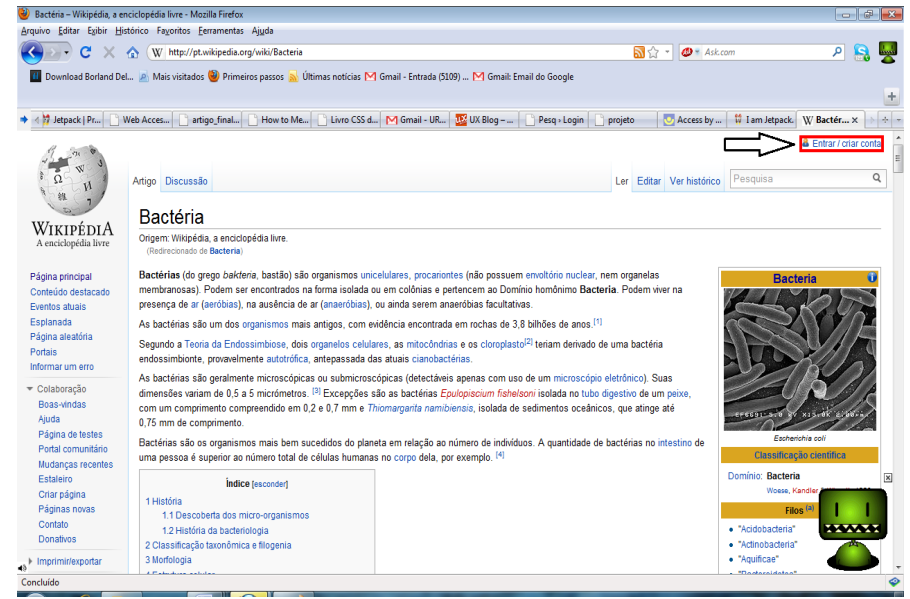

Figura 6.8: Mecanismo Tuki indicando a opção de login na página da Wikipédia

Caso a página Web em questão contenha um formulário, o mecanismo Tuki identifica seus elementos e coloca um contorno em volta dos campos de entrada para destacá-los, ao mesmo tempo em que instrui o usuário, via mensagem de voz, para clicar com o mouse no campo em destaque e iniciar a digitação utilizando o teclado, bem como a explicação sobre meios de acesso alternativos, tais como teclas de atalho, entre outras (Figura 6.10).

Imediatamente após o preenchimento do campo pelo usuário, o mecanismo Tuki emite uma mensagem de texto na interface "Campo preenchido!" e realiza o destaque do campo seguinte como mostra a Figura 6.11. Foi criado um conjunto pré-definido de mensagens para os principais elementos de marcação, tais como campos de entrada, caixas de seleção, botões de envio, menus, entre outros.

Para a implementação do mecanismo foi utilizada uma ferramenta de desenvolvimento de add-ons da Mozilla Labs chamada Jetpack (Mozilla Labs, 2012a). Essa ferramenta possibilita o desenvolvimento de scripts que podem alterar a interface de páginas que são exibidas pelo navegador Mozilla Firefox. Para a reprodução 


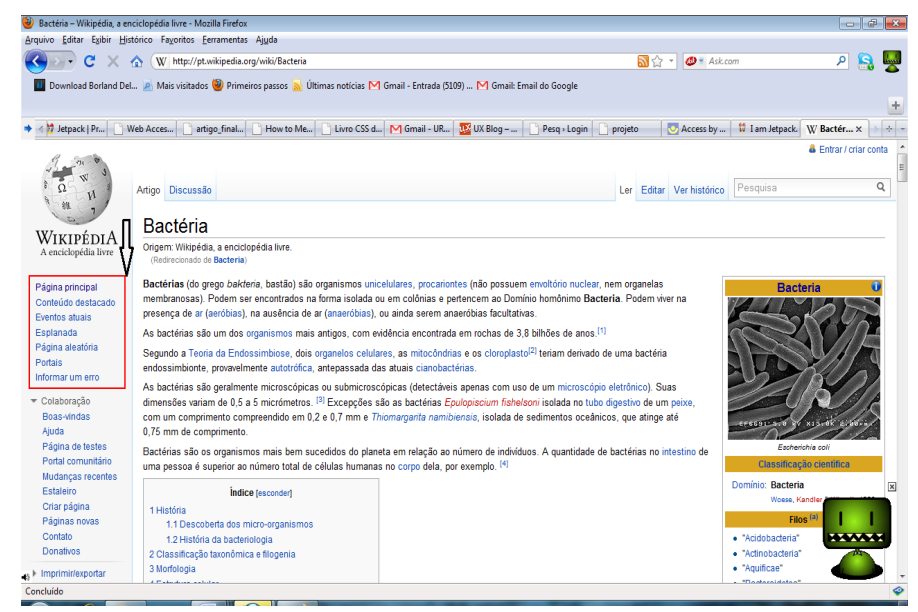

Figura 6.9: Mecanismo Tuki indicando a opção de menu na página da Wikipédia

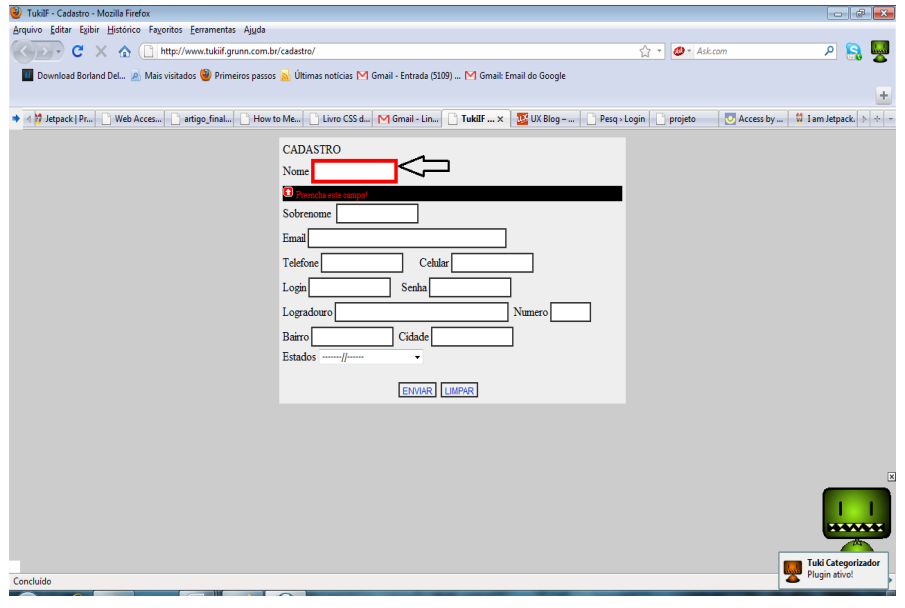

Figura 6.10: Mecanismo Tuki indicando o campo de formulário a ser preenchido

das mensagens via voz foi utilizado o software TextAloud ${ }^{1}$, que converte texto de documentos em vários formatos (.txt, .html, .pdf, .doc, .rtf, etc) em linguagem natural, inclusive em língua portuguesa.

Utilizando os recursos disponibilizados pela API Jetpack foram criadas algumas funcionalidades de transformação automática do layout da página, tais como: aumento do tamanho de fonte, alteração da cor dos links para azul, remoção de banners, entre outras. De acordo com o contexto e categoria da página é realizada uma descrição geral da mesma, tais como: páginas informativa, colaborativas, comerciais, bancárias e de cadastramento de informações. Caso a página seja classificada como de cadastramento de informações (páginas que contém formulários), o mecanismo explica como deve ser iniciado o preenchimento, destacando visualmente campo a campo e explicando detalhes específicos, como o formato do campo, por exemplo.

Para a escolha de uma plataforma de desenvolvimento foi levado em questão o potencial da ferramenta em relação ao apoio à interatividade com páginas Web e

\footnotetext{
${ }^{1}$ Disponível em http://www.nextup.com/
} 


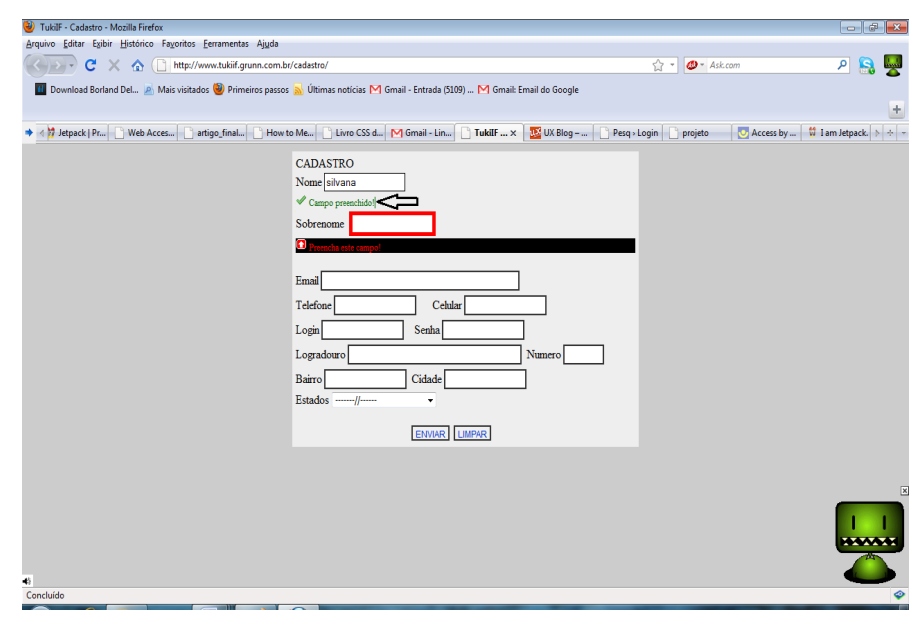

Figura 6.11: Mecanismo Tuki indicando o campo de formulário a ser preenchido

a facilidade de implementação, ou seja, foi priorizada a utilização de linguagens de programação Web já conhecidas e a possibilidade de utilização de regras e padrões sugeridos pela W3C.

Para as ferramentas pesquisadas para o desenvolvimento, naquele momento, foram consideradas características importantes do ponto de vista do desenvolvedor: a necessidade de documentação disponível, facilidade de uso e restrições dos navegadores, como pode ser observado na Tabela 6.1. Sendo assim, a escolha foi usar o Mozilla Jetpack, um projeto da Mozilla Labs que atendia aos requisitos citados acima e conferia alguns recursos extras como:

- Código aberto: possibilita a interação com outros desenvolvedores para melhoria da ferramenta, dando liberdade para possíveis extensões. Com isso a comunidade de desenvolvedores e a Mozilla melhoram a ferramenta frequentemente e dão possíveis soluções e sugestões para correção de módulos, como também apoiam a criação de novos módulos, deixando a documentação do Mozilla Jetpack bastante completa;

- Comunidade de desenvolvedores ativa: devido à grande campanha de desenvolvimento livre da Mozilla, a comunidade de desenvolvedores do Jetpack está sempre lançando dúvidas e respostas para os problemas do desenvolvimento alheio, contribuindo bastante com os testes e melhorias da ferramenta.

O Jetpack foi um projeto da Mozilla Labs, que possuía, nesta fase de desenvolvimento, duas vertentes, uma chamada Jetpack Prototype (Mozilla Labs, 2012b) que funcionava sobre um add-on instalado no navegador Mozilla Firefox e que basicamente respondia a comandos da linguagem JQuery. A evolução deste add-on 
Tabela 6.1: Comparação entre navegadores

\begin{tabular}{|l|c|c|c|c|c|c|}
\cline { 2 - 6 } \multicolumn{1}{c|}{} & $\begin{array}{l}\text { Mozilla } \\
\text { Jetpack }\end{array}$ & $\begin{array}{l}\text { Opera } \\
\text { Widgets } \\
\text { SDK }\end{array}$ & $\begin{array}{l}\text { Visual } \\
\text { Studio }\end{array}$ & Geeko & $\begin{array}{l}\text { Mozilla } \\
\text { Jetpack } \\
\text { SDK }\end{array}$ & $\begin{array}{l}\text { Google } \\
\text { Chrome } \\
\text { Extensions }\end{array}$ \\
\hline $\begin{array}{l}\text { 1. Documentação para } \\
\text { desenvolvimento de add-ons }\end{array}$ & completa & pouca & pouca & completa & completa & pouca \\
\hline 2. Suporte à depuração & $\operatorname{sim}$ & $\operatorname{sim}$ & $\operatorname{sim}$ & $\operatorname{sim}$ & $\operatorname{sim}$ & sim \\
\hline $\begin{array}{l}\text { 3. Necessidade de } \\
\text { conhecimento de linguagem } \\
\text { específica }\end{array}$ & pouca & média & muita & muita & pouca & muita \\
\hline $\begin{array}{l}\text { 4. Interface de } \\
\text { desenvolvimento amigável }\end{array}$ & média & sim & sim & média & média & média \\
\hline \begin{tabular}{l} 
5. Suporte dos navegadores \\
\hline
\end{tabular} & Firefox & Ópera & $\begin{array}{l}\text { Internet } \\
\text { Explorer }\end{array}$ & $\begin{array}{l}\text { Firefox/ } \\
\text { Ópera }\end{array}$ & Firefox & Chrome \\
\hline
\end{tabular}

deu origem a uma versão chamada Jetpack SDK (Mozilla Labs, 2012c), onde todo add-on é encapsulado com a API Jetpack e executa fora do navegador, dando maior controle à ferramenta e evitando danos de desempenho ao navegador.

Inicialmente foram estudados os objetivos da ferramenta Jetpack Prototype e exemplos de implementações, bem como tentativas de desenvolvimento de pequenos códigos para testes integrando códigos em HTML, CSS, JavaScript, JQuery e DOM. Foram testadas diversas funções encontradas na documentação e em exemplos, as quais contribuíram para a evolução do código, dando origem à primeira versão do mecanismo Tuki, que tinha por objetivo classificar a página Web corrente.

Ao iniciar os testes com o mecanismo classificador, foi observado que algumas páginas eram classificadas de forma errada e após vários refinamentos do mecanismo, observou-se também que os códigos-fontes de algumas páginas eram escritos sem qualquer padronização ou simplesmente não permitiam que seus códigos fossem analisados pelo add-on, por exemplo, as páginas de bancos on-line. A partir dessa limitação, optou-se pelo desenvolvimento de protótipos de páginas, seguindo padrões como HTML e CSS, de modo que fosse possível que o mecanismo Tuki pudesse reconhecer os elementos existentes e executar seu comportamento apropriado, de forma a auxiliar os usuários a interagirem melhor com a página em questão.

Durante a realização de implementações com o Jetpack Prototype foi lançado o Jetpack SDK, sendo o primeiro descontinuado. Na versão inicial, o Jetpack Prototype, era necessário instalar um ambiente de desenvolvimento no navegador Mozilla Firefox e a biblioteca API, no qual as extensões eram desenvolvidas e exportadas em JQuery. O Jetpack SKD apresenta uma nova metodologia de desenvolvimento, sendo que a grande modificação é que o desenvolvedor encapsula a versão utilizada da API junto com sua nova extensão, removendo a dependência 
de instalações que existia anteriormente e a necessidade de reiniciar o Firefox ao instalar e desinstalar uma nova extensão, como mostrado na Figura $6.12^{2}$.

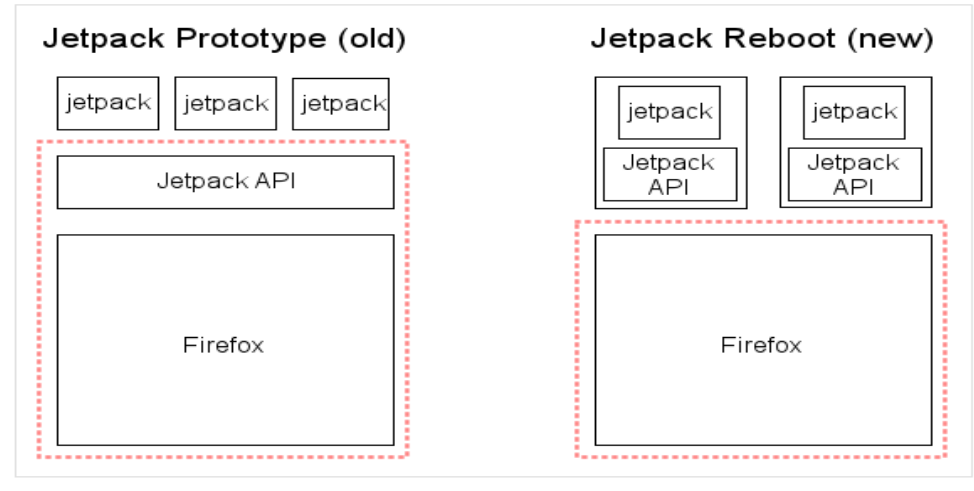

Figura 6.12: Arquitetura do Jetpack

Ao migrar alguns módulos do protótipo desenvolvido em Jetpack Prototype para Jetpack $S D K$ foram observadas várias incompatibilidades e constatou-se que algumas funções ainda não haviam sido desenvolvidas para a nova versão, o que gerou atrasos no desenvolvimento e consequentemente o retorno do desenvolvimento para a versão inicial do Jetpack Prototype.

Vale ressaltar que, com o mecanismo Tuki é possível extrair qualquer informação que esteja presente nas tags do código-fonte da página Web, e que quanto maior for o nível de informação contido nessas tags, melhor será sua atuação no auxílio à interação com as páginas.

O objetivo principal desse mecanismo de usabilidade e acessibilidade era incentivar os adultos mais velhos a superarem os obstáculos com os quais se deparam durante a utilização e usarem a Web no seu dia-a-dia, de modo a usufruírem dos benefícios que essa interação pode lhes proporcionar, principalmente quando atingirem a idade idosa, facilitando assim suas interações, seu aprendizado e a progressão no uso.

\subsubsection{Avaliação Heurística do Projeto Tuki}

Para avaliar a usabilidade do mecanismo Tuki, foi realizada uma avaliação heurística por cinco especialistas da área de Interação Humano-Computador. A avaliação heurística foi aplicada por se tratar de uma forma rápida e eficaz na avaliação de protótipos e designs iniciais (Nielsen, 1993). Foi realizada uma rodada de avaliação pelos especialistas e as respectivas correções priorizadas foram então realizadas. A seguir são apresentadas as heurísticas de Nielsen (Nielsen, 1993), os resultados consolidados da avaliação e as respectivas correções:

\footnotetext{
${ }^{2}$ Disponível em http://www.xuldev.org/blog/?p=441
} 
1. Visibilidade do estado do sistema

- avaliação: três dos especialistas sugeriram a inclusão de um sinal que indicasse se o mecanismo está ou não ativo (on/off);

- observação: o Tuki, quando instalado, permanece visível no canto superior direito do navegador Mozilla Firefox, podendo ser ativado pelo usuário no momento em que desejar. Em execução, permanece visível no canto inferior direito, podendo ser desativado em qualquer momento;

- correção: foi realizada alteração de cor no Tuki para indicar quando ele está ativo (verde:off /marrom:on).

2. Linguagem acessível ao usuário

- avaliação: nenhum problema foi mencionado;

- observação: as mensagens de voz utilizam terminologias familiares ao usuário, evitando a utilização de termos técnicos;

- correção: nenhuma.

3. Controle do usuário

- avaliação: nenhum problema foi mencionado;

- observação: o mecanismo oferece a opção de desativação no canto superior direito de sua imagem;

- correção: nenhuma.

4. Consistência

- avaliação: nenhum problema foi mencionado;

- observação: durante sua execução, a imagem do mecanismo Tuki é apresentada sempre no canto inferior direito da tela (juntamente com sua opção de desativação) e o Tuki apresenta um comportamento consistente ao circundar os elementos Web previamente reconhecidos na página, como forma de destaque desses elementos;

- correção: nenhuma.

5. Prevenção de erros

- avaliação: foi sugerido por um dos especialistas que o símbolo relativo à opção de fechar $[\mathrm{x}]$ fosse ampliado para evitar possíveis cliques na imagem do Tuki;

- observação: nenhuma;

- correção: foi realizada a alteração para aumentar o símbolo relativo à opção de fechar $[\mathrm{x}]$.

6. Reconhecimento ao invés de lembrança 
- avaliação: a maioria dos avaliadores achou a imagem utilizada pelo mecanismo bastante marcante para o usuário, embora não tenha sido reconhecido como um mecanismo de apoio à acessibilidade;

- observação: nenhuma;

- correção: nenhuma.

7. Flexibilidade e eficiência

- avaliação: todos os especialistas sugeriram que o mecanismo pudesse ser desativado por meio do teclado;

- observação: o mecanismo apresenta a opção fechar $[\mathrm{x}]$ apenas por meio do mouse;

- correção: nenhuma, com planejamento para momento posterior.

8. Design estético e minimalista

- avaliação: nenhum problema foi mencionado;

- observação: a maioria dos avaliadores aprovou o design do mecanismo Tuki, que é apresentado ao usuário num tamanho médio, sendo suficientemente visível para capturar sua atenção, mas sem ser intrusivo ao ponto de prejudicar a interação;

- correção: nenhuma.

9. Reconhecimento, diagnóstico e recuperação de erros

- avaliação: nenhum problema foi mencionado;

- observação: caso o usuário cancele a execução do mecanismo erroneamente, ele pode reativá-lo clicando na sua imagem que permanece no canto superior direito do navegador;

- correção: nenhuma.

10. Ajuda e documentação:

- avaliação: todos os especialistas apontaram a ausência de documentação e ajuda ao usuário na interface do mecanismo;

- observação: a falta de documentação ocorre em virtude do mecanismo Tuki ser um add-on para o navegador Mozilla Firefox, e que devido a sua natureza, deve ser bastante leve em sua atividade, de forma que a documentação a respeito de seu funcionamento será incluída na sua página de instalação;

- correção: nenhuma devido à natureza do mecanismo, porém planeja-se que um mecanismo de apoio sensível ao contexto possua uma documentação que o apresente nas primeiras interações. 
Vale ressaltar que esta avaliação não foi dedicada a tratar o processo de interação do mecanismo pelo usuário, uma vez que os usuários apenas ativam/desativam a execução do mecanismo Tuki.

Foi executada uma rodada de avaliação e uma rodada de correção dos problemas mencionados pelos especialistas. Foram priorizadas as correções e sugestões fornecidas, uma vez que elas contribuíram de fato para a realização dos testes com os usuários. A avaliação com os usuários é descrita a seguir.

\subsubsection{Avaliação com Usuários}

Para avaliar a viabilidade do protótipo Tuki como mecanismo de apoio sensível ao contexto foi elaborado um questionário para coletar feedbacks dos usuários. $\mathrm{Na}$ Figura 6.13 são apresentados dois questionários preenchidos, um deles por um adulto de meia-idade e outro por um idoso.

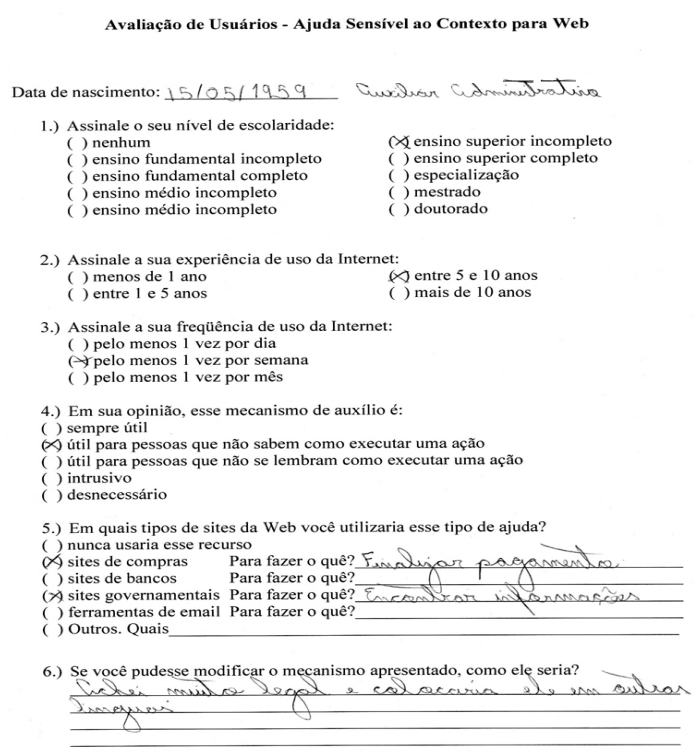

(a) Formulário preenchido por adulto de meia-idade

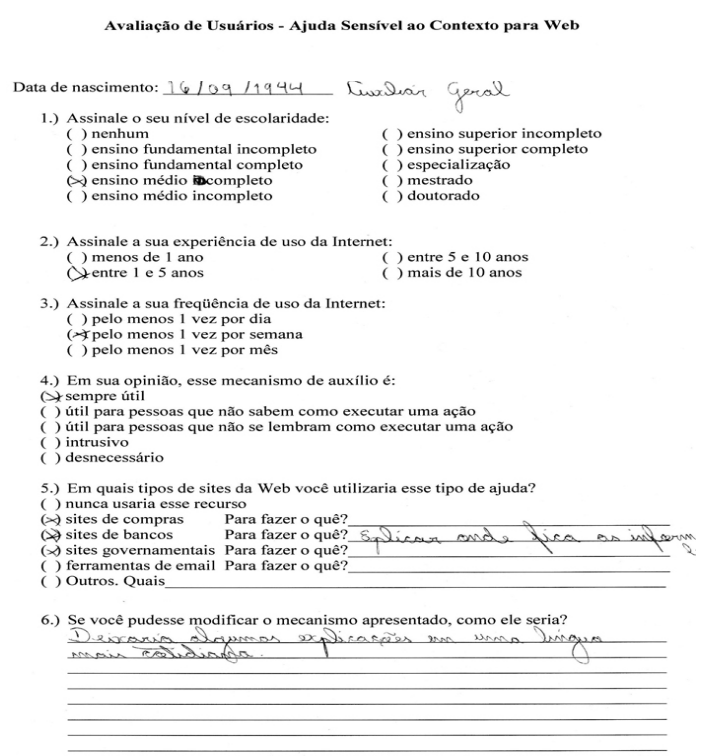

(b) Formulário preenchido por idoso

Figura 6.13: Questionário de avaliação do mecanismo Tuki

Para facilitar essa avaliação, foi definido que o usuário já tivesse instalado o Tuki, e portanto essa inicialização não seria uma barreira para prosseguir a avaliação. De fato, caso um usuário quisesse avaliar, bastaria baixar e instalar o add-on em seu navegador.

Visando reduzir potenciais problemas no que se refere aos detalhes técnicos dessa instalação, a avaliação foi conduzida da seguinte forma:

(a) Ao usuário era disponibilizado um navegador com o Tuki instalado; 
(b) A página inicial, que endereçava a página da Wikipédia, já estava carregada no navegador;

(c) Ao usuário era solicitado que ativasse o Tuki, por meio da sua imagem no canto superior direito do navegador, e visualizasse seu comportamento;

(d) Após a execução do mecanismo foi solicitado ao usuário que respondesse ao questionário.

O questionário foi entregue aos participantes como documento impresso e visava coletar impressões dos usuários após uma primeira experiência com o protótipo Tuki. Para esta avaliação, participaram 19 indivíduos, sendo 7 jovens, 9 adultos de meia idade e 3 idosos.

O convite para participação nesta avaliação foi realizado pessoalmente, direcionado a pessoas que tinham pouca experiência no uso da Web e que se dispuseram a colaborar com a pesquisa. Os aspectos de confidencialidade das informações fornecidas foram apresentados e os respondentes concordaram com a participação. Os questionários foram aplicados num período de 25 dias e demorava, em média, 14 minutos para ser respondido.

Dos 19 participantes, 12 possuíam nível de escolaridade que variava do ensino fundamental incompleto até o ensino superior incompleto, 5 possuíam ensino superior completo e dois possuíam especialização. Quanto à experiência de uso da Internet, seis participantes possuíam experiência entre 1 e 5 anos, oito participantes possuíam experiência entre 5 e 10 anos e cinco participantes utilizavam a Web há mais de 10 anos.

Em relação à frequência de acesso, 11 participantes acessavam a Web pelo menos uma vez por dia e oito pelo menos uma vez por semana.

Os participantes foram questionados a respeito da utilidade do mecanismo e os totais verificados são apresentados na Tabela 6.2.

Tabela 6.2: Avaliação sobre a utilidade do mecanismo

\begin{tabular}{|l|r|}
\hline Utilidade do mecanismo & Número de participantes \\
\hline Sempre útil & 8 \\
\hline Útil para pessoas que não sabem como executar uma ação & 4 \\
\hline Útil para pessoas que não se lembram como executar uma ação & 7 \\
\hline Intrusivo & 0 \\
\hline Desnecessário & 0 \\
\hline
\end{tabular}

Os participantes indicaram em quais tipos de sites eles utilizariam o mecanismo de apoio Tuki e para qual finalidade. A totalização por tipos de sites são mostradas na Tabela 6.3. 
Tabela 6.3: Avaliação sobre a utilização do mecanismo em sites

\begin{tabular}{|l|c|}
\hline Tipos de Sites & Número de participantes \\
\hline Nenhum & $4(21 \%)$ \\
\hline Compras & $9(47 \%)$ \\
\hline Bancos & $7(37 \%)$ \\
\hline Governamentais & $5(26 \%)$ \\
\hline E-mail & $6(32 \%)$ \\
\hline Outros & $2(11 \%)$ \\
\hline
\end{tabular}

Os comentários sobre a finalidade de uso do mecanismo para os tipos de sites elencados foram:

- nunca usaria:

“... mas indicaria para pessoas que tem dificuldade ..."

- site de compras:

“.. ajuda para completar as compras ..."

"... ajuda para explicar onde ficam as informações ..."

“... auxiliar pessoas que não costumam comprar ..."

“... finalizar pagamento ..."

- sites de bancos:

“... Ajudaria em tudo pois tenho dificuldade e medo ..."

“... Ver saldo de maneira fácil ...”

“... Executar ações complexas ..."

- sites governamentais:

"... Para buscar determinado assunto sem dificuldade ..."

“... Acho bastante complexo localizar informações ..."

“... Encontrar informações ..."

- ferramentas de e-mail:

“... Ajuda com anexos ..."

- Outros:

“... sites de busca ..."

“... sites de culinária ...”

Os comentários a respeito do que poderia ser modificado no mecanismo foram:

"Colocaria mais auxílios desse tipo para tornar a interface mais amigável" 
- "Seria bom ter o mecanismo em todos os navegadores"

- "Deixaria as explicações em linguagem mais cotidiana"

- "Opção de detalhar as funções da ferramenta"

- "Achei muito legal! Colocaria em outras línguas"

- "Adicionaria uma forma de salvar minhas ações em alguns sites"

- "Ampliaria a gama de sites que ele auxilia"

Foi possível observar com esta avaliação que as pessoas com menos experiência no uso da Web (frequência de uma vez por semana) opinaram que o mecanismo seria sempre útil (100\%) e as demais, que normalmente acessam a Web pelo menos uma vez por dia, julgam que não seria útil para elas mas que seria para as pessoas que não sabem ou não se lembram como executar determinada ação.

\subsection{Mecanismos de Apoio}

A investigação sobre as reais dificuldades e necessidades dos adultos mais velhos em suas interações com a Web, relatada no Capítulo 5, resultou na identificação dos principais problemas de utilização dos recursos da Web, pelos adultos mais velhos.

Assim, nas seções anteriores, foram apresentados tanto sugestões para extensão dos critérios de sucesso e sugestões para a solução de problemas (Seções 6.1 e 6.2) que priorizam orientações para que as aplicações Web propiciem interações adequadas aos adultos mais velhos, quanto um mecanismo de apoio sensível ao contexto, cujo protótipo Tuki foi desenvolvido como prova de conceito, que visa auxiliar os adultos mais velhos nas interações da Web.

Tais contribuições propostas, portanto, possibilitaram uma visão geral dos mecanismos que deveriam ser de apoio à interação na Web, especialmente para adultos mais velhos. Os mecanismos e respectivos critérios de sucesso segundo a WCAG 2.0, acrescidos das extensões propostas na Seção 6.1, bem como dos princípios de usabilidade, foram:

- M1: recurso para redimensionamento do tamanho da letra (A1.4.4 e U8);

- M2: recurso para aumento do contraste (A1.4.3 e U8);

- M3: recurso para abreviação do caminho (A2.4.5 e A2.4.8 e U7);

- M4: apoio para a utilização do campo de busca (A3.3.2 e U5);

- M5: recurso para eliminação de banners (A3.1.7* e U8);

- M6: recurso de indicação de barra de rolagem (A1.4.10* e U6); 
- M7: recurso para a visualização de resumo de texto (A3.1.1 e U7);

- M8: recurso de visualização de tópicos do texto (A3.1.1 e U7);

- M9: apoio para a utilização de links: assunto, segurança, endereçamento (A2.4.4 e U5);

- M10: recurso de escolha de cor para links visitados (A2.4.16* e U5);

- M11: recurso de escolha de cores para opções de menu (A2.4.17* e U5);

- M12: recurso para controle de velocidade de menus (A2.2.6* e U3);

- M13: recurso para diminuição da velocidade de apresentação de vídeo (A2.2.7* e U3);

- M14: recurso de áudio para figuras (A1.3.4* e U7);

- M15: recurso de guia de funcionalidades (A3.3.5 e U6);

- M16: recurso de divisão de formulário em unidades menores (A3.1.7* e U5);

- M17: recurso de lembrete de documentos da vida real (A3.3.8* e U2);

- M18: recurso para preenchimento de campos de entrada (A3.3.7* e U5);

- M19: apoio para reconhecimento de procedimentos (A3.3.5 e U6).

Dessa forma, foi realizada uma pesquisa qualitativa, adotando-se o método de Survey, para coletar informações diretamente de potenciais usuários (adultos mais velhos) sobre os mecanismos. Optou-se pelo desenvolvimento de uma pesquisa on-line que simulasse o funcionamento de novos mecanismos de apoio à interação Web, para apresentar os mecanismos citados, como se estivessem implementados.

Para cada questão foi elaborado um demonstrativo visual do recurso proposto. O respondente poderia então visualizar a demonstração do recurso quantas vezes fosse necessário até compreender totalmente sua funcionalidade. Todas as respostas bem como os dados pessoais fornecidos pelos usuários, foram armazenados em banco de dados e utilizados somente para os fins dessa pesquisa.

Nas próximas seções é descrito o procedimento realizado: as questões do questionário projetado, como foi a coleta de dados, o perfil dos participantes, a análise dos dados coletados e os resultados obtidos.

\subsubsection{Questões sobre os mecanismos}

A seguir, para cada uma das questões, é apresentada a motivação para a criação da questão, seu enunciado, suas alternativas e as imagens ilustrativas simulando o funcionamento do mecanismo antes do clique no botão "Visualizar" e após seu acionamento. 
Na Questão 1 é apresentado um recurso que pode ser encontrado em diversas páginas Web. Trata-se do mecanismo para redimensionamento do tamanho da fonte do texto e foi escolhido para fazer parte desse estudo com a finalidade de avaliar o uso efetivo de um recurso de acessibilidade pelos adultos mais velhos. Diretriz: 1.4 Discernivel, Critério de Sucesso: 1.4.4-Princípio de Usabilidade: Estética e design minimalista (U8).

Questão 1: Em uma página Web os aumentadores/diminuidores da fonte de texto alteram o tamanho do texto que é apresentado ao usuário. Qual das alternativas abaixo melhor descreve a forma com que você utiliza esse recurso? (Figura 6.14)

Alternativas: (a) Nunca uso esse recurso; (b) Uso muito pouco esse recurso; (c) Uso esse recurso sempre que necessito; (d) Uso frequentemente esse recurso; (e) Prefiro utilizar outro mecanismo que ofereça esse resultado.

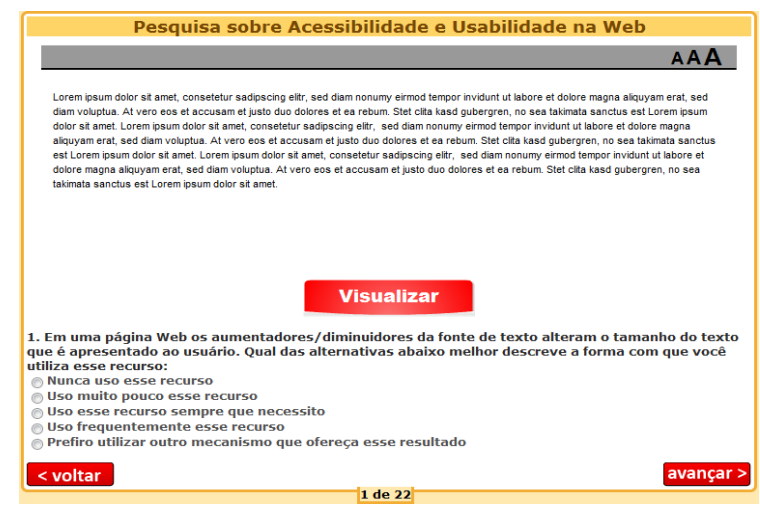

(a) Texto com tamanho de letra original

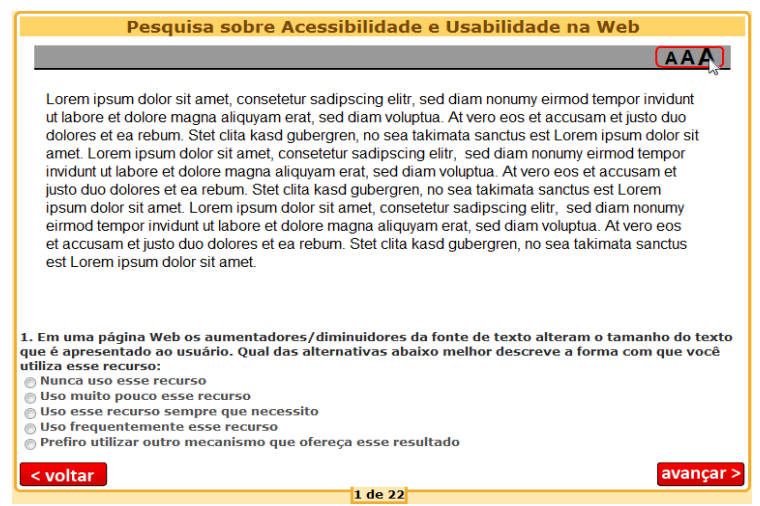

(b) Texto com tamanho de letra aumentado

Figura 6.14: Questão 1 - Recurso de aumento do tamanho da letra

Na Questão 2 é apresentado um recurso que atualmente também já pode ser encontrado em páginas Web, embora com menor frequência. Trata-se do mecanismo para controle do contraste entre cor de frente e cor de fundo. Com o mesmo propósito do anterior, também foi escolhido para fazer parte desse estudo com a finalidade de avaliar o uso efetivo de um recurso de acessibilidade pelos adultos mais velhos. Diretriz: 1.4 - Discernível, Critério de Sucesso: 1.4.3-Princípio de Usabilidade: Estética e design minimalista (U8).

Questão 2: Aumento ou alteração de contraste é um recurso visual com o qual se pode diferenciar cores que se sobrepõem. Quando duas cores diferentes entram em contato direto, o contraste intensifica as diferenças entre ambas. Considerando que esse recurso esteja disponível em páginas Web, qual das alternativas abaixo melhor descreve a forma com que você utiliza esse recurso? (Figura 6.15) 
Alternativas:(a) Nunca uso esse recurso; (b) Uso muito pouco esse recurso; (c) Uso esse recurso sempre que necessito; (d) Uso frequentemente esse recurso; (e) Prefiro utilizar outro mecanismo que ofereça esse resultado.

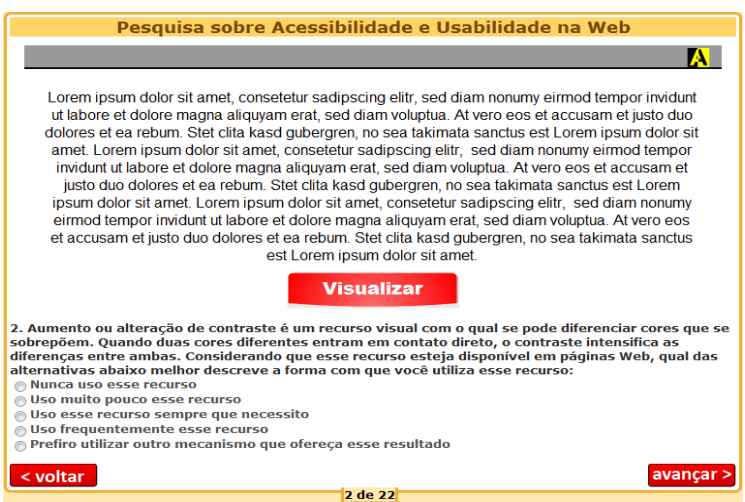

(a) Texto com contraste original

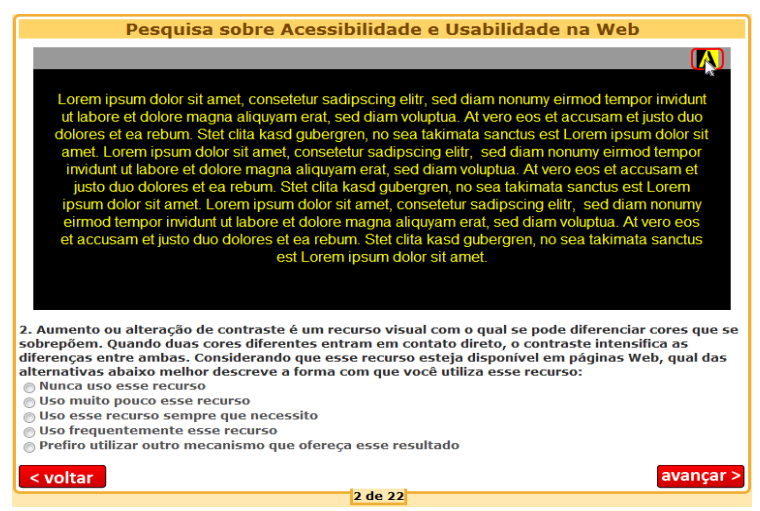

(b) Texto com aumento de contraste

Figura 6.15: Questão 2 - Recurso de aumento do contraste

A Questão 3 apresenta um recurso muito utilizado atualmente nas páginas Web, a navegação por "breadcrumbs". Esse recurso, quando provido de links, oferece para o usuário duas funcionalidades principais: um meio de localização dentro da estrutura de documentos e a possibilidade de clique em qualquer uma das páginas já visitadas, abreviando o caminho de navegação percorrido. Diretriz: 2.4 - Navegável, Critérios de Sucesso: 2.4 .5 e 2.4.8 - Princípio de Usabilidade: Flexibilidade e eficiência de uso (U' $)^{\prime}$.

Questão 3: Breadcrumbs, termo de origem inglês, significa "migalhas" é um recurso visual que mostra o caminho das páginas visitadas no site/portal. Esse recurso permite que o usuário possa "cortar caminhos" ao acessar páginas já visitadas. Qual das alternativas abaixo melhor descreve a forma com que você utiliza esse recurso? (Figura 6.16)

Alternativas:(a) Nunca uso esse recurso; (b) Uso muito pouco esse recurso; (c) Uso esse recurso sempre que necessito; (d) Uso frequentemente esse recurso; (e) Prefiro utilizar outro mecanismo que ofereça esse resultado.

A partir da Questão 4, no questionário, foram apresentados os mecanismos propostos nesta tese. Durante o período de observação em campo a pesquisadora presenciou, por várias vezes, a dificuldade no preenchimento de dados em uma caixa de busca e consequentemente a apresentação de resultados não condizentes com os resultados esperados pelos usuários. Esse recurso visa apoiar os usuários mais velhos fornecendo-lhes assistência na entrada de dados para a caixa de busca. Diretriz: 3.3 


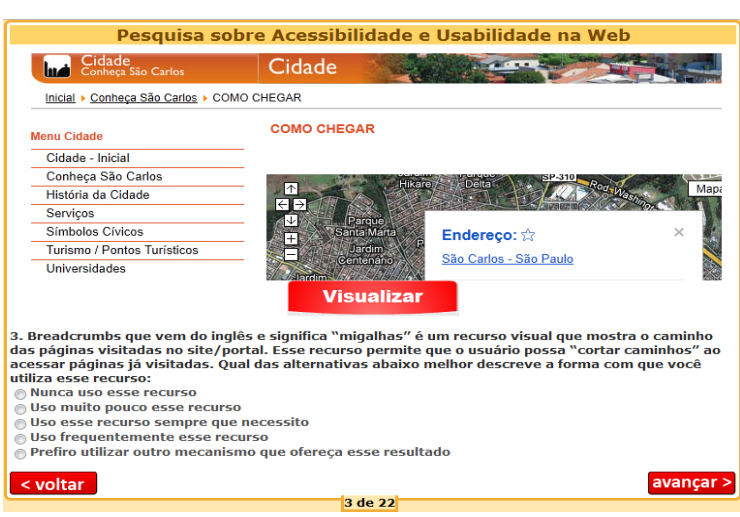

(a)

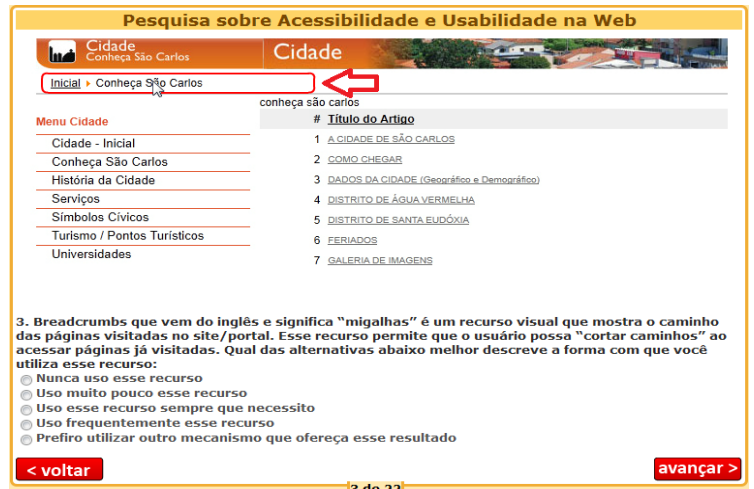

(b)

Figura 6.16: Questão 3 - Recurso de abreviação de caminho

- Assistência na entrada, Critério de Sucesso: 3.3.2 - Princípio de Usabilidade: Prevenção de erros (U5).

Questão 4: Em uma página Web, um "campo de busca" ou "caixa de pesquisa" é um recurso que facilita aos usuários encontrarem o que estão procurando dentro de um site por meio da busca por palavras-chave. Suponha que exista um recurso que explique como o usuário deve utilizar essas palavras-chave para conseguir realizar uma busca de forma satisfatória. Qual das alternativas abaixo melhor descreve o modo com que você utilizaria esse recurso? (Figura $6.17)$

Alternativas: (a) Nunca usaria esse recurso/(b) Usaria esse recurso quando sentisse necessidade/ (c) Utilizaria frequentemente esse recurso/ (d) Utilizaria outro mecanismo que oferecesse esse resultado.

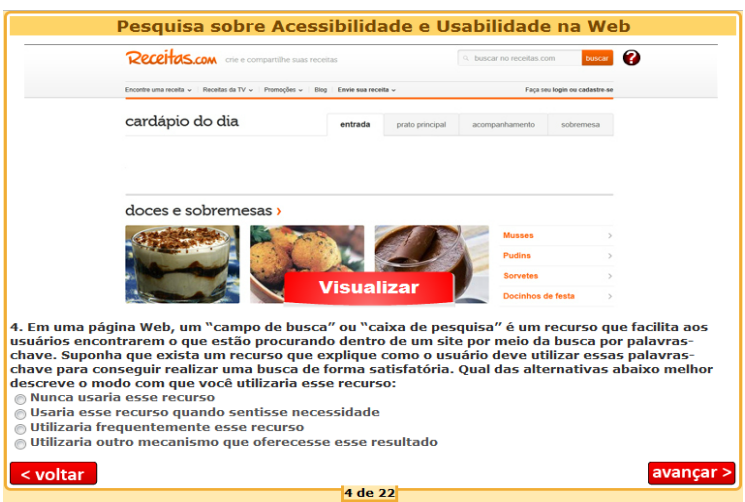

(a)

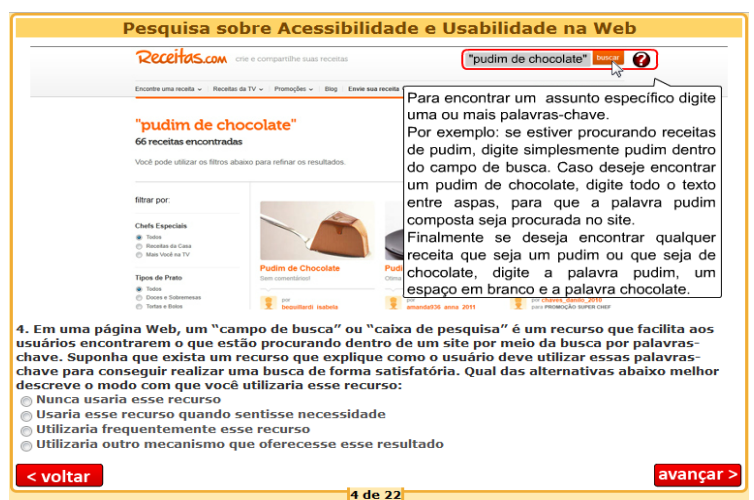

(b)

Figura 6.17: Questão 4 - Recurso para a assistência na entrada de dados da caixa de busca

O recurso proposto na Questão 5 visa reduzir a apresentação de informações irrelevantes e fixar a atenção dos adultos mais velhos no conteúdo da página Web, 
por meio da eliminação de banners e propagandas publicitárias. Diretriz 3.1: Legível e Compreensivel, Critério de Sucesso: 3.1.7* - Princípio de Usabilidade: Estética e design minimalista (U8).

Questão 5: É comum que uma página Web contenha várias propagandas publicitárias. A eliminação de banners e propagandas publicitárias normalmente deixa o conteúdo mais limpo e fácil de ler. Qual das alternativas abaixo melhor descreve a forma com que você utilizaria esse recurso caso ele estivesse disponível? (Figura 6.18)

Alternativas: (a) Nunca usaria esse recurso/(b) Usaria esse recurso quando sentisse necessidade/ (c) Utilizaria frequentemente esse recurso/ (d) Utilizaria outro mecanismo que oferecesse esse resultado.

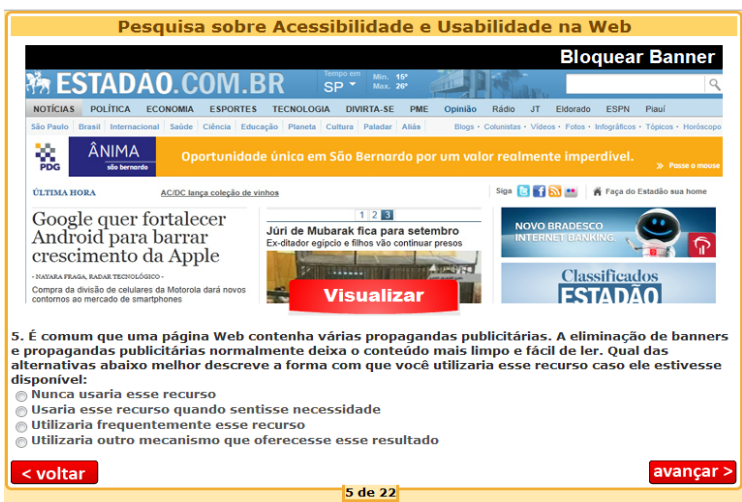

(a)

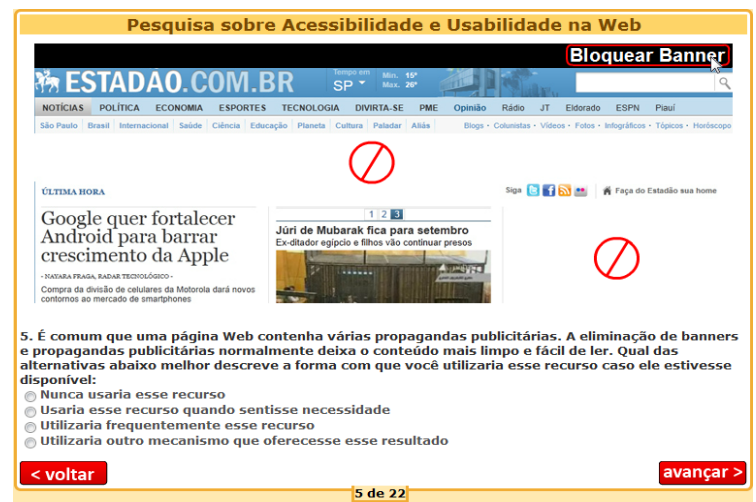

(b)

Figura 6.18: Questão 5 - Recurso de eliminação de banners

A motivação para a inclusão do sinalizador da barra de rolagem na Questão 6 também teve origem na observação de campo. Foi verificado que os adultos mais velhos, muitas vezes, não concluíam a leitura de um conteúdo ou o preenchimento de um formulário devido à não percepção da existência da barra de rolagem. Diretriz: 1.4 - Discernível, Critério de Sucesso: 1.4.10* - Princípio de Usabilidade: Reconhecimento ao invés de relembrança (U6).

Questão 6: É comum que uma página Web apresente um conteúdo que ultrapasse o tamanho da tela. Fazendo com que apareça a barra de rolagem ou scroll. Imagine que ao acessar uma página desse tipo você receba, após alguns segundos, um sinal visual e/ou uma mensagem de voz destacando a existência da barra de rolagem, para te lembrar que existe mais conteúdo abaixo da área visível da tela. Qual das alternativas abaixo melhor descreve a forma com que você utilizaria esse recurso caso ele estivesse disponível? (Figura 6.19) 
Alternativas: (a) Nunca usaria esse recurso/(b) Usaria esse recurso quando sentisse necessidade/ (c) Utilizaria frequentemente esse recurso/ (d) Utilizaria outro mecanismo que oferecesse esse resultado.

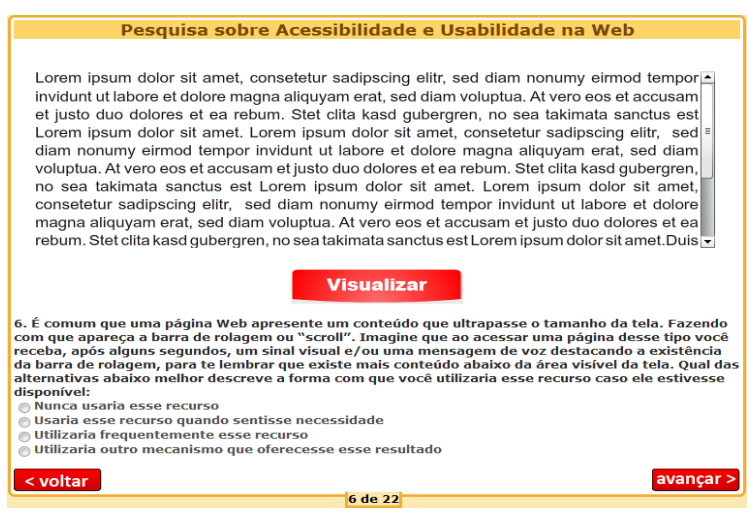

(a)

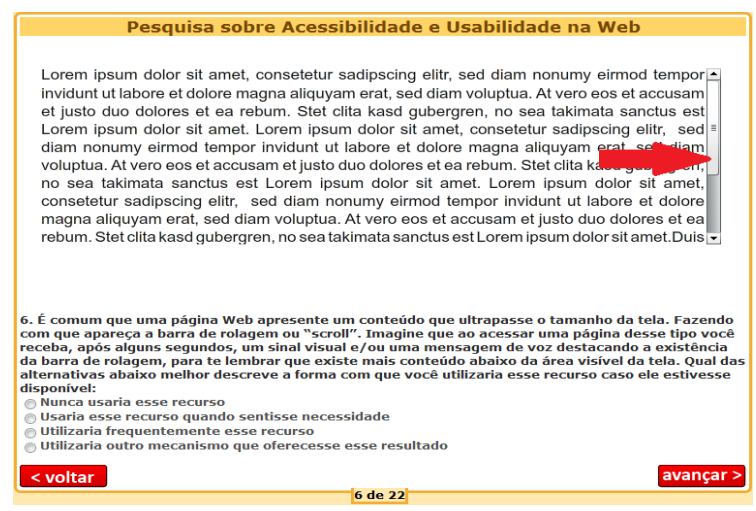

(b)

Figura 6.19: Questão 6 - Recurso de indicação de barra de rolagem

O recurso da Questão 7 foi incluído no questionário por se tratar de um facilitador da leitura de conteúdos, contribuindo para a manutenção da concentração dos adultos mais velhos nos pontos mais relevantes do conteúdo, por meio da apresentação de um resumo do texto principal. Diretriz: 3.1 - Legivel e Compreensivel, Critério de Sucesso: 3.1.1 - Princípio de Usabilidade: Flexibilidade e eficiência de uso (U7).

Questão 7: Suponha que ao acessar uma página com um conteúdo em formato texto bastante extenso, estivesse disponível uma opção de visualização do resumo desse mesmo texto. Qual das alternativas abaixo melhor descreve a forma com que você utilizaria esse recurso? (Figura 6.20)

Alternativas: (a) Nunca usaria esse recurso/(b) Usaria esse recurso quando sentisse necessidade/ (c) Utilizaria frequentemente esse recurso/ (d) Utilizaria outro mecanismo que oferecesse esse resultado.

Na Questão 8, visando reduzir a sobrecarga cognitiva e facilitar aos adultos mais velhos alcançarem a informação desejada com maior precisão e menor tempo, foi disponibilizado o recurso para a apresentação dos principais tópicos referentes ao conteúdo da página Web. Diretriz: 3.1 - Legível e Compreensível, Critério de Sucesso: 3.1.1 - Princípio de Usabilidade: Flexibilidade e eficiência de uso (Ư).

Questão 8: Suponha que ao acessar uma página com um conteúdo em formato texto bastante extenso, estivesse disponível uma opção de visualização dos principais tópicos em forma de links desse mesmo texto. Qual das alternativas abaixo melhor descreve a forma com que você utilizaria esse recurso? (Figura 6.21) 


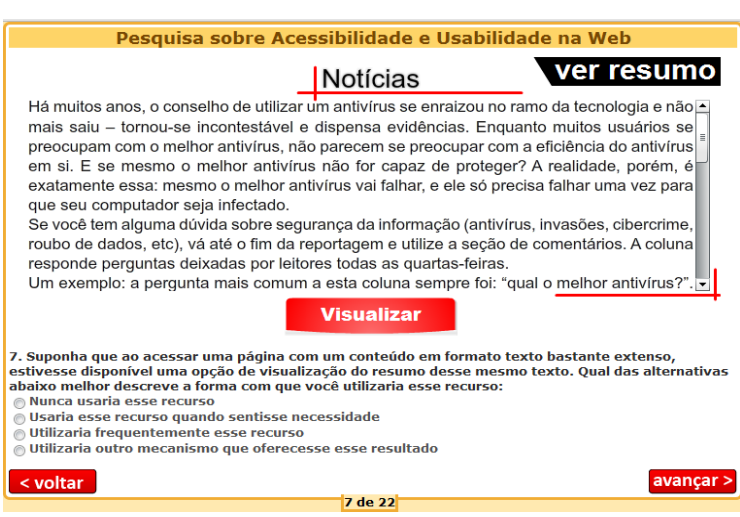

(a)

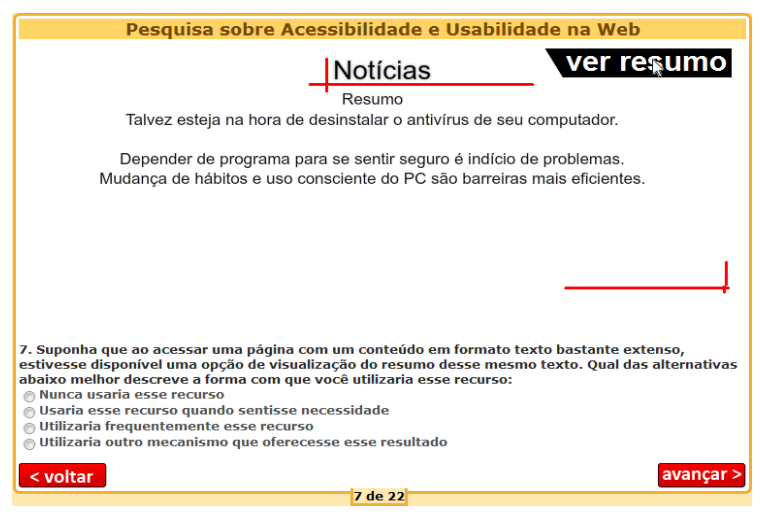

(b)

Figura 6.20: Questão 7 - Recurso de visualização de resumo de texto

Alternativas: (a) Nunca usaria esse recurso/(b) Usaria esse recurso quando sentisse necessidade/ (c) Utilizaria frequentemente esse recurso/ (d) Utilizaria outro mecanismo que oferecesse esse resultado.

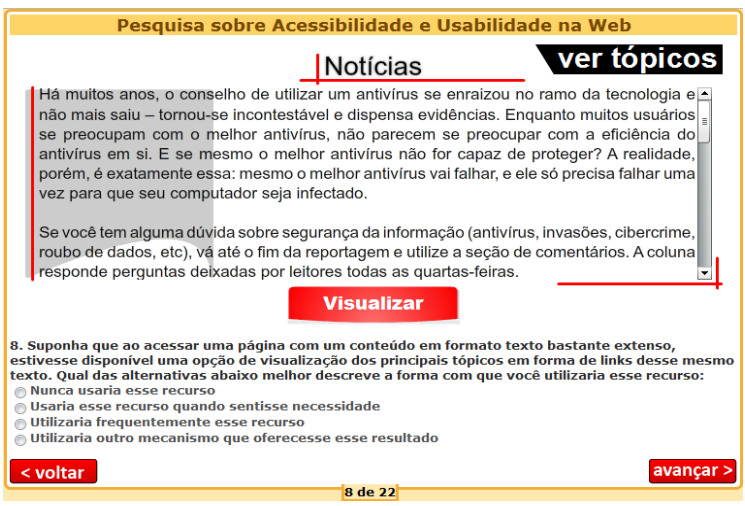

(a)

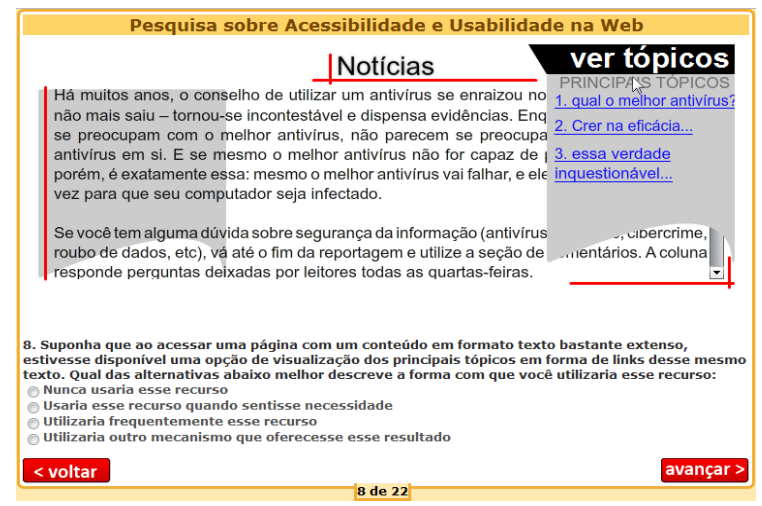

(b)

Figura 6.21: Questão 8 - Recurso de visualização de tópicos

Uma dificuldade evidenciada pelo questionário respondido pelos usuários mais experientes foi a insegurança com relação aos links. Para tentar minimizar essa situação de insegurança foi proposto na Questão 9 um recurso que informa ao usuário, por meio de texto ou voz, se o link é seguro, o assunto tratado e seu respectivo endereçamento. Diretriz: 2.4 - Navegável, Critério de Sucesso: 2.4.4 Princípio de Usabilidade: Prevenção de erros (U5).

Questão 9: Suponha que ao passar o mouse sobre um link em uma página Web fosse mostrada uma mensagem de texto e/ou voz informando sobre o assunto tratado por ele, se é seguro ou não e seu respectivo endereço na Web. Qual das alternativas abaixo melhor descreve a forma com que você utilizaria esse recurso? (Figura 6.22) 
Alternativas: (a) Nunca usaria esse recurso/(b) Usaria esse recurso quando sentisse necessidade/ (c) Utilizaria frequentemente esse recurso/ (d) Utilizaria outro mecanismo que oferecesse esse resultado.

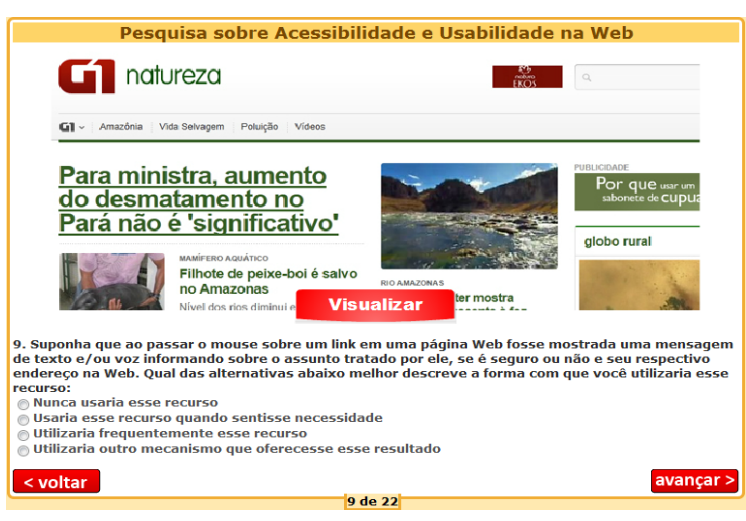

(a)

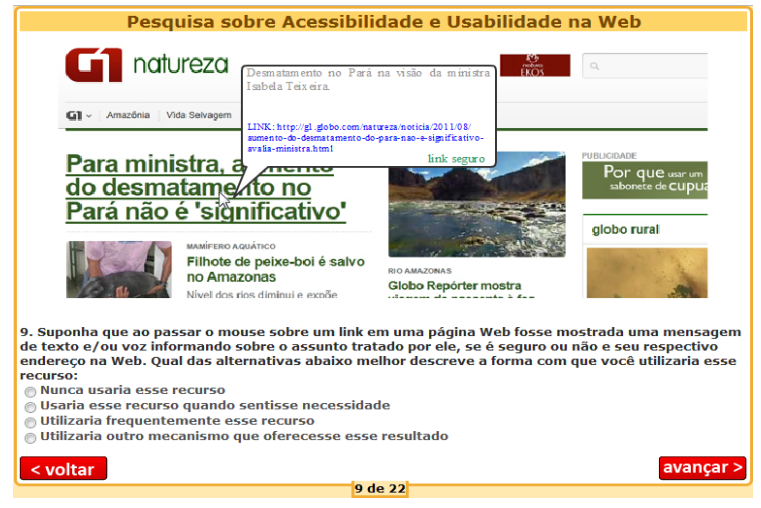

(b)

Figura 6.22: Questão 9 - Recurso sobre links: assunto, segurança e endereçamento

A motivação para a proposta do recurso da Questão 10 foi que, escolhendo a cor para os links visitados, os adultos mais velhos pudessem se sentir mais familiarizados com a interface e distinguir melhor entre os links visitados e os não visitados, reduzindo-se assim a sobrecarga cognitiva, facilitando o reconhecimento desses elementos e evitando cliques em links já vistos. Diretriz: 2.4 - Navegável, Critério de Sucesso: 2.4.16* - Princípio de Usabilidade: Prevenção de erros (U5).

Questão 10: Suponha que exista um recurso no qual você possa escolher a cor para indicar os links visitados. Qual das alternativas abaixo melhor descreve a forma com que você utilizaria esse recurso? (Figura 6.23)

Alternativas: (a) Nunca usaria esse recurso/(b) Usaria esse recurso quando sentisse necessidade/ (c) Utilizaria frequentemente esse recurso/ (d) Utilizaria outro mecanismo que oferecesse esse resultado.

A motivação para o recurso proposto na Questão 11 coincide com a motivação do recurso anterior, uma vez que durante as observações em campo era comum verificar que os adultos mais velhos acionavam várias vezes a mesma opção de menu, pensando que se tratava de uma opção ainda não visitada. A alteração de cor pode ser de grande auxílio nesse reconhecimento. Diretriz: 2.4 - Navegável, Critério de Sucesso: 2.4.17* - Princípio de Usabilidade: Prevenção de erros (U5).

Questão 11: Suponha que exista um recurso para alterar a cor das opções e sub-opções de menus suspensos que já foram visitadas por você. Qual das alternativas melhor descreve a forma com que você utilizaria esse recurso? (Figura $6.24)$ 


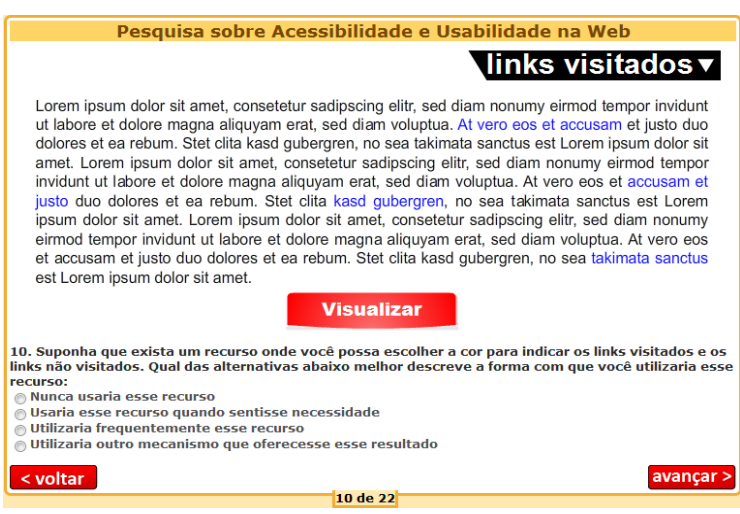

(a)

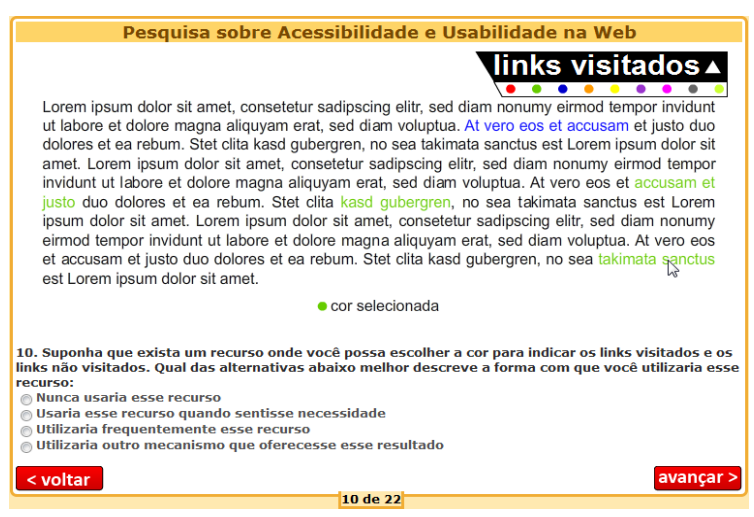

(b)

Figura 6.23: Questão 10 - Recurso de escolha de cor para links visitados

Alternativas: (a) Nunca usaria esse recurso/(b) Usaria esse recurso quando sentisse necessidade/ (c) Utilizaria frequentemente esse recurso/ (d) Utilizaria outro mecanismo que oferecesse esse resultado.

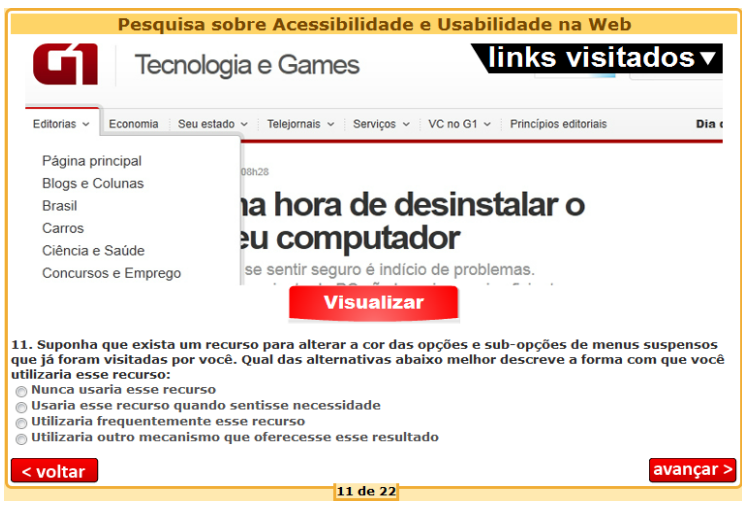

(a)

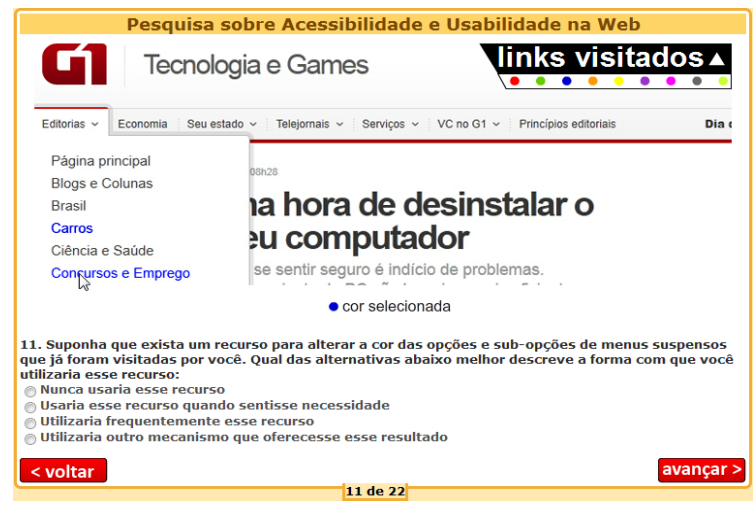

(b)

Figura 6.24: Questão 11 - Recurso de escolha de cores para opções do menu

Foi constatado durante as observações em campo que os adultos mais velhos apresentam grande dificuldade na manipulação de menus móveis e ágeis, normalmente acionando opções intermediárias ou erradas, devido à velocidade de apresentação das opções e seus subníveis. Assim, foi proposto na Questão 12 um recurso que possibilita ao usuário diminuir a velocidade de apresentação de menus. Diretriz: 2.2 - Tempo suficiente, Critério de Sucesso: 2.2.6* - Princípio de Usabilidade: Controle do usuário e liberdade (U3).

Questão 12: Suponha que exista um recurso que possa aumentar e/ou diminuir a velocidade de apresentação das opções de menus suspensos em páginas Web. Qual das alternativas abaixo melhor descreve a forma com que você utilizaria esse recurso? (Figura 6.25) 
Alternativas: (a) Nunca usaria esse recurso/(b) Usaria esse recurso quando sentisse necessidade/ (c) Utilizaria frequentemente esse recurso/ (d) Utilizaria outro mecanismo que oferecesse esse resultado.

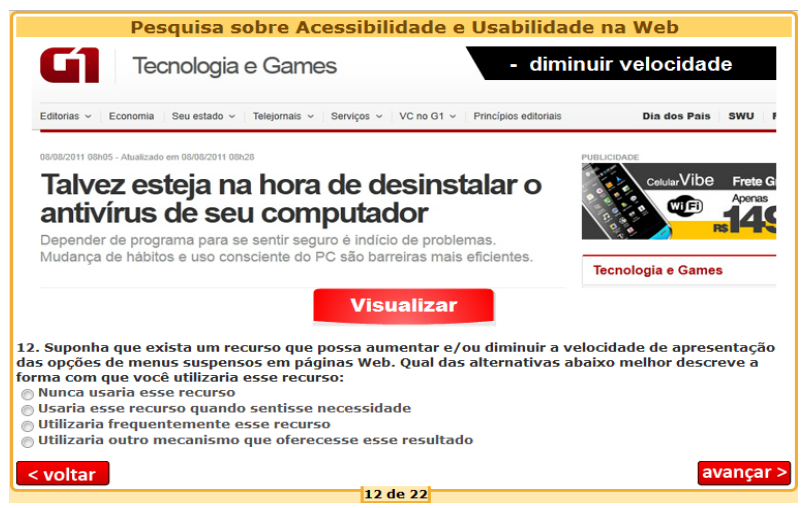

Figura 6.25: Questão 12 - Recurso de diminuição da velocidade de menus

Na Questão 13 é proposto um recurso que visa apoiar os adultos mais velhos na compreensão de conteúdos de vídeo, por meio do controle da velocidade de sua reprodução. Diretriz: 2.2 - Tempo suficiente, Critério de Sucesso: 2.2.7* - Princípio de Usabilidade: Controle do usuário e liberdade (U3).

Questão 13: Suponha que, ao visualizar um vídeo em uma página Web você pudesse diminuir a velocidade de reprodução de vídeo para poder observá-lo em maiores detalhes. Qual das alternativas abaixo melhor descreve a forma com que você utilizaria esse recurso? (Figura 6.26)

Alternativas: (a) Nunca usaria esse recurso/(b) Usaria esse recurso quando sentisse necessidade/ (c) Utilizaria frequentemente esse recurso/ (d) Utilizaria outro mecanismo que oferecesse esse resultado.

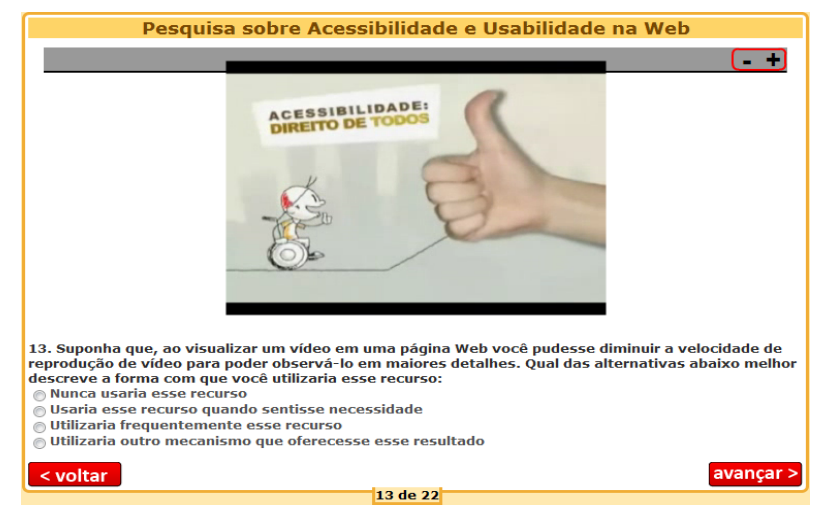

Figura 6.26: Questão 13 - Recurso de diminuição da velocidade do vídeo

A motivação para o recurso da Questão 14 é que durante a pesquisa constatou-se que os adultos mais velhos preferem ouvir uma descrição ao ler um texto. Esse 
recurso possibilita que a descrição de uma imagem seja reproduzida por voz sem a necessidade do uso de um programa de tecnologia assistiva. Diretriz: 1.3 Adaptável, Critério de Sucesso: 1.3.4* - Princípio de Usabilidade: Flexibilidade e eficiência de uso (U'Y).

Questão 14: Suponha que ao acessar uma página Web que contém figuras exista uma opção ao lado de cada uma delas que as explique utilizando mensagem de voz. Qual das alternativas abaixo melhor descreve a forma com que você utilizaria esse recurso? (Figura 6.27)

Alternativas: (a) Nunca usaria esse recurso/(b) Usaria esse recurso quando sentisse necessidade/ (c) Utilizaria frequentemente esse recurso/ (d) Utilizaria outro mecanismo que oferecesse esse resultado.

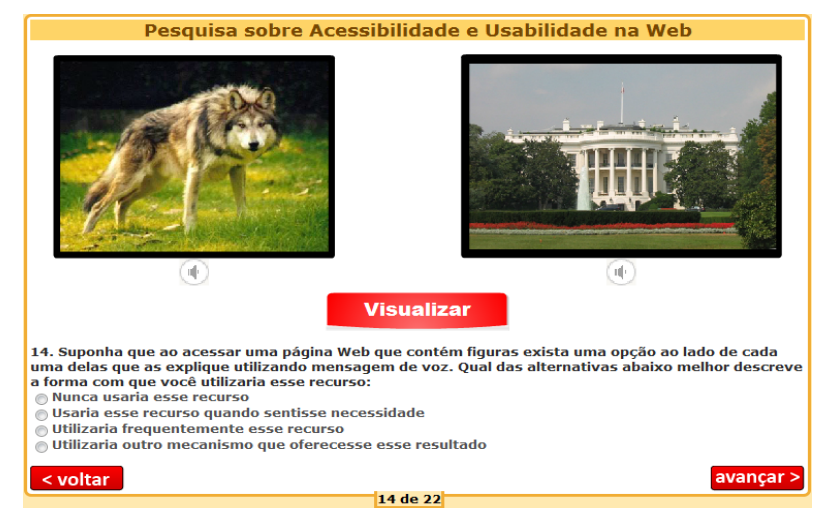

Figura 6.27: Questão 14 - Recurso de áudio para figuras

A motivação para a proposta do recurso apresentado na Questão 15 é de que ele funcionasse como um apoio humano, "imitando o apoio presencial" e fornecendo dicas a respeito das funcionalidades disponíveis na tela. Diretriz: 3.3 - Assistência na entrada, Critério de Sucesso: 3.3.5 - Princípio de Usabilidade: Reconhecimento ao invés de relembrança (U6).

Questão 15: Suponha que você acesse uma página Web pela primeira vez e que exista um recurso que funcione como um guia, isto é, ao ser acionado esse recurso mostra ao usuário tudo o que ele pode fazer naquela página, destacando visualmente os elementos e emitindo mensagens de voz correspondentes. Qual das alternativas abaixo melhor descreve a forma com que você utilizaria esse recurso? (Figura 6.28)

Alternativas: (a) Nunca usaria esse recurso/(b) Usaria esse recurso quando sentisse necessidade/ (c) Utilizaria frequentemente esse recurso/ (d) Utilizaria outro mecanismo que oferecesse esse resultado. 


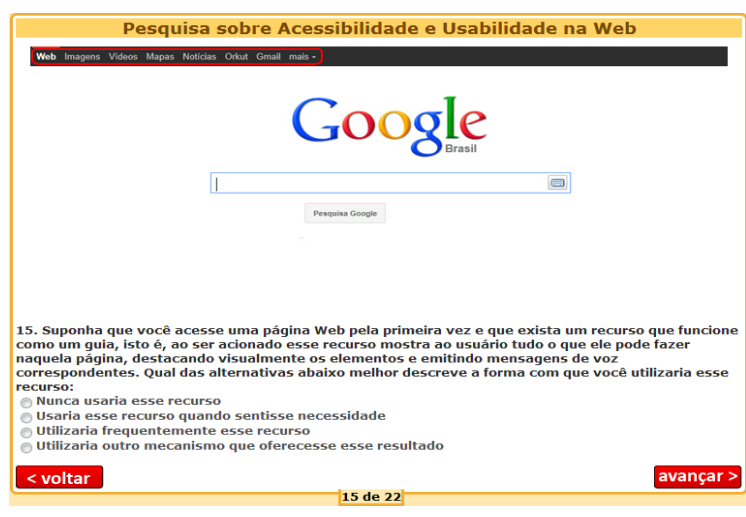

(a)

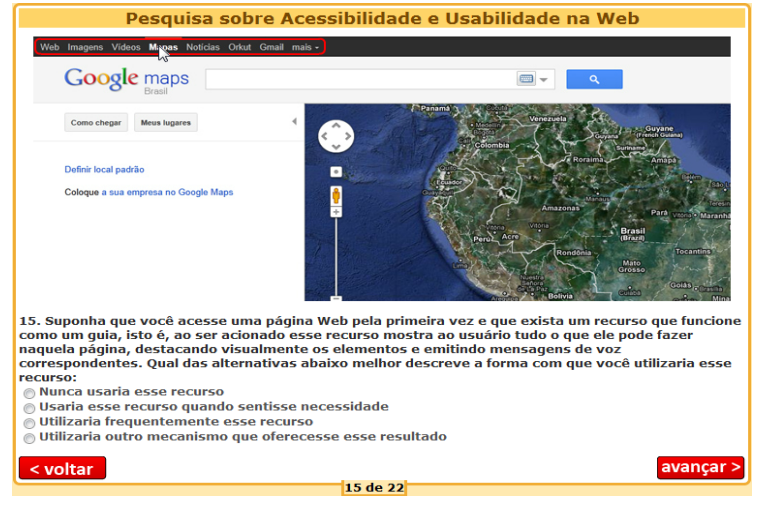

(b)

Figura 6.28: Questão 15 - Recurso de guia de funcionalidades

Durante a observação em campo foi verificado que os adultos mais velhos demoravam muito para preencher formulários extensos, muitas vezes devido à não percepção que o formulário continuava abaixo do conteúdo apresentado na tela ou mesmo pelas dúvidas e dificuldades na digitação das informações, fazendo com que a sessão expirasse e o usuário tivesse que começar a preencher tudo novamente. Assim, na Questão 16, é proposto o recurso de quebra de formulário em partes menores. Diretriz: 3.1 - Legível e Compreensível, Critérios de Sucesso: 3.1.7* - Princípio de Usabilidade: Prevenção de erros (U5).

Questão 16: Suponha que você tenha que preencher um extenso formulário, com diversos campos, tendo inclusive que utilizar a barra de rolagem para conseguir chegar ao final da página. Caso você tivesse a opção de "quebrar" essa página em várias páginas menores, sem barra de rolagem e com botões de "continuar" ao final de cada uma delas. Qual das alternativas abaixo melhor descreve a forma com que você utilizaria esse recurso?(Figura 6.29)

Alternativas: (a) Nunca usaria esse recurso/(b) Usaria esse recurso quando sentisse necessidade/ (c) Utilizaria frequentemente esse recurso/ (d) Utilizaria outro mecanismo que oferecesse esse resultado.

A motivação para a inclusão do recurso apresentado na Questão 17 (Figura 6.30) veio das respostas do questionário aplicado aos adultos mais velhos e mais experientes no uso da Web, onde foi relatado que a sessão da página expirava porque os usuários eram obrigados a interromper o preenchimento de um formulário extenso para procurar os documentos requeridos pela página. Diretriz: 3.3 - Assistência na entrada, Critério de Sucesso: 3.3.8* - Princípio de Usabilidade: Compatibilidade do sistema com o mundo real (U2). 


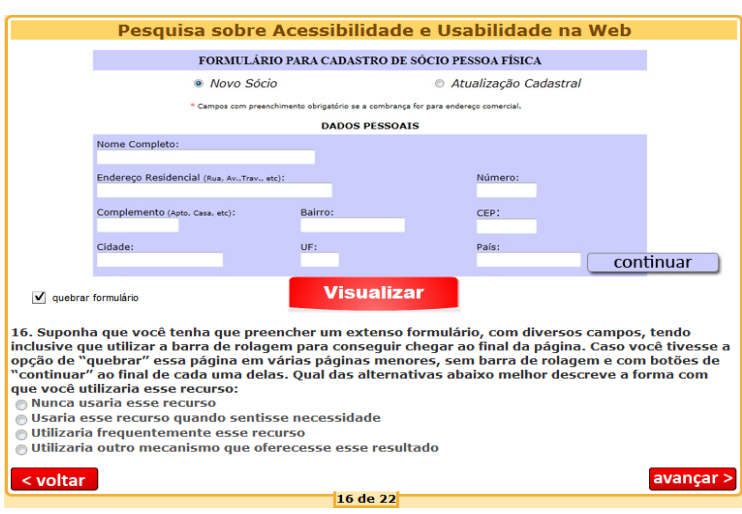

(a)

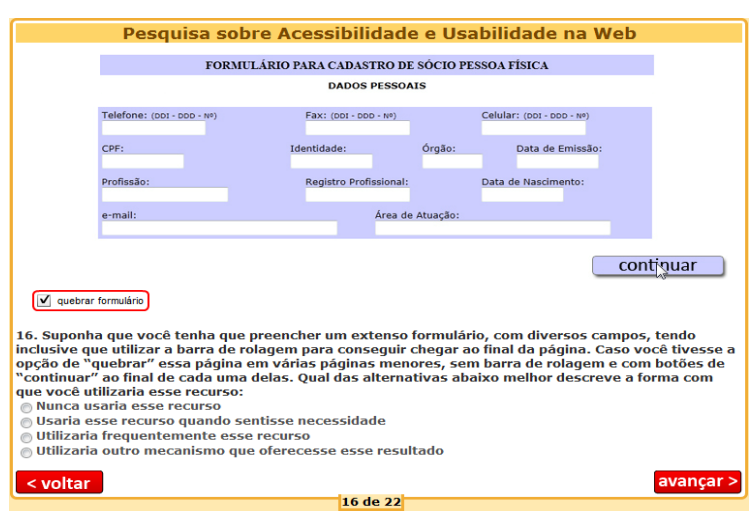

(b)

Figura 6.29: Questão 16 - Recurso de quebra de formulário

Questão 17: Suponha que, em uma página contendo um extenso formulário, com diversos campos a serem preenchidos, você tivesse a opção de ouvir quais os documentos precisa ter em mãos para preencher os campos, você:

Alternativas: (a) Nunca usaria esse recurso/(b) Usaria esse recurso quando sentisse necessidade/ (c) Utilizaria frequentemente esse recurso/ (d) Utilizaria outro mecanismo que oferecesse esse resultado.

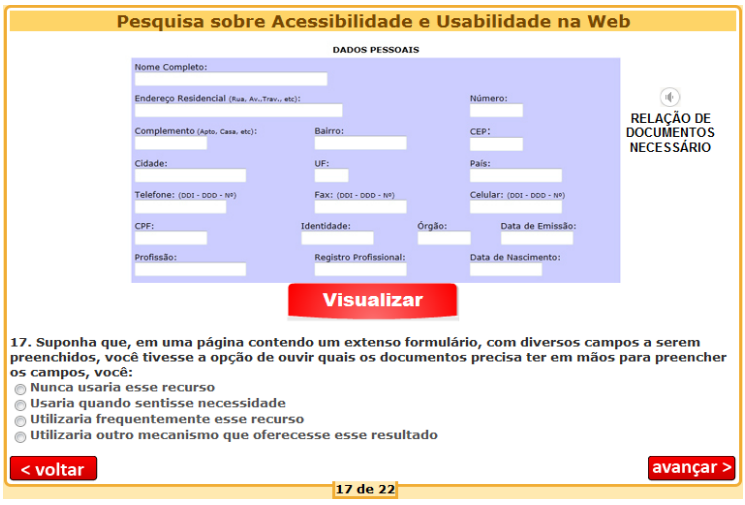

(a)

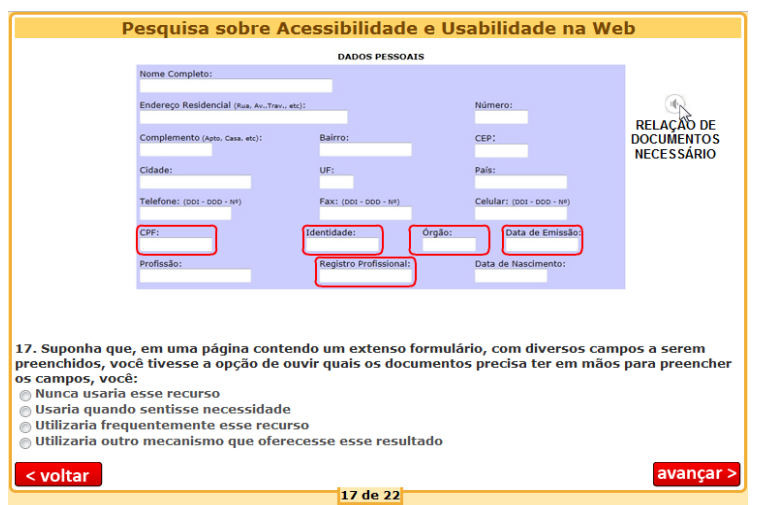

(b)

Figura 6.30: Questão 17 - Recurso de lembrete de documentos

A falta de informação sobre o tipo de informação e sua respectiva formatação nos campos de entrada prejudica a interação dos adultos mais velhos com a Web. A opção da reprodução por voz dessas informações pode ajudá-los a compreender melhor as mensagens, pois como foi mencionado anteriormente, os adultos mais velhos preferem ouvir a ler textos. Diretriz: 3.3 - Assistência na entrada, Critério de Sucesso: 3.3.7* - Princípio de Usabilidade: Prevenção de erros (U5).

Questão 18: Suponha que numa página Web contendo formulário, exista um botão ao lado de cada campo de entrada que diga em mensagem de voz, 
qual informação deve ser preenchida e seu respectivo formato. Qual das alternativas abaixo melhor descreve a forma com que você utilizaria esse recurso? (Figura 6.31)

Alternativas: (a) Nunca usaria esse recurso/(b) Usaria esse recurso quando sentisse necessidade/ (c) Utilizaria frequentemente esse recurso/ (d) Utilizaria outro mecanismo que oferecesse esse resultado.

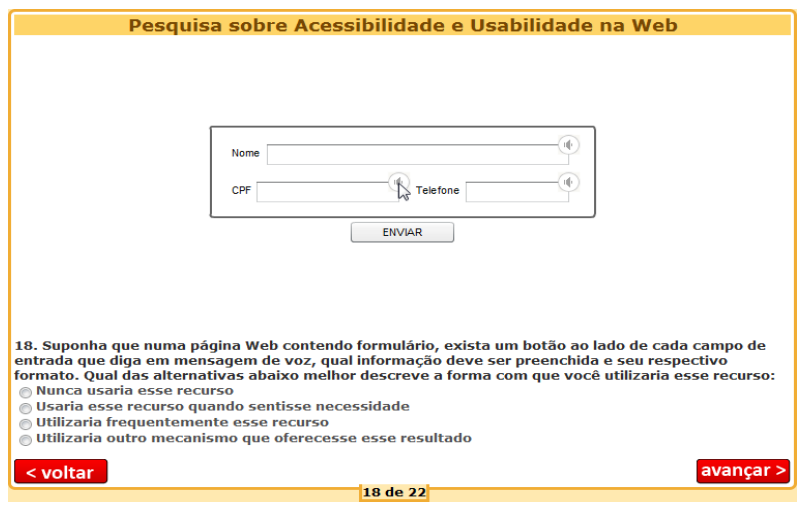

Figura 6.31: Questão 18 - Recurso para preenchimento de informações

A motivação para a inclusão do recurso apresentado na Questão 19 visa amenizar um dos principais problemas enfrentados pelos adultos mais velhos. Trata-se do recurso para apoio ao reconhecimento de passos e aprendizado de uma tarefa específica. Diretriz: 3.3 - Assistência na entrada, Critério de Sucesso: 3.3 .5 - Princípio de Usabilidade: Reconhecimento ao invés de relembrança (U6).

Questão 19: Suponha que numa página de banco você tenha um recurso que reproduza os passos que você realizou para conseguir concluir uma tarefa, como uma transferência bancária, por exemplo, ou seja, você reveria como já realizou um procedimento para lembrar como deve fazê-lo novamente. Qual das alternativas abaixo melhor descreve a forma com que você utilizaria esse recurso? (Figura 6.32)

Alternativas: (a) Nunca usaria esse recurso/(b) Usaria esse recurso quando sentisse necessidade/ (c) Utilizaria frequentemente esse recurso/ (d) Utilizaria outro mecanismo que oferecesse esse resultado.

As Questões 20 e 21 foram inseridas no questionário com a finalidade de avaliar a proporção de adultos mais velhos que realiza operações mais complexas na Web, como compras e operações financeiras, bem como coletar sugestões a respeito de recursos que poderiam ser criados para facilitar tais operações.

Questão 20: Você realiza compras pela Internet? 


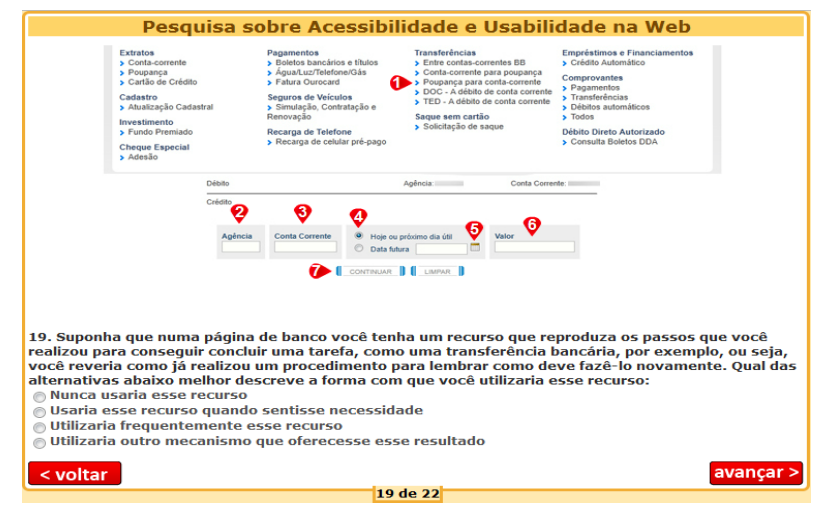

Figura 6.32: Questão 19 - Recurso de reconhecimento de procedimentos

\section{Alternativas: Sim/Não}

Se você pudesse inventar um recurso para te ajudar a fazer compras pela Internet com mais facilidade, como ele seria?

Comentários: campo em aberto

Questão 21: Você utiliza bancos pela Internet?

Alternativas: Sim/Não

Se você pudesse inventar um recurso para te ajudar a realizar operações bancárias pela Internet com mais facilidade, como ele seria?

\section{Comentários: - campo em aberto}

Questão 22: Descreva no campo abaixo um ou mais recursos que o auxiliariam a utilizar melhor a Internet.

Comentários: - campo em aberto

\subsubsection{Coleta de Dados}

O convite para participar desta pesquisa sobre os mecanismos de apoio para a interação de adultos mais velhos foi enviado por e-mail aos participantes, solicitando para que encaminhassem o convite para outros possíveis interessados, desde que tivessem idade igual ou superior a 40 anos, preferencialmente. Os jovens não foram impedidos de participar e também puderam contribuir com suas opiniões.

Ao acessar o endereço do Survey ${ }^{3}$, o usuário visualizava uma página de apresentação e em seguida preenchia um formulário com informações sobre seu perfil. Neste

\footnotetext{
${ }^{3}$ http://agua.intermidia.icmc.usp.br/questionario
} 
formulário, o participante deveria informar: data de nascimento, e-mail, ocupação, escolaridade, tempo de experiência de uso da Web e frequência de uso.

Após o preenchimento do formulário, o participante iniciava suas respostas do questionário propriamente dito, por meio da visualização de cada questão com sua respectiva demonstração, conforme descrito na Subseção 6.4.1.

O questionário continha 22 questões, sendo 19 de múltipla escolha e 3 questões abertas, que abordavam conhecimentos relativos a recursos já existentes (aumentadores de fonte, aumentadores de contrate e breadcrumbs) e novos recursos propostos, bem como coletava a opinião do usuário sobre o que poderia ser melhorado no comércio eletrônico, em bancos on-line e na Web de modo geral.

Conforme mencionado, na mensagem inicial de apresentação sobre a pesquisa, já havia um comunicado de que os dados fornecidos para essa pesquisa não seriam utilizados para nenhum outro fim, sendo mantido sigilo total sobre os mesmos. Os dados do perfil dos usuários e das respostas do questionário foram armazenados em base de dados para análise posterior.

O questionário ficou disponível desde a sua divulgação e convite por e-mail, no período de novembro/2011 a abril/2012. Muitos dos participantes também repassaram a pesquisa para outros interessados, e assim, dos 66 convites enviados inicialmente, foi obtido um total de 313 respondentes para o questionário até a data de 27/04/2012. Nas próximas seções são apresentados os dados analisados a partir das respostas obtidas.

\subsubsection{Perfil dos participantes}

Nesta seção são apresentados os dados que caracterizam o perfil dos participantes que responderam ao questionário sobre os mecanismos de apoio para a interação de adultos mais velhos na Web. A idade mínima registrada foi de 17 anos e a máxima de 85 anos como pode ser visualizado na Tabela 6.4. Em função das diferentes quantidades de indivíduos nas faixas etárias, a média foi de 38,28 anos de idade na amostra.

Tabela 6.4: Idade mínima e idade máxima da amostra de dados

\begin{tabular}{|l|l|l|l|l|l|}
\cline { 2 - 6 } \multicolumn{1}{c|}{} & N & Mínimo & Máximo & Média & Desvio Padrão \\
\hline Idade & 313 & 17 & 85 & 38,28 & 13,719 \\
\hline N válido & 313 & & & & \\
\hline
\end{tabular}

Ao realizar uma classificação dos dados por faixa etária (jovens, meia-idade e idosos), as quantidades e percentuais obtidos estão apresentados na Tabela 6.5. Observa-se 
que 44,5\% dos participantes (139 pessoas) correspondia ao público de maior interesse nesta pesquisa (idosos e adultos de meia-idade).

Tabela 6.5: Quantidade e percentual de usuários por faixa etária

\begin{tabular}{|c|r|r|r|r|}
\hline & Frequência & Percentual & Percentual Válido & Percentual Cumulativo \\
\hline Idoso & 18 & 5,8 & 5,8 & 5,8 \\
\hline Meia-Idade & 121 & 38,7 & 38,7 & 44,4 \\
\hline Jovem & 174 & 55,6 & 55,6 & 100,00 \\
\hline Total & 313 & 100,00 & 100,00 & \\
\hline
\end{tabular}

Ao verificar a concentração dos respondentes por faixa etária versus experiência pôde-se observar, por meio da Tabela 6.6, que o grupo de idosos, com o total de 18 indivíduos, possui aproximadamente a mesma quantidade de pessoas em cada uma das categorias de experiência, característica que não é observada no grupo da meia-idade e jovens, nos quais a grande parcela de usuários já possui mais que 10 anos de experiência.

Tabela 6.6: Experiência dos usuários por faixa etária

\begin{tabular}{|l|r|r|r|r|}
\cline { 2 - 5 } \multicolumn{1}{c|}{} & \multicolumn{4}{|c|}{ Experiência } \\
\hline Faixa Etária & Até 5 anos & Entre 5 e 10 anos & Mais que 10 anos & \multicolumn{1}{c|}{ Total } \\
\hline Idoso & $33,3 \%(6)$ & $27,8 \%(5)$ & $38,9 \%(7)$ & $100 \%(18)$ \\
\hline Meia-Idade & $5,0 \%(6)$ & $15,7 \%(19)$ & $79,3 \%(96)$ & $100 \%(121)$ \\
\hline Jovem & $10,9 \%(19)$ & $30,5 \%(53)$ & $58,6 \%(102)$ & $100 \%(174)$ \\
\hline Total & $9,9 \%(31)$ & $24,6 \%(77)$ & $65,5 \%(205)$ & $100 \%(313)$ \\
\hline
\end{tabular}

\subsubsection{Análises e Discussões}

Análise da Questão 1: sobre o recurso para o redimensionamento do tamanho da letra, como pode-se observar pelo gráfico mostrado na Figura 6.33, a maioria das pessoas utiliza o recurso apenas quando necessita. O fato de aproximadamente $21,5 \%$ dos idosos nunca utilizarem o mecanismo pode ser um indício do desconhecimento da presença do mecanismo nas páginas Web.

Em função do indício identificado, foram analisados somente os dados das pessoas que utilizam a Web uma vez por semana ou menos, e os resultados obtidos são mostrados na Figura 6.34.

Observa-se que nenhuma das faixas etárias utiliza frequentemente esse recurso, sendo utilizado apenas por idosos e adultos de meia-idade quando surge a necessidade.

Análise da Questão 2: talvez pelo fato da disponibilidade do recurso de aumento de contraste ser menos frequente do que o recurso de redimensionamento de fonte em páginas Web, percebe-se que o mesmo é muito pouco utilizado, sendo que o percentual de uso do "Nunca" na Figura 6.35 (entre $40 \%$ e 65\%) e do "Muito pouco" 


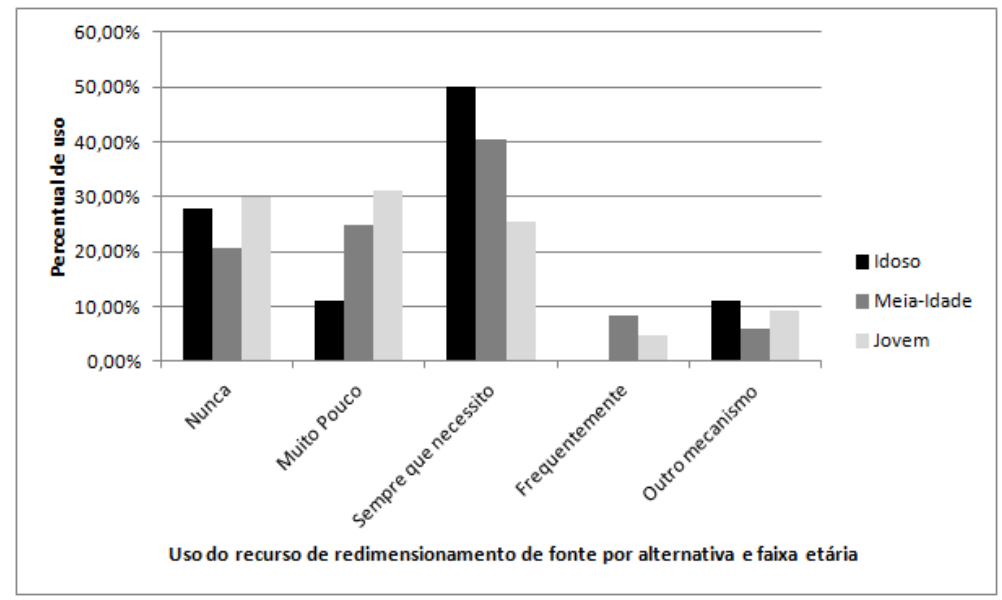

Figura 6.33: Uso do recurso de aumento de fonte agrupados por alternativa e faixa etária

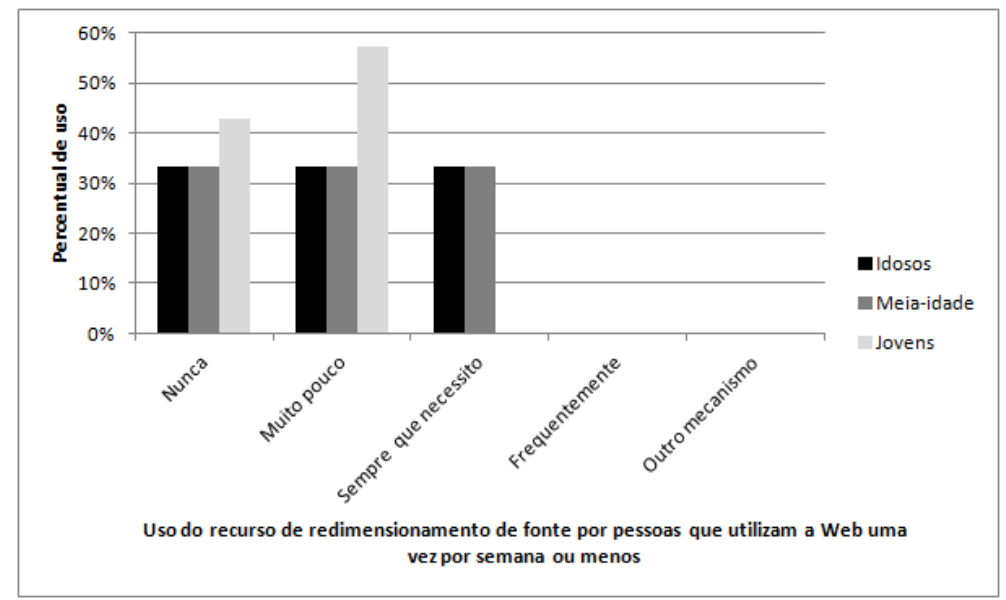

Figura 6.34: Uso do recurso de aumento de fonte por pessoas que utilizam a Web uma vez por semana ou menos agrupados por faixa etária

(aproximadamente entre 15\% e 30\%) predominam em todas as faixas etárias. Dentre os participantes que usam o recurso, pode-se observar a predominância dos adultos mais velhos.

Análise da Questão 3: o recurso de abreviação de caminho encontra-se disponível na maioria das páginas Web por facilitar a localização do usuário e permitir a navegação estruturada. Pelos resultados observados na Figura 6.36 pode-se verificar que trata-se de um recurso amplamente utilizado pelos adultos de meia-idade e jovens, mas ainda muito pouco explorado pelos idosos. Durante a observação em campo, foi observado que os idosos apresentam muita insegurança na navegação e sentem medo em se perder, retornando várias vezes para a página inicial ao invés de acessar os links intermediários oferecidos pelos breadcrumbs.

Análise da Questão 4: o apoio para utilização do campo de busca foi incluído nesse estudo pela pesquisadora devido às dificuldades observadas em campo, pelos 


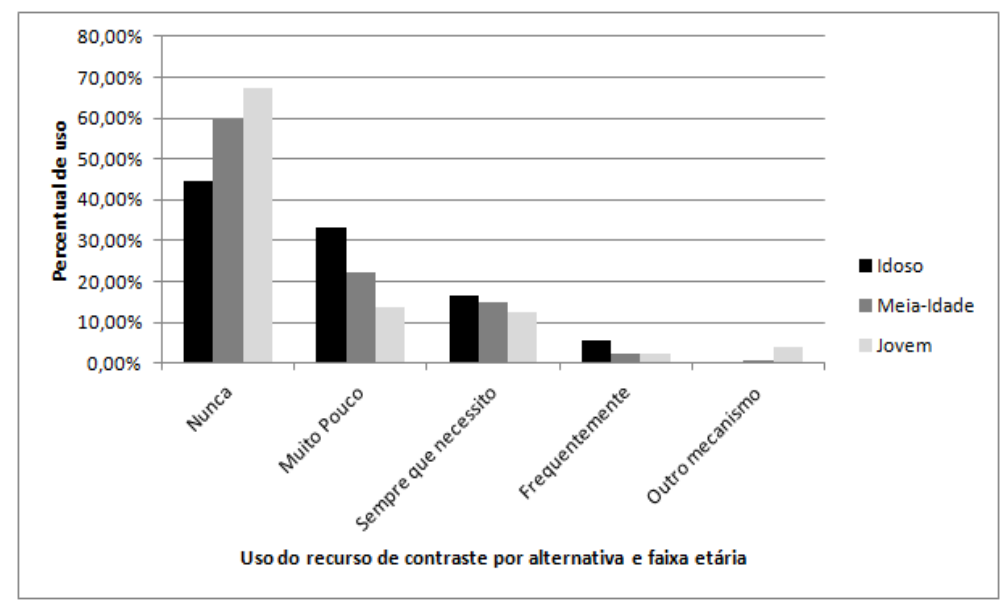

Figura 6.35: Uso do recurso de aumento de contraste agrupados por alternativa e faixa etária

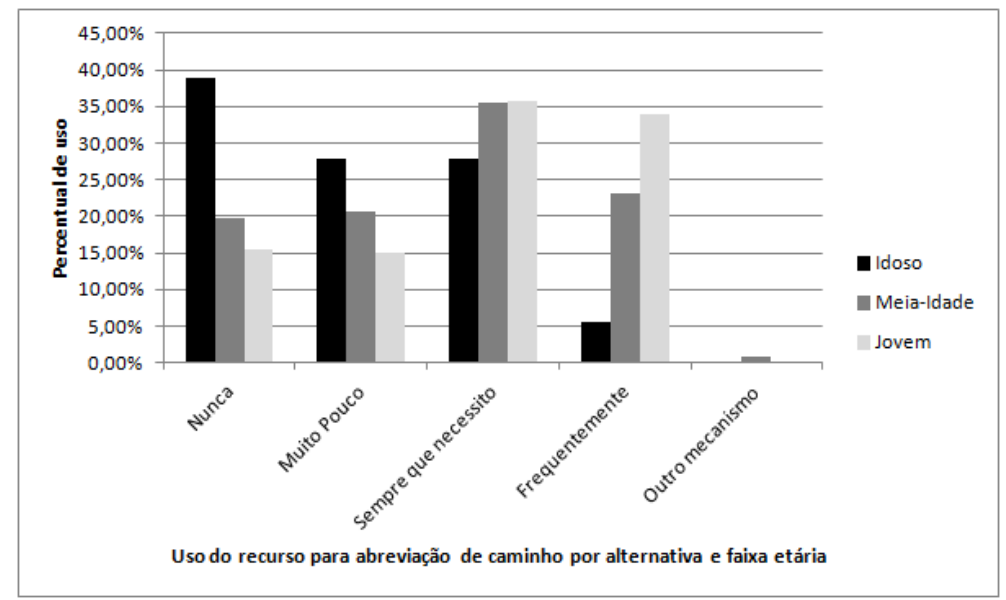

Figura 6.36: Uso do recurso de abreviação do caminho agrupados por alternativa e faixa etária

adultos mais velhos e com pouca experiência no uso da Web, quanto pelas dificuldades relatadas em localizar a informação desejada pelos adultos mais velhos experientes. Foi possível verificar que, muitas vezes, o usuário não encontra a informação desejada porque não utilizou a caixa de busca de forma correta. Pode-se observar na Figura 6.37 as altas taxas de uso desse recurso por todas as faixas etárias, mostrando que um recurso que muitas vezes visa atender determinado público-alvo (adultos mais velhos) pode ser útil também para os mais jovens.

Análise da Questão 5: com o objetivo de manter o foco de atenção dos adultos mais velhos no conteúdo principal da página Web foi idealizado o recurso para eliminação de banners e campanhas publicitárias. Pelos resultados obtidos (Figura 6.38) pode-se constatar a alta aceitação do recurso pelos adultos mais velhos, no qual mais de $70 \%$ deles o usariam frequentemente. O recurso também foi bem aceito pelos jovens, mas não com tanta intensidade, visto que parte deles o usaria apenas 


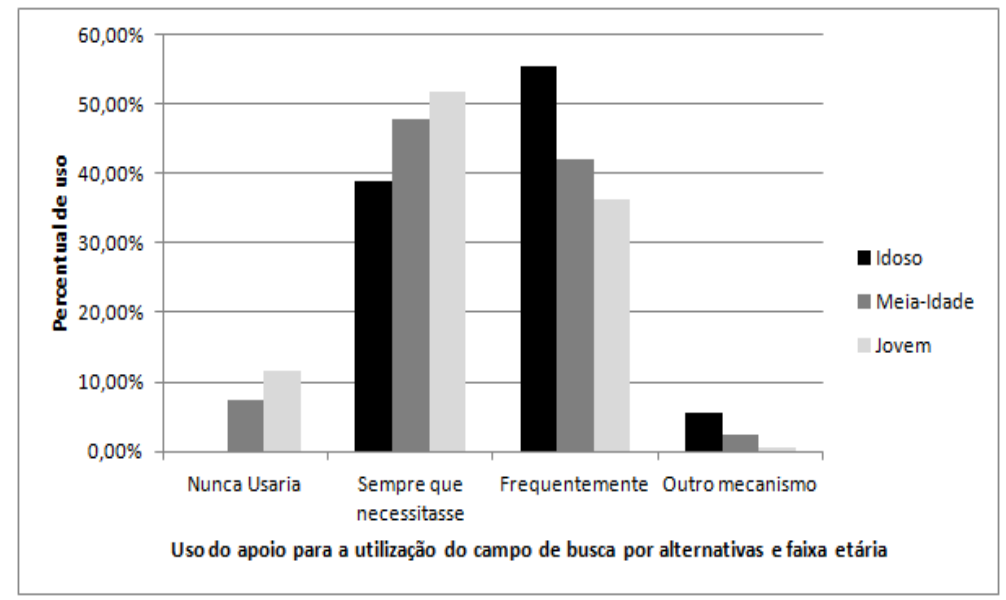

Figura 6.37: Uso do apoio para utilização do campo de busca agrupados por alternativa e faixa etária

quando necessitasse, demonstrando que muitos jovens também se interessam pelas propagandas publicitárias.

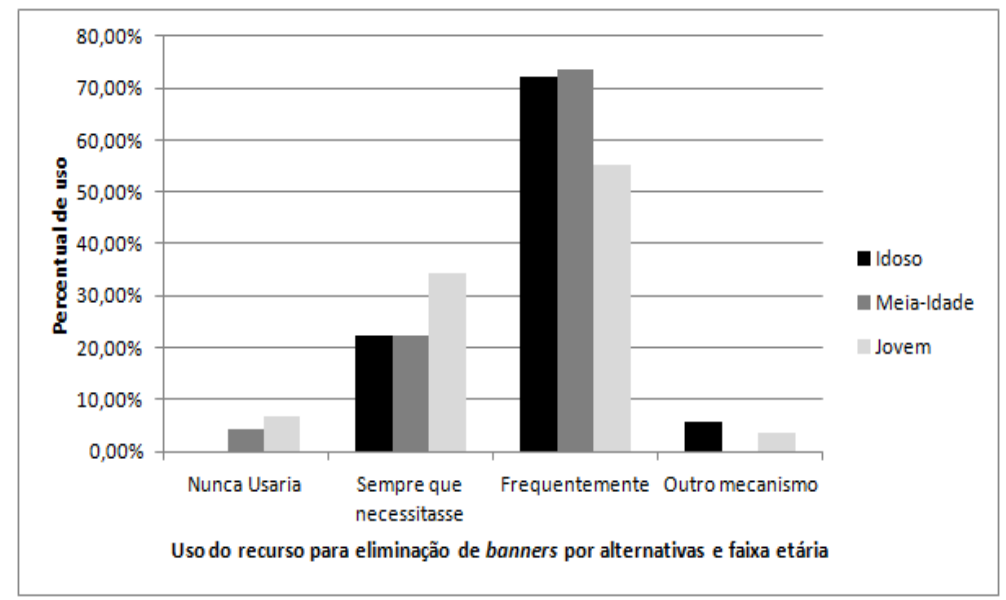

Figura 6.38: Uso do recurso para eliminação de banners agrupados por alternativa e faixa etária

Análise da Questão 6: conforme já mencionado anteriormente, os adultos mais velhos, muitas vezes, não percebem a existência da barra de rolagem na margem direita e não concluem suas tarefas, nem mesmo a leitura de um texto extenso, o que motivou a inclusão de um recurso de indicação de barra de rolagem. Pelos resultados, pode-se verificar que esse recurso foi mais bem aceito pelos idosos (mais de $60 \%$ entre "usaria quando sentisse necessidade" e "frequentemente"), embora as taxas ficassem divididas. A rejeição do mecanismo pelos jovens ficou em aproximadamente $50 \%$.

Análise da Questão 7: O recurso de visualização de resumo de texto foi amplamente aceito por todas as faixas etárias, como pode ser observado na Figura 6.40 , sendo utilizado frequentemente por mais de $70 \%$ dos adultos mais velhos. Vale ressaltar que houve a rejeição do mecanismo por aproximadamente $10 \%$ dos idosos, 


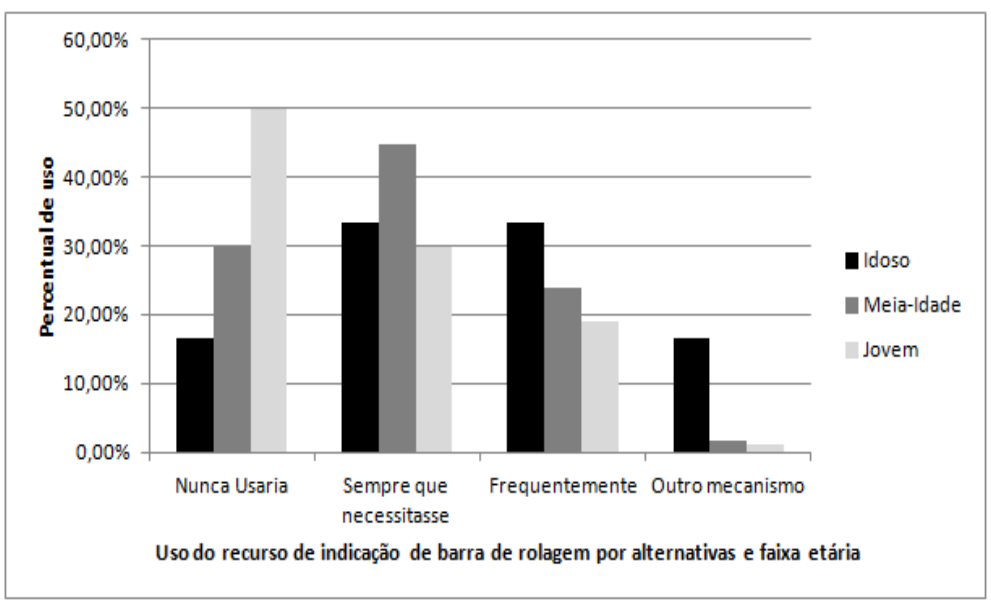

Figura 6.39: Uso do recurso de indicação de barra de rolagem agrupados por alternativa e faixa etária

cujos motivos que podem ser hipotetizados, a partir do contato desta pesquisadora com esse público durante a observação em campo, são: maior tempo disponível para a leitura de todo o conteúdo e o sentimento de compreensão total do assunto, que poderia não ocorrer a partir da leitura do resumo.

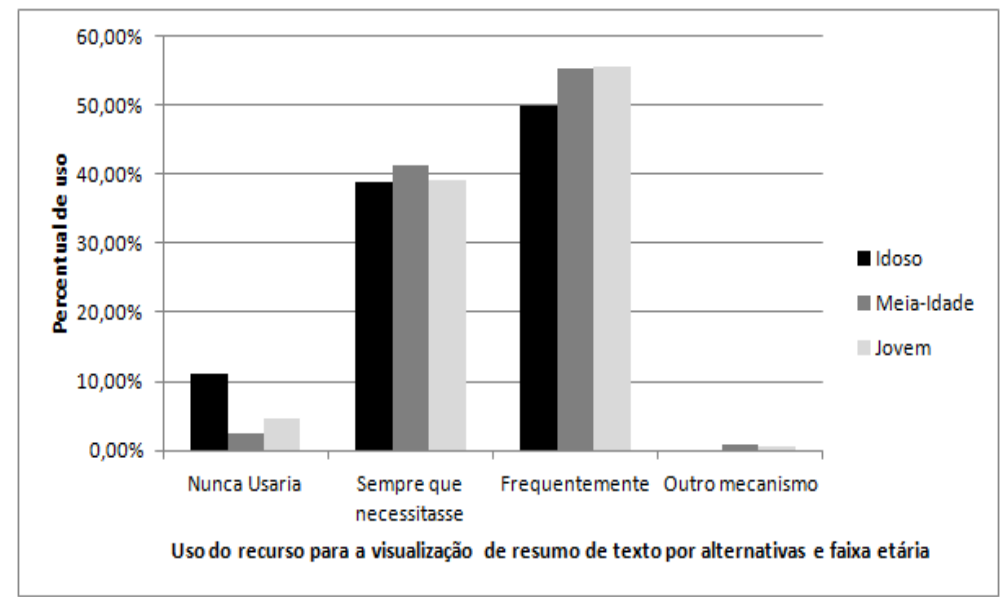

Figura 6.40: Uso do recurso de visualização de resumo de texto agrupados por alternativa e faixa etária

Análise da Questão 8: O recurso de visualização de tópicos do texto também foi muito bem aceito por todas as faixas etárias (Figura 6.41), destacando novamente a rejeição de aproximadamente $10 \%$ dos idosos (somando-se os percentuais de "Nunca usaria" com "Outro mecanismo"). O motivo dessa rejeição, a partir da percepção desta pesquisadora, que pode ser hipotetizado é: os idosos preferem a leitura sequêncial para a compreensão do conteúdo, devido à redução da sobrecarga cognitiva, ao invés da construção do modelo mental do "todo" a partir de suas "partes". 


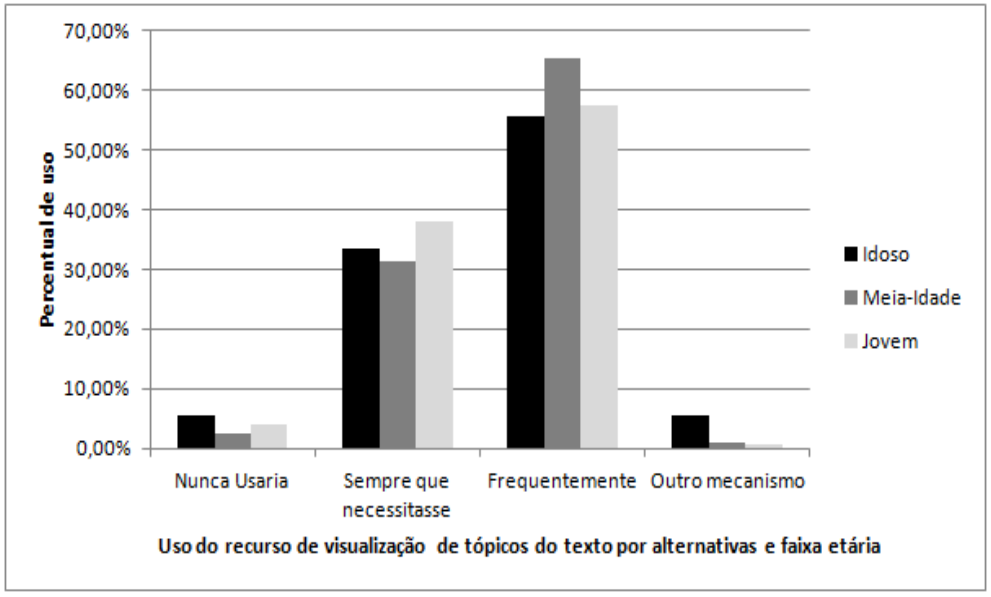

Figura 6.41: Uso do recurso de visualização de tópicos do texto agrupados por alternativa e faixa etária

Análise da Questão 9: o apoio para a utilização de links que mostra antecipadamente o assunto, seu nível de segurança e o endereço do link propriamente dito foi uma das dificuldades/sugestões obtidas por meio do questionário aplicado aos usuários mais experientes, que se sentiam inseguros durante os acionamentos. Por meio da Figura 6.42 pode-se constatar que trata-se mesmo de uma necessidade dos adultos de meia-idade, talvez por apresentarem um perfil mais conservador quanto comparados aos jovens. Vale ressaltar que a taxa de rejeição apresentada pelos idosos foi de aproximadamente $25 \%$.

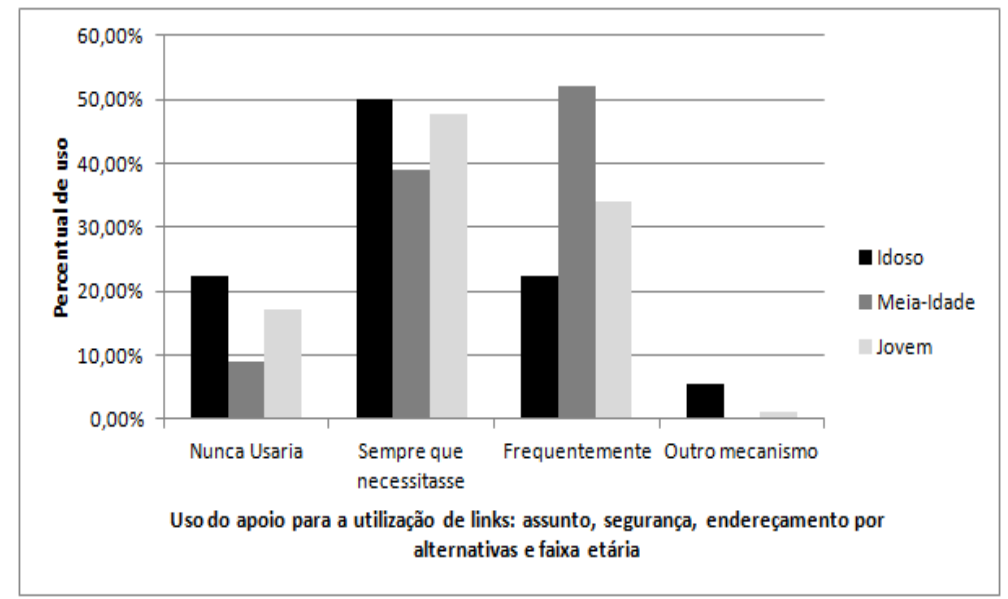

Figura 6.42: Uso do apoio para a utilização de links: assunto, segurança, endereçamento agrupados por alternativa e faixa etária

Análise da Questão 10: com a finalidade de reduzir a sobrecarga cognitiva dos adultos mais velhos, foi proposto o recurso de escolha de cor para links visitados e não visitados. Ao observar as taxas da opção "Frequentemente" na Figura 6.43, percebe-se que trata-se de um recurso voltado para os adultos mais velhos, visto que aproximadamente $50 \%$ de idosos e $40 \%$ de adultos de meia-idade o aceitaram para 
uso frequente e entre $30 \%$ e $40 \%$ deles o usariam quando sentissem necessidade. A maior taxa de rejeição foi a dos jovens, cerca de $30 \%$.

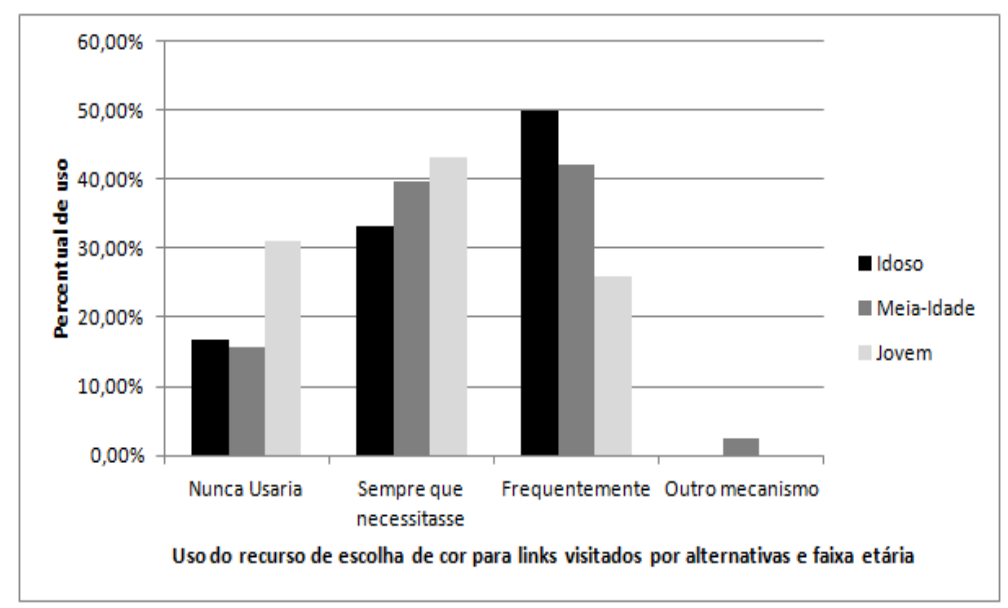

Figura 6.43: Uso do recurso de escolha de cor para links visitados agrupados por alternativa e faixa etária

Análise da Questão 11: com a mesma finalidade do recurso anterior, o recurso de escolha de cores para opções de menu visa reduzir o acionamento de opções de menus já visitadas, e com exceção de cerca de $5 \%$ dos idosos que rejeitou sua utilização (Figura 6.44), esse recurso teve grande aceitação por parte dos adultos mais velhos. As taxas de rejeição dos adultos de meia-idade e dos jovens foram de aproximadamente $23 \%$ e $30 \%$, respectivamente.

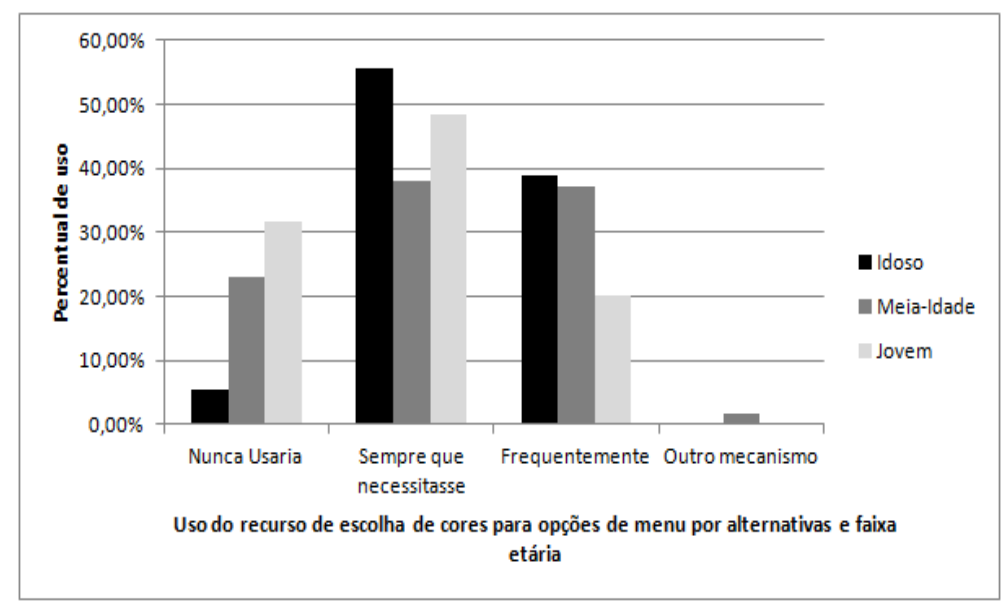

Figura 6.44: Uso do recurso de escolha de cores para opções de menu agrupados por alternativa e faixa etária

Análise da Questão 12: o recurso para controle de velocidade de menus visa proporcionar o tempo sufiente e adequado para que os usuários possam acionar corretamente a opção desejada dentro da hierarquia de níveis dos menus. Durante as observações em campo foi comum verificar que os usuários eram conduzidos a visitar páginas que não queriam devido à imprecisão do clique na opção, geralmente 
acionando opções erradas ou em níveis intermediários na hierarquia dos menus. Pelos resultados foi possível constatar, um nível crescente de uso entre as faixas etárias nas taxas da opção "Sempre que necessitasse" e decrescente na opção "Frequentemente", o que indica o maior nível de aceitação do recurso entre os adultos mais velhos.

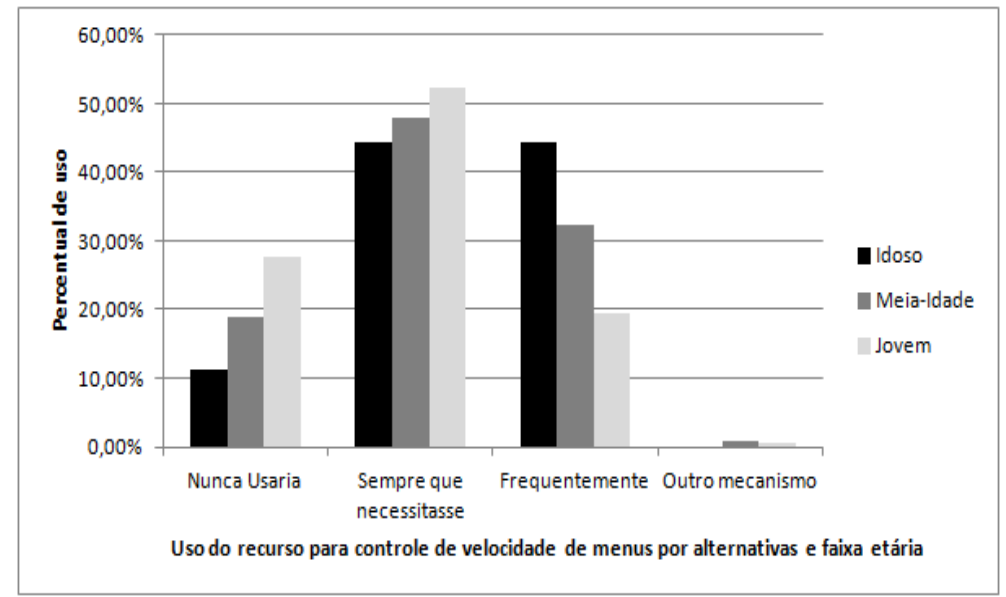

Figura 6.45: Uso do recurso para controle de velocidade de menus agrupados por alternativa e faixa etária

Análise da Questão 13: o recurso para diminuição da velocidade de apresentação de vídeo apresentou resultados muito próximos em todas as opções para todas as faixas etárias, no qual cerca de $30 \%$ dos participantes o usariam frequentemente e $60 \%$ o usariam quando sentissem necessidade conforme pode ser observado na Figura 6.46. Tais resultados indicam que esse recurso, além de ser importante para os adultos mais velhos devido à diminuição de suas habilidades sensoriais, traria também maior conforto para o público jovem.

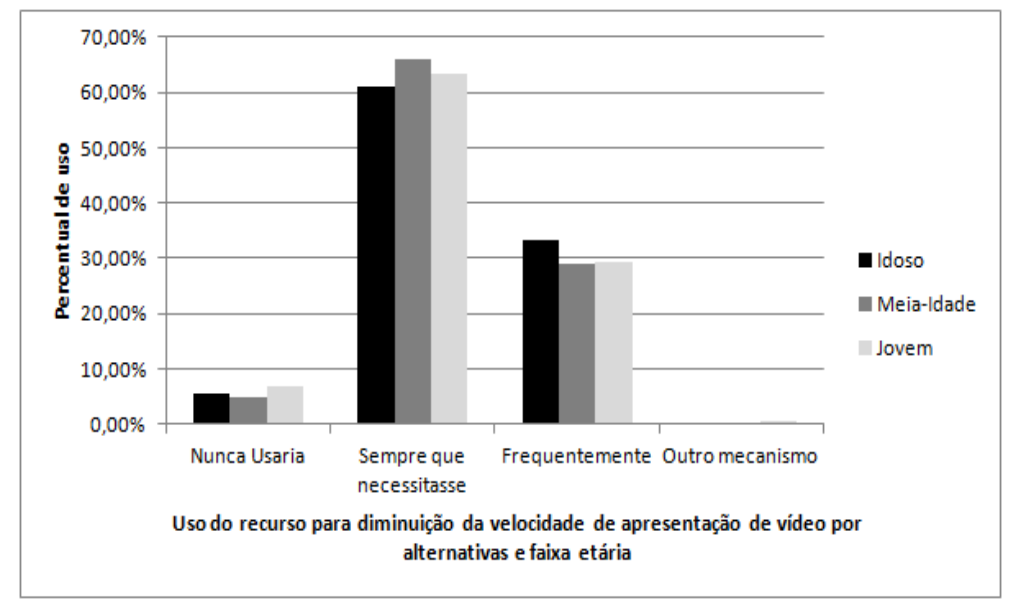

Figura 6.46: Uso do recurso para diminuição da velocidade de apresentação de vídeo agrupados por alternativa e faixa etária

Análise da Questão 14: conforme constatado em observações em campo, os adultos mais velhos preferem ouvir a ler um conteúdo na Web. O recurso de áudio 
para figuras foi prosposto para oferecer essa flexibilidade de uso para os adultos mais velhos. Pelos resultados visualizados na Figura 6.47 pode-se verificar que o recurso não foi rejeitado por nenhum dos idosos participantes, sendo que $50 \%$ optaram por usá-lo frequentemente e $50 \%$ quando necessitassem. Dos adultos de meia-idade, aproximadamente $15 \%$ o utilizariam frequentemente e $70 \%$ quando necessitassem. Cerca de $25 \%$ dos jovens rejeitaram o uso do recurso.

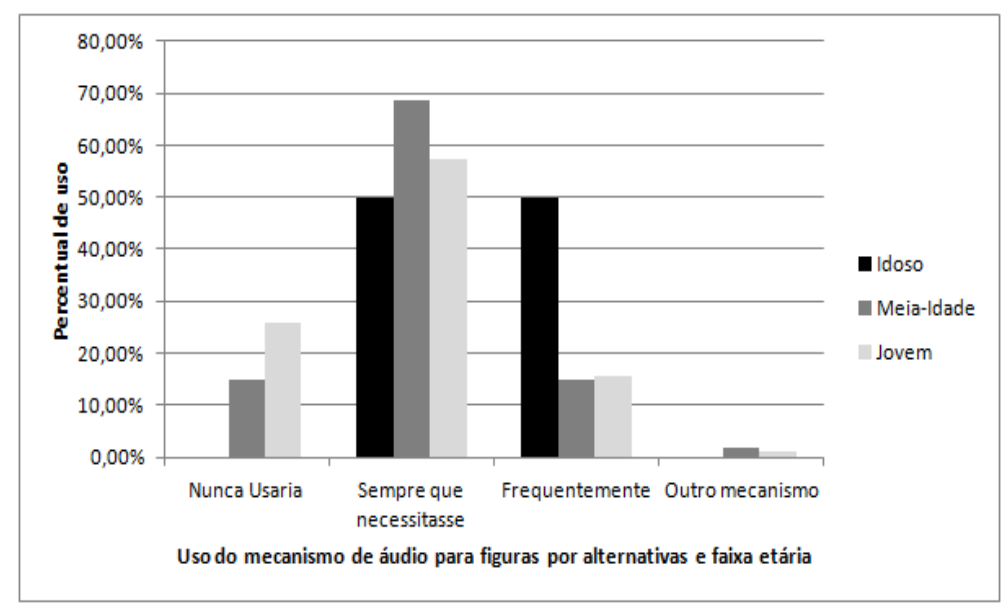

Figura 6.47: Uso do recurso de áudio para figuras agrupados por alternativa e faixa etária

Análise da Questão 15: o recurso de guia de funcionalidades visa destacar, para os adultos mais velhos, as possibilidades funcionais presentes na página Web. Como pode ser observado na Figura 6.48 esse recurso foi amplamente aceito pelos idosos, sendo que aproximadamente $50 \%$ deles o usariam frequentemente e $45 \%$ quando sentissem necessidade. Para os adultos de meia-idade e jovens a taxa mais expressiva foi de que, aproximadamente $60 \%$ deles o usariam quando sentissem necessidade.

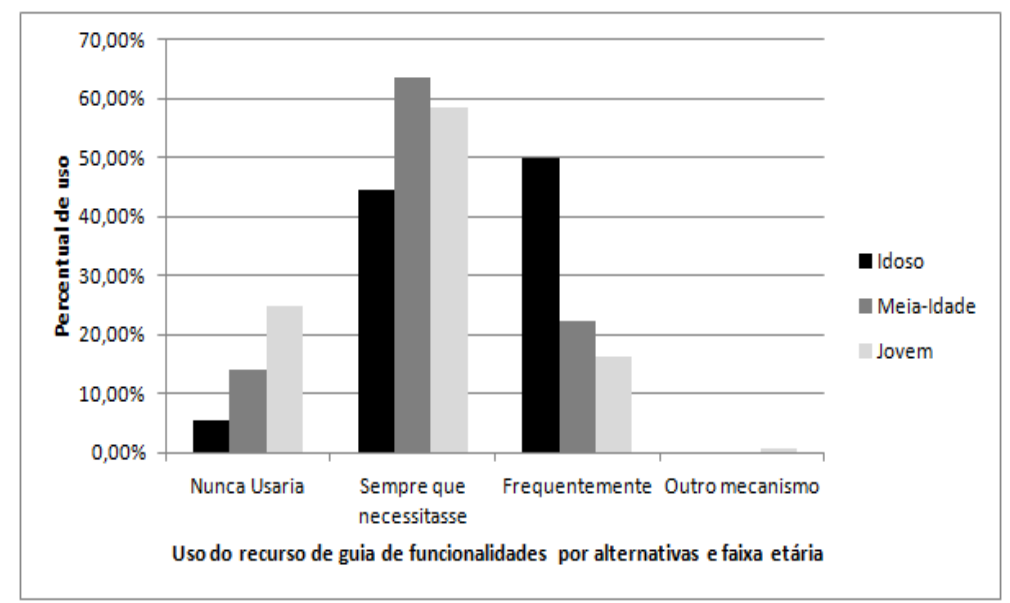

Figura 6.48: Uso do recurso de guia de funcionalidades agrupados por alternativa e faixa etária 
Análise da Questão 16: com a finalidade de evitar que a sessão Web de uma tarefa expire devido à demora no preenchimento de campos de formulário, foi proposto o recurso de divisão de formulário em unidades menores. Tal recurso foi amplamente aceito pelos idosos, sendo que cerca de $60 \%$ o usariam frequentemente e mais de $20 \%$ quando sentissem necessidade. Entre os adultos de meia-idade predominou a escolha pela opção "Sempre que necessitasse" com aproximadamente $50 \%$ das escolhas sendo acompanhada de cerca de $38 \%$ para a opção "Frequentemente". Para a faixa etária dos jovens as taxas ficaram muito próximas para as 3 principais opções (em torno de $32 \%$ ), como pode ser visualizado na Figura 6.49.

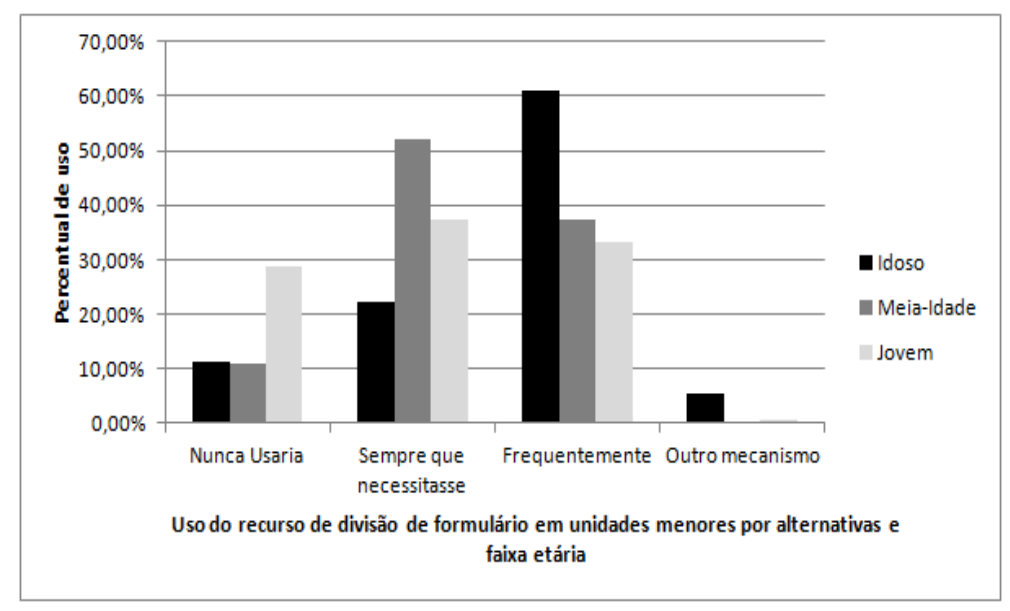

Figura 6.49: Uso do recurso de divisão de formulário em unidades menores agrupados por alternativa e faixa etária

Análise da Questão 17: o recurso de lembrete de documentos da vida real também foi incluído neste estudo devido à dificuldade/sugestão extraída do questionário aplicado aos usuários mais experientes no uso da Web. As taxas observadas para os adultos mais velhos foram muito próximas, sendo em torno de $45 \%$ de uso frequente e de $40 \%$ quando sentissem necessidade (Figura 6.51). Vale destacar que entre os jovens não houve grande diferenciação entre as opções que ficaram em torno de $34 \%, 40 \%$ e $24 \%$ de uso para as opções "Nunca", "Sempre que necessitasse" e "Frequentemente", respectivamente

Análise da Questão 18: quanto ao apoio para preenchimento de campos de entrada, pode-se observar na Figura 6.51 que cerca de 50\% dos participantes de todas as faixas etárias usariam o recurso quando sentissem necessidade. As taxas de uso frequente aparecem de forma decrescente entre idosos, adultos de meia-idade e jovens, o que era um resultado esperado. Da mesma forma, as taxas de rejeição aparecem de forma crescente, sendo o maior índice, de aproximadamente 39\% para os jovens.

Análise da Questão 19: o recurso para reconhecimento de procedimentos foi proposto especialmente para os adultos mais velhos e tem por objetivo facilitar 


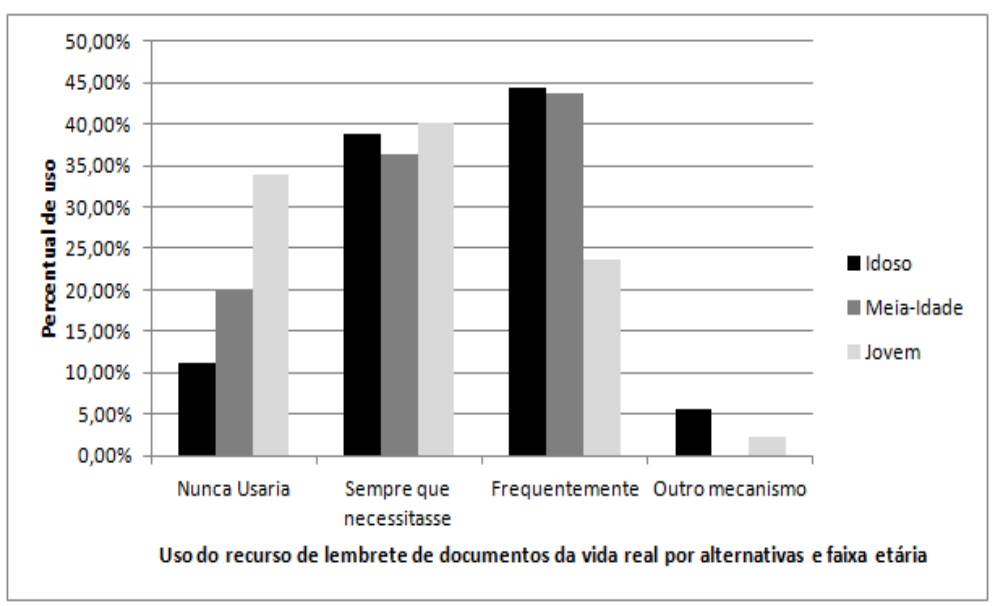

Figura 6.50: Uso do recurso de lembrete de documentos da vida real agrupados por alternativa e faixa etária

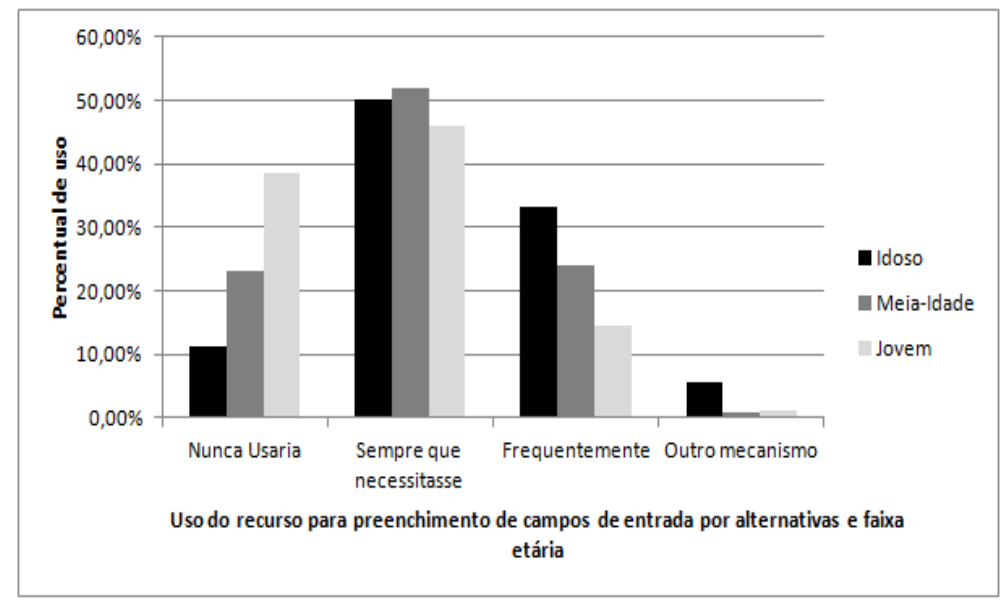

Figura 6.51: Uso do apoio para preenchimento de campos de entrada agrupados por alternativa e faixa etária

o reconhecimento de um procedimento até obter seu aprendizado. Conforme era esperado e pode ser visualizado na Figura 6.52, as maiores taxas de aceitação do recurso para uso frequente foram verificadas para os idosos, seguidos pelos adultos de meia-idade e jovens $(50 \%, 34 \%, 20 \%$ respectivamente). De forma inversa e crescente tem-se $28 \%, 50 \%$ e $61 \%$ para as taxas da opção "Sempre que necessitasse" para os idosos, adultos de meia-idade e jovens respectivamente.

\subsubsection{Resultados}

A partir dos dados coletados, foram realizadas análises estatísticas a respeito da amostra, que contemplou o total de 313 respostas. Para a execução das análises foi utilizado o software estatístico SPSS (Statistical Package for the Social Sciences) ${ }^{4}$.

\footnotetext{
${ }^{4}$ IBM Products - http://www-01.ibm.com/software/analytics/spss/products/statistics/
} 


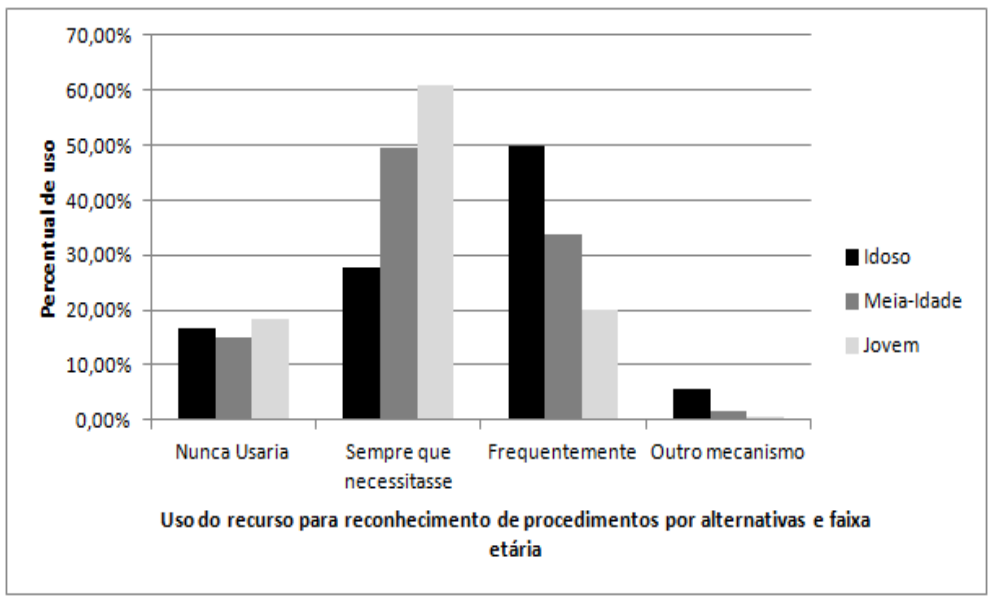

Figura 6.52: Uso do recurso para reconhecimento de procedimentos agrupados por alternativa e faixa etária

A análise das questões de 1 a 3 foi realizada de forma separada das demais, uma vez que tratava de mecanismos que já existem atualmente em algumas páginas Web e eram questões em que fazia sentido a pessoa escolher a alternativa "prefiro utilizar outro mecanismo que ofereça esse resultado". Nas questões de 4 a 19 essa alternativa foi colocada como um meio para o usuário não escolher nennhuma das alternativas anteriores e, portanto, foi descartada da análise.

Foi aplicado o teste Qui-Quadrado (Greenwood e Nikulin, 1996) para avaliar as respostas. O teste Qui-Quadrado é um teste de hipóteses que se destina a encontrar o valor da dispersão para duas variáveis nominais e avaliar a associação existente entre variáveis qualitativas. É um teste não paramétrico, ou seja, não depende de parâmetros populacionais, como média e variância. O princípio básico deste método é comparar proporções, isto é, as possíveis divergências entre as frequências observadas e esperadas para um certo evento.

O teste Qui-Quadrado "FaixaEtária x Alternativas" foi aplicado para todas as questões e avalia a hipótese de independência da faixa etária na escolha das alternativas que foram respondidas. Quando o valor do nível descritivo do teste (valor de $p$ ) for menor que 0,05 essa hipótese é rejeitada e significa que a escolha das alternativas varia de acordo com a faixa etária. As questões cuja independência de faixa etária foi verificada $(p>0,05)$ foram: $2,4,7,8$ e 13, indicando que todas as faixas etárias produziram resultados semelhantes nessas cinco questões.

Nas tabelas das análises a seguir é apresentado o valor de $p$ do teste Qui-Quadrado ou o valor do Teste Exato de Fisher $\left(^{*}\right)$ nos casos em que o valor esperado de pelo menos 1 célula foi menor do que 5. Caso o valor de $p$ seja menor que 0,01 este será indicado por " $<0,01 "$. 
Na Questão 1, em que foi avaliado o uso atual do recurso de aumento do tamanho da fonte, foi obtido um valor de $p$ igual a 0,041 (Tabela 6.7), indicando que os resultados diferem entre as faixas etárias. Pode-se observar que esse recurso não é utilizado frequentemente por nenhuma faixa etária, sendo que a dependência do teste se verifica por ser usado mediante a necessidade por grande parcela de idosos (50\%) e adultos de meia-idade (40,5\%), e muito pouco pelos jovens (25,3\%). É interessante notar que a taxa de rejeição (nunca uso esse recurso) ficou muito próxima entre jovens e idosos.

Tabela 6.7: Análise das respostas da Questão 1

\begin{tabular}{|l|l|l|l|l|l|c|}
\hline Questão 1 & Nunca & Pouco & $\begin{array}{c}\text { Sempre que } \\
\text { necessito }\end{array}$ & $\begin{array}{c}\text { Frequente- } \\
\text { mente }\end{array}$ & Outro & $\begin{array}{c}\text { Valor } \\
\text { de } \boldsymbol{p}\end{array}$ \\
\cline { 1 - 6 } Idosos & $27,8 \%(5)$ & $11,1 \%(2)$ & $50,0 \%(9)$ & $0,0 \%(0)$ & $11,1 \%(2)$ & \\
\cline { 1 - 3 } & $20,7 \%(25)$ & $24,8 \%(30)$ & $40,5 \%(49)$ & $8,3 \%(10)$ & $5,8 \%(7)$ & 0,041 \\
\cline { 1 - 5 } Jovens & $29,9 \%(52)$ & $31,0 \%(54)$ & $25,3 \%(44)$ & $4,6 \%(8)$ & $9,2 \%(16)$ & \\
\hline
\end{tabular}

Na Questão 2, o recurso avaliado foi o aumento de contraste entre cores de frente e fundo da página e os resultados, que podem ser visualizados na Tabela 6.8, mostram que a maior parte dos usuários "nunca" utiliza esse recurso: idoso (44,4\%), meia-idade $(59,5 \%)$ e jovens $(67,2 \%)$. O resultado do valor de p também mostra que os resultados independem da faixa etária observada, pois foi igual 0,182. Uma possível causa do alto índice de rejeição seja a ausência ou o desconhecimento do recurso, ou ainda a pouca necessidade do mesmo, na maioria das páginas Web.

Tabela 6.8: Análise das respostas da Questão 2

\begin{tabular}{|l|l|l|l|l|l|c|}
\hline Questão 2 & Nunca & Pouco & $\begin{array}{c}\text { Sempre que } \\
\text { necessito }\end{array}$ & $\begin{array}{c}\text { Frequente- } \\
\text { mente }\end{array}$ & Outro & $\begin{array}{c}\text { Valor } \\
\text { de } \boldsymbol{p}\end{array}$ \\
\cline { 1 - 6 } Idosos & $44,4 \%(8)$ & $33,3 \%(6)$ & $16,7 \%(3)$ & $5,6 \%(1)$ & $0,0 \%(0)$ & \\
\cline { 1 - 5 } Meidade & $59,5 \%(72)$ & $22,3 \%(27)$ & $14,9 \%(18)$ & $2,5 \%(3)$ & $8 \%(1)$ & \multirow{2}{*}{0,182} \\
\cline { 1 - 5 } & $67,2 \%(117)$ & $13,8 \%(24)$ & $12,6 \%(22)$ & $2,3 \%(4)$ & $4,0 \%(7)$ & \\
\hline
\end{tabular}

Na Questão 3, cujos resultados estão contabilizados na Tabela 6.9, foi avaliada a utilização de "breadcrumbs" e o valor de $p$ atesta que os resultados são dependentes da faixa etária. Percebe-se uma menor taxa de uso desse recurso por parte da população idosa, pois 38,9\% deles afirma que "nunca utiliza o recurso", que somada a $27,8 \%$ que o utiliza "pouco" totaliza $66,7 \%$ dos usuários idosos. Este resultado pode indicar o desconhecimento do recurso por parte da população idosa, mas ao mesmo tempo confirma os resultados da observação em campo, na qual foi verificado que os idosos preferem, na maior parte das vezes, retomar sua navegação da página inicial e ir percorrendo passo a passo as páginas até atingir seu objetivo. Um dos motivos seria a não necessidade de "quebrar mentalmente" o conteúdo percorrido nos trechos oferecidos pelo recurso, evitando assim a sobrecarga cognitiva. 
Tabela 6.9: Análise das respostas da Questão 3

\begin{tabular}{|l|l|l|l|l|l|c|}
\hline Questão 3 & Nunca & Pouco & $\begin{array}{c}\text { Sempre que } \\
\text { necessito }\end{array}$ & $\begin{array}{c}\text { Frequente- } \\
\text { mente }\end{array}$ & Outro & $\begin{array}{c}\text { Valor } \\
\text { de } \boldsymbol{p}\end{array}$ \\
\cline { 1 - 6 } Idosos & $38,9 \%(7)$ & $27,8 \%(5)$ & $27,8 \%(5)$ & $5,6 \%(1)$ & $0,0 \%(0)$ & \multirow{2}{*}{0,048} \\
\hline Meia-idade & $19,8 \%(24)$ & $20,7 \%(25)$ & $35,5 \%(43)$ & $23,1 \%(28)$ & $8 \%(1)$ & \\
\hline Jovens & $15,5 \%(27)$ & $14,9 \%(26)$ & $35,6 \%(62)$ & $33,9 \%(59)$ & $0 \%(0)$ & \\
\hline
\end{tabular}

Para facilitar a compreensão e a análise dos resultados das questões de 4 a 19 foi excluída a coluna da alternativa "utilizaria outro mecanismo que oferecesse esse resultado", visto que, como são novos recursos propostos, em geral não há outro mecanismo disponível até o momento para oferecer o mesmo resultado. A intenção ao colocar essa alternativa no questionário foi para que o usuário pudesse prosseguir sem ter que responder fielmente à questão. Os resultados obtidos para as questões de 4 a 19 (mecanismos propostos) podem ser visualizados nas Tabelas 6.10 e 6.11.

Tabela 6.10: Análise das respostas das questões de 4 a 11

\begin{tabular}{|c|c|c|c|c|c|}
\hline & Faixa Etária & Nunca & $\begin{array}{l}\text { Sempre que } \\
\text { necessitasse }\end{array}$ & Frequentemente & Valor de $p$ \\
\hline \multirow{3}{*}{ Questão 4} & Idosos & $0 \%(0)$ & $41,2 \%(7)$ & $58,8 \%(10)$ & \multirow{3}{*}{0,230} \\
\hline & Meia-Idade & $7,6 \%(9)$ & $49,2 \%(58)$ & $43,2 \%(51)$ & \\
\hline & Jovens & $11,6 \%(20)$ & $52,0 \%(90)$ & $36,4 \%(63)$ & \\
\hline \multirow{3}{*}{ Questão 5} & Idosos & $0 \%(0)$ & $23,5 \%(4)$ & $76,5 \%(13)$ & \multirow{3}{*}{0,041} \\
\hline & Meia-Idade & $4,1 \%(5)$ & $22,3 \%(27)$ & $73,6 \%(89)$ & \\
\hline & Jovens & $7,1 \%(12)$ & $35,7 \%(60)$ & $57,1 \%(96)$ & \\
\hline \multirow{3}{*}{ Questão 6} & Idosos & $20 \%(3)$ & $40 \%(6)$ & $40 \%(6)$ & \multirow{3}{*}{$<0,01$} \\
\hline & Meia-Idade & $30,3 \%(36)$ & $45,4 \%(54)$ & $24,4 \%(29)$ & \\
\hline & Jovens & $50,6 \%(87)$ & $30,2 \%(52)$ & $19,2 \%(33)$ & \\
\hline \multirow{3}{*}{ Questão 7} & Idosos & $11,1 \%(2)$ & $38,9 \%(7)$ & $50 \%(9)$ & \multirow{3}{*}{0.529} \\
\hline & Meia-Idade & $2,5 \%(3)$ & $41,7 \%(50)$ & $55,8 \%(67)$ & \\
\hline & Jovens & $4,6 \%(8)$ & $39,3 \%(68)$ & $56,1 \%(97)$ & \\
\hline \multirow{3}{*}{ Questão 8} & Idosos & $5,9 \%(1)$ & $35,3 \%(6)$ & $58,8 \%(10)$ & \multirow{3}{*}{0.671} \\
\hline & Meia-Idade & $2,5 \%(3)$ & $31,7 \%(38)$ & $65,8 \%(79)$ & \\
\hline & Jovens & $4,0 \%(7)$ & $38,2 \%(66)$ & $57,8 \%(100)$ & \\
\hline \multirow{3}{*}{ Questão 9} & Idosos & $23,5 \%(4)$ & $52,9 \%(9)$ & $23,5 \%(4)$ & \multirow{3}{*}{0.012} \\
\hline & Meia-Idade & $9,1 \%(11)$ & $38,8 \%(47)$ & $52,1 \%(63)$ & \\
\hline & Jovens & $17,4 \%(30)$ & $48,3 \%(83)$ & $34,3 \%(59)$ & \\
\hline \multirow{3}{*}{ Questão 10} & Idosos & $16,7 \%(3)$ & $33,3 \%(6)$ & $50 \%(9)$ & \multirow{3}{*}{$<0,01$} \\
\hline & Meia-idade & $16,1 \%(19)$ & $40,7 \%(48)$ & $43,2 \%(51)$ & \\
\hline & Jovens & $31,0 \%(54)$ & $43,1 \%(75)$ & $25,9 \%(45)$ & \\
\hline \multirow{3}{*}{ Questão 11} & Idosos & $5,6 \%(1)$ & $55,6 \%(10)$ & $38,9 \%(7)$ & \multirow{3}{*}{$<0,01$} \\
\hline & Meia-Idade & $23,5 \%(28)$ & $38,7 \%(46)$ & $37,8 \%(45)$ & \\
\hline & Jovens & $31,6 \%(55)$ & $48,3 \%(84)$ & $20,1 \%(35)$ & \\
\hline
\end{tabular}

Na Questão 4, que trata do apoio ao preenchimento do campo de busca, é interessante notar as altas taxas de uso (sempre que necessitasse e frequentemente) 
Tabela 6.11: Análise das respostas das questões de 12 a 19

\begin{tabular}{|c|c|c|c|c|c|}
\hline & Faixa Etária & Nunca & $\begin{array}{l}\text { Sempre que } \\
\text { necessitasse }\end{array}$ & Frequentemente & Valor de $p$ \\
\hline \multirow{3}{*}{ Questão 12} & Idosos & $11,1 \%(2)$ & $44,4 \%(8)$ & $44,4 \%(8)$ & \multirow{3}{*}{0.029} \\
\hline & Meia-Idade & $19,2 \%(23)$ & $48,3 \%(58)$ & $32,5 \%(39)$ & \\
\hline & Jovens & $27,7 \%(48)$ & $52,6 \%(91)$ & $19,7 \%(34)$ & \\
\hline \multirow{3}{*}{ Questão 13} & Idosos & $5,6 \%(1)$ & $61,1 \%(11)$ & $33,3 \%(6)$ & \multirow{3}{*}{0.955} \\
\hline & Meia-Idade & $5,0 \%(6)$ & $66,1 \%(80)$ & $28,9 \%(35)$ & \\
\hline & Jovens & $6,9 \%(12)$ & $63,6 \%(110)$ & $29,5 \%(51)$ & \\
\hline \multirow{3}{*}{ Questão 14} & Idosos & $0 \%(0)$ & $50 \%(9)$ & $50 \%(9)$ & \multirow{3}{*}{$<0,01$} \\
\hline & Meia-Idade & $15,1 \%(18)$ & $69,7 \%(83)$ & $15,1 \%(18)$ & \\
\hline & Jovens & $26,2 \%(45)$ & $58,1 \%(100)$ & $15,7 \%(27)$ & \\
\hline \multirow{3}{*}{ Questão 15} & Idosos & $5,6 \%(1)$ & $44,4(8)$ & $50 \%(9)$ & \multirow{3}{*}{$<0,01$} \\
\hline & Meia-Idade & $14,0 \%(17)$ & $63,6 \%(77)$ & $22,3 \%(27)$ & \\
\hline & Jovens & $24,9 \%(43)$ & $59,0 \%(102)$ & $16,2 \%(28)$ & \\
\hline \multirow{3}{*}{ Questão 16} & Idosos & $11,8 \%(2)$ & $23,5 \%(4)$ & $64,7 \%(11)$ & \multirow{3}{*}{$<0,01$} \\
\hline & Meia-Idade & $10,7 \%(13)$ & $52,1 \%(63)$ & $37,2 \%(45)$ & \\
\hline & Jovens & $28,9 \%(50)$ & $37,6 \%(65)$ & $33,5 \%(58)$ & \\
\hline \multirow{3}{*}{ Questão 17} & Idosos & $11,8 \%(2)$ & $41,2 \%(7)$ & $47,1 \%(8)$ & \multirow{3}{*}{$<0,01$} \\
\hline & Meia-Idade & $19,8 \%(24)$ & $36,4 \%(44)$ & $43,8 \%(53)$ & \\
\hline & Jovens & $34,7 \%(59)$ & $41,2 \%(70)$ & $24,1 \%(41)$ & \\
\hline \multirow{3}{*}{ Questão 18} & Idosos & $11,8 \%(2)$ & $52,9 \%(9)$ & $35,3 \%(6)$ & \multirow{3}{*}{$<0,01$} \\
\hline & Meia-Idade & $23,3 \%(28)$ & $52,5 \%(63)$ & $24,2 \%(29)$ & \\
\hline & Jovens & $39,0 \%(67)$ & $46,5 \%(80)$ & $14,5 \%(25)$ & \\
\hline \multirow{3}{*}{ Questão 19} & Idosos & $17,6 \%(3)$ & $29,4 \%(5)$ & $52,9 \%(9)$ & \multirow{3}{*}{$<0,01$} \\
\hline & Meia-Idade & $15,1 \%(18)$ & $50,4 \%(60)$ & $34,5 \%(41)$ & \\
\hline & Jovens & $18,5 \%(32)$ & $61,3 \%(106)$ & $20,2 \%(35)$ & \\
\hline
\end{tabular}


até mesmo pelos jovens (52\%), o que pode indicar uma falta de padronização na forma de execução de buscas entre páginas Web e a ampla aceitação do mecanismo de apoio para a realização da tarefa.

$\mathrm{Na}$ análise referente à Questão 7, que trata da disponibilização de "resumos do conteúdo", ficou constatada a sua importância pois em todas as faixas etárias a alternativa "usaria frequentemente esse recurso" apresentou mais de $50 \%$ de aceitação e a alternativa "usaria quando sentisse necessidade" ficou em torno de $40 \%$.

A Questão 8, que trata da disponibilização de "tópicos de conteúdo", também apresentou ampla aceitação mostrando percentuais em torno de $60 \%$ para a alternativa "usaria frequentemente esse recurso".

Na Questão 13 foram verificados percentuais acima de 60\% para a alternativa "usaria esse recurso quando sentisse necessidade" para todas as faixas etárias, o que indica que a diminuição da velocidade de apresentação de vídeos seria um recurso que traria um conforto a mais (quando necessário) para todas as faixas etárias.

Nas demais questões, nas quais foram constatadas diferenças significativas entre as faixas etárias $(p<0,05)$, foi possível obervar situações cujas análises são:

- o bloqueio de banners e propagandas publicitárias (Questão 5) foi muito bem aceito pelos idosos e adultos de meia-idade, com taxas acima de $70 \%$ para o uso frequente, enquanto que os jovens também aceitaram (57\%), mas não com tanta ênfase;

- a indicação da barra de rolagem (Questão 6) foi um recurso rejeitado por mais de $50 \%$ dos jovens (nunca), ao passo que $40 \%$ dos idosos o utilizariam frequentemente;

- a preocupação com a segurança a respeito de um link (Questão 9) se concentra principalmente entre os adultos de meia-idade, que apontaram o uso frequente do recurso em mais de $50 \%$ dos casos, ao passo que os idosos e os jovens só o utilizariam se sentissem necessidade. Esse resultado pode indicar a realização de transações mais arriscadas e que envolvam valores, em maior parte pelos adultos de meia-idade do que pelas demais faixas etárias;

- os resultados das Questões 10 e 11, as quais tratam do uso de cores distintas para diferenciar links visitados e opções de menus já visitadas, mostram o que já era esperado após as observações em campo, ou seja, validam a necessidade de mecanismos que orientem a navegação e diminuam a sobrecarga cognitiva;

- o controle da velocidade dos menus (Questão 13) apresentou taxas de aceitação que variaram de $20 \%$ a $45 \%$ aproximadamente, e também taxas de rejeição 
(de $11 \%$ a 28\%). É interessante notar que a faixa etária que mais indicou sua utilização quando sentisse necessidade foi a faixa etária dos jovens (52\%), contra $48 \%$ da meia-idade e $44 \%$ dos idosos;

- o recurso da explicação de imagem via mensagem de voz (Questão 14) foi totalmente aceito pelos idosos, sendo que $50 \%$ o utilizariam frequentemente e $50 \%$ quando sentissem necessidade, ao passo que apenas $15 \%$ dos adultos de meia-idade e jovens o utilizariam frequentemente, embora grandes parcelas destes últimos o utilizariam se sentissem necessidade (69\% e $58 \%$ respectivamente);

- o recurso de guia - o quê fazer e como fazer - apresentado na Questão 15, foi muito bem aceito pelos idosos (50\% de uso frequente e $44 \%$ quando sentisse necessidade), sendo que as taxas de uso frequente caíram para $22 \%$ para os adultos de meia-idade e $16 \%$ para os jovens, embora as taxas para o uso quando necessário tenha se mantido em torno de $60 \%$ para as duas faixas etárias. Em observação de campo foi verificado que os usuários idosos são aqueles que mais se "desesperam" frente a uma tarefa desconhecida para realizar e imediatamente solicitam o auxílio presencial para lhes explicar onde ir e o que fazer, pois não conseguem procurar instruções em documentos disponibilizados por meio de helps;

- a quebra de formulário, proposta na Questão 16, obteve aceitação de cerca de $65 \%$ dos idosos para o uso frequente contra cerca de $35 \%$ das demais faixas etárias para a mesma alternativa. Os adultos de meia-idade preferem utilizá-lo apenas quando sentirem necessidade (52\%) e cerca de $30 \%$ dos jovens rejeitaram o uso do recurso. A necessidade de quebra de formulário para os idosos também foi verificada na pesquisa de campo (Seção 5.1), pois muitas vezes, ao clicar no botão para enviar o formulário preenchido o usuário recebia uma mensagem que o tempo de sessão havia expirado;

- o recurso que indica quais documentos são necessários ao preenchimento de um formulário via mensagem de voz, proposto na Questão 17, foi bem aceito pelos adultos mais velhos (meia-idade e idosos) e rejeitada por cerca de $35 \%$ dos jovens;

- o recurso de explicação de formatação de campos por meio de voz (Questão 18) também foi bem aceito pelos adultos mais velhos, com percentuais em torno de $50 \%$ e dos jovens em torno de $47 \%$, embora os jovens tenham apresentado um alto índice de rejeição (39\%);

- o recurso de sequência de passos da tarefa (Questão 19) teve opção de uso frequente por parte dos idosos com cerca de $53 \%$ de aceitação; a maior parte dos 
adultos de meia-idade $(50,4 \%)$ e jovens $(61,3 \%)$ optaram por usá-lo somente quando sentissem necessidade.

Foi analisada a influência da variável "experiência de uso da Web" na escolha entre não usaria/usaria o mecanismo de apoio. Para fins de facilitar a execução do teste Qui-Quadrado a coluna "Usaria" consolidou os resultados das alternativas "Usaria quando sentisse necessidade" e "Usaria frequentemente". A alternativa "Usaria outro mecanismo" foi desprezada em virtude da sua baixa ocorrência e dificuldade de interpretação.

Os valores referentes à experiência foram consolidados em 3 grupos: "Até 5 anos", "Entre 5 e 10 anos" e "Mais que 10 anos". Um exemplo de execução do teste está representado na Tabela 6.12 .

Tabela 6.12: Influência da experiência nas opções de uso dos mecanismos na Questão 1

\begin{tabular}{|l|l|l|l|}
\hline \multicolumn{4}{|c|}{ Questão 1 } \\
\hline Experiência & Nunca & Usaria & Total \\
\hline Até 5 anos & $22,6 \%(7)$ & $77,4 \%(24)$ & $100 \%(31)$ \\
\hline Entre 5 e 10 anos & $24,7 \%(19)$ & $75,3 \%(58)$ & $100 \%(77)$ \\
\hline Mais que 10 anos & $28,6 \%(58)$ & $71,4 \%(145)$ & $100 \%(203)$ \\
\hline Total & $27 \%(84)$ & $73 \%(227)$ & $100 \%(311)$ \\
\hline
\end{tabular}

Para todas as questões foi constatada a independência entre os níveis de experiência, ou seja, não há diferenças significativas entre os níveis, visto que o p-valor de todas as questões foi maior que 0,05, o que significa que todos os níveis de experiência produziram resultados semelhantes na escolha das alternativas. Um exemplo do teste, executado para a Questão 1, pode ser visualizado na Tabela 6.13.

Tabela 6.13: Teste Qui-Quadrado para a influência da experiência nas opções de uso dos mecanismos na Questão 1

\begin{tabular}{|l|l|l|r|}
\hline \multicolumn{4}{|c|}{ Questão 1 } \\
\hline & Value & df & Asymp. Sig (2-sided) \\
\hline Pearson Chi-Square &, 772 & 2 &, 680 \\
\hline Likelihood Ratio &, 785 & 2 &, 675 \\
\hline Linear-by-Linear Association &, 752 & 1 &, 386 \\
\hline N of Valid Cases & 311 & & \\
\hline
\end{tabular}

Foi analisada a influência da variável "frequência de uso da Web" na escolha entre não usaria/usaria o mecanismo de apoio. De forma análoga à análise da experiência, a coluna "Usaria" consolidou os resultados das alternativas "Usaria quando sentisse necessidade" e "Usaria frequentemente". A alternativa "Usaria outro mecanismo" foi novamente desprezada em virtude da sua baixa ocorrência e dificuldade de interpretação.

A frequência de uso foi consolidada em 2 grupos: "Pouco" e "Frequentemente", onde a coluna "Pouco" consolidou os dados das opções "pelo menos 1 vez por semana" 
e "pelo menos 1 vez por mês". Um exemplo de execução do teste é mostrado na Tabela 6.14 .

Tabela 6.14: Influência da frequência de uso nas opções de uso dos mecanismos na Questão 6

\begin{tabular}{|l|l|l|l|}
\hline \multicolumn{4}{|c|}{ Questão 6 } \\
\hline Frequência de uso & Nunca & Usaria & Total \\
\hline Pouco & $8,3 \%(1)$ & $91,7 \%(11)$ & $100 \%(12)$ \\
\hline Frequentemente & $42,5 \%(125)$ & $57,5 \%(169)$ & $100 \%(294)$ \\
\hline Total & $41,2 \%(126)$ & $58,8 \%(180)$ & $100 \%(306)$ \\
\hline
\end{tabular}

Tabela 6.15: Teste Qui-Quadrado para a influência da frequência de uso nas opções de uso dos mecanismos na Questão 6

\begin{tabular}{|l|l|l|r|r|c|}
\hline \multicolumn{7}{|c|}{ Questão 6 } \\
\hline & Value & df & $\begin{array}{c}\text { Asymp. Sig } \\
(\text { 2-sided })\end{array}$ & $\begin{array}{c}\text { Exact Sig } \\
\text { (2-sided) }\end{array}$ & $\begin{array}{c}\text { Exact Sig } \\
\text { (1-sided) }\end{array}$ \\
\hline Pearson Chi-Square & 5,562 & 1 &, 018 & & \\
\hline Continuity Correction & 4,240 & 1 &, 039 & & \\
\hline Likelihood Ratio & 6,782 & 1 &, 009 & & \\
\hline Fisher's Exact Test & & & & 0,018 & 0,018 \\
\hline Linear-by-Linear Association & 5,544 & 1 &, 019 & & \\
\hline N of Valid Cases & 306 & & & & \\
\hline
\end{tabular}

O exemplo apresentado na Tabela 6.15, referente à análise da Questão 6, que trata da indicação da barra de rolagem, mostra um caso em que a frequência de uso influenciou na escolha da alternativa, visto que o valor de $p$ igual 0,018 foi obtido pelo Teste Qui-Quadrado (Asymp. Sig. (2-sided)) e pelo Teste Exato de Fisher (Exact Sig. (2-sided)). Este resultado era um resultado esperado visto que o recurso de sinalização da existência de rolagem da tela se faz útil para as pessoas que não estão muito habituadas a utilizarem a Web.

Na Questão 8, que apresentava a opção de visualização do conteúdo da página por tópicos, o teste Qui-Quadrado constatou a influência da frequência de uso na escolha da alternativa (valor de p igual a 0,018), mas o Teste Exato de Fisher não confirmou tal afirmação (valor igual a 0,072), como pode ser observado nas Tabelas 6.16 e 6.17. Como existe uma célula com tamanho da amostra menor que 5 (que é o tamanho mínimo esperado para o Teste Qui-Quadrado), o resultado do Teste Exato de Fisher é o que deve ser considerado, ou seja, a frequência de uso não influencia a escolha da alternativa na Questão 8.

Por meio dessa análise, constatou-se influência da frequência na escolha entre usaria/não usaria o mecanismo de apoio apenas na Questão 6, cujo mecanismo trata da indicação de existência da barra de rolagem.

A partir da consolidação das respostas em dois grupos ("Usaria" e "Não Usaria") conforme indicado anteriormente, foi realizada uma avaliação para verificar se havia 
Tabela 6.16: Influência da frequência de uso nas opções dos mecanismos na Questão 8

\begin{tabular}{|l|l|l|l|}
\hline \multicolumn{4}{|c|}{ Questão 8 } \\
\hline Frequência de uso & Nunca & Usaria & Total \\
\hline Muito pouco & $15,4 \%(2)$ & $84,6 \%(11)$ & $100 \%(13)$ \\
\hline Frequentemente & $3,0 \%(9)$ & $97,0 \%(288)$ & $100 \%(297)$ \\
\hline Total & $3,5 \%(11)$ & $96,5 \%(299)$ & $100 \%(310)$ \\
\hline
\end{tabular}

Tabela 6.17: Teste Qui-Quadrado para a influência da frequência de uso nas opções dos mecanismos na Questão 8

\begin{tabular}{|c|c|c|c|c|c|}
\hline \multicolumn{6}{|c|}{ Questão 8} \\
\hline & Value & df & $\begin{array}{l}\text { Asymp. Sig } \\
\text { (2-sided) }\end{array}$ & $\begin{array}{l}\text { Exact Sig } \\
\text { (2-sided) }\end{array}$ & $\begin{array}{c}\text { Exact Sig } \\
\text { (1-sided) }\end{array}$ \\
\hline Pearson Chi-Square & 5,554 & 1 &, 018 & & \\
\hline Continuity Correction & 2,531 & 1 &, 112 & & \\
\hline Likelihood Ratio & 3,232 & 1 &, 072 & & \\
\hline Fisher's Exact Test & & & & 0,072 & 0,072 \\
\hline Linear-by-Linear Association & 5,536 & 1 &, 019 & & \\
\hline $\mathrm{N}$ of Valid Cases & 310 & & & & \\
\hline
\end{tabular}

diferença significativa de idade entre o grupo que "usaria" e o grupo que "não usaria" os mecanismos de apoio propostos.

Foi realizado o teste de Kolmogorov Smirnov (Siegel e Castellan, 1988) para verificar se a idade possuía uma distribuição normal e foi rejeitada a hipótese de normalidade da idade na amostra. O teste de Kolmogorov-Smirnov destina-se a avaliar se uma amostra pode ser considerada como proveniente de uma população com uma determinada distribuição e é particularmente indicado para distribuições contínuas.

A partir da constatação da não normalidade da idade, foi utilizado o teste Não Paramétrico de Mann-Whitney (Siegel e Castellan, 1988), que é indicado quando a variável de interesse (idade) não tem distribuição normal, para os 2 grupos de observação independentes (usaria/não usaria). O teste verifica se há diferença significativa nas idades entre os dois grupos. Foi observada a diferença de idade entre o grupo que usaria e o que não usaria nas seguintes questões: 6, 10, 11, 14, 15, 16, 17 e 18, como pode ser visualizado na Tabela 6.18. Nessa tabela o valor de $\mathrm{N}$ representa o tamanho das amostras dos grupos.

Em geral essa diferença indicou que o maior valor para a mediana das idades (41 anos) está no grupo que "Usaria" os mecanismos de apoio, sendo que os valores das medianas das idades para esse grupo variam de 35 a 41 anos. No grupo que "Não usaria" os mecanismos de apoio os valores das medianas das idades variam entre 30 e 36 anos de idade.

Na Tabela 6.19 são apresentados os três mecanismos mais aceitos e os três mais rejeitados por cada uma das faixas etárias. Vale ressaltar que os mecanismos de 
Tabela 6.18: Análise da idade em relação aos grupos de uso

\begin{tabular}{|l|l|c|c|c|c|c|c|}
\cline { 2 - 7 } \multicolumn{1}{c|}{} & \multicolumn{3}{c|}{ Usaria } & \multicolumn{3}{c|}{ Não Usaria } & \multicolumn{1}{c|}{} \\
\cline { 2 - 7 } \multicolumn{1}{c|}{} & $\mathbf{N}$ & $\begin{array}{c}\text { Média das } \\
\text { Idades }\end{array}$ & $\begin{array}{c}\text { Mediana das } \\
\text { Idades }\end{array}$ & $\mathbf{N}$ & $\begin{array}{c}\text { Média das } \\
\text { Idades }\end{array}$ & $\begin{array}{c}\text { Mediana das } \\
\text { Idades }\end{array}$ & $\begin{array}{c}\text { Valor } \\
\text { de p }\end{array}$ \\
\hline Q4 & 279 & 38,54 & 35 & 29 & 34,03 & 33 & 0,113 \\
\hline Q5 & 289 & 38,63 & 36 & 17 & 34,76 & 33 & 0,340 \\
\hline Q6 & 180 & 40,24 & 41 & 126 & 35,00 & 32 & $<0,01$ \\
\hline Q7 & 298 & 38,21 & 35 & 13 & 39,69 & 36 & 0,803 \\
\hline Q8 & 299 & 38,14 & 35 & 11 & 39,45 & 34 & 0,708 \\
\hline Q9 & 265 & 38,67 & 36 & 45 & 35,73 & 32 & 0,146 \\
\hline Q10 & 234 & 39,29 & 38 & 76 & 34,61 & 31,5 & 0,015 \\
\hline Q11 & 227 & 39,30 & 37 & 84 & 35,27 & 33 & 0,039 \\
\hline Q12 & 238 & 39,10 & 36,5 & 73 & 35,60 & 32 & 0,077 \\
\hline Q13 & 293 & 38,33 & 35 & 19 & 38,05 & 36 & 0,838 \\
\hline Q14 & 246 & 39,40 & 38 & 63 & 33,92 & 32 & $<0,01$ \\
\hline Q15 & 251 & 39,25 & 38 & 61 & 34,43 & 32 & 0,014 \\
\hline Q16 & 246 & 39,69 & 39,5 & 65 & 32,74 & 30 & $<0,01$ \\
\hline Q17 & 223 & 40,05 & 40 & 85 & 33,92 & 32 & $<0,01$ \\
\hline Q18 & 212 & 39,96 & 40 & 97 & 34,43 & 32 & $<0,01$ \\
\hline Q19 & 256 & 38,34 & 35 & 53 & 37,42 & 34 & 0,818 \\
\hline
\end{tabular}

bloqueio de banners e tópicos do texto foram os mais bem aceitos pelas três faixas etárias, diferindo apenas em ordem de preferência.

Os idosos aceitaram muito bem os recursos de "Ajuda na Busca" e "Quebra de formulário", enquanto que os adultos de meia-idade e os jovens priorizaram o mecanismo de "Resumo de texto".

Os três maiores índices de rejeição não indicam exatamente que o mecanismo foi rejeitado pela faixa etária, mas sim o maior percentual dentre os percentuais da coluna "nunca usaria esse recurso".

Tabela 6.19: Levantamento dos 3 mecanismos mais aceitos e mais rejeitados por faixa etária

\begin{tabular}{|l|l|l|}
\cline { 2 - 3 } \multicolumn{1}{c|}{} & 3 mecanismos mais aceitos (Frequentemente) & 3 mecanismos mais rejeitados (Nunca) \\
\hline \multirow{4}{*}{ Idosos } & Bloqueio de banners - 76,5\% & Link (segurança e endereçamento) - 23,5\% \\
\cline { 2 - 3 } & Quebra de Formulário - $64,7 \%$ & Indicação de rolagem da tela - 20\% \\
\cline { 2 - 3 } & Ajuda na Busca/Tópicos de Texto - $58,8 \%$ & Sequência de passos da tarefa - $17,6 \%$ \\
\hline \multirow{4}{*}{$\begin{array}{l}\text { Meia- } \\
\text { Idade }\end{array}$} & Bloqueio de banners - $73,6 \%$ & Indicação de rolagem da tela - $30,3 \%$ \\
\cline { 2 - 3 } & Tópicos de Texto - $65,8 \%$ & Cor das opções de menus visitadas - $23,5 \%$ \\
\cline { 2 - 3 } & Resumos de Texto - $55,8 \%$ & Formatação via mensagem de voz - 23,3\% \\
\cline { 2 - 3 } Jovens & Tópicos de Texto - $57,8 \%$ & Indicação de rolagem da tela - $50,6 \%$ \\
\cline { 2 - 3 } & Bloqueio de banners - $57,1 \%$ & Formatação via mensagem de voz - $39 \%$ \\
\cline { 2 - 3 } & Resumos de Texto - $56,1 \%$ & Documentos necessários - $34,7 \%$ \\
\hline
\end{tabular}

Em uma última análise foi verificado se há diferença significativa no índice de utilização dos mecanismos propostos entre as faixas etárias. Com base nas respostas dos participantes foram gerados "índices de utilização" dos mecanismos propostos, 
considerando o número de mecanismos que o respondente "usaria" de alguma forma (frequentemente ou quando necessitasse). Os resultados dessa análise podem ser visualizados na Tabela 6.20, na qual a coluna "N" representa o número de participantes da amostra por faixa etária.

Tabela 6.20: Estatísticas a respeito dos índices de utilização dos 16 novos mecanismos

\begin{tabular}{|l|l|l|l|l|}
\hline Faixa Etária & Média & $\mathbf{N}$ & Desvio Padrão & Mediana \\
\hline Idoso & 13,89 & 18 & 2,540 & 15,00 \\
\hline Meia-Idade & 13,74 & 121 & 2,564 & 15,00 \\
\hline Jovem & 12,25 & 174 & 3,032 & 13,00 \\
\hline Total & 12,92 & 313 & 2,923 & 14,00 \\
\hline
\end{tabular}

A partir dos dados obtidos para as medianas (Tabela 6.20) e como o índice não tem distribuição normal, foram realizados testes não paramétricos para verificar a igualdade das medianas dos grupos. Assim como o teste de Mann-Whitney, o teste de Kruskal-Wallis (Siegel e Castellan, 1988) é não paramétrico, e primeiramente converte os dados em postos (converte cada observação em posições crescentes em uma única fila), primeiramente ordenando os dados e então somando os postos dentro de cada grupo. O teste Kruskall Wallis rejeitou que a mediana dos índices seja a mesma nos três grupos (jovens, meia-idade e idosos) pois o valor de $p$ foi menor que 0,001

Os testes dois a dois Mann-Whitney verificaram que a mediana do índice é diferente entre "jovens X meia-idade" e entre "jovens X idosos". Entretanto entre meia-idade e idosos, não foi observada diferença nas medianas. Assim sendo pode-se concluir que, os adultos de meia-idade e idosos usariam mais os recursos propostos em relação aos jovens, com significância estatística.

As questões 20 e 21 investigaram o uso de comércio eletrônico e bancos on-line por faixa etária e apresentaram apenas 2 alternativas (Sim/Não). Os resultados que podem ser visualizados na Tabela 6.21 mostram que os idosos ainda apresentam grande resistência na utilização de tarefas que envolvam transações financeiras, quando comparados com os jovens e adultos de meia-idade. O percentual de idosos que realiza compras pela Web (55\%) foi um pouco maior do que os que realizam transações financeiras (44\%). Praticamente a mesma diferença em percentual foi verificada entre os adultos de meia-idade que realizam transações de comércio eletrônico $(82 \%)$ e transações financeiras em bancos on-line $(70 \%)$.

Para as duas questões foram solicitadas sugestões de melhorias, que podem ser visualizadas na íntegra no Apêndice D, das quais pode-se citar alguns comentários que revelam os principais anseios dos participantes. Para os idosos, os comentários mais relevantes para a melhoria do comércio eletrônico foram:

- "seria com palavras de fácil entendimento e com segurança"; 
Tabela 6.21: Análise de uso de comércio eletrônico e bancos on-line pelas faixas etárias

\begin{tabular}{|c|l|l|l|c|}
\hline Questão & Faixa Etária & \multicolumn{1}{|c|}{ Sim } & \multicolumn{1}{|c|}{ Não } & Valor de p \\
\hline \multirow{2}{*}{$\begin{array}{c}20 \\
\text { (comércio }\end{array}$} & Idosos & $55,6 \%(10)$ & $44,4 \%(8)$ & \\
\cline { 2 - 4 } & Meia-Idade & $81,8 \%(99)$ & $18,2 \%(22)$ & \multirow{2}{*}{$<0,01$} \\
\cline { 2 - 4 } $\begin{array}{c}21 \\
\text { (banco) }\end{array}$ & Jovens & $85,1 \%(148)$ & $14,9 \%(26)$ & \\
\cline { 2 - 4 } & Idosos & $44,4 \%(8)$ & $55,6 \%(10)$ & \multirow{2}{*}{0,029} \\
\cline { 2 - 4 } & Meia-Idade & $69,4 \%(84)$ & $30,6 \%(37)$ & \\
\cline { 2 - 4 } & Jovens & $74,1 \%(129)$ & $25,9 \%(45)$ & \\
\hline
\end{tabular}

- "maior rapidez para preencher os campos necessários e menos burocracia";

- "exibir vídeos demonstrativos, autorizações oficiais tais como: ANVISA, INMETRO, ISO, ABRINC".

Para os adultos de meia-idade, os comentários mais relevantes para a melhoria do comércio eletrônico foram:

- "queria receber notificação por e-mail dos passos que realizei, pois as vezes eu quero ter um guia dos meus passos, mesmo que nao tivesse concluído a compra";

- "com certeza com mensagem de voz indicando se os passos para a compra estão corretos ou como fazê-lo";

- "o site deveria apresentar ao cliente a partir de sua segunda compra, quais foram as opções que ele utilizou na sua primeira compra, como forma de pagamento, como sugestão para se efetuar a segunda compra".

Para os jovens, os comentários mais relevantes para a melhoria do comércio eletrônico foram:

- "uma central com um cadastro único para não precisar digitar várias vezes em sites diferentes a mesma informação (nome, endereco, número de cartão, etc), uma vez cadastrado nesta central, todos os sites de venda pela internet teria acesso a este cadastro";

- "eu faria um guia na sequência de finalização de compra. Tipo um boneco que explica de maneira geral o que é preciso fazer no atual formulário e ao clicar em um campo, ele explica como deve ser preenchido o campo selecionado. Teria a opção de ouvir o áudio e ler a explicação também (balão de quadrinhos, por exemplo)";

- "um mecanismo de busca contextual que utilizaria o histórico de visitas a outros sites de compras e j mostárasse o que eu estivesse procurando ao acessar aquele site. Por exemplo, vou no site das casas Bahia e procuro por tv LED, ao acessar o site do Magazine Luiza já apareceria as opções de tvs LEDs... etc..."; 
- "que pudesse ter mais modelos de compras para me auxilar".

Pelos comentários mencionados pode-se observar que os aspectos mais relevantes para os idosos são a facilidade na interação e a segurança do site (autenticidade, sigilo das informações pessoais, etc.). Para os adultos de meia-idade são destacados os aspectos relacionados a memória e a sobrecarga cognitiva, visto que suas sugestões se referem principalmente a guias, resumos e roteiros, para que possam ter certeza da corretude de suas ações e a possibilidade de relembrá-las em momentos posteriores. Os jovens expressam o anseio por maior facilidade e rapidez no preenchimento de informações e a ajuda contextual ou por meio de exemplos para agilizar a execução do procedimento de compra.

Para os sites de bancos, as principais sugestões dos idosos foram:

- "achei esse procedimento de voz dando as dicas quando você procura um serviço ajudaria muito. Em alguns casos de serviço que voce deseja utilizar o caminho é muito confuso";

- "poder com uma única senha eletrônica (mesmo com senhas diferentes nos cartões magnéticos) juntar todas as contas de uma determinada agência bancária - poupanca, conta corrente. Assim poderíamos em um único acesso, verificar saldos, fazer diversas operações, sem que houvesse necessidade de entrar em cada conta separadamente".

As principais sugestões dos adultos de meia-idade para os sites de banco foram:

- "queria receber algum alerta mais evidente, para confirmar quando uma operação está sendo completada.. mudar as cores, ou um destaque mais claro de que aquele é um ponto crítico da transacao";

- "maior poblema é a tal de senha, que esqueço sempre, que tal a impressão digital?";

- "o recurso seria: um conjunto das minhas operações frequentes, para as quais eu vou com um clique só";

- "mostrar as minhas últimas ações, pois, não uso com muita frequência e acabo esquecendo o passo-a-passo";

- "relatório enviado ao e-mail pessoal de todas as operações realizadas no mês, semana ou conforme a vontade".

Finalmente, as principais sugestões dos jovens para os sites de banco foram:

- "leitor biometrico para credenciar minhas autorizações no site";

- "Um lembrete das últimas operações feitas, podendo executá-las novamente"; 
- "um menu com as operações mais realizadas por mim";

- "simplesmente possuir explicações mais detalhadas (seja em texto ou voz) de qualquer recurso disponível e/ou qualquer ação a ser tomada".

Para os bancos on-line ficou evidenciado que as maiores dificuldades, independente da faixa etária, estão relacionadas à memória e à sobrecarga cognitiva, no que se refere à lembrança de senhas e passos para a execução dos procedimentos, bem como à insegurança de que as ações estão corretas.

A realização deste estudo trouxe importantes esclarescimentos a respeito de quais seriam os mecanismos mais utilizados pelos adultos de meia-idade e idosos para facilitar suas interações com a Web. Os comentários também ajudam a identificar as necessidades do público que já utiliza os recursos disponíveis e anseia por melhorias.

\subsection{Considerações finais}

Neste capítulo foram apresentadas as sugestões que estendem os critérios de sucesso da WCAG 2.0 visando principalmente atender às necessidades dos adultos mais velhos na interação com Web. Vale ressaltar que o objetivo dessa proposta não é alterar a WCAG 2.0, mas sim especializá-la quando considerado o público-alvo dos adultos de meia-idade e idosos.

Além disso, foram elencadas sugestões para minimizar os principais problemas identificados nesta pesquisa (Seção 6.2), agrupadas nos sete grupos de dificuldades, conforme a seguir:

1. Dificuldade de leitura e compreensão de textos;

2. Dificuldade de reconhecimento e acesso aos links;

3. Dificuldade de navegação;

4. Dificuldade na realização de tarefas específicas;

5. Dificuldade na realização de compras e lojas on-line;

6. Dificuldade na busca e localização da informação;

7. Dificuldade na comunicação com os responsáveis pelo site.

Para validar a possibilidade de implementação de um mecanismo de apoio, como prova de conceito, foi desenvolvido um add-on, denominado Tuki. Desempenhando o papel de um recurso de tecnologia assistiva, o Tuki visa fornecer estímulos visuais e sonoros de forma a incentivar e apoiar a interação de adultos mais velhos com a Web. Uma avaliação com usuários foi realizada para comprovar sua utilidade, 
especialmente, para as pessoas que não sabem ou não se lembram como executar determinada ação durante a interação com a Web.

Finalmente, foi realizado um Survey para coletar informações diretamente dos adultos mais velhos, sobre a aceitação de 19 mecanismos identificados, no decorrer da pesquisa, como necessários para apoiá-los na interação com a Web. Nesta tese, a proposta desses mecanismos se configura como uma contribuição inédita por considerar os problemas e dificuldades dos adultos mais velhos, incluindo os adultos de meia-idade e suas características inerentes do processo de envelhecimento. Como resultado, foram analisadas as respostas obtidas no Survey e elaboradas as seguintes conclusões quanto à priorização dos aspectos que influenciam positivamente a interação com a Web:

- para os idosos são: a facilidade na interação e a segurança do site;

- para os adultos de meia-idade são: apoio à memória e à redução da sobrecarga cognitiva.

Os resultados obtidos apresentaram diferenças significativas na priorização do que deve ser tratado como necessário para apoiar os adultos mais velhos. Assim, os seguintes doze mecanismos que foram evidenciados como mais relevantes e sua respectiva classificação por prioridade de escolha, considerando-se as respostas para o uso frequente, para os idosos foram:

1. recurso para eliminação de banners;

2. recurso de divisão de formulário em unidades menores;

3. apoio para reconhecimento de procedimentos;

4. recurso de escolha de cor para links visitados, recurso de áudio para figuras e recurso de guia de funcionalidades;

5. recurso de lembrete de documentos da vida real;

6. recurso de indicação de barra de rolagem;

7. recurso de escolha de cores para opções de menu;

8. recurso para preenchimento de campos de entrada;

9. recurso para diminuição da velocidade de apresentação de vídeo;

10. apoio para a utilização de links: assunto, segurança, endereçamento.

Para os adultos de meia-idade, os doze mecanismos que foram evidenciados como mais relevantes e sua respectiva classificação por prioridade de escolha, considerando-se as respostas para o uso frequente, foram: 
1. recurso para eliminação de banners;

2. apoio para a utilização de links: assunto, segurança, endereçamento;

3. recurso de lembrete de documentos da vida real;

4. recurso de escolha de cor para links visitados;

5. recurso de escolha de cores para opções de menu;

6. recurso de divisão de formulário em unidades menores;

7. apoio para reconhecimento de procedimentos;

8. recurso para diminuição da velocidade de apresentação de vídeo;

9. recurso de indicação de barra de rolagem;

10. recurso para preenchimento de campos de entrada;

11. recurso de guia de funcionalidades;

12. recurso de áudio para figuras.

Diante de tais priorizações pode-se verificar que tanto para os idosos quanto para os adultos de meia-idade, o princípio de estética e design minimalista (U8), bem como a diretriz de legibilidade e compreensibilidade (A3.1) foram requisitos que mais se sobressaíram na escolha dos mecanismos definidos. Na sequência, o princípio de prevenção de erros (U5) relacionado às diretrizes de assistência na entrada (A3.3) e auxílio à navegação (A2.4) foram priorizados. Vale destacar que como terceira prioridade de escolha, os idosos indicaram que o princípio do reconhecimento ao invés de relembrança (U6) deve ser levado em consideração, ao passo que para os adultos de meia-idade a indicação foi do princípio da compatibilidade do sistema com o mundo real (U2).

Essas priorizações representam as reais necessidades dos adultos mais velhos, e de fato, refletem a similaridade dos requisitos em função do processo natural de envelhecimento. Nesta tese, argumenta-se a relevância para com os adultos mais velhos em geral, incluindo as observações registradas com os experimentos com os adultos de meia-idade. 


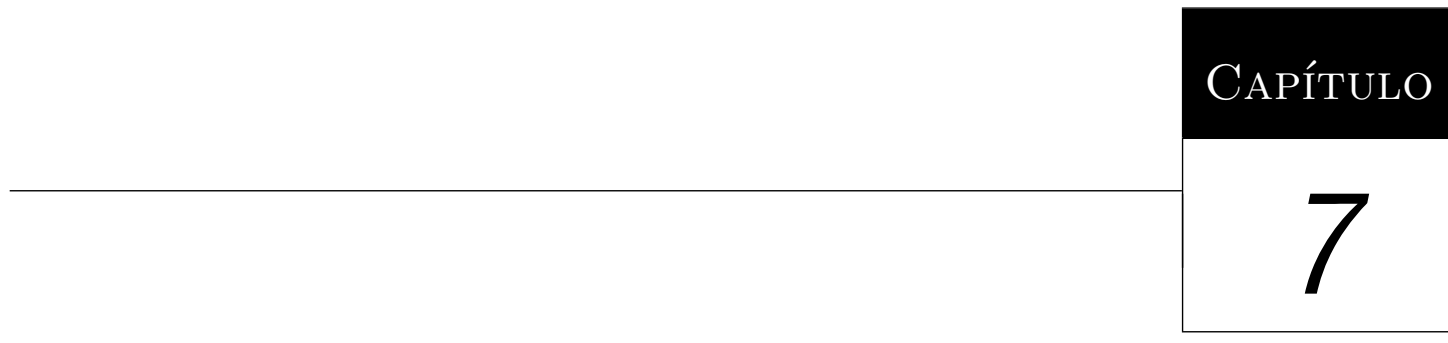

\section{Conclusões}

Usabilidade e acessibilidade são requisitos de qualidade constantemente almejados pelos desenvolvedores de interfaces Web que se preocupam com o efetivo alcance das informações disponibilizadas em seus sites. Os conceitos de que, o desenvolvimento visando acessibilidade implica em limitações na usabilidade, e que seguir princípios de usabilidade e diretrizes de acessibilidade requer mais investimentos em profissionais qualificados e tempo para o desenvolvimento de um projeto, devem ser revistos pelos desenvolvedores.

As pesquisas e trabalhos apresentados nesta tese evidenciaram que os adultos mais velhos apresentam necessidades diferenciadas para ser capazes de utilizar a Web de forma satisfatória. É preciso levar em consideração a heterogeneidade do perfil desses usuários mais velhos, a forma como agem e reagem em suas experiências com a Web, de modo que o uso da tecnologia não se transforme numa barreira para esse público-alvo.

No âmbito técnico, a falta de padronização no desenvolvimento do código-fonte, a utilização de diversas tecnologias que também não seguem os padrões e a falta de conhecimento das reais dificuldades dos adultos mais velhos em suas interações com a Web, acabam gerando barreiras que constantemente evoluem para o abandono da experiência e a desmotivação de uso, visto que as dificuldades se intensificam ao longo do processo de envelhecimento.

Nas próximas seções são resumidas as principais contribuições desta tese, as limitações e as oportunidades de trabalhos futuros. 


\subsection{Principais contribuições}

Nesta tese buscou-se minimizar o problema da utilização da Web pelos adultos mais velhos, dadas as suas dificuldades que naturalmente decorrem do processo de envelhecimento. Após a realização dos procedimentos de pesquisa relatados nos capítulos anteriores, foi elaborada uma sugestão de extensão dos critérios de sucesso das diretrizes de acessibilidade para acomodar as necessidades dos adultos mais velhos. Mecanismos de apoio à usabilidade e à acessibilidade em interações com a Web foram avaliados pelo público-alvo em questão. Neste contexto, as principais atividades desenvolvidas foram:

- Realização de experimentos: observação em campo, questionários e testes com protótipos que evidenciaram as necessidades mais relevantes dos adultos mais velhos em vários segmentos da interação com a Web;

- Identificação de um conjunto de critérios de sucesso a serem integrados aos atuais critérios de sucesso das diretrizes da WCAG 2.0;

- Identificação de um conjunto de sugestões de solução para os principais problemas encontrados no decorrer dos experimentos;

- Identificação de um conjunto de mecanismos de usabilidade e acessibilidade que podem ser incorporados em páginas Web de uso geral, de forma a melhorar a flexibilidade no uso e atender às necessidades específicas dos adultos mais velhos.

As atividades foram realizadas de acordo com o caráter científico e acadêmico desta pesquisa. Além disso, os resultados dessas atividades apontam melhorias e aspectos ainda pouco explorados na literatura para o público-alvo em questão.

Durante esta pesquisa, foram realizados estudos com o público-alvo e utilizadas diferentes tecnologias de desenvolvimento Web para apoiar a investigação dos mecanismos para usabilidade e acessibilidade na interação de adultos mais velhos na Web. Nesse período, pode-se perceber a evolução das ferramentas relacionadas à tecnologia Web, visto que, inicialmente, a interação com os navegadores Web era bastante limitada e as páginas Web não eram tão interativas. Na época da realização do estudo sobre o reconhecimento de elementos presentes nas páginas, ainda não era possível realizar uma busca por meio da caixa de entrada da URL, como é possível de ser feita em alguns navegadores atualmente.

A realização dos estudos em campo também proporcionou o aprendizado de importantes lições. A principal delas foi a verificação da dependência do apoio presencial para que a interação entre adultos mais velhos e a Web se efetivasse. Foi possível 
constatar o quanto era importante, para esse público, a criação de mecanismos facilitadores, que levassem em consideração suas necessidades específicas, tanto físicas quanto cognitivas.

O conjunto de contribuições obtidas pode ser descrito a partir das questões de pesquisa definidas nesta tese, conforme a seguir:

\section{Como identificar quais as principais dificuldades relativas à interação de adultos de meia-idade e idosos com a Web?}

Tendo por base as dificuldades observadas nos experimentos descritos no Capítulo 5 foram elencadas na Seção 6.2 sugestões de desenvolvimento visando a superação de tais barreiras. As principais dificuldades, obtidas por meio de observação de grupos de usuários, foram agrupadas nos sete seguintes grupos:

1. Dificuldade de leitura e compreensão de textos;

2. Dificuldade de reconhecimento e acesso aos links;

3. Dificuldade de navegação;

4. Dificuldade na realização de tarefas específicas;

5. Dificuldade na realização de compras e lojas on-line;

6. Dificuldade na busca e localização da informação;

7. Dificuldade na comunicação com os responsáveis pelo site.

Para cada uma das dificuldades identificadas foram também elencadas sugestões sobre como minimizá-las.

\section{Quais mecanismos incluir para o apoio apropriado nas páginas sem ser intrusivo o suficiente para interferir negativamente na interação?}

Os mecanismos a serem incluídos, de forma geral, para apoiar os adultos mais velhos em suas interações com a Web foram apresentados na Seção 6.4.

No entanto, os procedimentos de pesquisa descritos no Capítulo 5 evidenciaram que usuários mais velhos, muitas vezes, são incapazes de usar a Web sem ajuda e para os quais o apoio que "imite" o suporte presencial é essencial.

Na Seção 6.3 foi elaborado, como prova de conceito, um mecanismo de apoio contextual à interação com o objetivo de reduzir as demandas da memória de trabalho, facilitar e estimular a interação de adultos de meia-idade e idosos com a Web. Por meio da avaliação com os usuários ficou comprovado que o mecanismo não é intrusivo e que pode ajudar o público-alvo em diversas situações durante suas interações com a Web. 
3. Com qual prioridade devem ser tratados os aspectos como visualização, reconhecimento de elementos, foco da atenção, estruturação da informação e navegação de modo a influenciar positivamente a interação?

Na Seção 6.4 foram apresentados os resultados obtidos por meio de uma pesquisa qualitativa (survey) que coletou infomações diretamente dos adultos mais velhos sobre potenciais mecanismos de apoio à usabilidade e acessibilidade na interação com a Web. A partir dos resultados foram evidenciadas diferenças significativas na priorização do que deve ser tratado como necessário para apoiar os adultos mais velhos. Assim, os seguintes mecanismos, evidenciados como mais relevantes e sua respectiva classificação por prioridade de escolha, para os idosos, foram:

1. recurso para eliminação de banners;

2. recurso de divisão de formulário em unidades menores;

3. apoio para reconhecimento de procedimentos;

4. recurso de escolha de cor para links visitados, recurso de áudio para figuras e recurso de guia de funcionalidades;

5. recurso de lembrete de documentos da vida real;

6. recurso de indicação de barra de rolagem;

7. recurso de escolha de cores para opções de menu;

8. recurso para preenchimento de campos de entrada;

9. apoio para a utilização de links: assunto, segurança, endereçamento.

Para os adultos de meia-idade, os mecanismos que foram evidenciados como mais relevantes e sua respectiva classificação por prioridade de escolha, foram:

1. recurso para eliminação de banners;

2. apoio para a utilização de links: assunto, segurança, endereçamento;

3. recurso de lembrete de documentos da vida real;

4. recurso de escolha de cor para links visitados;

5. recurso de escolha de cores para opções de menu;

6. recurso de divisão de formulário em unidades menores;

7. apoio para reconhecimento de procedimentos;

8. recurso de indicação de barra de rolagem;

9. recurso para preenchimento de campos de entrada;

10. recurso de guia de funcionalidades; 
11. recurso de áudio para figuras.

Uma importante constatação durante a pesquisa desta tese diz respeito à variedade de trabalhos envolvendo idosos e a Web, existentes na literatura, mas muito poucos envolvendo os adultos de meia-idade. Os adultos de meia-idade sofrem atualmente as pressões sociais e do mercado de trabalho, tendo muitas vezes que realizarem operações que envolvem valores, como compras e transações bancárias, se comunicarem por meio de ferramentas de e-mail, participarem de redes sociais para se sentirem em contato com familiares e amigos, etc. Esse indivíduo, que não teve uma "cultura Web" durante seu amadurecimento, muitas vezes se sente inseguro e se julga incapaz de compreender tamanha quantidade de informações. As contribuições alcançadas nesta tese comprovam que há espaço para atender também a esse público-alvo.

\subsection{Limitações e Trabalhos futuros}

Foram identificadas também oportunidades para trabalhos futuros, que não puderam ser investigados nesta tese, tais como:

- Continuação com os estudos empíricos: embora os avanços tecnológicos na Web ainda estejam em franca evolução, estudos empíricos devem ser continuamente realizados com os adultos mais velhos pois o processo de envelhecimento é inerente ao ser humano. Assim, outras dificuldades podem vir a ser identificadas, e com elas novas possibilidades de solução devem ser pesquisadas. Nesta tese, foi considerado o usuário e suas características como elemento principal para a formulação dos mecanismos propostos. Dessa forma, é preciso que haja uma constante observação desse público para que suas necessidades sejam melhores atendidas;

- Detalhamento técnico dos critérios de sucesso sugeridos: nesta tese, o foco da pesquisa se concentrou nas características da interação de usuários mais velhos na Web e suas dificuldades, de modo que não houve um aprofundamento dos detalhes técnicos relacionados aos critérios de sucesso sugeridos na Seção 6.1. Assim, visando melhorar a compreensão e aplicação de tais critérios, pode-se realizar o desenvolvimento das técnicas relacionadas, identificação das falhas comuns e respectivos testes, de maneira a completar o formalismo requerido conforme o documento da WCAG 2.0;

- Padronização semântica de conteúdo e operações específicas no código-fonte: para que seja possível desenvolver ferramentas de apoio contextual que imite o apoio presencial e que possam atuar sobre páginas de qualquer 
tipo na Web, a partir de navegadores, é peciso que haja uma classificação semântica de conteúdos e operações, de forma que, uma transferência entre contas bancárias, por exemplo, possua os mesmos elementos com as mesmas denominações no código-fonte, seja qual for o banco on-line utilizado. Dessa forma, os usuários poderiam ser ativamente guiados durante a execução de tarefas que acarretam maior sobrecarga cognitiva;

- Investigação de extensões para tags no HTML5: mecanismos de apoio contextual sugeridos nesta tese poderiam ser implementados se novas diretivas de marcação fossem adicionadas a elementos do HTML5, por exemplo:

- em formulário, acrescentar um indicador para ordem dos passos (quebra de formulário em partes menores): <form step=1> ;

- em imagem, acrescentar uma legenda para ser reproduzida via sintetizador de voz: <image $\operatorname{src}=$ (") alt=" ")' audio="'msg de audio a ser sintetizada na lingua correspondente', language=' (PT' '>;

- em campo texto, acrescentar atributos para indicar a formatação e a descrição a ser reproduzida via sintetizador de voz: <input type $=$ ' 'text') name= 'cpf' ' format $=$ ' '999.999.999-99' ' audio=" forneça o número de seu $\mathrm{CPF}$ ')";

- em campo de busca, habilitar um elemento que ative uma máquina de busca específica e um atributo contendo a descrição a ser reproduzida via sintetizador de voz: <input type="'search' name=" 'buscatextual' ' audio=" Digite a palavra chave para a busca que deseja realizar...'" language= ' $\mathrm{PT}$ ', >.

\section{- Investigação de métodos de Engenharia Web considerando os adultos} mais velhos: nesta tese não foi feita associação dos mecanismos de apoio para usabilidade e acessibilidade para adultos mais velhos com nenhum método de Engenharia Web. Dessa forma, um trabalho futuro poderia formalizar os requisitos discutidos nos experimentos realizados num método que incluísse, em suas etapas, as necessidades desse público-alvo.

\subsection{Considerações finais}

Nesta tese foram investigadas as principais características relacionadas com acessibilidade e usabilidade na Web para adultos mais velhos. A expectativa de vida continua aumentando e compreender o processo de envelhecimento é fundamental para que se possa elaborar um conjunto de orientações que permitam contribuir para a melhoria das interações dos adultos mais velhos com a Web. Enquanto muitos 
autores buscam definições sobre usabilidade e acessibilidade e as discutem do ponto de vista teórico, nesta tese, procurou-se aliar as melhores características de cada uma delas de modo a prover orientações baseadas nas reais dificuldades dos adultos mais velhos em suas interações com a Web.

Nesta tese foram descritos os procedimentos científicos realizados e as principais atividades foram: revisão bibliográfica, observação de campo, entrevistas, questionários (surveys) e testes com protótipos funcionais. Assim, a partir do levantamento das principais dificuldades foi sugerida uma proposta dos mecanismos de apoio aos adultos mais velhos por meio de extensão dos critérios de sucesso para as diretrizes de acessibilidade da WCAG 2.0 (W3C, 2008b) e também foi proposto um conjunto de mecanismos de apoio, que deu origem a um questionário on-line para verificar a aceitação dos mesmos pelo público-alvo.

Esta tese apresentou os resultados de uma pesquisa descritiva, que buscou identificar as reais necessidades dos adultos mais velhos em suas interações com a Web, e buscou melhorias tanto no que diz respeito às diretrizes, com a sugestão de extensão de seus critérios de sucesso, quanto na identificação de mecanismos funcionais de apoio à interação, oferecendo assim um suporte combinado para a melhoria das aplicações Web destinadas a esse público-alvo. Os resultados foram relevantes, principalmente no sentido de que observaram e registraram comportamentos, opiniões e anseios dos adultos mais velhos em relação à Web.

Existe ainda muito trabalho a ser feito nas áreas de acessibilidade e usabilidade para adultos mais velhos na Web. Construir interfaces usáveis e acessíveis para esse público pode ser visto como um único e grande desafio, mas com várias perspectivas distintas, visto que as pessoas mais velhas podem apresentar necessidades especiais de vários tipos e de forma combinada.

Esta tese não foi exaustiva quanto à exploração do universo de dificuldades dos adultos mais velhos, mas sim, é um passo inicial em direção à inclusão digital dos adultos mais velhos na Web, considerando suas reais necessidades em função do processo natural de envelhecimento, contribuindo para a qualidade de vida e para o envelhecimento ativo. Essa pesquisa proporcionou experiências pessoais enriquecedoras para a pesquisadora, dado o convívio com a serenidade, humildade e vontade de aprender dos adultos mais velhos. 


\section{Referências Bibliográficas}

Aztiria, A.; Augusto, J. C.; Basagoiti, R.; Izaguirre, A.; Cook, D. J. Discovering frequent user-environment interactions in intelligent environments. Personal Ubiquitous Comput., v. 16, n. 1, p. 91-103, 2012.

Barbosa, M. B. Elaboração de normas ténicas voltadas à acessibilidade na comunicação. In: Anais do II Seminário ATIID - Acessibilidade, Tecnologia da Informação e Inclusão Digital, São Paulo - SP: Faculdade de Saúde Pública - USP, disponível em: http://www.prodam.sp.gov.br/multimidia/midia/cd_atiid/conteudo/ATIID2003/ MR2/06/NormasTecAcessibiliddComunicacao.pdf. Acessado em julho/2012, 2003, p. $1-5$.

Bastos, J.; Rocha, C. Análise de sobrevivência: Conceitos Básicos. Arq Med, v. 20, n. 5-6, p. 185-187, disponível em: http://www.scielo.oces.mctes.pt/scielo.php?script=sci_arttext\&pid=S0871-34132 006000400007\&lng=pt\&nrm=\&tlng=pt. Acessado em julho/2012, 2006.

Bevan, N.; Curson, I. Planning and implementing user-centred design. In: CHI '99 Extended Abstracts on Human Factors in Computing Systems, New York, NY, USA: ACM, 1999, p. 137-138.

Brasil e-MAG: Modelo de Acessibilidade de Governo Eletrônico, versão 3.0. Portal de Governo Eletrônico do Brasil. Disponível em: http://www.governoeletronico.gov.br/acoes-e-projetos/e-MAG. Acessado em maio/2012, 2011.

British Medical Journal Timing of onset of cognitive decline: results from Whitehall II prospective cohort study. Disponível em: http://www.bmj.com/content/344/bmj.d7622. Acessado em abril/2012, 2012.

Burdick, D. C. The aging imperative: designing for an aging population. In: Proceedings of the Mini-Conference of the South Jersey Human Factors and Ergonomics Society: Human Factors in Complex Sociotechnical Systems, Pomona, New Jersey: SJHFES, 2005, p. 131-135. 
Card, S.; Moran, T.; Newell, A. The psychology of human-computer interaction. L. Erlbaum Associates, disponível em: http://books.google.com.br/books?id=lt9QAAAAMAAJ, 1983.

Chou, J.-R.; Hsiao, S.-W. A usability study on human-computer interface for middle-aged learners. Computers in Human Behavior, v. 23, n. 4, p. 2040-2063, 2007.

Colosimo, E. A.; Giolo, S. R. Análise de Sobrevivência Aplicada. São Paulo: Edgard Blücher, 392 p., 2006.

Cook, D.; Crandall, A.; Thomas, B.; Krishnan, N. CASAS: A Smart Home in a Box. Computer, v. PP, n. 99, p. 1, 2012.

Coyne, K. P.; Nielsen, J. Web Usability for Senior Citizens:46 Design Guidelines Based on Usability Studies with People Age 65 and Older. Nielsen Norman Group, 2002.

Debert, G. G. Antropologia e Velhice. Textos Didáticos, v. 19, p. 118, 1998.

Di Blas, N.; Paolini, P.; Speroni, M. Usable accessibility to the Web for blind users. In: In: Proceedings of 8th ERCIM Workshop: User Interfaces for All, Vienna, Austria: Springer, 2004, p. 28-29.

Dickinson, A.; Smith, M. J.; Arnott, J. L.; Newell, A. F.; Hill, R. L. Approaches to web search and navigation for older computer novices. In: $C H I$ '0\%: Proceedings of the SIGCHI Conference on Human Factors in Computing Systems, New York, NY, USA: ACM, 2007, p. 281-290.

Disability Rights Commission The Web: access and inclusion for disabled people. London: The Stationery Office. Disponível em: http://www-hcid.soi.city.ac.uk/research/DRC_Report.pdf. Acessado em março/2012, 2004.

European Commission The social situation in the European Union 2005-2006. European Commission, disponível em: http://ec.europa.eu/employment_social/social_situation/docs/ssr2005_2006_en.pdf. Acessado em julho/2012, 2007.

FARKAS, D. K. The role of balloon help. SIGDOC Asterisk J. Comput. Doc., v. 17, n. 2, p. 3-19, disponível em: http://doi.acm.org/10.1145/154425.154426. Acesso julho/2012, 1993. 
Fernando Daquino Casas inteligentes serão realidade em 10 anos, afirmam cientistas. Disponível em: http://www.tecmundo.com.br/casas/21501-casas-inteligentes-serao-realidade-em-10-anos-afirm Acessado em dezembro/2012, 2012.

Fisk, A.; Rogers, W.; Charness, N.; Czaja, S.; Sharit, J. Designing for Older Adults: Principles and Creative Human Factors Approaches. Human Factors \& Aging Series. Atlanta, Georgia: CRC Press, disponível em: http://books.google.com.br/ books?id=uSXmGIHXyZUC, 2009.

Fleming, J. Web navigation: designing the user experience. N. v. 1 in Learn by example. O'Reilly, disponível em: http://books.google.com.br/books?id=ufdSAAAAMAAJ, 1998.

Fortes, R. P. M.; Lara, S. M. A.; Freire, A. P.; Pansanato, L. T. E. Acessibilidade no Projeto de Aplicações Web, v. 1, cáp. 7.1 ed Belo Horizonte-MG: FuMARC Editora, p. 197-226, 2005.

G1 Em 50 anos percentual de idosos mais que dobra no Brasil. Disponível em: http://g1.globo.com/brasil/noticia/2012/04/em-50-anos-percentual-de-idosos-ma is-que-dobra-no-brasil.html. Acessado em Junho/2012, 2012.

Gartner Top 10 Strategic Technology Trends for 2013. Disponível em: http://www.gartner.com/it/page.jsp?id=2209615. Acessado em dezembro/2012, 2012.

GıL, A. C. Como elaborar projetos de pesquisa. São Paulo: Atlas, 176 p., 2008.

Goble, C.; Harper, S.; Stevens, R. The travails of visually impaired web travellers. In: Proceedings of the eleventh ACM on Hypertext and hypermedia, New York, NY, USA: ACM, disponível em: http://doi.acm.org/10.1145/336296.336304, 2000, p. 1-10 (HYPERTEXT '00, v.1).

Gonçalves, V. P.; De Almeida Neris, V. P.; Ueyama, J. Interação de idosos com celulares: flexibilidade para atender a diversidade. In: Proceedings of the 10th Brazilian Symposium on on Human Factors in Computing Systems and the 5th Latin American Conference on Human-Computer Interaction, Porto Alegre, RS, Brazil: Brazilian Computer Society, disponível em: http://dl.acm.org/citation.cfm?id=2254436.2254493, 2011, p. 343-352 $(I H C+C L I H C$ '11, v.1). 
Goodall, S. D. Online help: a part of documentation. In: Proceedings of the 10th Annual International Conference on Systems Documentation, New York, NY, USA: ACM, disponível em: http://doi.acm.org/10.1145/147001.147024, 1992, p. 169-174 (SIGDOC'92, v.1).

Greenwood, P.; Nikulin, M. A Guide to Chi-Squared Testing. Wiley series in probability and mathematical statistics. Probability and mathematical statistics. Wiley, disponível em http://books.google.com.br/books?id=bc8zfQSKOwIC, 1996.

Grossman, T.; Fitzmaurice, G. W. ToolClips: an investigation of contextual video assistance for functionality understanding. In: Mynatt, E. D.; Schoner, D.; Fitzpatrick, G.; Hudson, S. E.; Edwards, W. K.; Rodden, T., eds. CHI, ACM, disponível em: http://dblp.uni-trier.de/db/conf/chi/chi2010.html\#GrossmanF10, 2010, p. $1515-1524$.

Hanson, V. L. The User Experience: Designs and Adaptations. In: Proceedings of the 2004 international Cross-Disciplinary Workshop on Web Accessibility (W4A), New York City, New York: ACM, 2004, p. 1-11.

Hanson, V. L. Technology skill and age: what will be the same 20\&\#x00a0;years from now? Univers. Access Inf. Soc., v. 10, n. 4, p. 443-452, 2011.

Hawthorn, D. Possible implications of aging for interface designers. Interacting with Computers, v. 12, n. 5, p. 507-528, disponível em: http://www.ingentaconnect.com/content/els/09535438/2000/00000012/00000005 /art00021, 2000.

Hawthorn, D. How universal is good design for older users? In: Proceedings of the 2003 conference on Universal usability, New York, NY, USA: ACM, disponível em http://doi.acm.org/10.1145/957205.957213, 2003, p. 38-45 (CUU'03, v.1).

Hayflick, L. Como e por que envelhecemos. Rio de Janeiro: Editora Campus, 1996.

Hellman, R. Universal design and mobile devices. In: Proceedings of the 4th International Conference on Universal Access in Human Computer Interaction: Coping with Diversity, Berlin, Heidelberg: Springer-Verlag, disponível em: http://dl.acm.org/citation.cfm?id=1766311.1766329, 2007, p. 147-156 (UAHCI'0\%, v.1). 
HenRY, S. Introduction to Web accessibility. Disponível em: http://www.w3.org/WAI/intro/accessibility.php. Acessado em março/2012, 2005.

Hogeboom, D. L.; McDermott, R. J.; Perrin, K. M.; Osman, H.; Bell-Ellison, B. A. Internet Use and Social Networking Among Middle Aged and Older Adults. Educational Gerontology, v. 36, n. 2, p. 93-111, 2010.

Hull, L. Accessibility: it's not just for disabilities any more. Interactions, v. 11, n. 2, p. 36-41, 2004.

IBGE Síntese de Indicadores Sociais 2005. Estudos e Pesquisas: Informação Demográfica e Socioeconômica. Página Web, disponível em: http://biblioteca.ibge.gov.br/visualizacao/monografias/GEBIS\%20-\%20RJ/sinte se_indic/ indic_sociais2005.pdf. Acessado em maio/2012, 2006.

IBGE Síntese de Indicadores Sociais 2007. Uma Análise das Condições de Vida da População Brasileira. Página Web, disponível em: http://www.ibge.gov.br/home/estatistica/populacao/condicaodevida/indicadore sminimos/ sinteseindicsociais2007/indic_sociais2007.pdf. Acessado em julho/2012, 2007.

IBGE Política do Idoso no Brasil. Página Web, disponível em: http://www.ibge.gov.br/ibgeteen/datas. Acessado em maio/2012, 2008a.

IBGE Síntese de Indicadores Sociais 2008. Uma análise das condições de vida da população brasileira. Disponível em: http://www.ibge.gov.br/home/estatistica/populacao/condicaodevida/indicadore sminimos/ sinteseindicsociais2008/indic_sociais2008.pdf. Acessado em maio/2012, 2008b.

IBGE Censo Demográfico 2010 - Resultados Gerais da Amostra. Disponível em: ftp://ftp.ibge.gov.br/Censos. Acessado em maio/2012, 2010a.

IBGE Pesquisa Nacional por Amostra de Domicílios - Síntese de Indicadores 2009. Disponível em: http://www.ibge.gov.br/home/estatistica/populacao/trabalhoerendimento/pnad 2009/pnad_sintese_2009.pdf. Acessado em julho/2012, 2010b.

IEEE_STD_1061 Software Quality Metrics Methodology. 1998.

IPEA Instituto de Pesquisa e Econômica Aplicada. Disponível em: http://www.ipea.gov.br/default.jsp. Acessado em março/2012, 2007. 
ISO_25010 Systems and software engineering - Systems and software Quality Requirements and Evaluation (SQuaRE) - System and software quality models. 2010.

ISO_9126 Software Product Evaluation: Quality Characteristics and Guidelines for their Use. 1991.

ISO_9241 Standard 9241: Ergonomic requirements for office work with visual display terminals. Disponível em: http://www.iso.org. Acessado em março/2012, 2000 .

KAnG, N. E.; Yoon, W. C. Age- and experience-related user behavior differences in the use of complicated electronic devices. Int. J. Hum.-Comput. Stud., v. 66, n. 6 , p. $425-437,2008$.

KATHRYN ZickUHR Generation and their gadgets. Disponível em: http://pewinternet.org/Reports/2011/Generations-and-gadgets/Report/Background.aspx. Acessado em dezembro/2012, 2011.

Kelly, B.; Sloan, D.; Brown, S.; Seale, J.; Petrie, H.; Lauke, P.; Ball, S. Accessibility 2.0: people, policies and processes. In: W4A'0\%: Proceedings of the $200^{\prime} 7$ International Cross-Disciplinary Workshop on Web Accessibility (W4A), ACM, disponível em: http://dblp.uni-trier.de/db/conf/w4a/w4a2007.html\#KellySBSPLB07, 2007, p. 138-147 (ACM International Conference Proceeding Series, v.225).

Kelly, B.; Sloan, D.; Phipps, L.; Petrie, H.; Hamilton, F. Forcing standardization or accommodating diversity?: a framework for applying the wcag in the real world. In: W4A'05: Proceedings of the 2005 International Cross-Disciplinary Workshop on Web Accessibility (W4A), New York, NY, USA: ACM, 2005, p. 46-54 (ACM International Conference Proceeding Series, v.1).

Kogan, S. L. Human-computer interaction and older adults. State of the Science Exchange on Modality Independent Interaction, Seattle, WA, 2001.

Kurniawan, S. H.; Zaphiris, P. Research-derived web design guidelines for older people. In: ASSETS, ACM, disponível em: http://dblp.uni-trier.de/db/conf/assets/assets2005.html\#KurniawanZ05， 2005, p. $129-135$.

LAI, Y.-R.; WAugh, M. L. From Information Searching to Learning: A Comparison of Contrasting Hypertextual Menu Designs for 
Computer-Based Instructional Documents. American Educational Research Association Conference Presentations (AERA '94), disponível em: http://education.illinois.edu/tta/eval.conf.AERA.html. Acessado em julho/2012, 1994.

Lakatos, E. M.; Marconi, M. A. Metodologia do Trabalho Científico: procedimentos básicos, pesquisa bibliográfica, projeto e relatório, publicações e trabalhos científicos. 7 ed. São Paulo: Editora Atlas S.A., 228 p., 2007.

Lakatos, E. M.; Marconi, M. A. Técnicas de Pesquisa: Planejamento e execução de pesquisas. Amostragens e técnicas de pesquisa. Elaboração, análise e interpretação de dados. 7 ed. São Paulo: Editora Atlas S.A., 296 p., 2008.

Lara, S. M. A.; Fortes, R. P. M. Usabilidade universal para adultos de meia-idade em interações com a web. In: XXXV Latin American Informatics Conference (CLEI 2009), Pelotas, RS: SBC, 2009, p. 1-10.

Lara, S. M. A.; Oliveira, D.; Fortes, R. P. M. Accessibility Context Sensitive to Middle-Aged Adults and Elderly in Web Systems. In: Proceedings of the 29th ACM International Conference on Design of Communication (ACM SIGDOC'11), Pisa, Italy: ACM, 2011a, p. 33-36.

Lara, S. M. A.; Oliveira, D.; Fortes, R. P. M. Acessibilidade Sensível ao Contexto para Adultos Mais Velhos em Sistemas Web. In: Anais do X Simpósio de Fatores Humanos em Sistemas Computacionais, Porto de Galinhas, PE: SBC, 2011b, p. 353-357.

Lara, S. M. A.; Pietronero, W.; Fortes, R. P. M. Acessibilidade para Adultos de Meia-Idade e Idosos em e-Commerce. In: XVI Simpósio Brasileiro de Sistemas Multimídia e Web - WebMedia 2010, Belo Horizonte, MG: SBC, 2010a.

Lara, S. M. A.; Watanabe, W. M.; Santos, E. P. B.; Fortes, R. P. M. Improving WCAG for elderly web accessibility. In: Proceedings of the 28th ACM International Conference on Design of Communication, São Carlos, SP: ACM, 2010b, p. 175-182 (SIGDOC' '10, v.1).

Laverson, A.; Norman, K.; Shneiderman, B. An evaluation of jump-ahead techniques in menu selection. Behaviour \&6 Information Technology, v. 6, n. 2, p. 97-108, disponível em: http://www.informaworld.com/openurl?genre=article\&doi=10.1080/0144929870 $8901820,1987$. 
Marplan Ipsos Marplan Instituto de Pesquisas. Página Web, http://www.ipsos.com.br/default.asp?resolucao=1024X768. Acessado em julho/2012, 2008.

Melo, A. M.; Baranauskas, M. C. C. Design e Avaliação de Tecnologia Web-acessível. In: Jornadas de Atualização em Informática - Congresso da SBC, 2005, Porto Alegre, RS: SBC, 2005, p. 1500-1545.

Mennicken, S.; HuAng, E. M. Hacking the natural habitat: an in-the-wild study of smart homes, their development, and the people who live in them. In: Proceedings of the 10th international conference on Pervasive Computing, Berlin, Heidelberg: Springer-Verlag, 2012, p. 143-160.

Meyer, B.; Sit, R. A.; Spaulding, V. A.; Mead, S. E.; Walker, N. Age group differences in world wide web navigation. In: CHI '97 extended abstracts on Human factors in computing systems: looking to the future, New York, NY, USA: ACM, disponível em http://doi.acm.org/10.1145/1120212.1120401, 1997, p. 295-296 (CHI EA' '97, v.1).

Minister OF Industry Learning a Living - First Results of the Adult Literacy and Life Skills Survey. Canada and Organisation for Economic Cooperation and Development (OECD), Paris, 2005. Disponível em: http://www.nald.ca/fulltext/learnliv/learnliv.pdf. Acessado em Junho/2012, 2005 .

Monk, A.; Wright, P.; HABer, J.; DAVEnport, L. Improving your human-computer interface: a practical technique. BCS practitioner series. Upper Saddle River, New Jersey: Prentice Hall, disponível em: http://books.google.com.br/books?id=JN9QAAAAMAAJ, 1993.

Mozilla LABS Jetpack Project. Disponível em: https://addons.mozilla.org/en-US/developers/. Acessado em fevereiro/2012, $2012 \mathrm{a}$.

Mozilla LABS Jetpack Prototype. Disponível em: https://jetpack.mozillalabs.com/prototype.html. Acessado em fevereiro/2012, $2012 \mathrm{~b}$.

MozILla LABS Jetpack SDK. Disponível em: https://addons.mozilla.org/ en-US/developers/docs/sdk/latest/. Acessado em fevereiro/2012, 2012c.

NeErincx, M.; Lindenberg, J. Supporting Individual Situation Awareness in Web-environments. Página Web, disponível em: 
http://projects.cwi.nl/uwish/papers/sapaper.pdf. Acessado em agosto/2012, 1999.

Neerincx, M. A.; Lindenberg, J.; Pemberton, S. Support concepts for Web navigation: a cognitive engineering approach. In: Proceedings of the 10th international conference on World Wide Web, New York, NY, USA: ACM, disponível em: http://doi.acm.org/10.1145/371920.371966, 2001, p. 119-128 ( $W W W$ '01, v.1).

Neri, A. L. Envelhecer bem no trabalho: Possibilidades individuais, organizacionais e sociais. Terceira Idade, v. 13 (24), p. 7-27, 2002.

Neri, A. L. Palavras Chave Em Gerontologia. Campinas, SP: Editora Alinea, 2005.

Neves, J. L. Pesquisa Qualitativa - Características, usos e possibilidades. Http://www.ead.fea.usp.br/cad-pesq/arquivos/C03-art06.pdf. Acessado em junho/2012, 1999.

Nielsen, J. Usability Engineering. Boston: Academic Press, 1993.

Nielsen, J. Designing Web Usability. Landmark Series. New Riders, disponível em: http://books.google.com.br/books?id=6exSAAAAMAAJ, 2000.

Nielsen, J.; Loranger, H. Usabilidade na WEB - Projetando Websites com qualidade. Rio de Janeiro: Editora Campus, 2007.

Norman, K.; Chin, J. The effect of tree structure on search in a hierarchical menu selection system. Behaviour \&6 Information Technology, v. 7, n. 1, p. 51-65, disponível em: http://www.informaworld.com/openurl?genre=article\&doi=10.1080/0144929880 8901862, 1988.

Oliveira, J. L. D.; Gonçalves, M. A.; Medeiros, C. B. A framework for designing and implementing the user interface of a geographic digital library. Int. J. on Digital Libraries, v. 2, n. 2-3, p. 190-206, disponível em: http://dx.doi.org/10.1007/s007990050047, 1999.

Paciello, M. G. Web Accessibility for People with Disabilities. 1 st ed. Lawrence, KS: CMP Books, 2000.

Parmanto, B.; Zeng, X. Metric for Web accessibility evaluation. Journal of the American Society for Information Science and Technology, v. 56, n. 33, p. 1394-1404, 2005. 
Petrie, H.; Hamilton, F.; King, N. Tension? what tension?: website accessibility and visual design. SIGCAPH Comput. Phys. Handicap., v. 1, n. 76, p. 6-7, 2003.

Petrie, H.; OMAR, K. The relationship between accessibility and usability of websites. In: CHI '0\%: Proceedings of the SIGCHI Conference on Human Factors in Computing Systems, San Jose, California, USA: ACM Press, 2007, p. 397-406.

Plaisant, C.; Shneiderman, B. Show Me! Guidelines for Producing Recorded Demonstrations. In: $V L / H C C$, IEEE Computer Society, disponível em: http://dblp.uni-trier.de/db/conf/vl/vlhcc2005.html\#PlaisantS05, 2005, p. 171-178.

PÁsCOA, G.; GIL, H. Facebook e os Idosos: A importância do software social na aprendizagem ao longo da vida. In: Proceedings of the 7 Conferencia Ibérica de Sistemas y Tecnologias de Información, Madrid, Espanha: AISTI UPM, disponível em: http://hdl.handle.net/10400.11/1346, 2012, p. 544-549 (CISTI'2012, v.1).

QI, X.; Davison, B. D. Web page classification: Features and algorithms. ACM Computing Surveys, v. 41, n. 2, p. 12:1-12:31, disponível em: http://doi.acm.org/10.1145/1459352.1459357, 2009.

R Development Core Team $R$ : A Language and Environment for Statistical Computing. R Foundation for Statistical Computing, Vienna, Austria, disponível em: http://www.R-project.org/, 2010.

Regan, B. Accessibility and design: a failure of the imagination. In: $W_{4} A$ '04: Proceedings of the 2004 International Cross-Disciplinary Workshop on Web Accessibility (W4A), New York, NY, USA: ACM Press, 2004, p. 29-37.

Rettig, M. Nobody Reads Documentation. Communications of the ACM, v. 34, n. 7, p. 19-24, 1991.

REUTERs Factbox - The outlook for Japan's ageing population. Reuters, disponível em: http://www.reuters.com/ article/inDepthNews/idUST2888420070917. Acessado em Maio/2012, 2007.

Revista Istó́ A vez dos idosos. Revista Isto É Independente - Economia e Negócios - Edicao:2087 - Página Web, disponível em: http://www.istoe.com.br/reportagens/8091_A+VEZ+DOS+IDOSOS?pathImage ns $=\&$ path $=\&$ actualArea $=$ internalPage. Acessado em julho/2012, 2009. 
Revista Veja Vida Digital A rede mais madura. Página Web, http://veja.abril.com.br/especiais/Digital3/pesquisa.html. Acessado em julho/2012, 2000.

Rocha, H. V.; Baranauskas, M. C. C. Design e Avaliação de Interfaces Humano-Computador. Campinas, SP: Editora Unicamp, 2003.

Sales, M. B. D.; CyBis, W. D. A. Development of a checklist for the evaluation of the web accessibility for the aged users. In: Proceedings of the Latin American conference on Human-computer interaction, Rio de Janeiro, Brazil: ACM, disponível em: http://dl.acm.org/citation.cfm?id=944519.944533, 2003, p. 125-133 (CLIHC'03, v.1).

Santos, E. P. B.; Lara, S. M. A.; Castro, M.; Fortes, R. P. M. Menus horizontais drop-down: um estudo de caso com prioridade para usuários de meia-idade. In: Centro Latinoamericano de Estudios en Informática, Quito, Equador: Elsevier Science B. V., 2011a, p. 1-10.

Santos, E. P. B.; Lara, S. M. A.; Watanabe, W. M.; Castro, M.; Fortes, R. P. M. Usability evaluation of horizontal navigation bar with drop-down menus by middle aged adults. In: The 29th ACM International Conference on Design of Communication (ACM SIGDOC'11), Pisa, Italy: ACM, 2011b, p. $145-150$.

SAntos, E. P. B. D. Acessibilidade em menus de navegação horizontais na Web para pessoas de meia idade. Dissertação de Mestrado. Universidade de São Paulo, USP, Brasil. 2012.

SBC Grandes Desafios da Pesquisa em Computação no Brasil 20062016. Relatório sobre o Seminário realizado em 8 e 9 de maio de 2006. Disponível em: http://www.sbc.org.br/index.php?option=com_jdownloads\&Itemid=195\&task= finish\&cid=11\&catid=50, 2006.

Seffah, A.; Metzker, E. The obstacles and myths of usability and software engineering. Communications of the ACM, v. 47, n. 12, p. 71-76, 2004.

SENAI Manual de iniciação à informática para deficientes visuais: iniciação ao Windows, Jaws, Virtual Vision, Dosvox. Disponível em: http://styx.nied.unicamp.br:8080/todosnos/acessibilidade/textos/leitores_de_tela s.html. Acessado em fevereiro/2012, 2012.

SEniorNet SeniorNet. Disponível em: http://www.seniornet.org/. Acessado em julho/2012, 2007. 
Shneiderman, B. Universal usability. Commun. ACM, v. 43, n. 5, p. 84-91, disponível em: http://doi.acm.org/10.1145/332833.332843, 2000.

Siegel, S.; Castellan, N. Nonparametric statistics for the behavioral sciences. Second ed. McGraw-Hill, Inc., 1988.

Singer, E.; von Thurn, D. R.; Miller, E. R. Confidentiality assurances and response: A quantitative review of the experimental literature. Public Opinion Quarterly, v. 59, p. 66-77, 1995.

SloAn, D. Two Cultures? The disconnect between the web standards movement and research-based web design guidelines for older people. Gerontechnology, v. 5, n. 2, p. 106-112, 2006.

Small, J.; Schallau, P.; Brown, K.; Appleyard, R. Web accessibility for people with cognitive disabilities. In: CHI '05 Extended Abstracts on Human Factors in Computing Systems, New York, NY, USA: ACM, 2005, p. 1793-1796.

Thatcher, J.; WADDELl, C. Constructing accessible web sites. Ex Peer Series. Glasshaus, disponível em: http://books.google.com.br/books?id=Y9DED4aOch8C, 2002.

U.S. Government Section 508. Disponível em: http://www.section508.gov. Acessado em março/2012, 2003.

VERAs, R. P. Atenção preventiva ao idoso - uma abordagem de saúde coletiva. Gerontologia: a velhice e o envelhecimento em visão globalizada, v. 19, p. 383 393, 1996.

W3C HTML 4.01 Specification. Disponível em: http://www.w3.org/TR/html4/. Acessado em julho/2012, 1999a.

W3C Web Content Acessibility Guidelines 1.0. Disponível em: http://www.w3.org/TR/WCAG10/. Acessado em julho/2012, 1999 b.

W3C Web Accessibility for Older Users: A Literature Review. W3C Working Draft. Disponível em: http://www.w3.org/TR/wai-age-literature/\#waiguide/. Acessado em julho/2012, 2008a.

W3C Web Content Acessibility Guidelines 2.0. Disponível em: http://www.w3.org/TR/WCAG20/. Acessado em julho/2012, 2008b.

W3C Cascading Style Sheets Level 2 Revision 1 (CSS 2.1) Specification. W3C Recommendation, disponível em: http://www.w3.org/TR/CSS2. Acessado em julho/2012, 2011. 
W3C Authoring tool accessibility guidelines 1.0. Disponível em: http://www.w3.org/TR/ATAG10/. Acessado em julho/2012, 2012a.

W3C User agent accessibility guidelines 1.0. Disponível em: http://www.w3.org/TR/WCAG10/. Acessado em julho/2012, 2012 b.

W3C Web Accessibility Initiative. Disponível em: http://www.w3.org/WAI/gettingstarted/Overview. html. Acessado em julho/2012, 2012c.

W3C Working Draft Success Criteria for Web Content Accessibility Guidelines 2.0. Disponível em: http://www.w3.org/TR/2005/WD-WCAG20-20051123/guidelines.html\#N1034D. Acessado em julho/2012, 2012.

W3C Working Group Note Techniques and Failures for Web Content Accessibility Guidelines 2.0. Disponível em: http://www.w3.org/TR/WCAG20-TECHS/. Acessado em julho/2012, 2012.

WUAUC Workshop on Universal Accessibility of Ubiquitous Computing: Providing for the Elderly. Página Web, disponível em: http://virtual.inesc.pt/wuauc01/. Acessado em julho/2012, 2001.

Yu, B.; RoH, S. The effects of menu design on information-seeking performance and user's attitude on the world wide web. J. Am. Soc. Inf. Sci. Technol., v. 53, n. 11, p. 923-933, 2002.

ZAJICEK, M. Interface design for older adults. In: WUAUC'01: Proceedings of the 2001 EC/NSF workshop on Universal accessibility of ubiquitous computing, New York, NY, USA: ACM, 2001, p. 60-65.

Zaphiris, P.; Ghiawadwala, M.; Mughal, S. Age-centered research-based web design guidelines. In: CHI '05: CHI '05 extended abstracts on Human factors in computing systems, New York, NY, USA: ACM, 2005, p. 1897-1900. 


\section{$A$}

\section{Questionário - Adultos Mais Velhos com Experiência na Web}

Questionário para Adultos Mais Velhos com Experiência no Uso da Web

O questionário abaixo foi enviado via e-mail para diversas pessoas com idades acima de 40 anos, mas, devido à rápida propagação na Web, muitas pessoas com idade abaixo de 40 anos também o responderam, o que serviu como parâmetro de comparação para as análises.

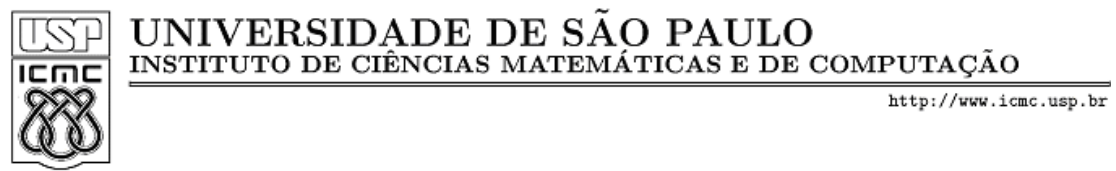

Pesquisa: Mecanismos de Apoio para acessibilidade na interação de adultos de meia-idade com a Web - Responsável:silvana@icmc.usp.br Identificação

Nome:

Sexo:

Estado Civil:
Idade:

Nível de Escolaridade:

Profissão:

Questões

1. Há quanto tempo você utiliza a Internet? (resposta única) 
( ) mais de 10 anos ( ) mais de 5 anos ( ) mais de 1 ano ( ) mais de 6 meses

( ) não uso a Internet

2. Quais dos dispositivos abaixo você tem alguma dificuldade em utilizar? (múltiplas respostas)

( ) teclado ( ) mouse ( ) monitor de vídeo ( ) impressora ( ) unidades de CD/DVD/Pen Drive () outro:

3. Caso você não utilize a Internet, qual é o principal motivo? (resposta única)

( ) não tenho computador ( ) não tenho conexão com a Internet ( ) não sei utilizar a Internet ( ) o custo da utilização da Internet é alto

4. Com que freqüência você utiliza a Internet? (resposta única)

( ) pelo menos uma vez por dia ( ) pelo menos uma vez por semana, mas não todo dia ( ) pelo menos uma vez por mês, mas não toda semana ( ) menos de uma vez por mês ( ) nunca

5. Qual(is) programa(s) (ou navegadores) você utiliza para acessar a Internet ?

6. Você sente medo ou insegurança ao utilizar a Internet?

( ) Não ( ) Sim. Por que?

7. Você gostaria de usar algum site na Internet que ainda não usa?

( ) Não ( ) Sim. Qual?

Por que não usa?

8. Você costuma se sentir perdido ou sem saber o que fazer quando navega pela Internet? (resposta única)

( ) sempre ( ) às vezes ( ) raramente ( ) nunca

9. Você costuma pedir ajuda a outras pessoas para navegar ou realizar operações na Internet? (resposta única)

( ) sempre ( ) às vezes ( ) raramente ( ) nunca

10. Você compreende bem as mensagens de erro que lhe são mostradas quando está navegando na internet? (resposta única)

( ) sempre ( ) às vezes ( ) raramente ( ) nunca

11. Com que freqüência você esquece as suas senhas de acessos de sites da Internet? (resposta única)

( ) sempre ( ) às vezes ( ) raramente ( ) nunca 
12. De que forma você costuma guardar suas senhas de sites na Internet?

13. Classifique os itens abaixo seguindo a ordem dos tipos de sites que você mais utiliza. Exemplo:

1 sites de e-mail Quais: e-mail do ICMC, Gmail, Yahoo

3 sites de bancos on-line Quais: Banco do Brasil, Nossa Caixa

2 ferramentas de busca Quais: Google

Coloque 0 (zero) para os tipos de sites que nunca utiliza.

--- e-mail Quais:

--- bancos on-line Quais:

--- ferramentas de busca Quais:

--- sites de interesse profissional Quais:

--- sites de relacionamento pessoal Quais:

--- sites de compras Quais:

_-_ sites de órgãos do governo Quais:

_-- sites de educação/aprendizado Quais:

--- sites de jornais/revistas Quais:

_-- sites de lazer/entretenimento Quais:

--- troca de mensagens instantâneas Quais:

--_ salas de bate-papo Quais:

--- ver ou gravar jogos/filmes/músicas Quais:

_-_ enviar imagens/filmes/músicas para a internet Quais:

--- outros sites Quais:

14. Quais são suas principais dificuldades para a realização de uma operação específica como compras, pagamento de contas, envio de e-mails, etc...?

15. Quais são suas principais dificuldades durante o uso dos sites da Internet (navegação na Internet)?

16. Você tem alguma sugestão (de qualquer tipo) sobre o que poderia melhorar nos sites para que suas experiências na utilização da Internet sejam melhores?

17. Você apresenta algum problema que afeta sua coordenação motora ou sua memória?

( ) Não ( ) Sim. Qual(is)? 
18. Você faz uso de algum medicamento do tipo remédios para insônia, memória, tremores, ou algum outro que gostaria de mencionar?

( ) Não ( ) Sim. Qual(is)?

Todas as respostas fornecidas são confidenciais e serão somente utilizadas para os fins desta pesquisa, e os pesquisadores responsáveis asseguram que as mesmas não serão utilizadas para nenhum outro fim.

Agradecemos sua colaboração e esperamos contribuir para melhorias no uso da Internet.

Renata Pontin M. Fortes e Silvana M. A de Lara 


\section{Questionário On-line - Reconhecimento de Elementos da Web}

\section{Questionário On-line para Reconhecimento de Elementos}

Ao ser acessado pelos respondentes, a página inicial do questionário apresentava a seguinte mensagem: "Este teste é parte integrante de uma pesquisa científica sobre familiaridade com elementos da Web. Todas as respostas fornecidas são confidenciais e serão somente utilizadas para os fins desta pesquisa, e os pesquisadores responsáveis asseguram que as mesmas não serão utilizadas para nenhum outro fim. Obrigada pela colaboração!

Renata Pontin M. Fortes e Silvana M. A de Lara"

\section{Perfil}

Para que fosse possível traçar o perfil das pessoas que colaboraram respondendo às questões propostas foram coletadas as seguintes informações: e-mail, idade, escolaridade, experiência no uso da Web e sua frequência de uso, conforme detalhado na Seção 5.4 .

\section{Questões}

1. O que deve ser digitado nessa caixa de texto?

a. Um endereço da Web que localiza um site 
b. O nome de um site

c. Seu nome

d. Sua senha

e. Nenhum dos anteriores

f. Não sei

2. O que significa o elemento abaixo?

-Boas-vindas - Guia - Perguntas freqüentes •Comunidade -Políticas da Wikipédia -Doações - Contatos
a. Rodapé de uma página da internet
b. Menu de opções de um site
c. Índice sem links
d. Texto simples sem links
e. Nenhum dos anteriores
f. Não sei

3. O que devo fazer para participar da discussão a respeito do artigo mostrado?

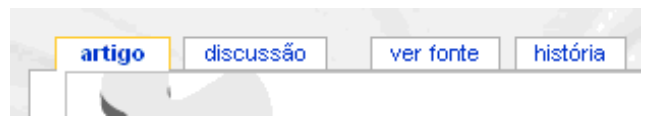
a. Clicar na aba "discussão"
b. Clicar na barra de rolagem da página
c. Clicar na aba "artigo"
d. Aguardar alguém iniciar a discussão
e. Nenhum dos anteriores
f. Não sei

4. O que significam os itens abaixo?
a. Passos para a realização de uma tarefa
b. Links de navegação 


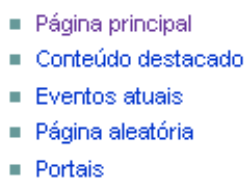

c. Índice sem links

d. Nomes de páginas da internet

e. Nenhum dos anteriores

f. Não sei

5. O que significa o item com destaque?

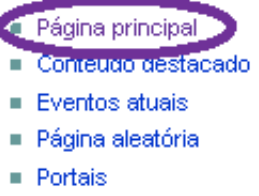

a. Título de uma página da internet

b. Link de navegação

c. Link de navegação já visitado

d. Texto simples

e. Nenhum dos anteriores

f. Não sei

6. O elemento abaixo é encontrado na maioria dos sites da Internet. Para que ele serve?

a. Para digitar um endereço de um site

b. Para fazer a busca de uma ou mais palavras dentro do site em que se encontra

c. Para fazer a busca de uma ou mais palavras na web toda

d. Para digitar o meu nome e minha senha

e. Nenhum dos anteriores

f. Não sei 


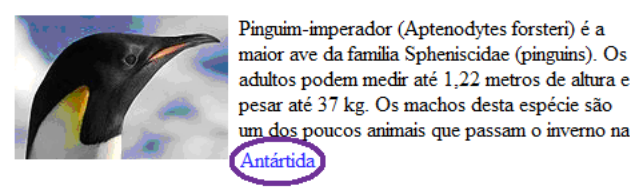

7. Para que serve o elemento destacado?

a. Para escrever a palavra Antártida

b. Para facilitar a leitura, alternando a cor do texto

c. Para acessar uma página a respeito da Antártida

d. Para indicar onde mora o pingüim

e. Nenhum dos anteriores

f. Não sei

8. Considere que ao clicar na imagem abaixo o usuário seja redirecionado para outra página da web. Isso significa que:

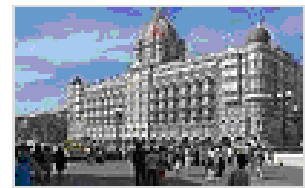

a. A imagem é um link de navegação

b. A explicação sobre a imagem deve estar em outra página

c. Essa imagem tem tamanho reduzido e na próxima página deve haver uma imagem maior

d. É uma simples imagem, sem funcionalidade nenhuma

e. Nenhum dos anteriores

f. Não sei

9. Considere que a figura em destaque carrega uma outra página web. O que representa essa figura?

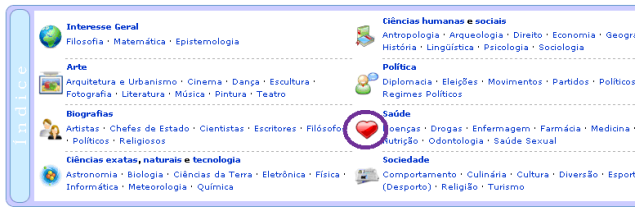

a. A figura de um coração 
b. Um ícone navegável que redireciona para a página contendo o tópico de Saúde

c. Um item de decoração do texto

d. Uma imagem simples

e. Nenhum dos anteriores

f. Não sei

10. O que acontece quando você clica com o mouse nessa seta assinalada?

\section{Sites.Específicos}

a. É permitida a digitação de texto dentro do campo

b. É exibida uma lista de itens e você pode escolher apenas um deles

c. É exibida uma lista de itens e você pode escolher vários deles

d. É exibida uma lista de itens apenas para visualização

e. Nenhum dos anteriores

f. Não sei

11. Qual a função dos itens abaixo?

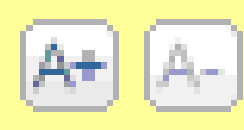

a. Aumentar e diminuir o brilho do texto da página

b. Aumentar e diminuir a intensidade de cor do texto da página

c. Aumentar e diminuir o tamanho do texto da página

d. Realizar alguma função específica para o site em questão

e. Nenhum dos anteriores

f. Não sei

12. O que significa esse elemento dentro de uma mensagem de e-mail? 
a. Um texto simples digitado pelo autor da mensagem

b. Um texto simples acoplado automaticamente à mensagem pelo provedor do e-mail

c. Um arquivo que veio anexado à mensagem

d. Um menu de opções de como visualizar o texto do corpo da mensagem

e. Nenhum dos anteriores

f. Não sei

13. O menu abaixo pertence a que tipo de ferramenta web?

\section{Caixa de entrada $(30$}

Com estrela is

Bate-papos $P$

E-mails enviados

Rascunhos (11)

Todos os e-mails

Spam (1091)

\section{Lixeira}

\section{$\underline{\text { Contatos }}$}

a. Salas de bate-papo

b. Ferramentas de busca na Internet

c. Menu de um blog

d. Menu de uma ferramenta de e-mail

e. Nenhum dos anteriores

f. Nenhum dos anteriores

g. Não sei

14. O que representa o item assinalado em uma ferramenta de e-mail?

$\begin{array}{ll}\text { Marli } & \text { Fwd: CULTURA GRATUITA - AMPLIE SEUS CONHECIMENTOS - Ola pessı } \\ \text { Shopping Center IguatemIs } & \text { Férias com Padrinhos Mágicos no Iguatemi Sẫo Carlos - Clique aqui para vis }\end{array}$

a. Um item de um menu

b. A pessoa para quem a mensagem vai ser enviada 

c. A pessoa que enviou a mensagem
d. O título de uma mensagem de e-mail
e. Nenhum dos anteriores
f. Nenhum dos anteriores
g. Não sei

15. O que representa o item assinalado em uma ferramenta de e-mail?

$\begin{array}{ll}\text { Marli } & \text { FWd CULTURA GRATUITA - AMPLIE SEUS CONHECIMENTOS - Ola pessı } \\ \text { Shopping Center Iguatemi. } & \text { Férias com Padrinhos Mágicos no Iguatemi São Carlos - Clique aqui para vis }\end{array}$
a. Faz parte do título da mensagem de e-mail
b. Que a mensagem foi recebida por Marli e encaminhada para mim
c. Que eu devo encaminhar essa mensagem para algum dos meus contatos
d. Um aviso de que a mensagem contém um arquivo em anexo
e. Nenhum dos anteriores
f. Não sei

16. Para ler a mensagem com título: CULTURA GRATUITA.... você deve clicar com o mouse sobre:

eBay
(Marl You Have Feedhark that You Need To Leave - Be An eBay Starl Leaw
a. O item assinalado em vermelho
b. O item assinalado em verde
c. Em qualquer um dos dois o texto da mensagem será exibido
d. Em nenhum dos dois itens assinalados
e. Nenhum dos anteriores
f. Não sei

17. O que representa o item assinalado?

Secao de Pos-Graduacao d. [pg-sce] Divulgaçẫo de concurso público - Urgente (fwơd) - Forwarded messa

a. Faz parte do título da mensagem de e-mail 
b. Que a mensagem deve ser apagada após ser lida

c. Que a mensagem deve ser arquivada no seu computador após ser lida

d. Um aviso de que a mensagem contém um arquivo em anexo

e. Nenhum dos anteriores

f. Não sei

18. Os elementos mostrados abaixo são característicos de:

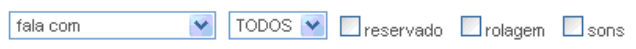
a. Uma ferramenta de e-mail
b. Uma ferramenta de busca
c. Uma sala de bate-papos
d. Uma ferramenta de blog
e. Nenhum dos anteriores
f. Não sei

19. Com que finalidade os elementos abaixo são utilizados?

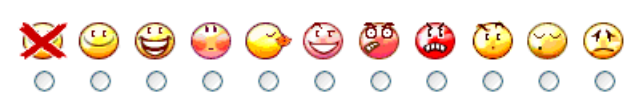

a. Para identificar pessoas em ferramentas da Internet

b. Para substituir o nome da pessoa em uma mensagem

c. Para expressar a emoção do autor em uma mensagem

d. Para escrever mensagens com animações

e. Nenhum dos anteriores

f. Não sei

20. Para que servem os elementos marcados abaixo?

a. Para acrescentar símbolos automaticamente durante a escrita de uma mensagem

b. Para substituir letras e imagens dentro de uma mensagem

c. Para formatar o texto de acordo com as preferências do autor

d. Para escrever mensagens com animações 


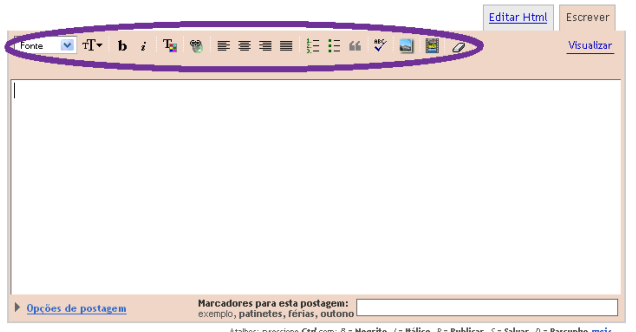

e. Nenhum dos anteriores

f. Não sei 


\section{Teste com protótipo - Menus Horizontais na Web}

\section{Teste On-line com Menus Horizontais}

Os oito menus apresentados no estudo de caso foram desenvolvidos utilizando as marcações HTML para gerenciar a hierarquia das opções. O visual e as propriedades dos menus foram implementadas utilizando CSS (W3C, 2011) e jQuery ${ }^{1}$. Para os oito menus apresentados foram observadas seis propriedades principais:

(a) Disposição: descreve em qual posição os submenus serão apresentados. A disposição pode variar dependendo do nível do submenu, sendo seus valores: Abaixo ( $\mathbf{\nabla})$, Acima $(\boldsymbol{\wedge})$ e Direita $(\boldsymbol{-})$;

(b) Velocidade: é a propriedade que representa o tempo para a apresentação do submenu. Essa propriedade foi classificada em três valores: rápido, com tempo de apresentação do submenu menor ou igual a 0,3 segundos; médio, com tempo de apresentação entre 0,4 a 0,6 segundos; lento, com tempo de apresentação maior que 0,6 segundos. Esses intervalos de tempo foram obtidos a partir dos estudos de Card et al. (1983), as representações dos seus valores são: Rápido

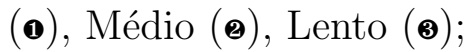

(c) Necessidade de clique: descreve a necessidade de realizar um clique com o mouse para ativar o submenu. Caso não seja necessário o clique, a ativação é realizada apenas com o posicionamento do ponteiro na região de ativação do submenu, seus valores são: $\operatorname{Sim}(\boldsymbol{v})$ e Não $(\mathbf{x})$;

\footnotetext{
${ }^{1}$ Disponível no site: http://jquery.com
} 
(d) Identificação de continuidade: descreve a existência de algum elemento visual para mostrar a existência de submenus para uma determinada subopção do menu, seus valores são: $\operatorname{Sim}(\boldsymbol{v})$ e Não $(\mathbf{x})$;

(e) Contraste de cores na seleção: ativa-se no momento em que o ponteiro está sobre a área de ativação e apresenta a troca de cores ou tamanho da fonte para melhorar a identificação do menu a ser acionado. As principais mudanças normalmente são a troca suave da cor de fundo da área referente à área de ativação, o sublinhado do texto ou uma troca de cor do fundo e da fonte do texto, seus valores são: $\operatorname{Sim}(\boldsymbol{v})$ e Não $(\boldsymbol{x})$;

(f) Apresentação da hierarquia: descreve a forma que é apresentada a hierarquia inerente ao menu. A hierarquia pode ser dividida com os níveis dos submenus ou com espaçamento em um mesmo bloco de conteúdo, seus valores são: Níveis (I) ou Bloco (汭;

(g) Presença de dica: descreve a presença de texto informativo no início do submenu, seus valores são: $\operatorname{Sim}(\boldsymbol{v})$ e Não $(\boldsymbol{x})$.

Na Tabela C.1 são resumidas as principais características dos oito tipos de menus selecionados, identificados por $\mathrm{M}[\mathrm{i}]$, onde i varia de 1 a 8 , representando cada menu i.

Tabela C.1: Propriedades dos oitos menus

\begin{tabular}{lcccccccc}
\hline Propriedades & M1 & M2 & M3 & M4 & M5 & M6 & M7 & M8 \\
\hline 1 Disposição & $\boldsymbol{\nabla}$ & $\boldsymbol{\nabla}$ & $\boldsymbol{\nabla}$ & $\boldsymbol{\nabla}$ & $\boldsymbol{\nabla}$ & $\mathbf{A}$ & $\boldsymbol{\nabla}$ & $\boldsymbol{\nabla}$ \\
2 Velocidade & $\mathbf{2}$ & $\mathbf{3}$ & $\mathbf{1}$ & $\mathbf{1}$ & $\mathbf{2}$ & $\mathbf{2}$ & $\mathbf{2}$ & $\mathbf{1}$ \\
3 Necessidade de clique & $\mathbf{x}$ & $\mathbf{x}$ & $\mathbf{x}$ & $\mathbf{x}$ & $\boldsymbol{V}$ & $\mathbf{x}$ & $\mathbf{x}$ & $\boldsymbol{\checkmark}$ \\
4 Continuidade & $\boldsymbol{V}$ & $\boldsymbol{V}$ & $\mathbf{x}$ & $\mathbf{x}$ & $\boldsymbol{V}$ & $\mathbf{x}$ & $\boldsymbol{V}$ & $\mathbf{x}$ \\
5 Contraste de cores & $\boldsymbol{V}$ & $\boldsymbol{V}$ & $\boldsymbol{V}$ & $\boldsymbol{V}$ & $\boldsymbol{V}$ & $\boldsymbol{V}$ & $\boldsymbol{V}$ & $\boldsymbol{\checkmark}$ \\
6 Apresentação da hierarquia & $\mathbf{I}$ & $\mathbf{\square}$ & $\mathbf{I}$ & $\mathbf{I}$ & $\mathbf{I}$ & $\mathbf{I}$ & $\mathbf{\square}$ & $\mathbf{I}$ \\
7 Presença de dica & $\mathbf{x}$ & $\mathbf{x}$ & $\mathbf{x}$ & $\mathbf{x}$ & $\mathbf{x}$ & $\mathbf{x}$ & $\mathbf{x}$ & $\boldsymbol{V}$ \\
\hline
\end{tabular}

O menu 1 denominado Superfish e está disponível em http://goo.gl/5krI1, é um menu horizontal amplamente utilizado em páginas Web. Apresenta sinalização de submenus (seta para baixo, do lado direito do texto) e sua área de ativação corresponde a toda a caixa do menu, sendo que cada divisão entre as opções é marcada por uma linha vertical. Os submenus são apresentados abaixo da opção principal com o efeito fade-in (suavemente) e apresenta um leve sombreamento de contorno. Não são apresentadas setas para o segundo nível de submenu, o qual é apresentado à direita do primeiro nível. O menu apresenta navegação pela tecla $<t a b>$ sendo possível acompanhar a navegação de forma visual (Figura C.1). Uma 
inconveniência desse estilo de menu é que o usuário deve percorrer todas as opções e subopções para perceber a forma com que as informações foram estruturadas.

O menu 2 denominado Mega Drop-Down Menu e está disponível em http://goo.gl/bQZK6, apresenta os links horizontalmente, mas sem divisão gráfica entre eles. A área de ativação é delimitada pelo texto do link mais a seta indicadora de submenu, de forma que o submenu pode ser ativado tanto pelo texto quanto pela seta que acompanha a identificação da opção de menu. As opções nesse menu são organizadas em grandes grupos e seus subgrupos são apresentados todos ao mesmo tempo; em cada subgrupo as opções são apresentadas como links lado a lado, como pode ser verificado na Figura C.1.
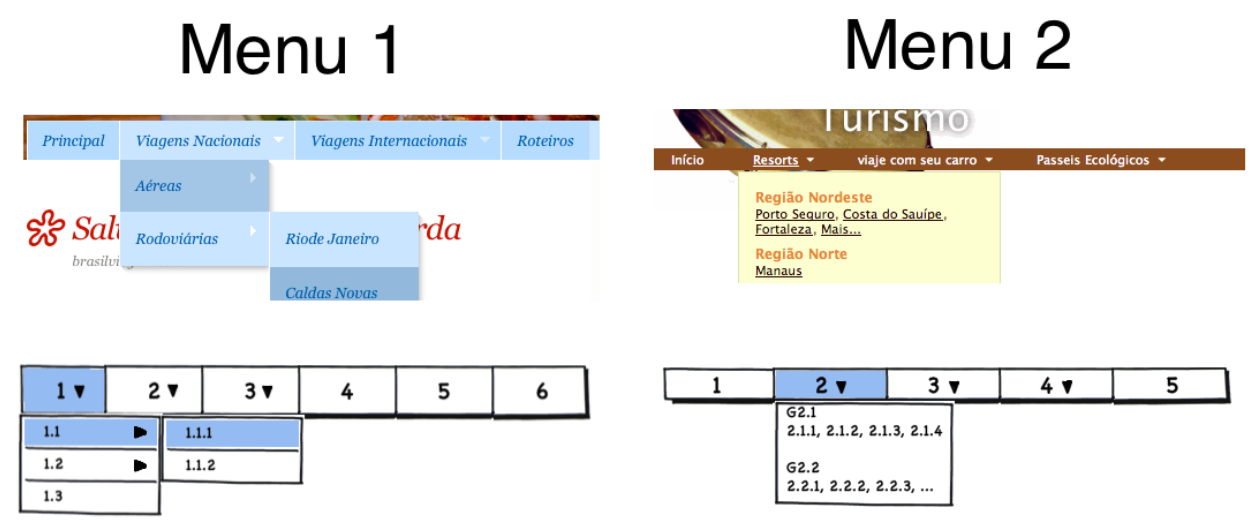

Figura C.1: Renderização e mockup dos menus 1 e 2

O menu 3 denominado Vimeo top navigation e está disponível em http://goo.gl/7TDzy, é bastante semelhante ao menu 1 no que se refere à apresentação de suas subopções, porém o menu 3 não apresenta o segundo nível de submenu. O menu 3 também não apresenta divisão visual entre as opções do menu e a área de ativação é o texto de identificação da opção acrescido de um pequeno espaço ao redor do texto.

Suas características especiais são a apresentação do nome ou logotipo do site como sua primeira opção, visual arredondado para todos os cantos do menu e seu posicionamento no topo da página, o que muitas vezes causa confusão na sua própria identificação como menu por parte dos usuários (Figura C.2). Este tipo de menu foi primeiramente empregado no site de serviço de publicação de vídeo pessoais, Vimeo, portanto é também conhecido como estilo vimeo (http://www.vimeo.com).

O menu 4 denominado Simple jQuery Dropdowns e está disponível em http://goo.gl/UF3iU, apresenta suas subopções abaixo da opção principal e o segundo nível de submenu é apresentado à direita do primeiro nível. A área de ativação do menu é delimitada pela caixa contendo a identificação textual da opção e a área de seu contorno. Apresenta uma barra vertical para delimitar cada opção 
do menu e no momento em que uma determinada opção é indicada com o ponteiro do mouse, uma cor diferenciada é apresentada, como pode ser visualizado na Figura C.2.

Seu diferencial é a indicação de próximos níveis de opções por meio das setas e a possibilidade de visualizar todas as categorias do submenu aberto, embora essa possibilidade tenha que ser implementada pelo desenvolvedor do site que pretende utilizar este tipo de menu.

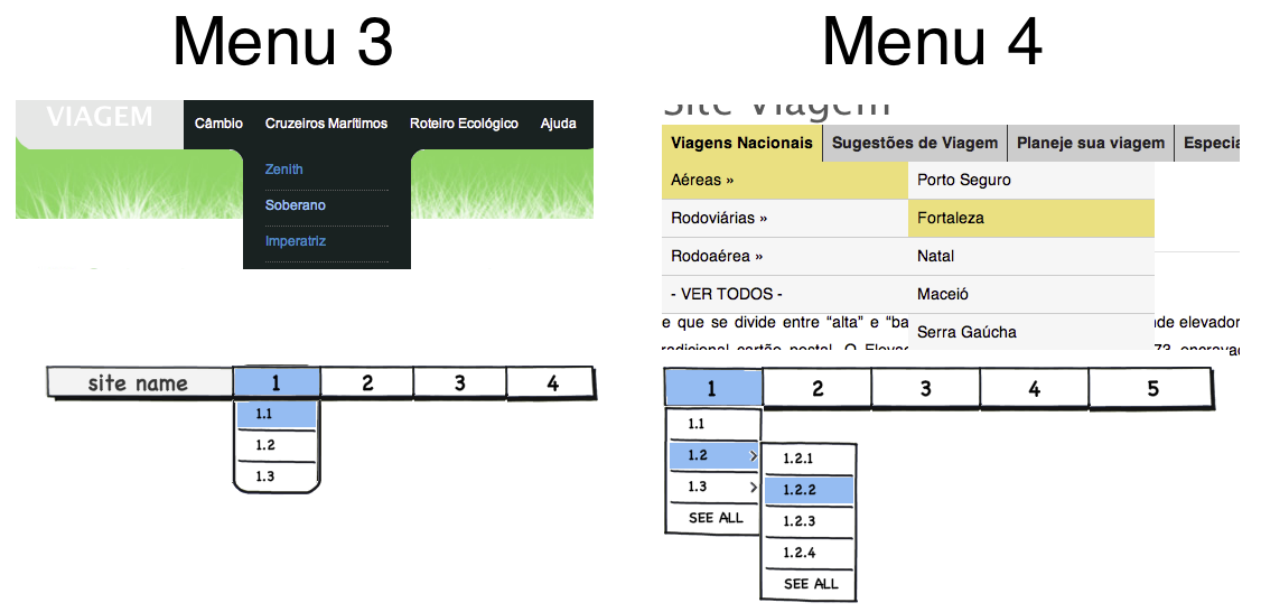

Figura C.2: Renderização e mockup dos menus 3 e 4

O menu 5 denominado Sexy Drop Down Menu e está disponível em http://goo.gl/3dgXF, apresenta alto contraste entre a cor do fundo e o texto das opções. Sua área de ativação é composta pela caixa que contém o texto. Ao sobrepor o ponteiro de navegação em uma das opções, a opção é apresentada com um suave efeito de luminosidade (Figura C.3).

A principal característica do menu 5 é a forma de ativação dos submenus, na qual o submenu de uma determinada opção só é ativado no momento em que o usuário clica na seta ao lado direito do texto da opção e não no próprio texto. Esse diferencial no acionamento dos submenus tornou-se um complicador para grande parte dos usuários, conforme identificamos no estudo de caso realizado.

No menu 6 denominado Different Top Navigation e está disponível em http://goo.gl/jgoxY, as subopções do menu principal são apresentadas acima do menu, provocando um deslocamento na apresentação do mesmo, tendo como diferencial o movimento e a alteração do comportamento padrão. A área de ativação das opções apresenta alto contraste de cor entre o fundo e o texto, embora não exista nenhuma barra vertical para a delimitação de cada opção do menu (Figura C.3).

O menu 7 também é denominado Mega Drop Down Menus porém, não está mais disponível no site do seu desenvolvedor, é semelhante ao menu 2 quanto 
Menu 5
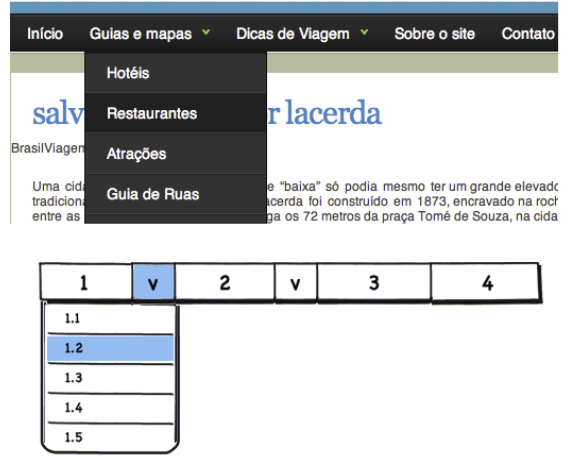

Menu 6

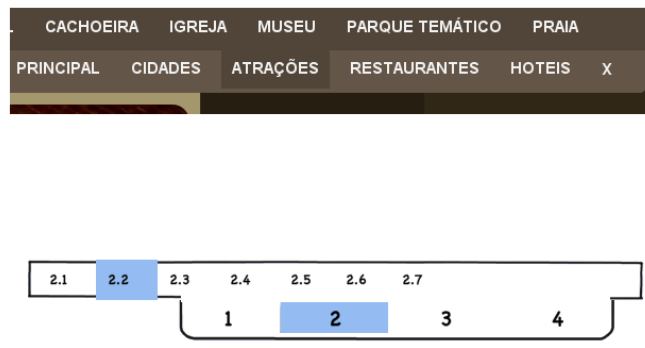

Figura C.3: Renderização e mockup dos menus 5 e 6

à distribuição das informações, isto é, a apresentação de todas as subopções de uma determinada opção é realizada de uma só vez, criando várias colunas para o agrupamento das informações. Os submenus podem ser acionados tanto pelo identificador da opção quanto pela seta indicativa. A área de ativação envolve o texto da opção e a área existente em volta dele, característica válida para os submenus. As opções com submenus são apresentadas com uma seta para baixo e ao lado direito do texto da opção (Figura C.4).

O menu 8 denominado (mb)Menu e está disponível em http://goo.gl/1bz7B, é semelhante ao menu 1 no que se refere a navegação pelos submenus. Não apresenta indicação dos submenus no primeiro nível, porém, apresenta uma modificação visual no momento em que o ponteiro do mouse é posicionado acima de cada opção do menu horizontal e para acionar os submenus é necessário clicar sobre a opção. A partir do primeiro nível de submenu, apresenta-se indicação por seta e não é mais necessário o clique com o mouse para a ativação. A área de ativação é composta pelo identificador da opção acrescida da área ao redor dele, característica válida também para os submenus. Cada opção nos submenus, em especial, pode conter um ícone à esquerda do textos, como pode ser visualizado na Figura C.4.

Esses oito menus que foram arbitrariamente selecionados para o teste, apresentavam características que mais se distinguiam a forma de interação a ser analisado e avaliado por parte de um público maior. 


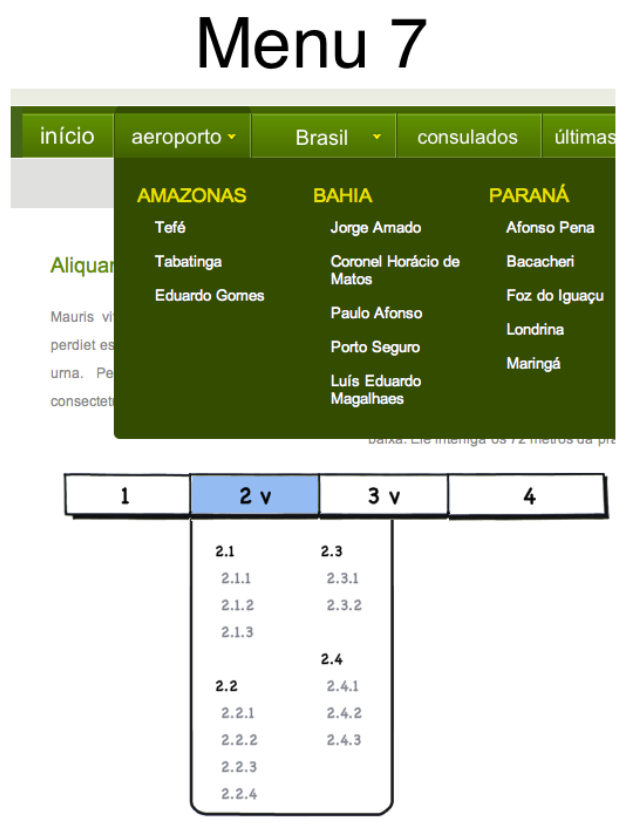

Menu 8

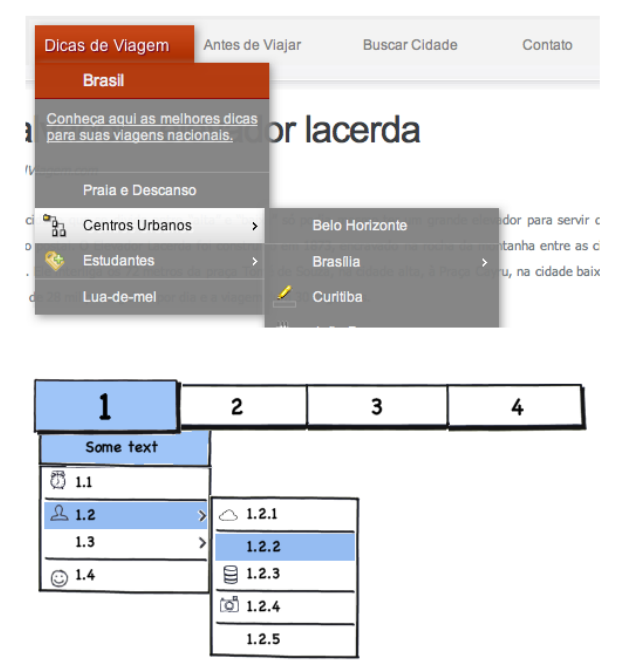

Figura C.4: Renderização e mockup dos menus 7 e 8 


\section{Comentários - Mecanismos de Apoio}

\section{Comentários sobre os Mecanismos de Apoio}

A seguir são reproduzidos os comentários feitos pelos participantes para as questões 20 (comércio eletrônico) e 21 (bancos on-line) do questionário de mecanismos de apoio. Os comentários mais relevantes para a melhoria do comércio eletrônico foram:

\section{- Idosos}

- "seria com palavras de fácil entendimento e com segurança";

- "maior rapidez para preencher os campos necessários e menos burocracia";

- "exibir vídeos demonstrativos, autorizações oficiais tais como: ANVISA, INMETRO, ISO, ABRINC".

- Adultos de meia-idade

- "queria receber notificação por email dos passos que realizei, pois às vezes eu quero ter um guia dos meus passos, mesmo que não tivesse concluído a compra";

- "se possível ao acessar sites de compra, aparecesse alerta quando o site tem problemas com clientes";

- "recomendação principalmente de confiabilidade na compra (índices indicando o quão confiável é o produto, o site, a entrega, o atendimento, o suporte, a assistência técnica, etc)";

- "pechinchar via Internet"; 
- "para determinados produtos, pode ser interessante que haja uma simulação do uso dos mesmos. Isso seria bom, por exemplo, para analisar a praticidade de uso, ou para verificação do resultado do uso de um produto. Portanto, seria bom encontrar uma forma de "experimentar" o produto antes de comprar";

- "manter a possibilidade de recuperar, quando desejar, compras não concluídas, com os campos já preenchidos";

- "seria um que garantisse que vc não precisa começar de novo toda vez que ou vc se enganou ao preencher ou por motivo alheio à sua vontade a página travou e que mostrasse onde vc parou. Principalmente passagens aéreas em promoção que sufoco!!!!";

- "com certeza com mensagem de voz indicando se os passos para a compra estão corretos ou como fazê-lo";

- "o site deveria apresentar ao cliente a partir de sua segunda compra, quais foram as opções que ele utilizou na sua primeira compra, como forma de pagamento, como sugestão para se efetuar a segunda compra";

- "teria armazenado os dados do formulário necessários para efetuar nova compra naquele mesmo site. Não consigo imaginar algo que facilitasse mais essa tarefa. Organizaria os meus sites preferidos por temas e neles eu teria um resumo das minhas últimas compras. Algo que visse maiores detalhes do produto. Segurança e uma vez os dados pessoais cadastrados não haveria necessidade de repetir tudo";

- "melhor visibilidade do produto e cotação conjunta de preços";

- "gostaria de poder utilizar um sistema de câmeras da loja, para em tempo real, passear remotamente pelos corredores da mesma, pois muitas vezes, não tenho nenhum produto específico que eu queira comprar, porém, ao caminhar pelos corredores, acabo me interessando por algo e muitas vezes compro";

- "colocaria alguns itens dessa pesquisa".

- Jovens

- "formulários menos intensos para concluir a compra";

- "normalmente é necessário preencher um cadastro para se efetuar compras pela internet. Neste contexto, gostaria que houvesse um recurso que possibilitasse a importação automática de todos os meus dados pessoais de um banco de dados, evitando-se assim o preenchimento reiterado das mesmas informações"; 
- "ao entrar na página, ter uma ferramenta que acessa páginas como o Reclame Aqui para ver se há reclamações sobre a loja e de que tipo elas são";

- "eu faria um guia na sequência de finalização de compra. Tipo um boneco que explica de maneira geral o que é preciso fazer no atual formulário e ao clicar em um campo, ele explica como deve ser preenchido o campo selecionado. Teria a opção de ouvir o áudio e ler a explicação também (balão de quadrinhos, por exemplo)";

- "um mecanismo de busca contextual que utilizaria o histórico de visitas a outros sites de compras e já mostrasse o que eu estivesse procurando ao acessar aquele site. Por exemplo, vou no site das casas Bahia e procuro por tv LED, ao acessar o site do Magazine Luiza já apareceria as opções de tvs LEDs... etc...";

- "uma central com um cadastro único para não precisar digitar várias vezes em sites diferentes a mesma informação (nome, endereço, número de cartão, etc), uma vez cadastrado nesta central, todos os sites de venda pela internet teria acesso a este cadastro";

- "um agente de software no qual eu simplesmente diria as especificações dos produtos com a faixa de preço e ele se encarregasse de efetuar todos os procedimentos";

- "um aviso em áudio alertando sobre a seguranca do site";

- "busca de reviews do produto/serviço pela internet, já que nem sempre e possível confiar nos comentários presentes na página.";

- "sistema drag and drop para colocar os produtos no carrinho de compras";

- "colocaria um roteiro no canto da página pra saber por quais campos já passei e quais serão os próximos";

- "algum mecanismo que assim que ligo o computador ele me daria as informações das minhas compras, isto é, ele faria contato com todos os sites e mecanismos de transportes e me daria todas as informações na minha área de trabalho sem que eu necessitasse por exemplo de ir no site do sistema de transportes ou no site da loja verificar os status de meus pedidos, gerando assim mais comodidade para mim e economizando tempo.";

- "opção de voz referentes a qualidades e especificações do produto e opiniões diversas de compradores anteriores";

- "uma busca integrada entre diferentes sites, em que fosse possível comparar o produto por um código identificador que me desse a certeza de que se trata do mesmo produto"; 
- "busca por foto de produtos e visualização tridimensional do produto, podendo ver ele em todos os ângulos";

- "Um recurso que possibilite a emissão de boleto bancário para compras nacionais e internacionais, neste último, com a conversão de câmbio compativel";

- "que explicasse passo a passo como fazer esta compra, que fosse feita a compra em conversa em áudio com o vendedor ";

- "que pudesse ter mais modelos de compras para me auxilar".

As sugestões para a melhoria dos sites de bancos on-line foram:

\section{- Idosos}

- "achei esse procedimento de voz dando as dicas quando você procura um serviço ajudaria muito. Em alguns casos de serviço que você deseja utilizar o caminho é muito confuso";

- "poder com uma única senha eletrônica (mesmo com senhas diferentes nos cartoes magnéticos) juntar todas as contas de uma determinada agência bancária - poupança, conta corrente. Assim poderíamos em um único acesso, verificar saldos, fazer diversas operações, sem que houvesse necessidade de entrar em cada conta separadamente".

\section{- Adutos de meia-idade}

- "queria receber algum alerta mais evidente, para confirmar quando uma operação está sendo completada... mudar as cores, ou um destaque mais claro de que aquele é um ponto crítico da transação";

- "maior poblema é a tal de senha, que esqueço sempre, que tal a impressão digital?";

- "como faço tudo praticamente uma vez por mês, seria interessante, se no fim de todas as operações, aparecesse um relatório resumido de tudo que fizemos naquele dia";

- "feedback seletivo por e-mail: capacidade de definir que tipo de operações bancárias eu gostaria de receber um feedback via e-mail, ou seja, ter uma classificação automática e configurável do nível de importância da transação, de modo a ser informado de transações especiais. Por exemplo, uma transação não usual, compra em lugares não usuais, eu gostaria de ser avisado, já o pagamento de um bloqueto de cobrança que é feito todos os meses não precisaria de aviso";

- "o recurso seria: um conjunto das minhas operações frequentes, para as quais eu vou com um clique só"; 
- "algo mais seguro e fácil para identificação, como pressionar impressão digital na tela, ou leitura da íris";

- "vejo que hoje o acesso via internet nos bancos, eles mudam o layout da página constantemente, deveria ter algo mais explicativo";

- "com mensagem de voz indicando caminhos corretos a seguir";

- "o banco deveria apresentar para o cliente quais são os serviços mais utilizados num menu principal, e inclusive guardar informações de pagamentos feitos regularmente, para que o preeenchimento dos dados de um pagamento fosse mais otimizado";

- "seria um recurso que memorizasse ações anteriores e que se repetem com frequência, trazendo os dados de uma transferência prévia, por exemplo. Uma ferramenta tal que, se eu digitasse: transferir para Maria Silva, ela abrisse a página correspondente já preenchida com os dados de Maria Silva";

- "mostrar as minhas últimas ações, pois, não uso com muita frequência e acabo esquecendo o passo-a-passo";

- "relatório enviado ao email pessoal de todas as operações realizadas no mês, semana ou conforme a vontade";

- "o recurso de que eu gostaria seria o de personalizar a interface para as funções que mais uso (tipicamente 3 ou 4 de um menu com dezenas). Por exemplo, na interface adequada para mim apareceriam apenas: extratos, transferências, aplicações, pagamentos e carga de celular";

- "um sistema de reconhecimento biométrico SIMPLES e EFICAZ que me permitisse jogar no lixo senhas e tokens...";

- "trabalho com várias contas e várias senhas. Seria interessante um recurso simples e seguro para ajudar a guardar e lembrar das senhas. Eu uso um arquivo criptografado, mas o sistema que uso não é de facil instalação e utilização para o usuário comum. Pessoas mais velhas têm ainda mais dificuldade";

- "acho que seria interessante ter o perfil do usuário e deixá-lo como primeira opção do mesmo ao entrar no site. Este perfil poderia ser cadastrado pelo cliente ou gerado automaticamente pelo sistema, com base nos acessos anteriormente feitos. ";

- "utilizaria a biometria para liberar as operações que hoje realizo, ao invés das tradicionais senhas".

\section{- Jovens}

- "um recurso de chat para falar com o gerente"; 
- "leitor biométrico para credenciar minhas autorizações no site";

- "gerenciador de comprovantes emitidos pelo internet banking";

- "Um lembrete das últimas operações feitas, podendo executá-las novamente";

- "aplicacao desktop onde fazia todos o processamento em uma máquina local e em um momento oportuno sincronizasse estas tarefas com a base de dados online. Serviria para adiantar operações bancárias em locais onde não há internet";

- "o usuario poderia escrever ao lado de cada lançamento do extrato alguma descrição e resumo simples por centro de custo";

- "apresentar uma interface mais próxima da observada em um caixa eletrônico";

- "montaria um sistema inteligente que baseado no aprendizado automático de minhas atividades já oferecesse um menu rápido com as atividades que executo frequentemente naquele dia, por exemplo: todo 5o. dia util acesso o extrato para ver o salário, depois faço transferência para poupanca. Nos dias 20 e 25 pago contas. Assim, quando acessasse o sistema no 5o. dia útil apareceria já o extrato e depois iria para a tranferência e ao acessar nos dias de pagar contas, já iria direto para o pagamento de contas";

- "um menu com as operações mais realizadas por mim";

- "gravar as últimas operações, para depois, ao invés de digitar novamente, preencher com o que foi previamente um dia digitado; contar quantos números atualmente estao na caixa de texto quando você vai digitar um código de barras sem usar um scanner, para nao se enganar com a quantidade de zeros, por exemplo; montar um menu com as suas operações mais realizadas; utilizar uma caixa de busca para procurar uma operação especifica;";

- "simuladores de transações bancárias que antecedessem a operação. Por exemplo, antes de realizar uma transferência, mostrar como ficaria o saldo da conta";

- "tenho frequentemente que lembrar vários números de contas para fazer transferências bancárias. Um recurso muito útil é aquele que lembra das transações anteriormente realizadas";

- "simplesmente possuir explicações mais detalhadas (seja em texto ou voz) de qualquer recurso disponível e/ou qualquer ação a ser tomada". 